UNIVERSIDADE DE SÃO PAULO

ESCOLA DE ENGENHARIA DE SÃO CARLOS

DEPARTAMENTO DE ENGENHARIA MECÂNICA

\title{
A Correlação entre os ERros de \\ RETILINEIDAde E ANGULARES NAS MÁQUINAS \\ de Medir a Três COORDENAdAS.
}

ALESSANDRO MARQUES

Dissertação apresentada à Escola de Engenharia de São Carlos da Universidade de São Paulo, como parte dos requisitos para obtenção do título de Mestre em Engenharia Mecânica

ORIENTADOR: Prof. Dr. Benedito Di Giacomo

São Carlos

1999 
Aos meus pais Moacyr e Evanilde por minha educação e apoio constante. À minha avó Amábile e ao meu avô João Coelho (em memória) 


\section{AgRADECIMENTOS}

Meus mais sinceros agradecimentos ao Prof. Dr. Benedito Di Giacomo pela orientação, discussão e apoio durante a realização deste trabalho. Juntamente com sua paciência e amizade, pudemos realizar esta dissertação de Mestrado.

Ao Prof. Dr. Mario Francisco Mucheroni e Prof. Dr. Eduardo Morgado Belo pelo incentivo, estímulo e apoio.

Ao Prof. Dr. Durval Duarte Junior pelo incentivo e dicas.

À Dra. Denise Pizarro Vieira Sato, pela dedicação nas correções e discussões que contribuíram preciosamente para a finalização deste trabalho.

Aos colegas de pós-graduação Aguinaldo, Alexandre Caporali, Antônio Almeida, Antônio Piratelli Filho, Marcello Barata, Fabricio Flores, Fernando Santoro, José Cláudio, Luiza Yoko Tanegutti, Rosana Camargo, Roxana M.M. Orrego, pelo apoio manifestado durante o trabalho.

À Renata Belluzzo Zirondi e Rosenda Valdes Arencibia pelas sugestões e ilustrações.

Ao Roberto Tsunaki e Vagner Augusto de Souza pela amizade e sugestões que transcenderam o ambiente de trabalho.

Aos técnicos Luiz Carlos Neves, Adão Santo Bolzan, José Carlos Risardi, José Carlos Botelho, Luís Carlos Bruno e Ivan Belo.

À meus pais, minha avó Amábile, meus irmãos Jú e Rosana, sobrinhos Daniel, Aline e Gabriel , ao Creso e Edmara por existirem.

Agradecimento especial à Erika Regina Bregagnolo motivo de alegria e força para vencer os obstáculos.

Ao CNPq pela bolsa de estudo concedida durante a realização do trabalho.

A todos aqueles que, direta ou indiretamente, contribuíram para o desenvolvimento deste trabalho.

À Deus, pela vida e por me dar saúde e força. 


\section{SUMÁRIO}

Lista de Figuras................................................... i

Lista de Tabelas..............................................

Lista de Acrônimos.............................................. vi

Lista de Símbolos.................................................. vii

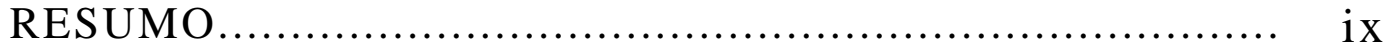

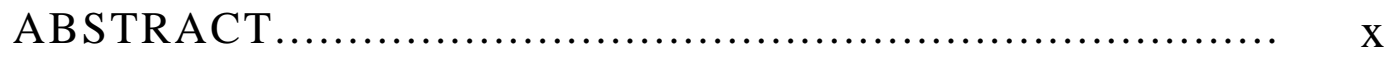

1. INTRODUÇÃ O............................................. 1

2. CONSIDERAÇÕES GERAIS SOBRE OS ERROS NAS MÁQUINAS FERRAMENTAS E MÁQUINAS DE MEDIR A TRÊS COORDENADAS.....................................

2.1 - Fontes e Fatores Causadores de Erros nas Máquinas Ferramentas e Máquina de Medir a Três Coordenadas......... 5

2.1.1 - Erros nas Máquinas Ferramentas..................... 5

2.1.2 - Erros nas Máquinas de Medir a Três Coordenadas 10

2.2 - Os Erros Geométricos.................................... 13

2.3 - Os Erros de Retilineidade................................. 15

2.3.1 - Definição dos Erros de Retilineidade................. 15

2.3.2 - Instrumentos para Medição de Erro de

Retilineidade...................................................... 18

2.3.3 - Métodos para Medição do Erro de Retilineidade... 25

2.3.4 - Algoritmos para Avaliação dos Erros de Retilineidade.................................................... 31 
2.4 - Os Erros Angulares

2.4.1 - Definição dos Erros Angulares......................... 34

2.4.2 - Instrumentos para Medição de Yaw e Pitch.......... 35

2.4.3 - Instrumentos para Medição de Roll................... 37

3. CONSIDERAÇÕES TEÓRICAS SOBRE ERROS E O TRATAMENTO ESTATÍSTICO DE DADOS

EXPERIMENTAIS ............................................. 40

3.1 - Conceitos Estatísticos Básicos para o Tratamento de Dados Experimentais................................................ 40

3.1.1 - Conceitos Básicos..................................... 41

3.1.2 - Classificação dos Erros Quanto ao seu Comportamento. .................................................. 43

3.1.3 - Análise de Regressão................................. 45

3.1.4 - Método de Newton para Sistemas Não-Lineares.... 49

3.2 - Análise dos Erros de Retilineidade .................................. 51

3.2.1 - Método Clássico das Reversões........................ 51

3.2.2 - Eliminação do Desalinhamento....................... 58

3.3 - O Estudo de Casos de Bryan............................... 61

3.4 - Modelagem Matemática das Máquinas de Medir a Três Coordenadas...................................................... 64

3.5 - Raio de Curvatura....................................... 68

4. MÉTODO PROPOSTO PARA A DETERMINAÇÃO DA CORRELAÇÃO ENTRE OS ERROS DE RETILINEIDADE E OS ERROS ANGULARES................................... 
5. DESENVOLVIMENTO DA METODOLOGIA

PROPOSTA PARA DETERMINAÇÃO DA CORRELAÇÃO

ENTRE OS ERROS DE RETILINEIDADE E OS ERROS

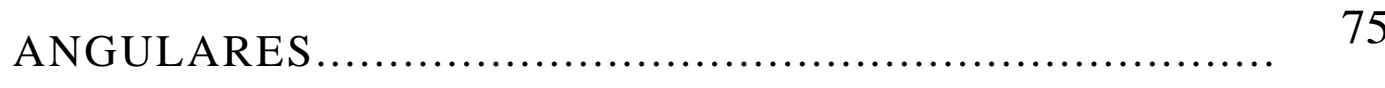

5.1 - Calibração dos Erros Geométricos.................... 77

5.1.1 - Calibração dos Erros Angulares..................... 79

5.1.2 - Calibração dos Erros de Retilineidade.............. 81

5.2 - Equacionamento Matemático....................... 87

5.3 - Determinação da Incerteza Padronizada Combinada... 92

6. RESULTADOS DOS TESTES EXPERIMENTAIS, DAS SIMULAÇÕES COMPUTACIONAIS E DISCUSSÕES....... 94

6.1 - Resultados da Calibração dos Erros De

Retilineidade e Erros Angulares da Máquina de Medir a

Três Coordenadas

95

6.1.1 - Erros de Retilineidade........................... 96

6.1 .2 - Erros Angulares................................. 101

6.2 - Análise dos Resultados da Aplicação da Formulação Matemática Proposta.......................................... 104

6.2.1 - Determinação do Erro Angular Yaw "Y”........... 104

6.2.2 - Determinação do Erro Angular Pitch "Y"......... 107

6.3 - Cálculo da Incerteza Padronizada Combinada.......... 110

7. CONCLUSÕES E SUGESTÕES PARA TRABALHOS

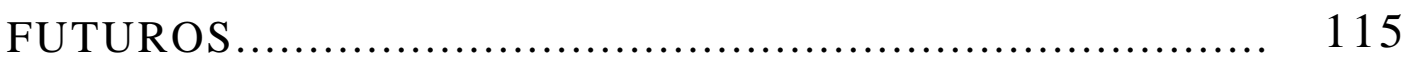

REFERÊNCIAS BIBLIOGRÁFICAS .......................... 118 
APÊNDICE 1- Dados da Máquina de Medir a Três Coordenadas................................................... 124

APÊNDICE 2 - Análise de Regressão Linear Múltipla........ 125

APÊNDICE 3 - O erro de retilineidade em função do erro angular..................................................... 128 


\section{LISTA DE FIGURAS}

Figura 2.1 - Fontes de erros térmicos em máquinas ferramentas............. 6

Figura 2.2 - Erros de batida de um eixo árvore..................................... 7

Figura 2.3: Micrômetro (Concordância com o Princípio de Abbé) e

Paquímetro (Transgressão do Princípio de Abbè).................................. 9

Figura 2.4 - Erros geométricos........................................................ 14

Figura 2.5 - Tolerância de retilineidade de uma linha............................. 16

Figura 2.6 - Desenho do campo de tolerância........................................ 17

Figura 2.7 - Desenho do campo de tolerância de retilineidade quando aplicado a dois planos perpendiculares entre si.................................. 17

Figura 2.8 - Tolerância de retilineidade em duas dimensões................... 18

Figura 2.9 - Montagens típicas da régua padrão....................................... 19

Figura 2.10 - Medição com fio esticado e microscópio........................... 20

Figura 2.11 - Laser de alinhamento................................................ 21

Figura 2.12 - Principio do interferômetro laser..................................... 22

Figura 2.13 - Esquema básico para medição de retilineidade.................. 24

Figura 2.14 - Esquema do método da superposição.............................. 26

Figura 2.15 - Princípio de medição de retilineidade usando o método

Heterodine de Moiré ..................................................................... 27

Figura 2.16 - Formação de franjas de interferências com o biprisma....... 28

Figura 2.17 - Montagens apresentadas para o método da distância.......... 30

Figura 2.18 - Condições de mínima zona para o erro de retilineidade...... 33

Figura 2.19 - Esquema dos erros de Pitch e Yaw................................. 34

Figura 2.20 - Esquema da Medição com o Nível Eletrônico.................... 35

Figura 2.21 - Esquema básico do sistema interferométrico laser para medir ângulo................................................................................... 36

Figura 2.22 - Princípio da Medição do erro angular utilizando instrumentação de retilineidade...................................................... 38

Figura 3.1 - Gráfico de uma curva normal reduzida (SPIEGEL,1993).... 43 
Figura 3.2 - Classificação dos erros quanto ao comportamento............... 44

Figura 3.3 -Forma de coleta de dados de um erro geométrico................ 45

Figura 3.4 - Parâmetros da reta de regressão........................................... 46

Figura 3.5 - Problema básico na medição de retilineidade usando

artefato mecânico.............................................................................. 52

Figura 3.6 - Esquema de reversão da régua........................................ 52

Figura 3.7 - Esquema após a reversão................................................. 53

Figura 3.8 - Esquema das ópticas do interferômetro de retilineidade...... 55

Figura 3.9 - Efeito da planicidade do espelho.................................... 57

Figura 3.10 - Provável desalinhamento............................................... 58

Figura 3.11 - Ilustração do método dos pontos extremos....................... 59

Figura 3.12 - Ilustração do método dos mínimos quadrados................... 60

Figura 3.13 - Erro de retilineidade e angular de uma guia em forma senoidal e distâncias dos mancais "b" igual a um comprimento de onda.

Figura 3.14 - Erro de retilineidade e angular de uma guia em forma senoidal e distâncias dos mancais " $b$ " igual a metade de um comprimento de onda.

Figura 3.15 - Erro de retilineidade e angular de uma guia em forma circular e distâncias dos mancais "b" conhecida..................................... 63

Figura 3.16 - Noção primordial de raio de curvatura............................ 69

Figura 4.1 - Esboço da MM3C com seus respectivos sistemas de coordenadas. 71

Figura 5.1 - Foto da MM3C.

Figura 5.2 - Princípio interferométrico para medir erros de Pitch e Yaw

Figura 5.3 - Montagem do erro angular $\mathrm{Yaw}^{\text {"Y }}$ "............................... 80

Figura 5.4 - Montagem do erro angular Pitch "Y" ............................. 80 
Figura 5.5 - Princípio interferométrico da medição de erro de

retilineidade

Figura 5.6 - Efeito de desalinhamento na medição de erros de retilineidade.

Figura 5.7 - Montagem do erro de retilineidade na direção "X" devido ao movimento em "Y", $\delta_{\mathrm{x}}(\mathrm{y})$

Figura 5.8 - Retilineidade na direção "Z" devido ao movimento no eixo "Y", $\delta_{\mathrm{z}}(\mathrm{y})$

Figura 5.9 - Montagem da régua padrão para a medição do erro de retilineidade na direção "X" devido ao movimento em "Y", $\delta_{\mathrm{x}}(\mathrm{y})$.

Figura 5.10 - Montagem da régua padrão após a reversão para a medição do erro de retilineidade na direção " $\mathrm{X}$ " devido ao movimento em "Y", $\delta_{\mathrm{x}}(\mathrm{y})$ 86

Figura 5.11 - Calibração hipotética de um erro de retilineidade 87

Figura 5.12 - Curva de erro no sentido de ida da figura 5.11. 88

Figura 5.13 - Curva de ajuste para o erro de retilineidade hipotético, no sentido de ida.

Figura 5.14 - Visão do carro da máquina sobre a curva de erro de retilineidade.

Figura 5.15 - Esquema para encontrar o erro angular.

Figura 6.1 - Máquina de Medir a Três Coordenadas tipo Ponte Móvel utilizada. 95

Figura 6.2 - Erro $\delta_{\mathrm{x}}(\mathrm{y})$ utilizando o Sistema Interferométrico Laser......... 98

Figura $6.3-$ Erro $\delta_{\mathrm{x}}(\mathrm{y})$ utilizando a régua padrão 98

Figura 6.4 - Erro de retilineidade na direção "Z" devido ao movimento no eixo "Y", $\delta_{\mathrm{z}}(\mathrm{y})$. 100

Figura 6.5 - Erro Yaw do eixo "Y" 102

Figura 6.6 - Erro Pitch do eixo "Y". 103

Figura 6.7 - Esquema da guia "Y" da MM3C.. 104 
Figura 6.8 - Detalhes do esquema da guia "Y" da MM3C.................... $105^{\text {iv }}$

Figura 6.9 - Erro de $\mathrm{Yaw}_{\text {" }} \mathrm{Y}$ " calculado........................................... 105

Figura 6.10 - Comparação dos resultados obtidos através da calibração

do erro de Yaw "Y" e do calculado através do método proposto............. 106

Figura 6.11 - Erro de Pitch "Y" calculado.......................................... 108

Figura 6.12 - Comparação dos resultados obtidos através da calibração

do erro de Pitch "Y" e do calculado através do método proposto............ 109

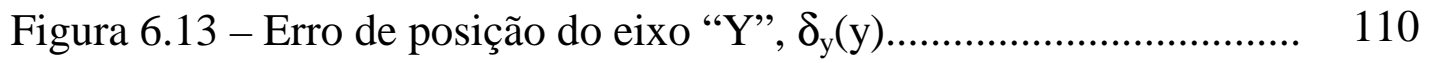

Figura A3.1-Erro de retilineidade em " $\mathrm{X}$ " devido ao movimento no eixo " $Z$ "

Figura A3.2 - Erro de rotação em torno do eixo "Y" devido ao

movimento no eixo "Z", Yaw do eixo "Z"

Figura A3.3 - Esquema das montagens do erro angular e do erro de retilineidade para o eixo " $\mathrm{Z}$ " da MM3C............................................... 131

Figura A3.4 - Esquema para o cálculo trigonométrico........................ 132

Figura A3.5 - Erro de retilineidade do eixo " $Z$ " ................................. 133 


\section{LISTA DE TABELAS}

Tabela 2.1 - Notações dos erros geométricos............................................. 14

Tabela 2.2 - Notações dos erros angulares.................................................. 34

Tabela 4.1 - Correlação entre os erros de retilineidade e angular............... 72

Tabela 5.1 - Características dos instrumentos disponíveis

comercialmente para medição de erros de retilineidade e erros angulares. $\quad 78$

Tabela 6.1 - Erro relativo entre as curvas de Yaw "Y"............................. 107

Tabela 6.2 - Erro relativo entre as curvas de Pitch "Y"........................... 109 


\title{
LISTA DE ACRÔNIMOS
}

\author{
ABNT Associação Brasileira de Normas Técnicas \\ CLRS Control Line Rotation Scheme \\ CNC Controle Numérico Computadorizado \\ EMQ Estimadores de Mínimos Quadrados \\ GIDEP Government- Industry Data Exchange Program \\ GPIB General Propose Interface Bus \\ HP Hewlett Packard \\ ISO International Standard Organization \\ LAMAFE Laboratório de Máquinas e Ferramentas da Escola de Engenharia \\ de São Carlos \\ LVDT Linearly Variable Differential Transformers \\ MM3Cs Máquinas de Medir a Três Coordenadas \\ NBR Norma Brasileira Registrada \\ VDI / VDE Verein Deutscher Ingeniere / Verband Deutscher Elektrotechniker
}




\section{LisTA DE Símbolos}

$\delta \theta_{\mathrm{a}}(\mathrm{b}) \quad$ - Erro angular em torno do eixo "a" devido ao movimento no eixo "b"

$\delta_{a}(a) \quad$ - Erro de translação do eixo "a" devido ao movimento no eixo "a"

$\delta_{\mathrm{a}}(\mathrm{b}) \quad$ - Erro de retilineidade na direção "a" devido ao movimento em "b"

$\delta \mathrm{x}(\mathrm{x})$ - erro de posição do eixo " $\mathrm{X}$ ".

$\delta y(y)$ - erro de posição do eixo "Y".

$\delta z(z) \quad$ - erro de posição do eixo " $Z$ ".

$\delta \mathrm{x}(\mathrm{y})$ - erro de retilineidade do eixo " $\mathrm{Y}$ " na direção " $\mathrm{X}$ ".

$\delta x(z) \quad$ - erro de retilineidade do eixo " $Z$ " na direção " $X$ ".

$\delta y(x) \quad$ - erro de retilineidade do eixo " $\mathrm{X}$ " na direção " $Y$ ".

$\delta y(z) \quad$ - erro de retilineidade do eixo " $Z$ " na direção "Y".

$\delta z(x) \quad$ - erro de retilineidade do eixo " $X$ " na direção " $Z$ ".

$\delta z(y) \quad$ - erro de retilineidade do eixo "Y" na direção " $Z$ ".

$\delta \theta \mathrm{y}(\mathrm{x})$ - erro Pitch do eixo " $\mathrm{X}$ ".

$\delta \theta \mathrm{x}(\mathrm{y})$ - erro Pitch do eixo " $\mathrm{Y}$ ".

$\delta \theta \mathrm{x}(\mathrm{z}) \quad$ - erro Pitch do eixo " $\mathrm{Z}$ ".

$\delta \theta z(\mathrm{x})$ - erro Yaw do eixo " $\mathrm{X}$ ".

$\delta \theta z(y)$ - erro Yaw do eixo "Y".

$\delta \theta y(z) \quad$ - erro Yaw do eixo " $Z$ ".

$\delta \theta \mathrm{x}(\mathrm{x})$ - erro Roll do eixo "X".

$\delta \theta \mathrm{y}(\mathrm{y})$ - erro Roll do eixo "Y".

$\delta \theta z(z) \quad$ - erro Roll do eixo " $Z$ ”.

$\bar{x} \quad$ - média de uma amostra.

$u_{c}^{2}(y)$ - variância combinada 
$\delta \quad$ - erro de Abbè

$\varphi \quad$ - ângulo de Abbè

$\chi^{2} \quad$ - variável aleatória Qui-quadrado.

$J(x) \quad$ - Jacobiano da função

$k$ - curvatura da função

$r \quad$ - raio de curavatura

$m \quad$ - coeficiente angular da reta

n - número de observações de uma amostra.

$\mathrm{r}^{2}$ - coeficiente de correlação amostral.

S $\quad$ - desvio padrão amostral.

t - variável aleatória padronizada t de Student.

$u_{c}(y) \quad$ - incerteza padronizada combinada

$\beta_{\mathrm{i}} \quad$ - coeficientes de regressão.

$\varepsilon_{\mathrm{i}} \quad-$ resíduos de regressão. 


\section{RESUMO}

MARQUES, A. (1999). A Correlação entre os Erros de Retilineidade e Angulares nas Máquinas de Medir a Três Coordenadas. São Carlos, 1999. 133p. Dissertação (Mestrado) - Escola de Engenharia de São Carlos, Universidade De São Paulo.

O desempenho metrológico de uma Máquina de Medir a Três Coordenadas (MM3C) está relacionado com a sua capacidade de medir peças com a precisão requerida ou desejada. No entanto, como todo instrumento de medição, essas máquinas possuem erros que afetam as medições gerando o que se convencionou chamar de erros volumétricos. Tais erros podem ser obtidos através de modelos matemáticos que descrevem como os erros individuais de todos os componentes da MM3C se combinam por todo o volume de trabalho. Atualmente, no modelamento dos erros, adota-se a independência entre os erros individuais, entretanto, se analisada a geometria estrutural da máquina, verifica-se que existe dependência entre os erros de retilineidade e os erros angulares. $\mathrm{O}$ objetivo deste trabalho é expressar o erro angular em função do erro de retilineidade, possibilitando assim minimizar o número de calibrações necessárias e, consequentemente, o tempo de máquina parada requerido para o levantamento do seu comportamento metrológico. Para que se pudesse atingir o objetivo proposto, foram levantados os erros de retilineidade e os angulares de uma Máquina de Medir a Três Coordenadas da marca Brown \& Sharp do tipo Ponte Móvel. Com esses dados e o conhecimento da geometria da máquina, os erros angulares foram equacionados, calculados e comparados com os obtidos experimentalmente.

Palavras-chaves: Máquina de Medir a Três Coordenadas (MM3C), Erro de retilineidade, Erro angular. 


\section{ABSTRACT}

MARQUES, A. (1999). The Correlation between the Straightness Errors and Angular Errors in Three Coordinate Measuring Machines. São Carlos, 1999. 133p. Dissertação (Mestrado) - Escola de Engenharia de São Carlos, Universidade de São Paulo.

The metrological performance of a Three Coordinate Measuring Machines (CMM) is related to the capacity of measuring workpieces with a required precision. As every measurement instrument, these machines undergo the effects of internal and external factors that affect the measurement, generating what has been denominated as volumetric errors. Such errors can be obtained through a mathematical model that simulates how the individual errors of the CMM are combined and propagated to any point within the machine working volume. Usually, the independence among the individual errors is adopted when the machine error model is built. However, if the machine geometry is analyzed, the dependence between the straightness error and the angular error can be noted. The objective of this work is to express the angular error as a function of the straightness error. The formulation proposed in this work to express this correlation minimizes the number of calibrations necessary to evaluate the machine behavior. A Brown \& Sharp Moving Bridge Coordinate Measuring Machine was used for the experimental evaluation. With this data set and knowing the machine geometry, a mathematical expression relating straightness and angular error was obtained. The calculated error values were then compared with the errors experimentally measured.

Key-words: Three Coordinate Measuring Machines(CMM), Straightness error, Angular error. 


\section{CAPÍTULO 1 \\ INTRODUÇÃO}

Na competição por maiores parcelas de mercado e com o advento do processo de globalização, as empresas tem procurado cruzar fronteiras com seus produtos. Tais produtos devem ter preços competitivos, promoções de vendas e sobretudo qualidade competitiva em mercados internacionais. Dentre muitos aspectos da qualidade um dos importantes é o produto estar de acordo com as especificações técnicas, o que garante a intercambiabilidade e a funcionalidade. Para isto existem as especificações técnicas e as normas nacionais e internacionais para garantir a precisão durante a fabricação.

O conceito de precisão de máquinas ferramentas está mudando juntamente com o desenvolvimento tecnológico. Antes considerada uma característica geométrica da máquina, agora é definida como a capacidade de produzir peças dentro de limites definidos, sem a intervenção substancial do operador e em diferentes condições de trabalho.

Mesmo nas mais diferentes condições de trabalho a procura pelo aumento do volume de produção e melhoria da qualidade dos produtos é constante e exige o aprimoramento dos mecanismos de Controle de Qualidade. As Máquinas de Medir a Três Coordenadas (MM3Cs) neste novo contexto se tornam necessárias ao ambiente das indústrias que procuram sistemas de medição flexíveis, rápidos e confiáveis, para a execução do controle dimensional de peças manufaturadas. 
Entretanto, estas máquinas são instrumentos fundamentalmente mecânicos, e estão sujeitas a erros. Estes erros são inerentes à sua estrutura e nas Máquinas de Medir a Três Coordenadas afetam a qualidade da medição. No caso das Máquinas Ferramentas, os erros afetam a qualidade dimensional final das peças. Os movimentos indesejáveis de cada um dos componentes da máquina são também conhecidos como erros geométricos.

Os testes de calibração tem crescido na sua importância, pois é através deles que se conhece o comportamento metrológico das máquinas, ou que se expede ou se aceita uma máquina.

E também através da calibração destes erros que o comportamento metrológico das máquinas pode ser conhecido e desta forma, sistemas de compensação de erros podem ser desenvolvidos. Alguns destes procedimentos de calibração visam avaliar os erros individualmente, erros de translação e de rotação de corpo rígido, em cada uma das direções preferenciais da máquina. São considerados erros de translação os erros de posicionamento e de retilineidade, os erros de rotação são os erros conhecidos como Pitch, Yaw e Roll.

Atualmente, no modelamento das componentes dos erros volumétricos de máquinas em geral, adota-se a independência entre os erros de retilineidade e os angulares. Entretanto, se analisada a geometria da máquina e o comportamento dos erros, pode-se verificar que eles são dependentes. Assim sendo, o erro angular pode ser escrito em função do erro de retilineidade.

Face ao exposto acima é objetivo deste trabalho expressar, através de uma formulação matemática, o erro angular em função do erro de retilineidade. Tal formulação permite que seja minimizado o número de calibrações necessárias e consequentemente o tempo requerido para o levantamento do comportamento metrológico de uma máquina. Nas indústrias, para execução desses levantamentos, é necessário que as máquinas fiquem inativas durante um certo período. Assim sendo, o tempo de calibração é de extrema importância. 
Para atingir este objetivo foi inicialmente feita a calibração dos erros de retilineidade e erros angulares da $\mathrm{MM} 3 \mathrm{C}$ para que se pudesse equacionar e comparar os erros angulares calculados e medidos. Este desenvolvimento foi realizado no Laboratório de Metrologia do LAMAFE e as experimentações em uma Máquina de Medir a Três Coordenadas tipo Ponte Móvel. Conhecendo-se, então, o comportamento dos erros de retilineidade e a estrutura da máquina, foi desenvolvida uma formulação matemática para o cálculo dos erros angulares.

Assim este trabalho desenvolveu-se como mostrado a seguir:

No capítulo dois, são apresentados uma revisão bibliográfica sobre os erros geométricos em MM3Cs e Máquinas Ferramentas, assim como os fatores que influenciam estes erros. É dado um enfoque especial aos erros de retilineidade e erros angulares.

No capítulo três são apresentados alguns conceitos básicos para análises estatísticas dos dados. Também são descritos as análises de tratamento dos erros de retilineidade e os estudos de casos de Bryan.

O capítulo quatro apresenta a proposta do trabalho, isto é, o desenvolvimento e associação entre o erro de retilineidade e o erro angular. As etapas envolvidas para a efetivação da proposta também são apresentadas.

No capítulo cinco está apresentado o desenvolvimento da metodologia proposta. Nele estão descritos o processo de calibração utilizado, a formulação matemática proposta, assim como um estudo de propagação dos erros.

No capítulo seis os resultados experimentais são apresentados e discutidos, e o método proposto é comparado com os resultados obtidos através das calibrações.

O capítulo sete apresenta as conclusões relativas ao trabalho desenvolvido e sugestões para futuros trabalhos. 


\section{CAPÍTULO 2}

CONSIDERAÇÕES GERAIS SOBRE OS ERROS

GEOMÉTRICOS NAS MÁQUinAs FERRAMENTAS E

MÁquina DE MEDIR A TRÊS COORDENADAS

A acuracidade nos processos de usinagem e de medição é influenciada por vários fatores. Tais fatores podem ser independentes da máquina ou inerentes à sua própria estrutura. Estes fatores causam movimentos indesejáveis nos componentes da máquina, e são denominados erros geométricos.

Apesar da evolução da tecnologia utilizada nos projetos das máquinas, os erros vão estar sempre presentes, provocando desvios com relação a um sistema de coordenadas de referência, que modificam a trajetória ideal da ferramenta ou peça, no caso das máquinas ferramentas, ou da sonda, no caso das MM3Cs. Este desvio é comumente chamado de erro volumétrico.

É imprescindível, portanto, conhecer os erros para que se possa interpretá-los corretamente e saber onde atuar para minimizar os seus efeitos. 


\title{
2.1 - Fontes E FATORES CAUSADORES DE ERROS NAS MÁquinas FERRAMENTAS E MÁQUINA DE MEDIR A TRÊS COORDENADAS
}

\begin{abstract}
São diversos os fatores que modificam a precisão das máquinas. A seguir estes fatores estão apresentados em dois grandes grupos: fatores de erros nas máquinas ferramentas e fatores de erros nas MM3Cs.
\end{abstract}

\subsection{1 - ERROS NAS MÁQUINAS FERRAMENTAS}

Segundo HOCKEN et al (1980), existem diversos fatores que podem ser identificados como causadores de erros nas máquinas ferramentas. Entre eles, as deformações térmicas, as deformações devido à carregamentos, erros do eixo árvore, erros devido a desgaste da ferramenta ou da máquina, erro de Abbè, entre outros.

\section{- Erros Causados Por Deformações Térmicas}

Os erros térmicos são causados por variações de temperatura da máquina ferramenta que provocam desvios na posição relativa planejada entre a ferramenta e a peça. Mesmo em condições de temperatura controlada, as máquinas assumem diversos estados térmicos até atingirem o estado de equilíbrio à temperatura de operação.

BRYAN (1990) afirmou que os erros térmicos constituem-se na maior fonte individual de erros em máquinas ferramentas. 
Observa-se na Figura 2.1, as possíveis fontes de calor que podem afetar as máquinas ferramentas. Possivelmente pode ser utilizada para localizar os pontos onde se deve atuar para diminuir as causas desses erros.

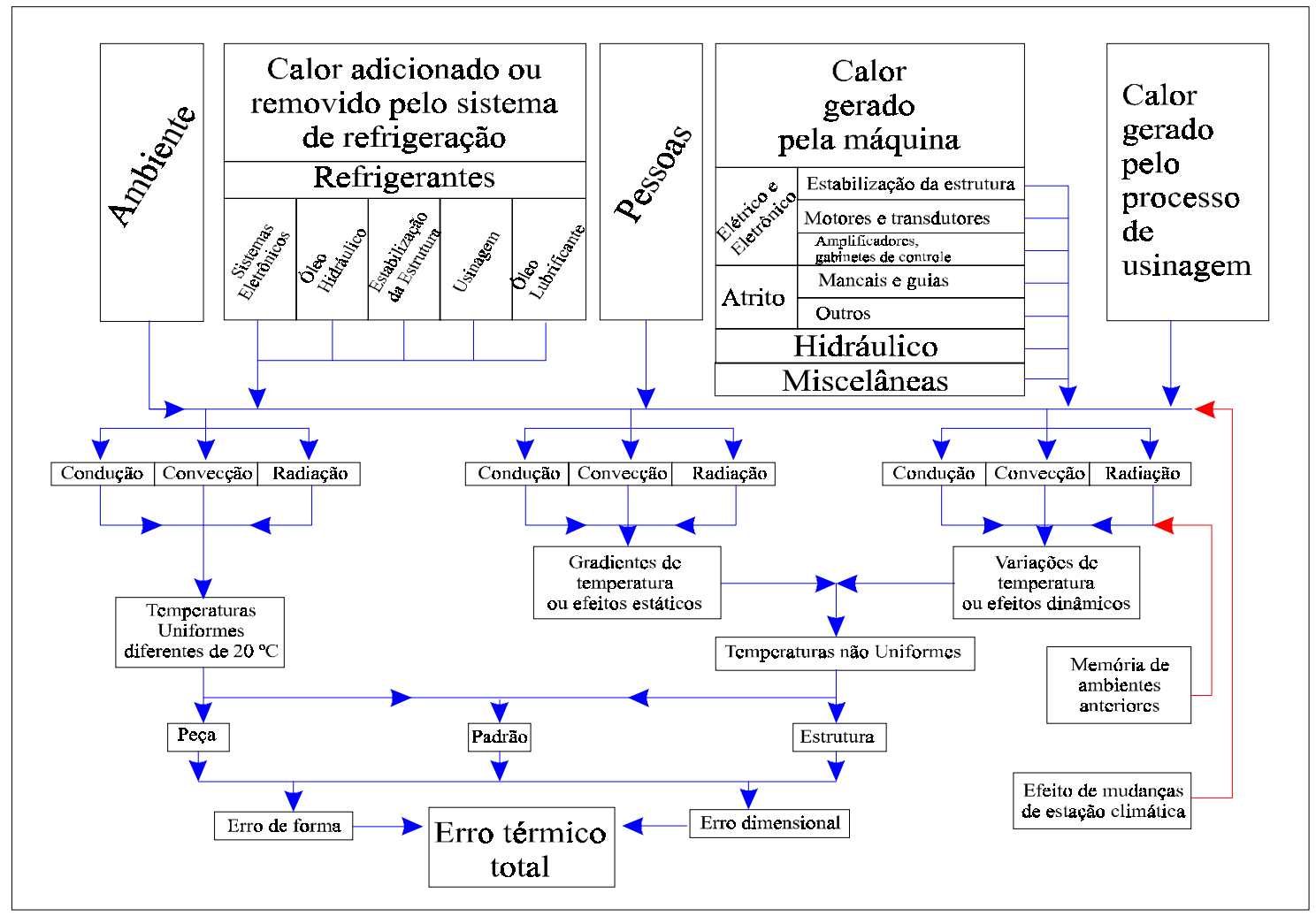

Figura 2.1 - Fontes de erros térmicos em máquinas ferramentas (VIEIRA

SATO, 1998)

\section{- Erros Causados Por Deformações devido à Carregamentos}

Os erros devido ao carregamento podem ser divididos em dois tipos básicos:

- Erros devido ao peso próprio da máquina. Estes erros ocorrem pois algumas partes são móveis e portanto a distribuição do peso não é constante;

- E erros devido ao peso das peças usinadas. Estes pesos podem assim produzir deformações nas guias e deflexões da estrutura da máquina. 
Os efeitos destes erros podem variar em função da geometria e rigidez da máquina além do tipo de operação.

\section{- ERros do EIXo ÁrVORE}

A maioria das máquinas ferramentas possuem um eixo árvore. Este em geral, é o responsável por um dos movimentos durante o processo de usinagem da peça.

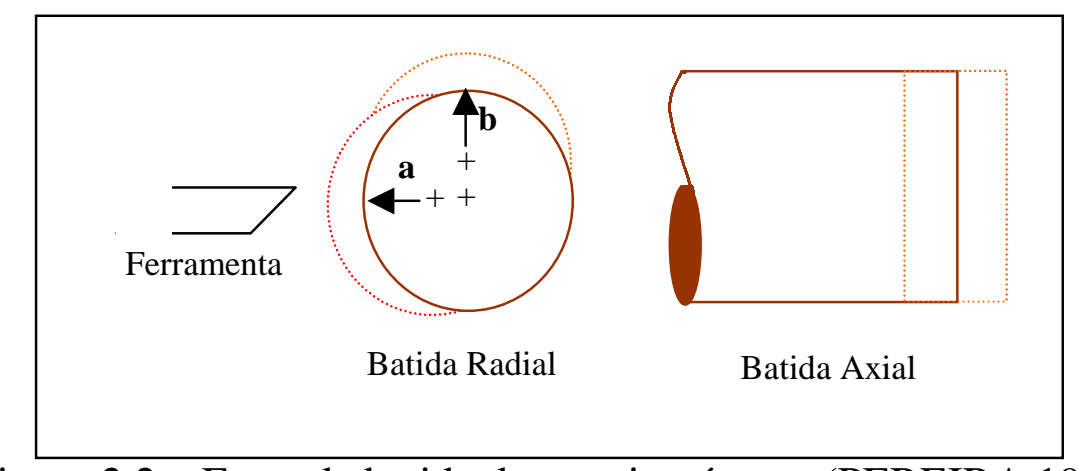

Figura 2.2 - Erros de batida de um eixo árvore (PEREIRA,1995)

O eixo árvore pode sustentar a própria peça, no caso dos tornos, ou a própria ferramenta como no caso das fresadoras e mandriladoras (BRYAN \& VANHERCK, 1975). Neste tipos de eixos podem ocorrer erros de batida radial e axial, Figura 2.2, provocando erros na peça usinada.

Os erros de batida radial podem ser decompostos nas direções a e b conforme mostra a Figura 2.2. Podem ser entendidas como sensitiva e não sensitiva, dependendo da máquina. Suponha que a Figura 2.2 ilustre um torneamento no qual a direção a é a sensitiva por estar na direção da profundidade de corte e $\mathbf{b}$ é a não sensitiva que é perpendicular ao movimento de penetração da ferramenta de corte. Pode-se, então, concluir que a direção sensitiva, interfere mais diretamente nos erros da peça por afetar a profundidade de corte. 
- ERros deVido aos Desgastes das Ferramentas ou da Máquina

O desgaste de ferramentas é uma fonte de erro que sempre está presente no processo de usinagem. $\mathrm{O}$ desgaste ocorre em consequiência do atrito existente entre a ferramenta e a peça, causando assim perda de dimensão desejada, alteração no acabamento da peça e deformação da peça.

As máquinas, após um certo tempo de uso, podem apresentar desgastes também, produzindo erros sistemáticos que influenciam as peças ali usinadas.

\section{- ERro De AbBè}

O Professor Abbè em 1890 publicou no "Journal for Instrumental Information" , a primeira concepção a respeito do uso de escalas graduadas como sistema de medição de comprimentos e os benefícios obtidos casos estas escalas estivessem alinhadas com o comprimento a ser medido (BRYAN,1979).

O primeiro e único princípio de projeto de máquinas ferramentas e da metrologia dimensional consiste na concepção de máquinas com o sistemas de medição colineares com os deslocamentos a serem medidos. Neste caso, diz-se que há concordância com o Princípio de Abbè. No entanto, a concepção de tais máquinas é praticamente impossível. Bryan reavaliou o Princípio de Abbè propondo o que se conhece como Princípio Generalizado de Abbè, que foi, assim enunciado:

"O sistema de medição de deslocamento deve estar colinear com o ponto funcional no qual o deslocamento é medido. Se isso não for possível, todas as guias que transferem o deslocamento devem estar livres de movimentos angulares ou os dados do movimento angular devem ser usados para calcular as consequência dos desvios."

A primeira sentença representa a recomendação original de Abbè, enquanto a segunda sentença sugere duas opções adicionais: uma quando não existe movimento angular e outra quando este está presente. 
É praticamente impossível obter guias absolutamente isentas de movimentos angulares pelos processos de fabricação atualmente existentes. Existindo então os movimentos angulares pode-se utilizar dados desses movimentos para cálculo e correção dos erros causados. Os mais modernos sistemas CNC (Controle Numérico Computadorizado) podem ser programados para aceitar dados do movimento angular, calcular e compensar os efeitos dos erros angulares (BRYAN,1979).

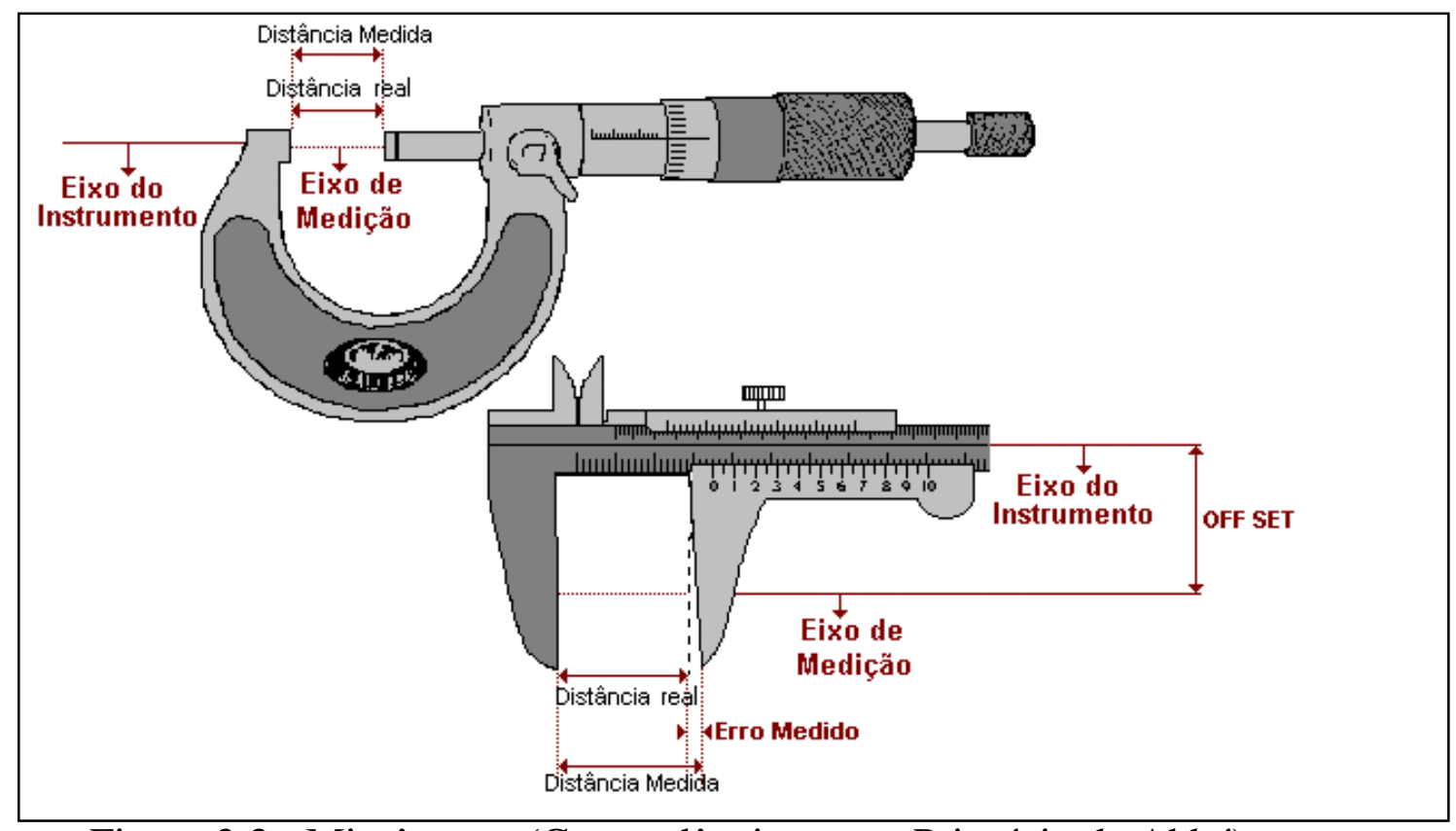

Figura 2.3 - Micrômetro (Concordância com o Princípio de Abbé) e Paquímetro (Transgressão do Princípio de Abbè)

Pode-se dizer que o erro de Abbè é dependente da distância entre a posição do ponto que se está medindo e a escala do seu respectivo eixo. Esta distância é conhecida como braço de Abbè e está ilustrada na Figura 2.3. Portanto, quanto maior o braço de Abbè, maior será o erro devido a transgressão do Princípio de Abbè.

ZHANG em 1989 propôs uma extensão para o princípio de Abbè, apresentando uma metodologia para o cálculo do Erro de Abbè para 2 e 3 dimensões com os seguintes termos e concepções: 
Qualquer medição dimensional é um processo de comparação do valor medido e o valor normalizado de peças padronizadas. As referências podem ser peças padrões, tais como: blocos padrões, escalas, réguas padrões, etc., ou referências naturais, tais como: comprimentos de onda, raios óticos, ou uma referência móvel, como um movimento linear padrão.

$\mathrm{O}$ erro de Abbè, para uma dimensão é dado:

$$
\delta=\Delta(\mathbf{L} \operatorname{sen}(\varphi))
$$

Onde L é a distância entre a referência, na direção da escala de leitura, e o ponto sensível, na direção de medição e paralelo a direção da escala de leitura, e $\varphi$ é o ângulo de Abbè igual a $90^{\circ}$ menos o ângulo entre a direção sensível, isto é, a reta que liga a referência e o ponto sensível. No caso de L ser constante a fórmula para calcular o erro de Abbè pode ser reescrita como:

$$
\delta=\mathbf{r} \Delta \varphi
$$

\section{- OUTROS TIPOS DE ERROS}

Além dos erros citados existem outros que ainda podem ser comentados, tais como: erro devido à fixação incorreta da peça e da ferramenta; vibrações mecânicas; pressão; atrito; erros de cosseno; oscilação na alimentação elétrica dos motores da máquina; variações ambientais; erros devido a fatores imprevisíveis, dentre eles, erros do operador da máquina, etc.

\subsection{2 - ERROS NAS MÁQUINAS DE MEDIR A TRÊS COORDENADAS}

Segundo SOSA (1995) existem 2 tipos de fatores que influenciam a medição a três coordenadas, os dependentes e os independentes da máquina. Alguns dos mais relevantes fatores dependentes são: transgressão do Princípio de Abbè; erros devido à sonda de medição; erros devido à forma das guias; o desempeno de referência; erros devido ao peso próprio; integridade dos 
programas computacionais. E os independentes são: influência do acabamento da peça; erros devido às variações de temperatura; entre outros.

\section{- Transgressão do Princípio de Abbè}

As MM3Cs podem ser encontradas em diferentes construções, tais como, Cantilever de Mesa Fixa ou Mesa Móvel, Ponte Móvel, Ponte Fixa, de Braço Horizontal com Mesa Fixa ou Mesa Móvel, Coluna, Ponte em forma de "L" e tipo Pórtico (ASME B89.1.12M, 1990). Estes diferentes tipos apresentam em comum a transgressão ao Princípio de Abbè (DI GIACOMO, 1986), isto é, a linha de medição das MM3Cs não corresponde à linha de referência do sistema de medição. A transgressão do Princípio de Abbè já foi tratada com detalhes no item 2.1.1

\section{- Erros Devido a Sonda de Medição}

A sonda de medição é responsável pela definição do ponto a ser medido. Ela funciona como uma interface entre a superfície geométrica em inspeção e o sistema de medição e pode ser classificada em função das suas características como sonda com contato e sonda sem contato. As sondas com contato podem ser do tipo rígida ou de gatilhamento e as sem contato do tipo laser ou sistemas de visão (BOSCH, 1995).

As fontes que influenciam a acuracidade do sistema apalpador, são: problemas eletrônicos, desgastes dos apoios cinemáticos, variações de forças devido a direção de contato e outras. Deve-se então sempre que possível conhecer o desempenho da sonda e seus erros para que se possa compensá-los nas medições das peças. (HARVIE, 1986)

\section{- ERros DeVIdo À Forma das GuIAS E do DESEMPENo de REFERÊNCIA}

As MM3Cs dependem fundamentalmente das guias e da precisão das mesmas. Os erros de forma das guias ocorridos durante o processo de usinagem, que tem como exemplo os erros de retilineidade, planicidade, etc... 
e produzem também movimentos indesejáveis da ponta da sonda. Então quanto menores forem os erros de forma das guias, menores serão os erros da máquina.

$\mathrm{O}$ desempeno de referência equipa todas as MM3Cs e serve para o posicionamento das peças. Ele é feito de granito natural, sintético ou ainda em ferro fundido. $\mathrm{O}$ erro de planicidade do desempeno de referência deve ser mínimo, senão, em conjunto com os erros geométricos pode resultar em um grande erro sistemático, e portanto, não serve para sua função primária, ou seja, servir como superfície de referência (PAHK \& BURDEKIN, 1991).

\section{- Erros Devido ho Peso Próprio}

Os erros devido ao peso próprio ocorrem em todas as máquinas, e a sua grandeza depende essencialmente do projeto da estrutura e da sua conseqüente rigidez .

\section{- INTEgRidade dos Programas Computacionais}

O software das MM3Cs tem a função de obter e avaliar os dados da medição. Além disso, nas máquinas controladas numericamente, os movimentos podem ser programados para efetuar sequiências de medição. A qualidade da avaliação dos dados pode ser questionada e um teste de verificação realizado. Dois caminhos de verificação podem ser tomados: um é avaliar o algoritmo conhecendo todos os detalhes deste, o que na prática é difícil por se tratar de um segredo dos fabricantes e outro é avaliar pontos que simulem uma superfície conhecida; neste caso, WECKENMANN \& HEINRICHOWSKI (1985) sugerem o uso de padrões volumétricos virtuais.

\section{- Influência do ACabamento Da PeÇa}

O acabamento da peça pode levar a erros de interpretação de resultados. Por este motivo, deve-se antes da medição fazer uma análise rápida da qualidade da peça quanto à tolerância dimensional, de forma e acabamento 
superficial. O diâmetro da ponta da sonda pode ser definido para minimizar essas influências.

\section{- Erros Devido A Variações De Temperatura}

A temperatura padrão para operação nas MM3Cs é definida em $20 \pm 1^{\circ} \mathrm{C}$. Caso contrário, podem ocorrer mudanças nos comprimentos das escalas de medição, nos elementos da máquina e nas peças a serem medidas. Para reduzir as influências térmicas são utilizados ambientes controlados para instalação das MM3Cs. Sistemas de compensação dos efeitos térmicos significativos podem ser aplicados com a escolha de materiais adequados e técnicas de projeto que consigam minimizar às reações às interferências térmicas (BALSAMO et al, 1990; LINGARD et al, 1991).

\section{- OUtros ERros}

Outros fatores que influem na medição nas MM3Cs, são: vibrações, falta de continuidade e uniformidade da energia elétrica, suprimento descontínuo do ar comprimido, umidade e pressão atmosférica.

\section{2 - OS ERROS GEOMÉTRICOS}

Os erros geométricos podem ser classificados em 2 grandes grupos, os paramétricos e os não paramétricos. Os paramétricos abrangem aqueles erros que são individuais a cada componente. Enquanto, os não paramétricos são aqueles que acontecem devido à relação entre elementos, tais como, os erros de perpendicularismo e os erros de paralelismo.

Para melhor entendimento, considere um carro de uma máquina como um corpo rígido, com a possibilidade de movimento de translação em apenas uma direção, como ilustra a Figura 2.4. Observe que o movimento de deslocamento é realizado na direção X. No entanto, a leitura na escala do eixo 
$\mathrm{X}$ não indica o valor exato do deslocamento experimentado pelo carro. Este erro é denominado erro de posição ou de escala e denota-se por $\delta_{\mathrm{x}}(\mathrm{x})$.

As translações nas outras direções e rotações indesejáveis, que o carro experimenta são denominados de erros de retilineidade e angulares, respectivamente. Os erros de rotação são comumente conhecidos como Pitch, Yaw e Roll conforme a direção do deslocamento do carro, e particularmente, para a ilustração da Figura 2.4, são respectivamente denotados por $\delta \theta_{\mathrm{y}}(\mathrm{x})$, $\delta \theta_{z}(x)$ e $\delta \theta_{x}(x)$.

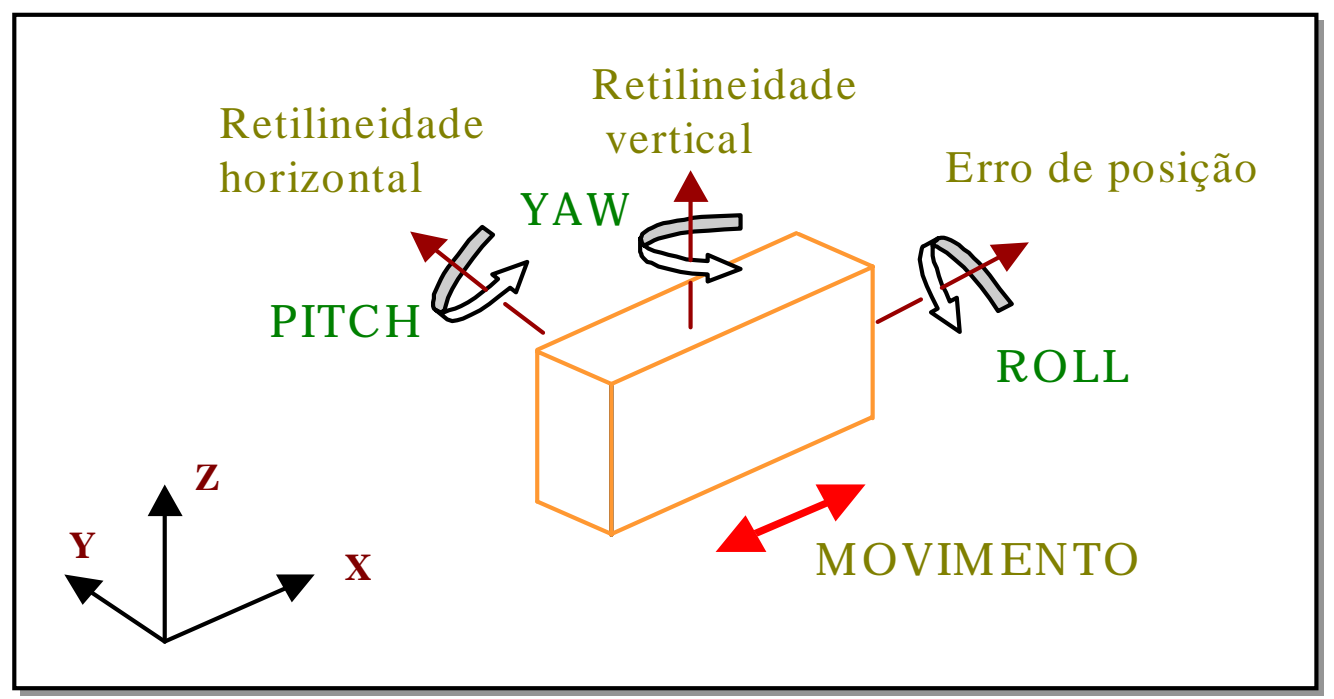

Figura 2.4 - Erros geométricos.

Tabela 2.1 - Notações dos erros geométricos (DI GIACOMO, 1986)

\begin{tabular}{|c|c|c|c||}
\hline \multicolumn{4}{|c|}{ Notações dos Erros Geométricos } \\
\hline \hline Direção & $\mathrm{X}$ & $\mathrm{Y}$ & $\mathrm{Z}$ \\
\hline \hline Posição & $\delta_{\mathrm{x}}(\mathrm{x})$ & $\delta_{\mathrm{y}}(\mathrm{y})$ & $\delta_{\mathrm{z}}(\mathrm{z})$ \\
\hline Retilineidade & $\delta_{\mathrm{y}}(\mathrm{x})$ & $\delta_{\mathrm{x}}(\mathrm{y})$ & $\delta_{\mathrm{x}}(\mathrm{z})$ \\
& $\delta_{\mathrm{z}}(\mathrm{x})$ & $\delta_{\mathrm{z}}(\mathrm{y})$ & $\delta_{\mathrm{y}}(\mathrm{z})$ \\
\hline Pitch & $\delta \theta_{\mathrm{y}}(\mathrm{x})$ & $\delta \theta_{\mathrm{x}}(\mathrm{y})$ & $\delta \theta_{\mathrm{x}}(\mathrm{z})$ \\
\hline Yaw & $\delta \theta_{\mathrm{z}}(\mathrm{x})$ & $\delta \theta_{\mathrm{z}}(\mathrm{y})$ & $\delta \theta_{\mathrm{y}}(\mathrm{z})$ \\
\hline Roll & $\delta \theta_{\mathrm{x}}(\mathrm{x})$ & $\delta \theta_{\mathrm{y}}(\mathrm{y})$ & $\delta \theta_{\mathrm{z}}(\mathrm{z})$ \\
\hline
\end{tabular}


Na Figura 2.4 tem-se o erro de retilineidade na direção Y devido ao movimento no eixo $\mathrm{X}$, denotado por $\delta_{\mathrm{y}}(\mathrm{x})$ e o erro de retilineidade na direção $\mathrm{Z}$ devido ao movimento no eixo $\mathrm{X}$, denotado por $\delta_{\mathrm{z}}(\mathrm{x})$. Se $\mathrm{X}$ e $\mathrm{Y}$ definem um plano horizontal, então $\delta_{\mathrm{y}}(\mathrm{x})$, é chamada de "retilineidade horizontal" e $\delta_{\mathrm{z}}(\mathrm{x})$ é chamada de "retilineidade vertical".

Neste capítulo será dada ênfase aos erros de retilineidade e aos erros angulares, pois são os pontos relevantes do trabalho.

\section{3 - OS ERROS DE RETILINEIDADE}

\subsection{1 - DEFINIÇÃO DOS ERROS DE RETILINEIDADE}

Na norma VDI/VDE 2617/Parte 3 (1989) encontra-se a seguinte definição de retilineidade: "Quando um ponto de referência sobre uma máquina move-se ao longo de um eixo coordenado ele descreve uma linha de movimento. $\mathrm{O}$ desvio desta linha de uma linha reta geométrica é denominado de erro de retilineidade".

Segundo BRYAN (1979) o erro de retilineidade de uma guia é o movimento linear transversal que um apalpador fixo observa com relação a uma régua perfeita ou o movimento linear transversal que um apalpador em movimento observa com relação a régua perfeita fixa.

Nomenclatura utilizada para os erros de retilineidade:

- $\delta_{\mathrm{y}}(\mathrm{x})$ e $\delta_{\mathrm{z}}(\mathrm{x})$ são os valores limites do desvio de retilineidade quando o carro se movimenta ao longo do eixo $\mathrm{X}$ e as medições dos desvios são feitas nas direções $\mathrm{Y}$ e Z, respectivamente.

- $\delta_{\mathrm{x}}(\mathrm{y})$ e $\delta_{\mathrm{z}}(\mathrm{y})$ são os valores limites do desvio de retilineidade quando o carro se movimenta ao longo do eixo $\mathrm{Y}$ e as medições dos desvios são feitas nas direções $\mathrm{X}$ e Z, respectivamente. 
- $\delta_{\mathrm{x}}(\mathrm{z})$ e $\delta_{\mathrm{y}}(\mathrm{z})$ são os valores limites do desvio de retilineidade quando o carro se movimenta ao longo do eixo $\mathrm{Z}$ e as medições dos desvios são feitas nas direções $\mathrm{X}$ e Y, respectivamente.

A seguir serão apresentadas algumas considerações sobre tolerância de retilineidade.

Tolerâncias são limites às variações dimensionais e geométricas das peças fabricadas. As tolerâncias são especificadas na fase de projeto do produto.

Denomina-se tolerância de retilineidade à zona de tolerância dentro da qual o elemento de superfície ou eixo considerado deve estar contido. Segundo a norma NBR 6409, que é baseada na norma internacional ISO, a zona de tolerância de retilineidade está dividida em 2 partes:

- tolerância de retilineidade de uma linha;

- tolerância de retilineidade de uma superfície em duas direções.

\section{- TOLERÂNCIA DE RETILINEIDADE DE UMA LINHA}

Uma tolerância de forma do elemento geométrico, no caso a linha, define o campo onde o elemento deve ficar situado. Este campo é limitado por um cilindro de diâmetro " $\mathrm{t}$ ".

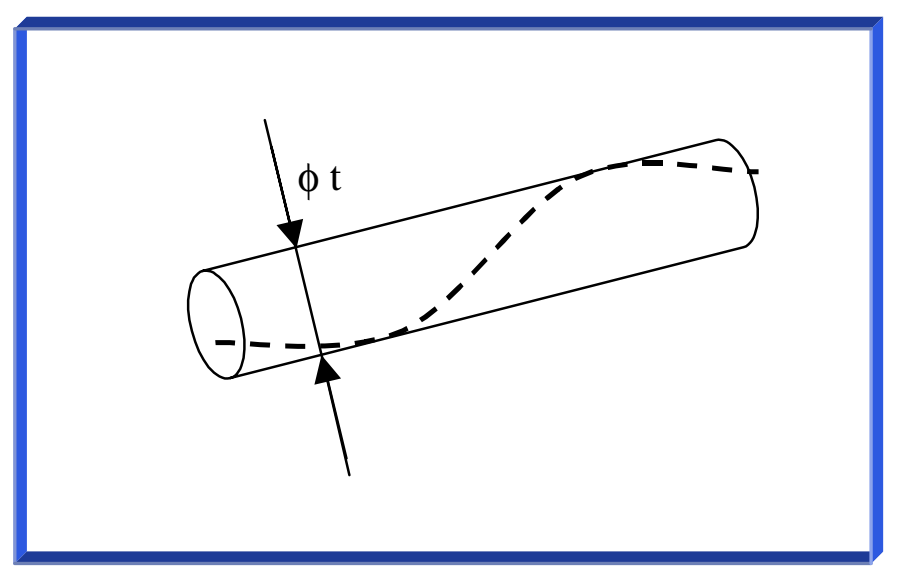

Figura 2.5 - Tolerância de retilineidade de uma linha 
Considerando a tolerância de retilineidade no plano de projeção do desenho sobre a qual ela está inscrita, o campo de tolerância fica limitado por duas retas paralelas, como ilustrado na Figura 2.6.

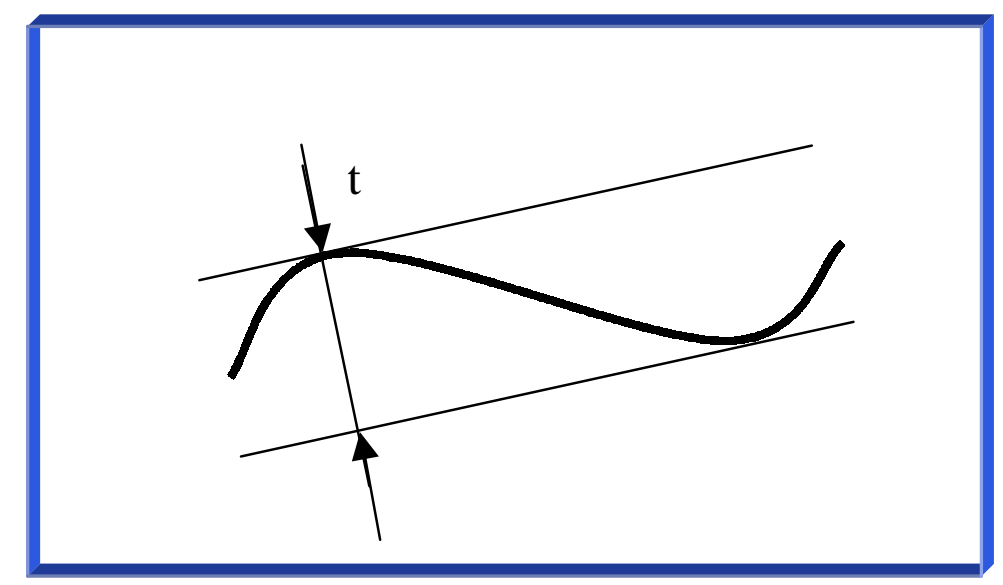

Figura 2.6 - Desenho do campo de tolerância

Se, por outro lado, a tolerância de retilineidade for aplicada a dois planos perpendiculares entre si, o campo de tolerância fica limitado ao espaço dentro de um paralelepípedo, como mostra a Figura 2.7.

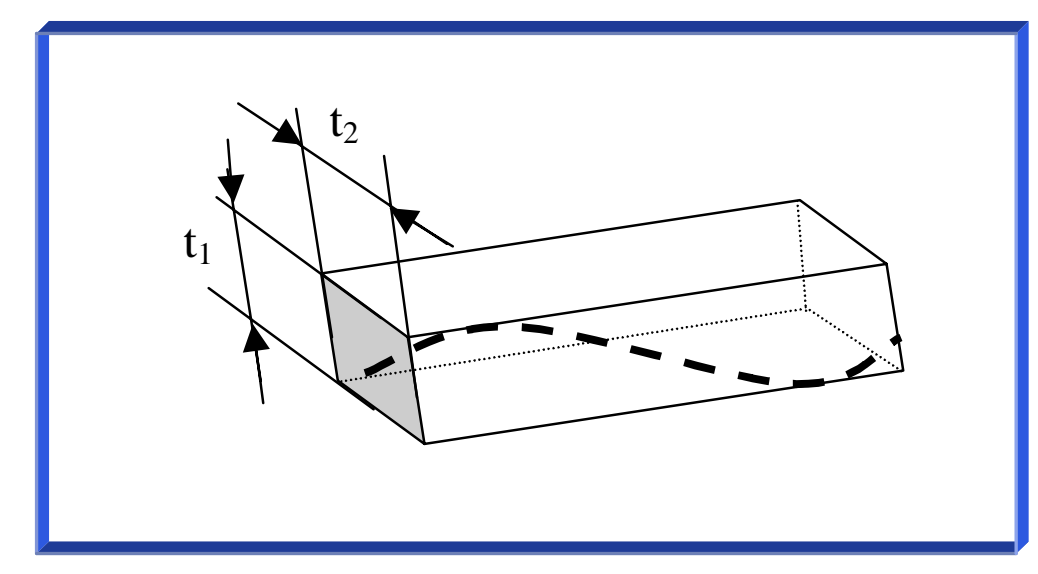

Figura 2.7 - Desenho do campo de tolerância de retilineidade quando aplicado a dois planos perpendiculares entre si 


\section{- TOLERÂNCIA DE RETILINEIDADE DE UMA SUPERFÍCIE}

A tolerância de retilineidade de uma superfície é aplicada em duas direções perpendiculares, de um mesmo plano conforme ilustrado na Figura 2.8 .

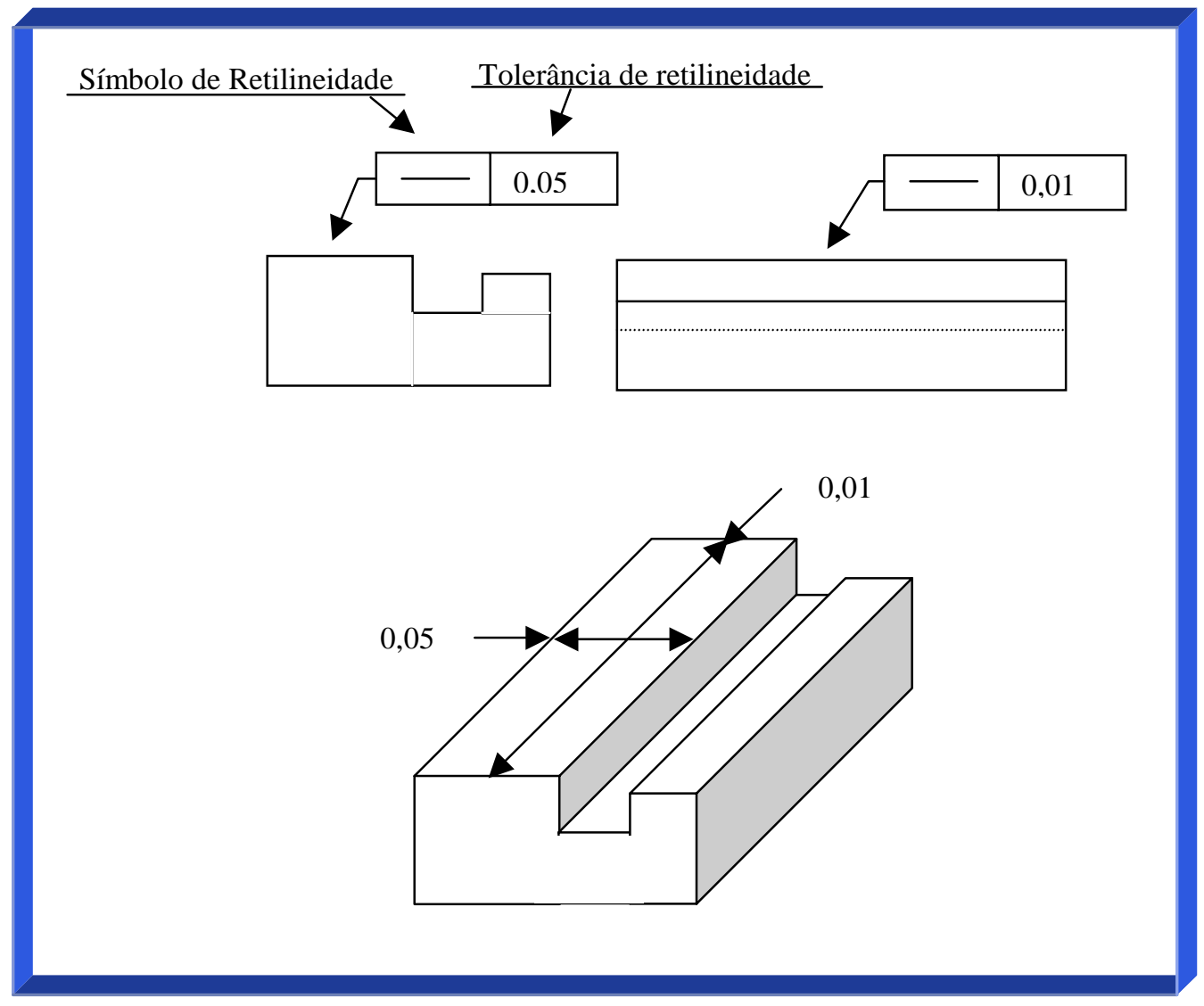

Figura 2.8 - Tolerância de retilineidade em duas dimensões

\subsection{2 - INSTRUMENTOS PARA MEDIÇÃO DOS ERROS DE RETILINEIDADE}

Os instrumentos mais comuns para a medição do erro de retilineidade nas máquinas são: régua padrão, o fio esticado com microscópio, o laser de alinhamento e o interferômetro laser (ESTLER, 1985). 


\section{- RÉGUa PAdRão}

As réguas padrões são equipamentos retangulares e sólidos feitos em aço, granito ou ferro fundido. Sua superfície de referência é geralmente rasqueteada no caso do ferro fundido, retificada para o aço e lapidada para o granito (HOCKEN, 1980). É muito usada para máquinas pequenas. A régua padrão é usada da seguinte forma: é alinhada paralelamente ao eixo guia. A medição é efetuada com um apalpador eletrônico ou mecânico, na direção transversal ao deslocamento realizado.

A pré-calibração da régua é requisito obrigatório por não ser perfeitamente retilínea, desta forma, pode-se avaliar o erro medido, utilizandose do método da reversão. Tal método consiste em se realizar medições ao longo da régua, numa determinada posição. Em seguida, efetuar uma rotação desta de $180^{\circ}$ sobre o seu próprio eixo e executar um novo processo de medição. Com os valores correspondentes aos dois conjuntos de leituras podese então calcular o erro da régua.

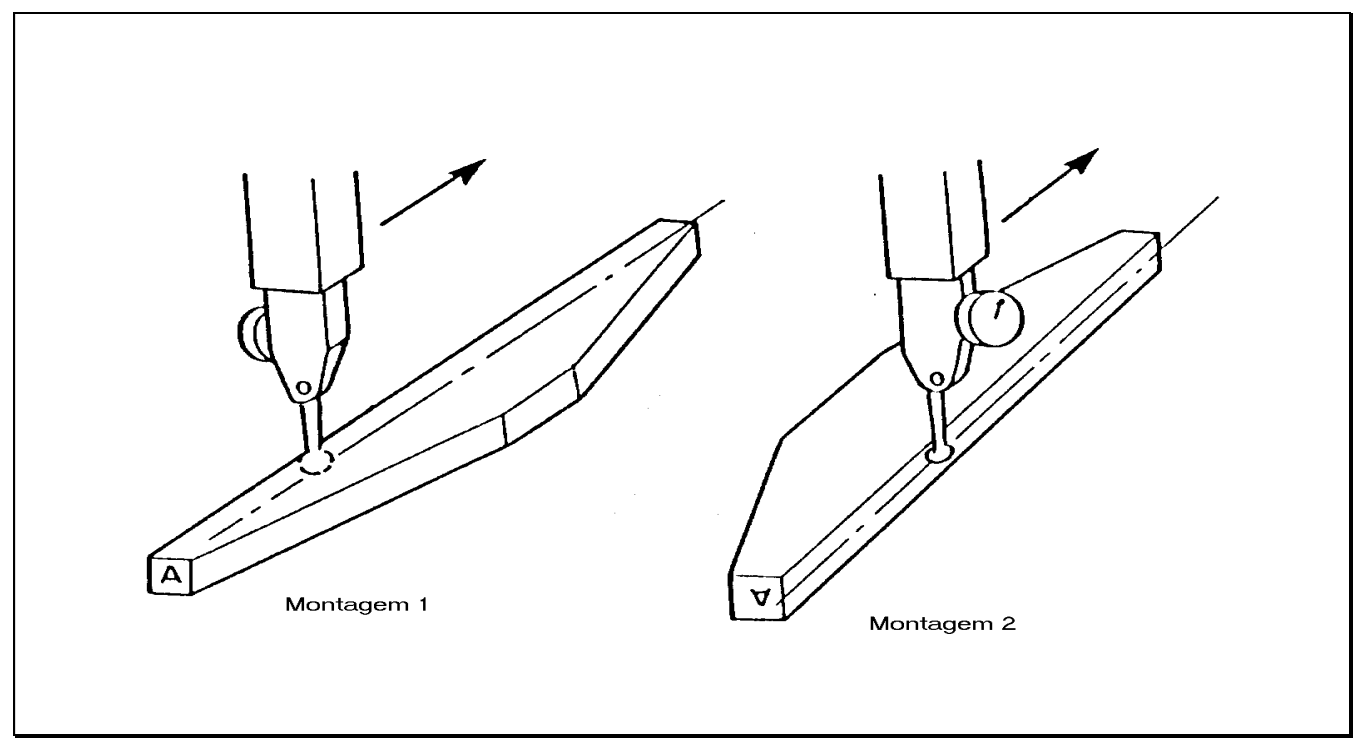

Figura 2.9 - Montagens típicas da régua padrão

Uma montagem típica é mostrada na Figura 2.9. Toda montagem deve ser feita cuidadosamente. Por exemplo, na montagem 1, Figura 2.9, se a leitura do apalpador é positiva, então, o erro de retilineidade é positivo. Na montagem 
2, se a leitura do apalpador for positiva, então o erro de retilineidade é negativo. No capítulo 3 estão apresentados mais detalhes sobre os métodos de reversão.

\section{- FIO ESTICADO E MICROSCÓPIO}

A montagem para medição com fio esticado e microscópio está mostrada na Figura 2.10. Este instrumento é muito utilizado em máquinas grandes. Um fio é esticado ao longo da superfície de uma máquina na direção do eixo em que se deseja executar a medição. Um microscópio é montado no eixo árvore ou na guia da máquina. A medição da retilineidade vertical com fios na horizontal é quase impraticável pois deve-se executar as correções devido a catenária (WECK, 1984).

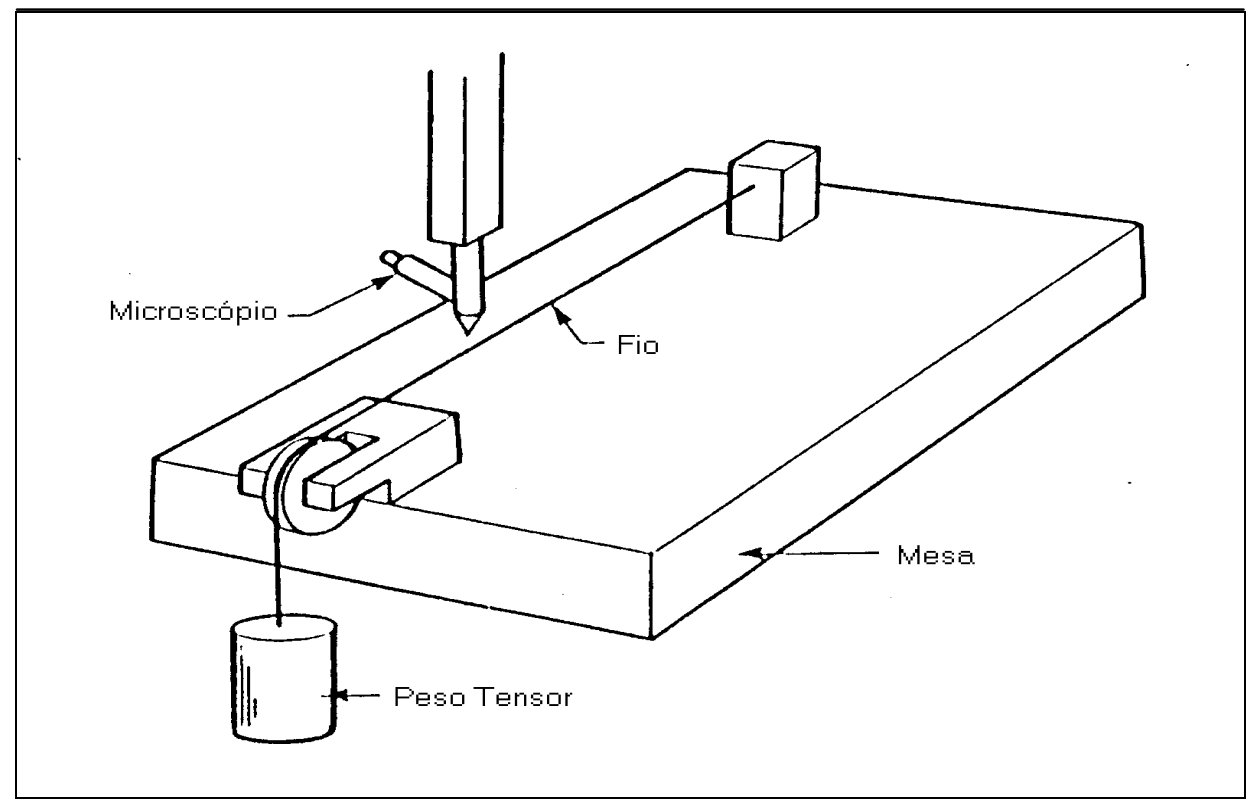

Figura 2.10 - Medição com fio esticado e microscópio 


\section{- LASER DE ALINHAMENTO}

A medição com o laser de alinhamento é mostrada na Figura 2.11. Usase a linha de centro de um feixe laser como a linha de referência para retilineidade. O laser é montado na parte fixa da máquina. Os desvios laterais da parte móvel em relação ao centro do feixe laser é sentido por uma fotocélula de quadrantes.

Um filtro de luz no sensor pode ser necessário para que se reduza os efeitos da luz ambiente. Uma vez que o feixe laser pode sofrer um pequena variação devido à distorção mecânica, instabilidade na cavidade do laser e correntes de ar, cuidados especiais devem ser tomados. Em alguns casos um ventilador é usado para eliminar os erros sistemáticos devido ao gradiente de temperatura de ar.

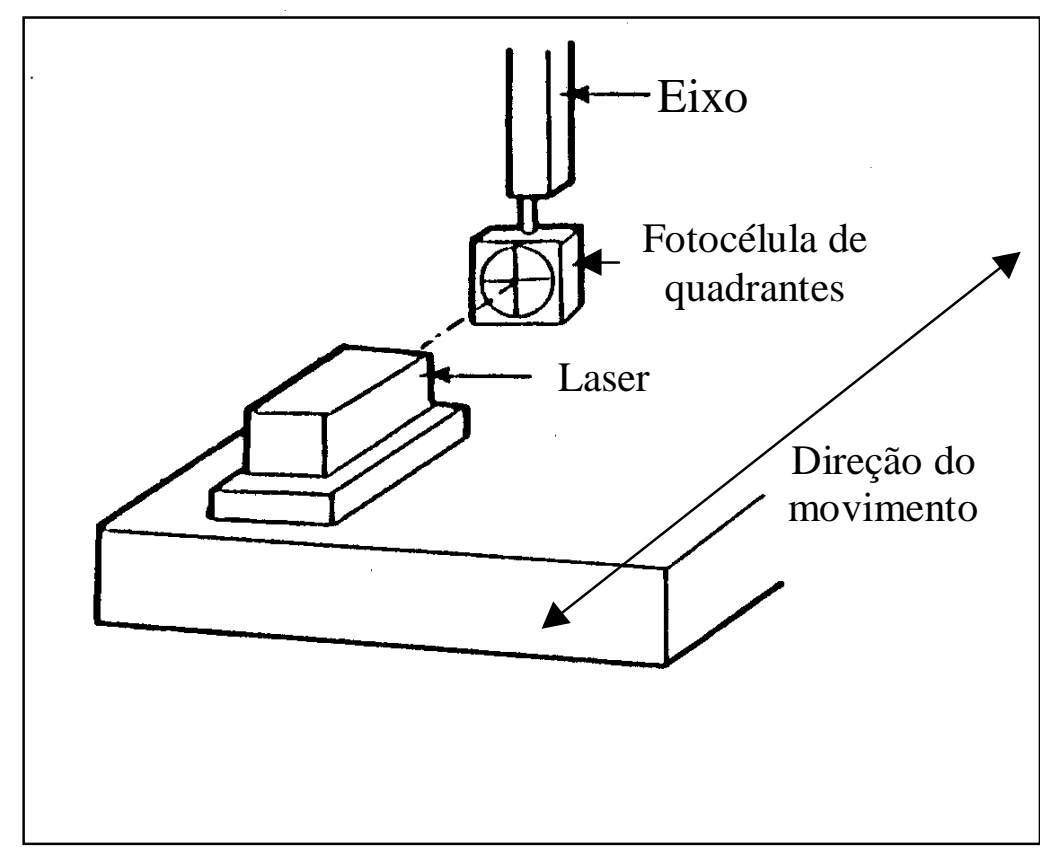

Figura 2.11 - Laser de alinhamento 


\section{- INTERFERÔMETRO LASER}

Os interferômetros são compostos por uma fonte de luz, um elemento divisor de feixes, um refletor e um detector para observação de franjas de interferência (THOMAS, 1974).

A medição interferométrica desses deslocamentos lineares é conseguida através do princípio de Michelson.

$\mathrm{O}$ interferômetro funciona basicamente da seguinte forma: uma fonte laser estabilizada " $L$ " emite um feixe de luz com comprimento de onda " $\lambda$ ", que incide em um espelho parcial "S", onde é separado em dois outros feixes "F1" e "F2". O feixe "F1" incide no espelho "E1", retornando para "S" e posteriormente ao receptor "R". Do mesmo modo, o feixe "F2" incide no espelho "E2", sendo refletido para "S", e em seguida para o receptor "R". Ao se dirigir para "R" os feixes "F1" e "F2" se recombinam, formando um sinal cuja intensidade é proporcional às amplitudes e à fase entre os dois feixes.

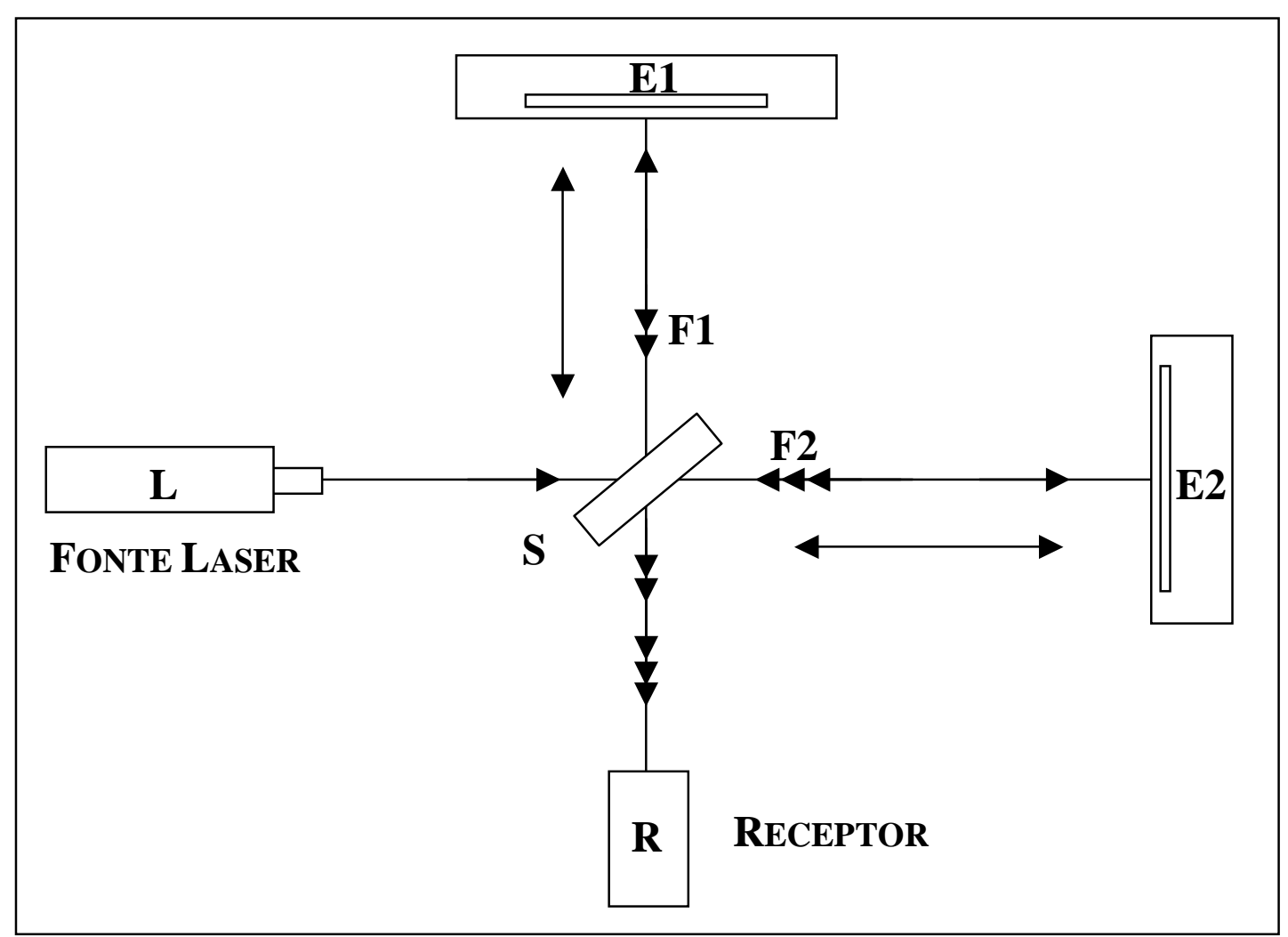

Figura 2.12 - Princípio do Interferômetro Laser 
Se o espelho "E1" é fixo em "S", a amplitude e a fase do feixe recombinado em "R", torna-se função somente da variação da posição do espelho "E2" em relação a "S". Considerando um deslocamento em "E2" de uma quantia que provoque a defasagem dos feixes de " $2 \mathrm{n}$ " meios comprimentos de onda, sendo " $\mathrm{n}$ " um número inteiro, verifica-se que em "R" ocorre uma coincidência das fases dos feixes "F1" e "F2" que torna máxima a intensidade do feixe recombinado. Nestas condições, diz-se ocorrer uma interferência construtiva entre "F1" e "F2", gerando um claro sobre o receptor "R". Se o deslocamento de "E2" provoca uma defasagem de " $2 n+1$ " meios comprimentos de onda, um sinal de intensidade mínima é gerado sobre "R", conseguindo assim uma interferência destrutiva dos feixes e uma região "escura" sobre o receptor. Deste modo, verifica-se que a cada " $\lambda / 2$ " de defasagem entre os feixes, "R" sofre uma transição de claro-escuro, sendo esta transição a responsável pela geração da escala de deslocamento definida pelo princípio da interferômetria.

A calibração dos erros de retilineidade pode ser realizada através do interferômetro laser e de uma montagem adequada das óticas. São duas as montagens básicas dessas óticas, uma para distâncias curtas e outra para distâncias longas. O princípio básico de medição deste erro, também tem como suporte as duas freqüências "F1" e "F2" no feixe emitido pela unidade laser. Essas duas freqüências ao atingir o interferômetro "Prisma de Wollaston" são separados em dois outros que percorrem caminhos diferentes até o espelho refletor. Os feixes refletidos voltam ao interferômetro, onde são recombinados. São obtidas então variações de frequiências $\Delta \mathrm{f}_{1}$ e $\Delta \mathrm{f}_{2}$ devido ao comprimento relativo entre Wollaston e o espelho. Estes sinais recebidos pela fotocélula na unidade laser, são processados eletronicamente e convertidos em deslocamentos transversais à direção preferencial (Figura 2.13).

Os sistemas interferométricos a laser para fins metrológicos tem sido aceitos como ferramentas de grande acuracidade há alguns anos. Entretanto, 
para sua aplicação alguns cuidados devem ser tomados com respeito as condições do ambiente onde serão realizadas as medições.

A acuracidade da medição efetuada com o interferômetro laser é em grande parte dependente da estabilidade do comprimento de onda da luz do laser. Este é influenciado por fatores do meio ambiente, tais como: pressão do ar, temperatura, umidade, quantidade de dióxido de carbono e condições operacionais do laser. Consequentemente as condições do meio ambiente devem ser monitoradas durante o processo de inspeção e medição.

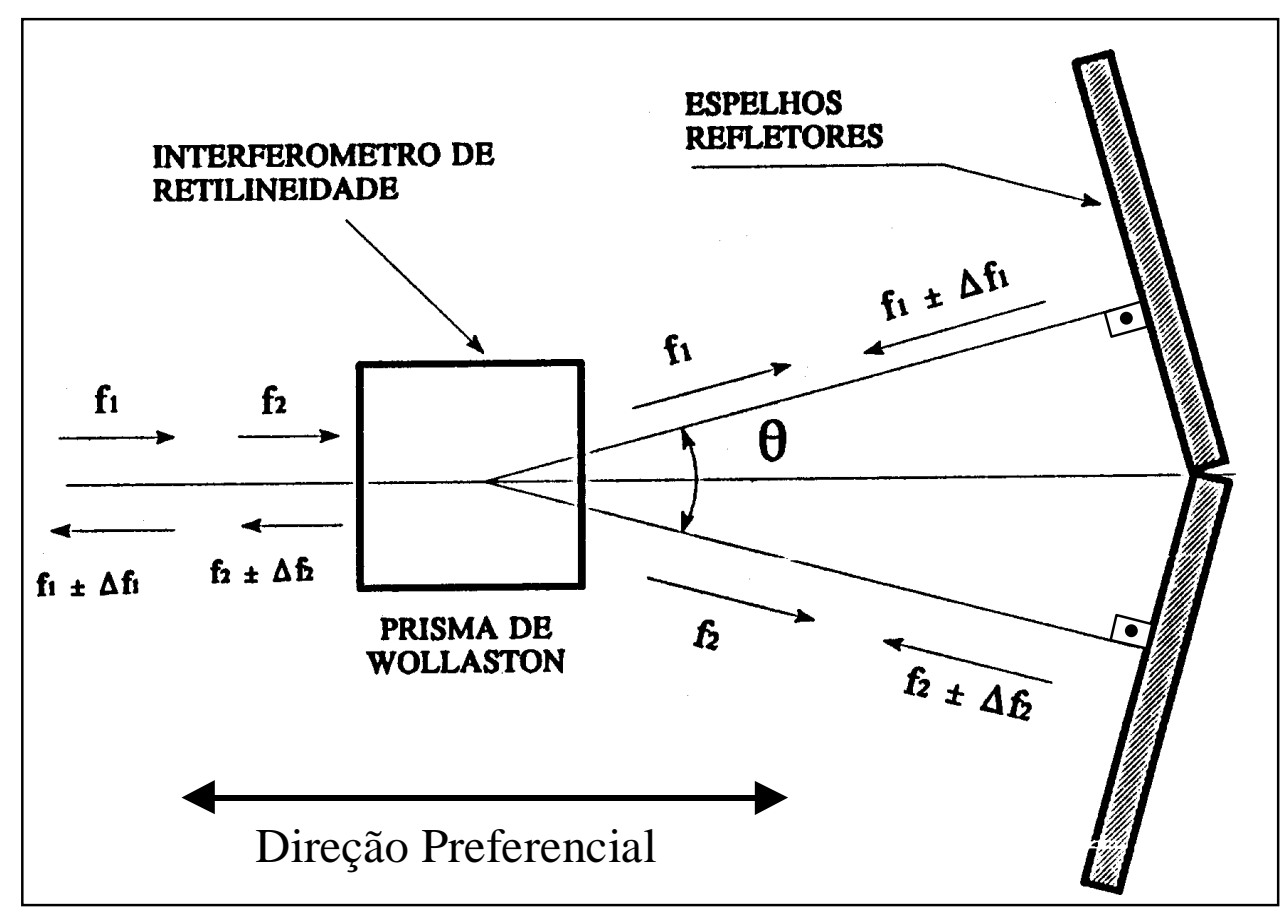

Figura 2.13 - Esquema básico para medição de retilineidade

Durante a medição de retilineidade, alguns requisitos devem ser cumpridos, entre eles estão: a distância mínima entre o interferômetro e o refletor deve ser igual a $100 \mathrm{~mm}$ e o alinhamento do sistema interferométrico deve ser melhor que 50\% (SOSA CARDOZA, 1995). 


\subsection{3 - MÉTOdos PARA MEDIÇÃo DO ERRO DE RETILINEIDADE}

$\mathrm{Na}$ literatura são encontrados diferentes métodos para se medir o erro de retilineidade. $\mathrm{O}$ estudo destes métodos oferece a possibilidade de se determinar um processo de calibração adequado, com maior facilidade na percepção dos erros. Na escolha do método a ser utilizado, deve-se levar em consideração a acuracidade da técnica de medição. Esta é afetada pelo esquema de amostra, erros sistemáticos, e ruídos aleatórios dos dados (CARR \& FERREIRA, 1995).

A seguir serão apresentados alguns destes métodos.

\section{- MÉTOdo STEPPING-OFF}

O método proposto por YAMAMOTO \& IWASAKI em 1985 é o método "stepping-off", popularmente usado na indústria com auxílio de um autocolimador. Tal método consiste na montagem, em uma superfície, de um espelho com duas bases com uma distância $l$ entre elas, e na medição do ângulo de inclinação do espelho por um autocolimador. O ângulo é denotado por $\theta_{i},(i=1,2, \ldots, \mathrm{n})$ e a diferença de altura entre duas posições vizinhas $(i-1) \mathrm{e}$ (i) podem ser calculadas por [2.4]:

$$
\Delta \mathrm{h}_{\mathrm{i}}=1 \times \theta_{\mathrm{i}}
$$

Integrando $\Delta h_{i}$ da posição 1 a n, é obtida uma linha em "zigzag”. Desta forma, o erro de retilineidade da superfície é dada pela máxima largura do desvio dos dados. A linha de referência pode ser representada por uma linha reta que passa pelo primeiro e pelo último ponto.

\section{- MÉTOdo de Superposição de DAdOS}

O método proposto por KASEI e ONDA em 1987 é o método de superposição de dados. Segundo os autores este é um método prático para 
medição de retilineidade e possui as seguintes características: melhora da acuracidade de medição por média dos dados; aumenta a faixa de medição por superposição de dados; e pode ser usado para instrumentos convencionais de fabricação própria.

Um esquema é mostrado na Figura 2.14, onde os valores das medições $\mathrm{Y}_{1}$ e $\mathrm{Y}_{2}$ das faixas 1 e 2, respectivamente, são associados, e consequentemente uma ampliação da faixa de medição é efetuada. A correção do valor $Y_{2}^{\prime}$ para $\mathrm{Y}_{2}$ é expressa por uma equação de otimização através do método de mínimos quadrados. São considerados e mostrados, neste método, assuntos básicos relativos a tratamento de dados, variância de erros e melhoramento da acuracidade de medição.

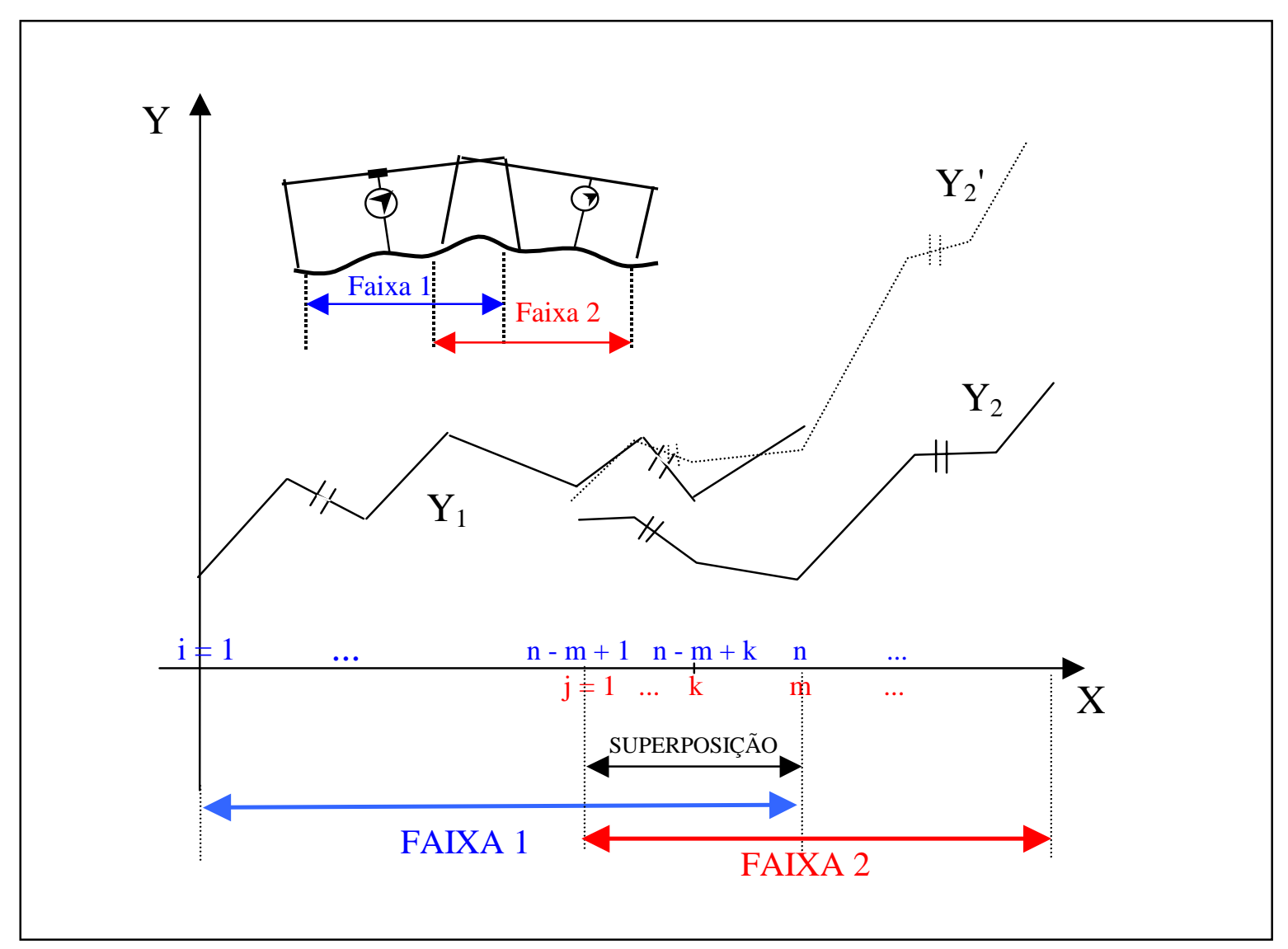

Figura 2.14 - Esquema do método da superposição 


\section{- MÉTOdo Heterodine de MoIré}

O método proposto por SAKUMA \& WADA em 1987 é o método heterodine de Moiré. O desenho das franjas é visível e observável tanto nos interferômetros tradicionais como pelo método de Moiré. A intensidade das franjas $\mathrm{I}(\mathrm{x}, \mathrm{y})$ pode ser expressa por :

$$
I(x, y)=a(x, y)+b(x, y) \cos \{\phi(x, y)\}
$$

A fase de um ponto dado é obtida da intensidade $\mathrm{I}(\mathrm{x}, \mathrm{y})$, assumindo como coeficiente de intensidade $\mathrm{a}(\mathrm{x}, \mathrm{y})$ e $\mathrm{b}(\mathrm{x}, \mathrm{y})$ que são constantes espaciais. De qualquer modo a intensidade uniforme é de difícil obtenção porque a refração é irregular no elemento ótico e na superfície do objeto. A intensidade da franja é modulada.

$I(x, y, t)=a(x, y)+b(x, y) \cos \{\phi(x, y)+2 \pi f t\}$

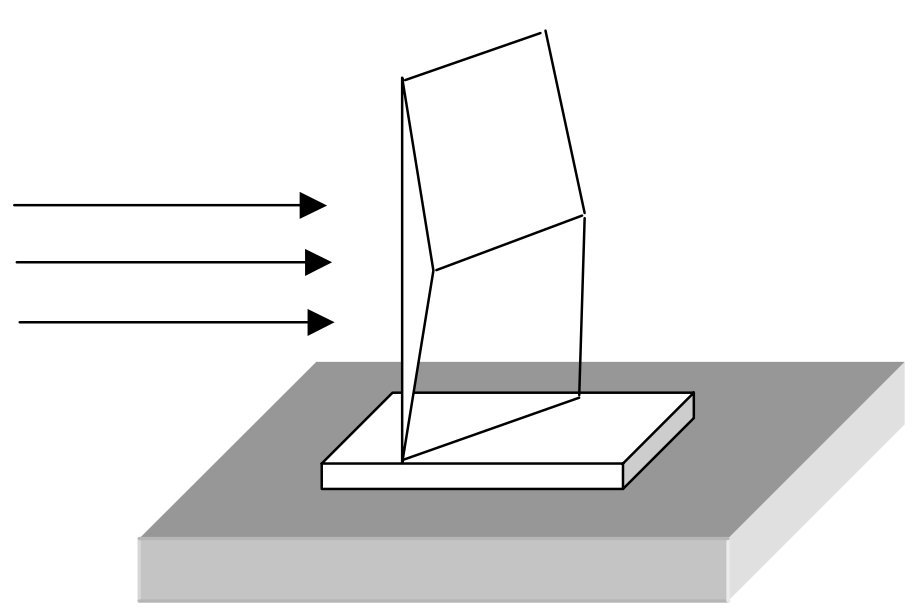

Figura 2.15 - Princípio de medição de retilineidade usando o método Heterodine de Moiré 
O princípio de medição de retilineidade pelo método heterodine de Moiré é o seguinte: uma luz coerente ilumina o biprisma que está preso no transporte móvel (Figura 2.15). As franjas de interferência são formadas paralelas ao eixo que se deseja medir na máquina. $\mathrm{O}$ espelho é movido ao longo da superfície; o movimento vertical das franjas de interferência corresponde ao perfil da superfície. As franjas de Moiré são formadas por superposição das franjas de interferência e o eixo de referência.

Como cada prisma proporciona uma direção oposta, deslocando o raio de entrada. A diferença de fase das duas partes das franjas de Moiré é o dobro das franjas de interferências. A intensidade das franjas de Moiré é modulada pela translação do eixo.

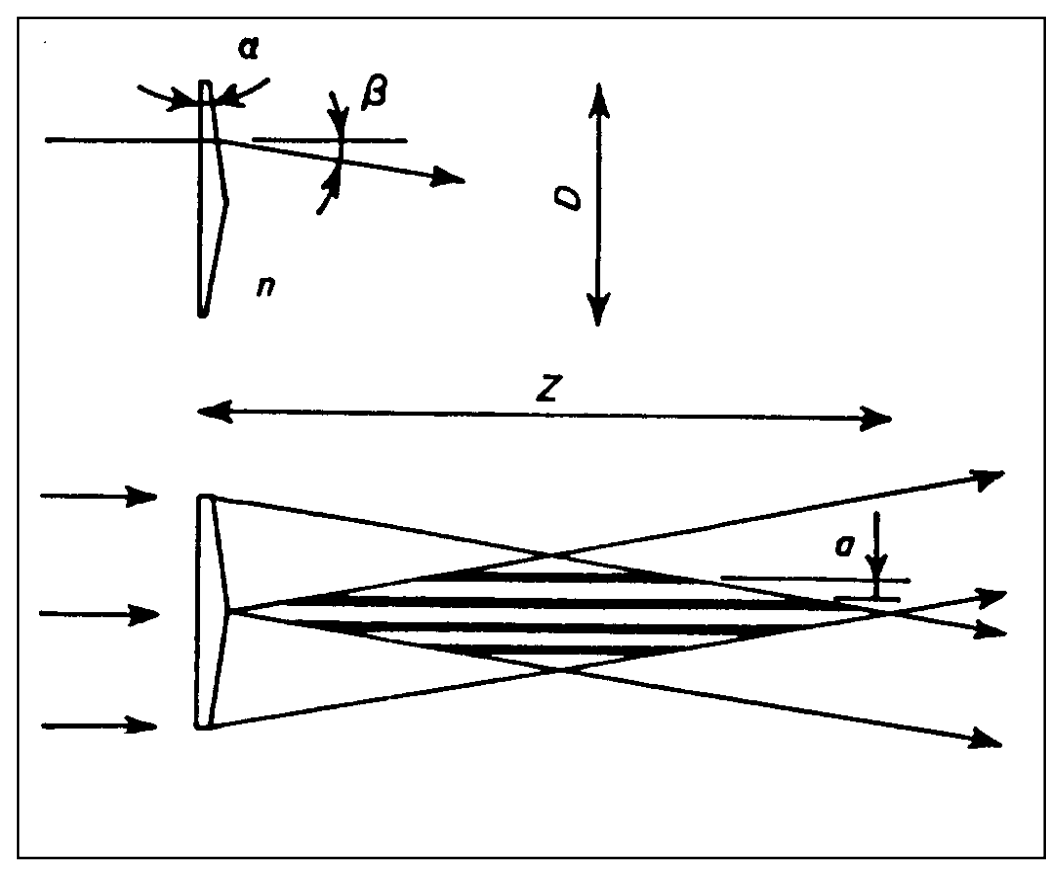

Figura 2.16 - Formação de franjas de interferências com o biprisma

A intensidade de dois pontos é transformada em sinal eletrônico por um foto sensor, e a diferença de fase dos sinais é medida por um sensor de fases.

$\mathrm{O}$ ângulo do desvio $ß$ e o espaçamento de fase a é dado por :

$$
\beta=(n-1) \alpha, a=\frac{\lambda}{2 \operatorname{sen} \beta}
$$


onde $\alpha$ é o ângulo da parte do prisma (Figura 2.16), n é o índice de refração e $\lambda$ é o comprimento de onda. $\mathrm{O}$ comprimento da franja $Z$ é dado por :

$$
Z=\frac{D}{2 \tan \beta},
$$

onde $D$ é a altura do biprisma.

Este método tem a vantagem de que franjas de Moiré podem ser detectadas com alta acuracidade. A retilineidade pode ser medida com a acuracidade de microns do metro e o sistema ótico consiste de elementos simples.

\section{- MÉTOdO DA DISTÂNCIA}

Um outro método proposto por ZHANG et al em 1992 é o método da distância. Esse método possui três montagens possíveis para medição de retilineidade, que podem ser utilizados na Máquina de Medir a Três Coordenadas.

Primeira montagem (Figura 2.17a): tomando o ponto $\mathrm{O}_{1}$ como origem do sistema de coordenadas, passando uma reta através de $\mathrm{O}_{1}$ e $\mathrm{O}_{2}$ que é definida como eixo $\mathrm{X}$, a distância entre $\mathrm{O}_{1}$ e $\mathrm{O}_{2}$ é igual a L. A distância do ponto $\mathrm{P}$ de $\mathrm{O}_{1}$ e de $\mathrm{O}_{2}$ é igual a $\boldsymbol{a}$ e $\boldsymbol{b}$, respectivamente, tem-se assim, as coordenadas do ponto $\mathrm{P}(\mathrm{x}, \mathrm{y})$ :

$$
\begin{gathered}
x=\frac{a^{2}-b^{2}+L^{2}}{2 L} \\
y=\sqrt{\frac{a^{2}-\left(L^{2}+a^{2}-b^{2}\right)^{2}}{4 L^{2}}}
\end{gathered}
$$

Quando uma série de pontos $\mathrm{P}$ são medidos, uma série de coordenadas $\mathrm{x}$ e y podem ser encontradas e assim o erro de retilineidade no ponto $\mathrm{P}$ é o desvio de y que é uma função linear associada a x. 
$\mathrm{Na}$ segunda montagem (Figura 2.17b), $\mathrm{O}_{1}$ e $\mathrm{O}_{2}$ são localizados em diferentes lados da reta onde a retilineidade é medida. As fórmulas [2.3] e [2.4] são usadas neste caso. $O$ desvio de $x$ da função linear de y resulta no erro de retilineidade do ponto P. Este diagrama pode ser usado para medição de retilineidade do eixo de movimento de uma máquina.

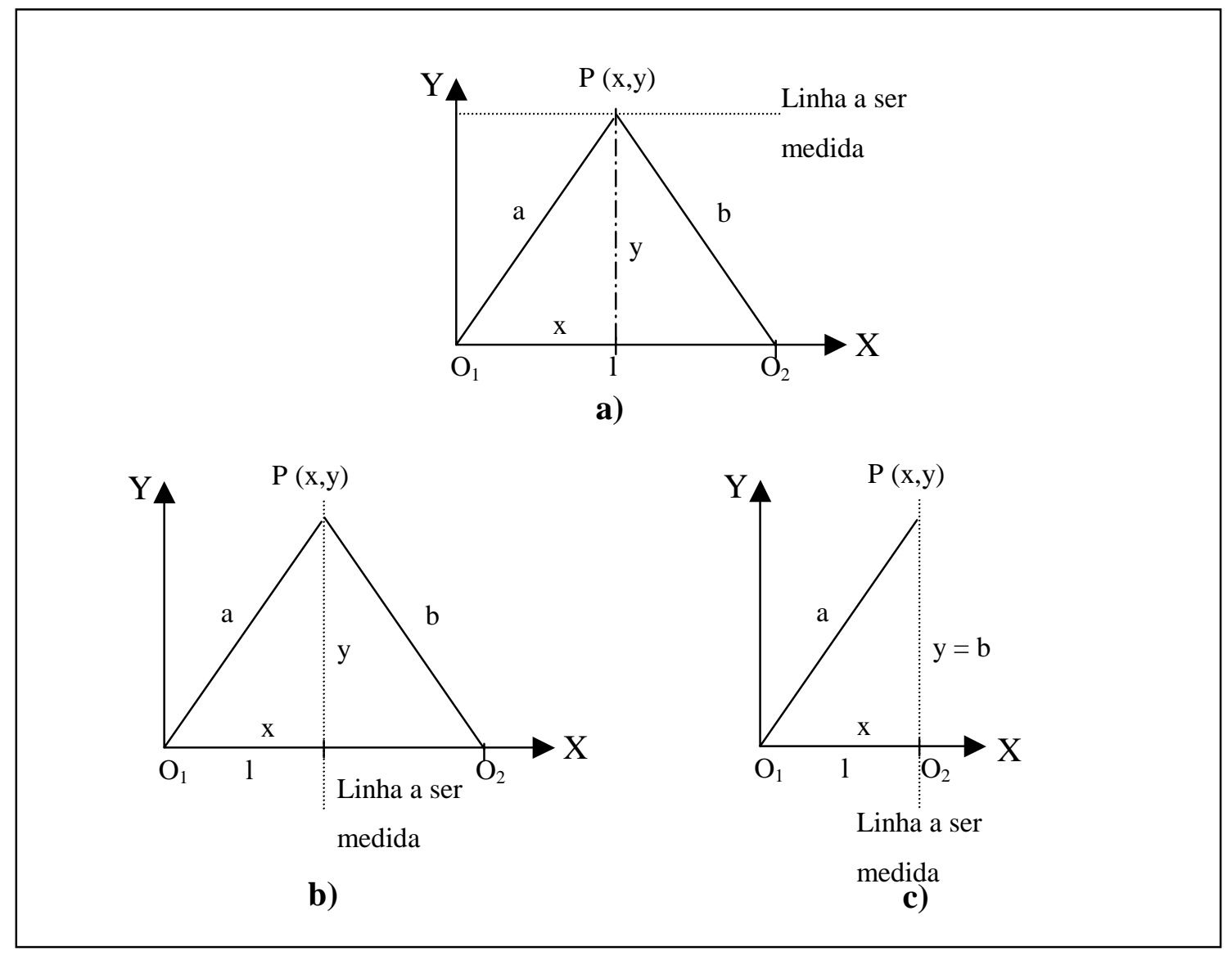

Figura 2.17 - Montagens apresentadas para o método da distância

A terceira montagem (Figura 2.17c), $\mathrm{O}_{2}$ é localizado na linha onde a retilineidade é medida. $\mathrm{L}=\mathrm{x}, \mathrm{y}=\mathrm{b}$. Desta forma, a fórmula [2.3] ficaria :

$$
x=\sqrt{a^{2}-b^{2}}
$$


$\mathrm{O}$ desvio de $\mathrm{x}$ da função linear de y resulta no erro de retilineidade do ponto $\mathrm{P}$.

O método da distância traz a apresentação de três montagens que possibilitam a verificação de desvios perpendiculares ao eixo de movimentação a partir de um determinado ponto P. Esse método possui resultados satisfatórios desde que $0<\mathrm{x}<\mathrm{L}$ e y $>\mathrm{L} / 2$ que é o parâmetro mais apropriado para o sistema de medição. $\mathrm{O}$ método proporciona amplas aplicações práticas na calibração geométrica de máquinas.

\subsection{4 - Algoritmos PARA AVAliaÇÃo dos ERros DE RETILINEIDADE}

Segundo CARR \& FERREIRA (1995), em 1988 alertou-se para os diferentes algoritmos para a verificação dos erros de retilineidade que produzem diferentes resultados tendo-se o mesmo conjunto de dados. Este problema é especialmente verdadeiro para tolerâncias de forma.

A norma ISO/R1101 (1983) detalha os erros de forma de modo geral, fazendo menção ao conceito de mínima zona para os erros de forma.

Vários algoritmos tem sido desenvolvidos para avaliar os erros de retilineidade. O método de mínimos quadrados é o mais usado na indústria para avaliação dos erros de forma, devido à simplicidade computacional (HUANG et al , 1993). Esta técnica fornece apenas uma solução aproximada e não garante um valor preciso do erro de retilineidade, (CHERAGHI et al, 1996). A seguir, são citados alguns destes algoritmos.

O método de verificação direta para determinação da solução de mínima zona foi mencionado primeiro por MURTHY \& ABDIN (1980), que propuseram e compararam vários métodos, tais como: o Método Monte Carlo sobre a solução de mínimos quadrados; o Método Simplex, que começava com 
solução de mínimos quadrados e terminava depois de um número de interações e uma técnica da Pesquisa Espiral.

KANADA \& SUZUKI (1993) discutiram a aplicação de varias técnicas computacionais tais como o Método Simplex Nelder - Mead; Método de Pesquisa Linear com Interpolação Quadrática (QIM method); Método de Pesquisa Linear com secção áurea (GSM method); Método de Linearização (TKM method) e o Método Misturado de Método de Linearização e Método de Pesquisa Linear com Interpolação Quadrática (TQM method).

Outras aproximações gerais para a solução de mínima zona é baseada na teoria geométrica computacional. ETESAMI \& QIAO (1990) usaram a casca convexa de duas dimensões (2-D) para solução de um problema de retilineidade de duas dimensões. Este método garante encontrar a solução de mínima zona entretanto com grande custo computacional.

Um novo algoritmo, o método MINMAX proposto por FAN \& BURDEKIN (1986), usa o conceito de rotação das linhas de controle com respeito a um ponto de contato particular.

A chamada mínima zona é definida pela distância mínima entre dois traços paralelos de forma perfeita, mantendo algumas localização relativa e/ou orientação. Todos os pontos dados estão entre os dois traços. Para estender a definição para o erro de retilineidade, diz-se que a solução de mínima zona para o erro de retilineidade é a distância mínima entre duas retas paralelas onde todos os pontos dados estejam entre estas duas retas (SUEN \& CHANG, 1997) e o critério para a solução de mínima zona para o erro de retilineidade na fase final deve ser cumprida as seguintes condições:

- Três pontos devem estar em contato com duas retas paralelas;

- Estes três pontos devem estar na sequência Superior-InferiorSuperior ou Inferior-Superior-Inferior. 
Os pontos de contato são chamados de pontos de controle e as retas de retas de controle, conforme observa-se na Figura 2.18.

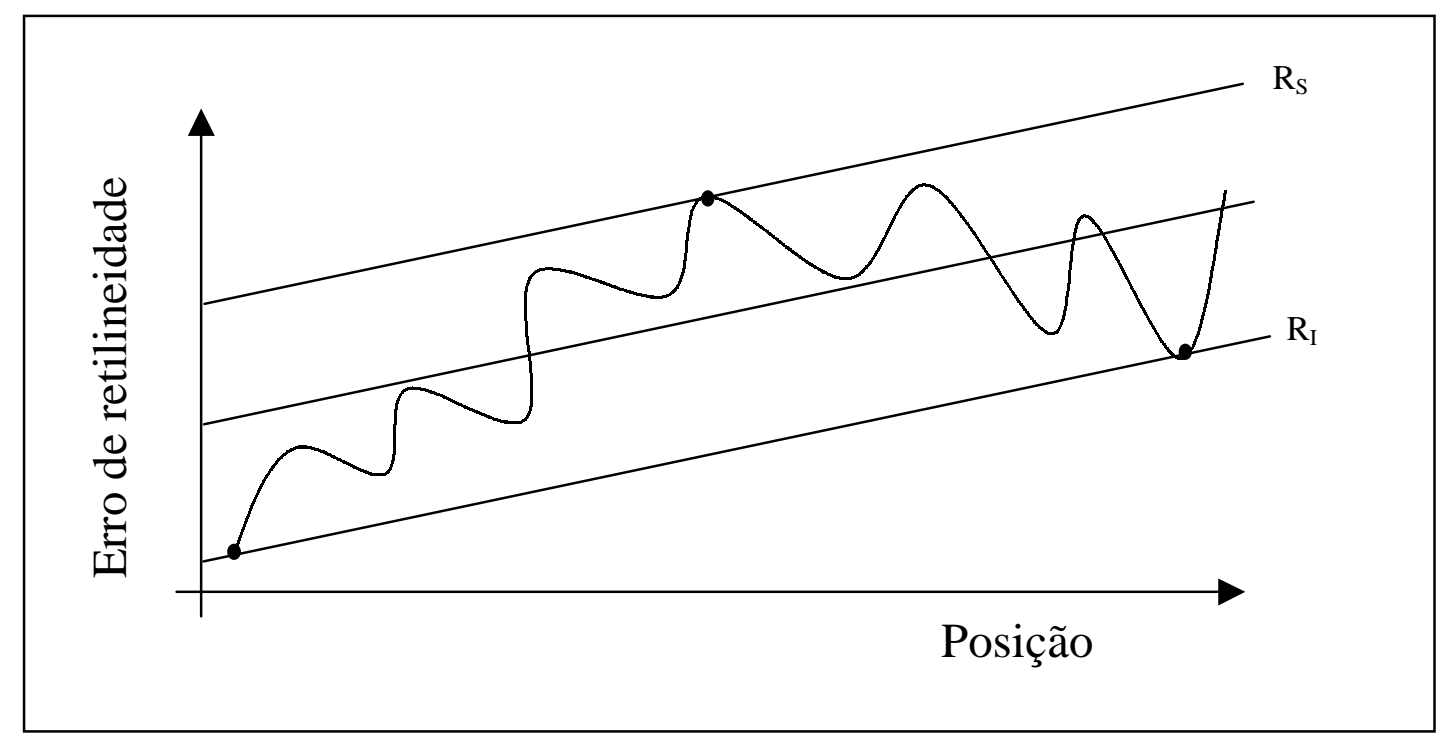

Figura 2.18 - Condições de mínima zona para o erro de retilineidade

HUANG, et al (1993), propuseram um método de mínima zona chamado de esquema de rotação da linha de controle ( CLRS ). O CLRS se inicia com um modelo 1-1, onde cada ponto de controle pertence a uma das retas de controle e a base do sistema é a reta de mínimos quadrados. O modelo 2-1, prevê dois pontos de controle sobre uma das linhas de controle, o terceiro ponto de controle está sobre outra reta de controle. Usando a regra do esquema de rotação da linha de controle ( CLRS ), que é desenvolvido baseado no critério de solução de mínima zona. Com poucos passos de troca de dados por interação no modelo 2-1, a solução de mínima zona pode ser facilmente obtida.

SUEN \& CHANG (1997) aplicaram um método de regressão por intervalos utilizando redes neurais por mínima zona, aplicando análises de regressão linear. Este algoritmo foi desenvolvido para resolver problemas de programação linear, onde não é possível aplicar o método dos mínimos quadrados. $\mathrm{O}$ progresso das redes neurais poderá melhorar este algoritmo no futuro. 


\section{4 - OS ERROS ANGULARES}

\subsection{1 - DEFINIÇÃO DOS ERROS ANGULARES}

$\mathrm{O}$ erro angular é o movimento angular em torno dos eixos $\mathrm{X}, \mathrm{Y}$ ou $\mathrm{Z}$ que são conhecidos como PITCH, YAW e ROLL, onde o PITCH e YAW são rotações sobre os eixos perpendiculares ao eixo do movimento e o ROLL é a rotação em torno do eixo do movimento principal.

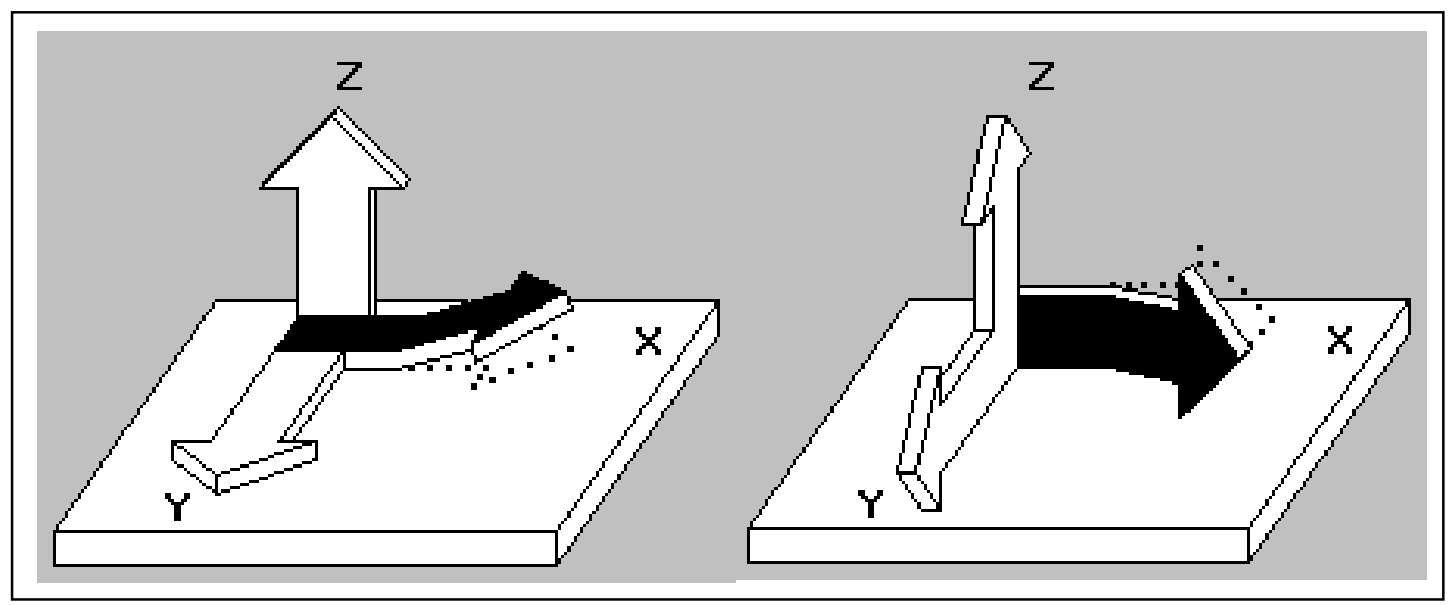

Figura 2.19 - Esquema dos erros de $P I T C H$ e $Y A W$

Tabela 2.2 - Notações dos erros angulares

\begin{tabular}{|c|c|c|c|c|c|c|}
\hline \multicolumn{7}{|c|}{ CONVENCÕES DOS ERROS ANGULARES } \\
\hline Movimentos & \multicolumn{2}{|c|}{$\mathrm{X}$} & \multicolumn{2}{|c|}{$\mathrm{Y}$} & \multicolumn{2}{c|}{$\mathrm{Z}$} \\
\hline Rotações & Plano & Notação & Plano & Notação & Plano & Notação \\
\hline Pitch & $\mathrm{XZ}$ & $\delta \theta_{\mathrm{y}}(\mathrm{x})$ & $\mathrm{YZ}$ & $\delta \theta_{\mathrm{x}}(\mathrm{y})$ & $\mathrm{YZ}$ & $\delta \theta_{\mathrm{x}}(\mathrm{z})$ \\
\hline Yaw & $\mathrm{XY}$ & $\delta \theta_{\mathrm{z}}(\mathrm{x})$ & $\mathrm{XY}$ & $\delta \theta_{\mathrm{z}}(\mathrm{y})$ & $\mathrm{XZ}$ & $\delta \theta_{\mathrm{y}}(\mathrm{z})$ \\
\hline Roll & $\mathrm{YZ}$ & $\delta \theta_{\mathrm{x}}(\mathrm{x})$ & $\mathrm{XZ}$ & $\delta \theta_{\mathrm{y}}(\mathrm{y})$ & $\mathrm{XY}$ & $\delta \theta_{\mathrm{z}}(\mathrm{z})$ \\
\hline
\end{tabular}




\subsection{2 - InSTRUMENTOS PARA MEDIÇÃO DE YAW E PITCH}

Os instrumentos comumente utilizados para medição de $P I T C H$ e $Y A W$ são níveis eletrônicos, níveis de bolha, autocolimadores, interferômetros laser, etc. (PARAMETRIC CALIBRATION OF COORDINATE MEASURING MACHINE, 1991). Em seguida são mostradas as características principais de alguns destes instrumentos.

\section{- NÍVEIS ELETRôNICOS}

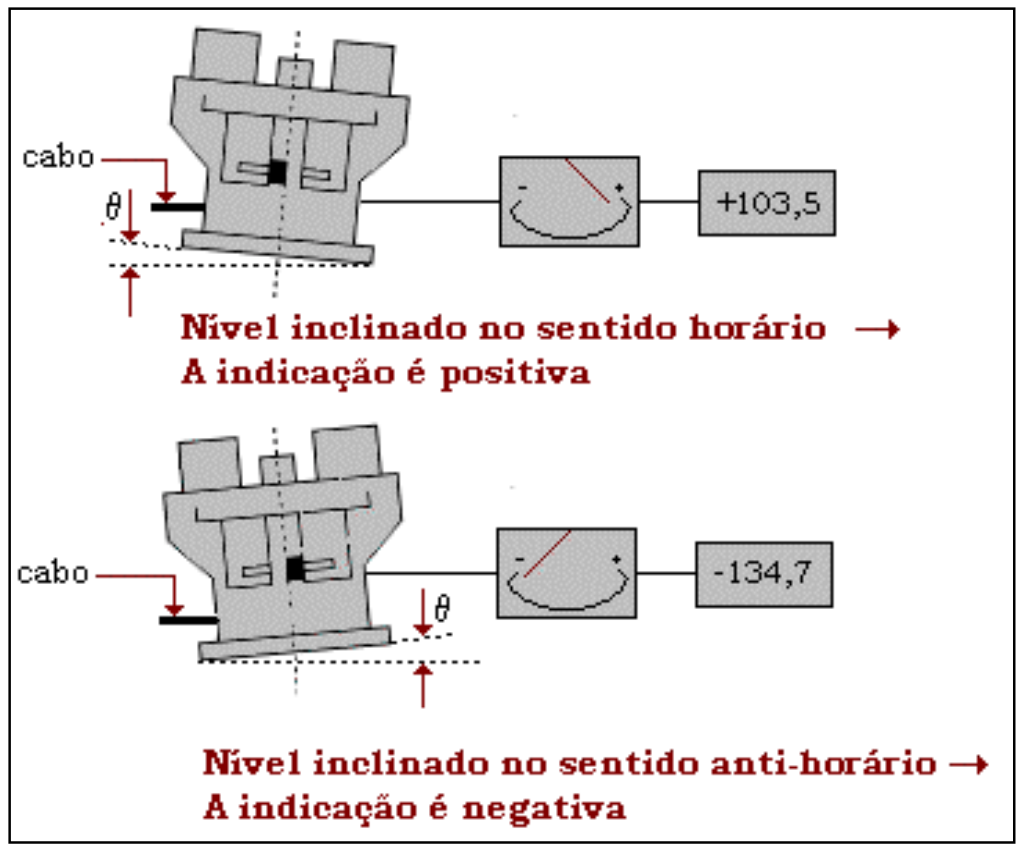

Figura 2.20 - Esquema da medição com o nível eletrônico

Os níveis eletrônicos diferenciais fornecem um meio rápido e eficiente para medição de Pitch para todos os eixos, e Yaw para eixos verticais ou horizontais. Como mostra a Figura 2.20, um nível de referência pode ser colocado fixo à mesa da máquina, enquanto, o nível da medição é colocado sobre a parte móvel. A leitura de saída é a diferença entre os dois níveis. Neste tipo de medição algumas precauções devem ser tomadas como por exemplo o peso dos níveis não podem causar deflexão significante que possam afetar os resultados. 
Outro problema ocorre com máquinas que são acometidas de abalos no movimento, por exemplo, máquinas que vibram. Nestes casos, diferenças entre os dois níveis podem ser significantes comparados ao Yaw e Pitch" a serem medidos. Os níveis podem ser checados um contra o outro, isto é, colocando-os lado a lado.

\section{- Autocolimador}

O autocolimador pode ser usado para todas as medições de Yaw e Pitch. Um instrumento de qualidade com espelho plano e calibrado é obrigatório. Para máquinas maiores são prováveis os problemas de gradiente térmico do ar, que podem ser corrigidos com uso de ventiladores, como é feito na medição de retilineidade com a utilização do laser.

\section{- INTERFERÔMETRO LASER ANGULAR}

O Interferômetro Laser com óptica angular pode executar medições de Yaw e Pitch. Uma montagem típica é mostrada na Figura 2.21.

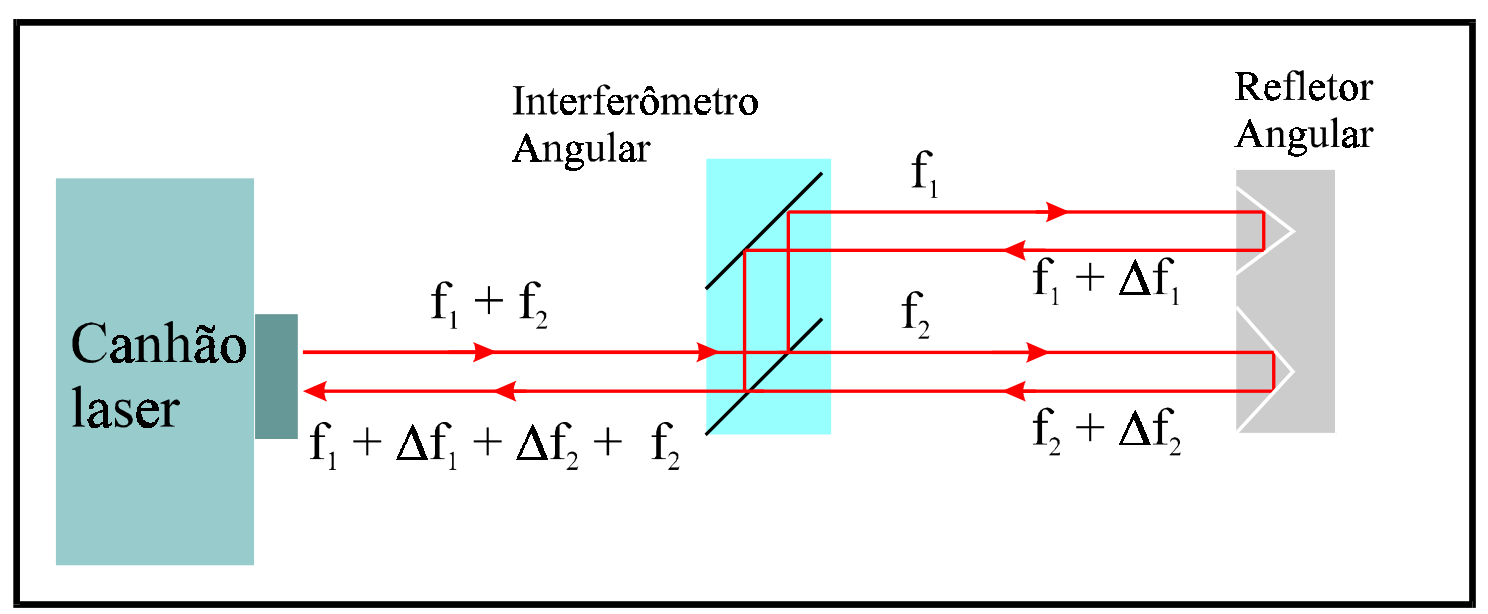

Figura 2.21 - Esquema básico do sistema Interferométrico Laser para medir ângulo.

O feixe de laser é dividido em dois feixes paralelos por meio de um interferômetro que está fixo. Os feixes paralelos são retornados por dois retrorefletores que se movimentam. As mudanças no padrão de interferência 
dos feixes que retornam ao canhão laser são indicadores da diferenças entre os caminhos percorridos. A variação desta diferença dividida pela distância entre os dois feixes é a tangente do deslocamento angular desejado, Yaw ou Pitch dependendo da posição dos espelhos.

\section{- Erro Angular Utilizando InStrumentaÇÃo do ERro de Posição}

O Yaw ou Pitch podem ser também determinados através da medição do erro de posição de dois pontos num componente móvel, sendo o erro angular a diferença entre os dois erros de posição dividida por um componente da distância, os dois pontos normais à direção da medição e no plano do Yaw ou Pitch. Uma vantagem deste método é que a acuracidade pode ser melhorada através do uso de uma longa linha de base. Uma desvantagem é a mudança de geometria da máquina entre os intervalos de medição, e diferenças nas condições ao longo do trajeto de medição podem causar erros.

\subsection{3 - INSTRUMENTOS PARA MEDIÇÃO DE ROLL}

Os instrumentos comumente utilizados para medição de Roll são níveis eletrônicos ou instrumentação de retilineidade .

\section{- NÍvEIS ELETRôNICOS}

Níveis de precisão podem ser usados para a medição de Roll de um eixo horizontal. O princípio de medição é similar ao usado na calibração de erros de Yaw e Pitch. 


\section{- INSTRUMENTAÇ̃̃o dO ERRO DE RETILINEIDADE}

A medição de Roll para eixos verticais, e opcionalmente para horizontais, pode ser feita por duas montagens distintas para a medição de retilineidade.

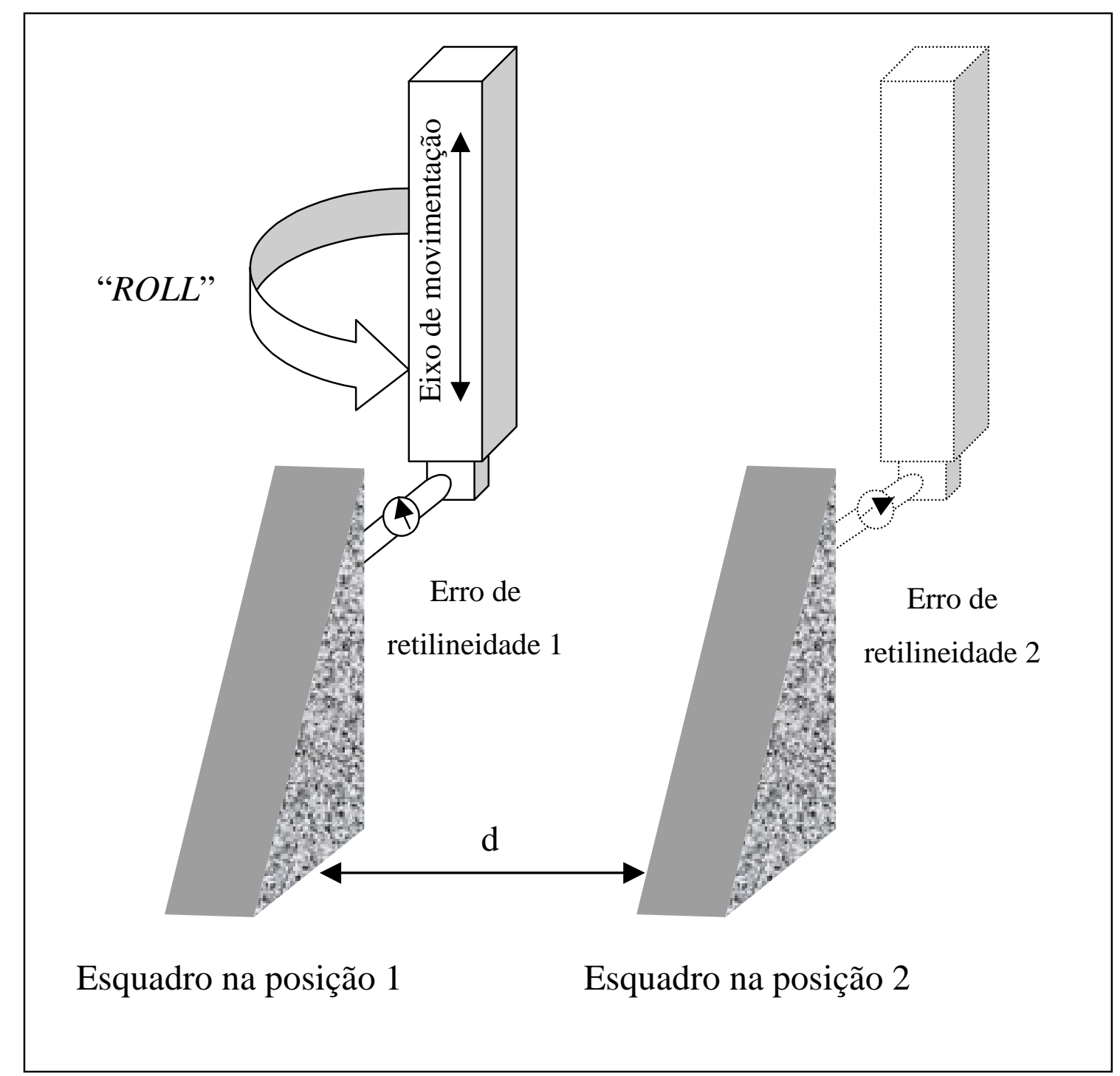

Figura 2.22 - Princípio da medição do erro angular utilizando instrumentação de retilineidade

O princípio é visto na Figura 2.22, que mostra a montagem da medição de Roll de um eixo vertical por meio de um esquadro e um apalpador. O método pode ser modificado para usar qualquer outro método de medição de retilineidade em qualquer eixo. 
O esquadro e o apalpador são montados para medir retilineidade no plano axial. Depois da medição de retilineidade, a parte móvel é movimentada no eixo normal ao plano de medição de retilineidade, o apalpador é montado em uma extensão d, e a retilineidade é medida novamente. O Roll em qualquer posição vertical, em radianos, é a diferença entre as duas medições de retilineidade, naquela posição, dividida pela distância entre as duas posições da parte móvel. 


\section{CAPÍTUlo 3}

\section{CONSIDERAÇÕES TEÓRICAS SOBRE ERROS E O TRATAMENTO ESTATÍSTICO DE DADOS EXPERIMENTAIS.}

Neste capítulo serão abordados técnicas estatísticas utilizadas para o tratamento dos dados levantados durante a calibração de erros. Além disto, será também apresentado o procedimento de análise para os erros de retilineidade.

\section{1 - CONCEITOS ESTATÍSTICOS BÁSICOS PARA O TRATAMENTO DE DADOS EXPERIMENTAIS.}

Para que uma equação seja utilizada na representação de um determinado erro individual, há necessidade de executar uma análise estatística dos dados colhidos durante o processo de calibração da máquina analisada. Alguns conceitos básicos de estatística estão apresentados na sequiência, tais como, teste de aderência, média e desvio padrão. 


\subsection{1 - CONCEITOS BÁSICOS}

\section{- TeSTES DE ADERÊNCIA}

Os testes de aderência são utilizados para verificar se o modelo é adequado à distribuição adotada, que neste trabalho, é a distribuição Gaussiana.

A distribuição gaussiana, também chamada distribuição normal, é um importante exemplo de distribuição contínua e é definida pela equação [3.1] :

$$
\mathrm{Y}=\frac{1}{\sigma \sqrt{2 \pi}} \mathrm{e}^{-1 / 2(\mathrm{X}-\mu)^{2} / \sigma^{2}} \text { para }-\infty<\mathrm{x}<\infty
$$

onde:

- $\mu$ é a média dos dados;

- $\sigma$ é o desvio padrão dos dados

- $\pi=3,14159 \ldots ; \mathrm{e}=2,71828 \ldots$

Um dos testes mais utilizados para a verificação de aderência é o chamado teste de Chi - quadrado que foi desenvolvido por Karl Pearson. A quantidade $\chi^{2}$ é baseada na seguinte formulação estatística (DOEBELIN,1990) dado pela equação [3.2]:

$$
\chi^{2}=\sum_{\mathrm{i}=1}^{\mathrm{n}} \frac{\left(\mathrm{n}_{\mathrm{o}}-\mathrm{n}_{\mathrm{e}}\right)^{2}}{\mathrm{n}_{\mathrm{e}}},
$$

onde:

- $\mathrm{n}_{\mathrm{o}}$ é o número de leituras observadas em determinado grupo;

- $\mathrm{n}_{\mathrm{e}}$ é o número de leituras observadas no mesmo grupo se a distribuição for Gaussiana $\operatorname{com} \mu=\overline{\mathrm{x}}$ e $\sigma=\mathrm{s}$;

- n é o número de grupos. 
Para calcular o $n_{e}$ utiliza-se a tabela de distribuição Gaussiana . Nela são encontrados os valores de $\mathrm{F}(\mathrm{w})$, isto é, a probabilidade da leitura estar no intervalo de $-\infty$ até w. O valor de $\mathbf{w}$ é dado pela expressão [3.3]

$$
\mathrm{w}=\frac{\mathrm{X}-\mu}{\sigma}
$$

onde :

- X é o limite de cada grupo;

- $\mu$ é a média dos dados;

- $\sigma$ é o desvio padrão dos dados.

Desta forma, os valores de w, equação [3.3], para os limites inferiores $\mathbf{w}_{\text {inf }}$ e superior $\mathbf{w}_{\text {sup }}$ são calculados, bem como a probabilidade da leitura estar entre $\mathbf{w}_{\text {inf }}$ e $\mathbf{w}_{\text {sup }}$.

Com o auxílio de uma tabela de distribuição normal, determina-se o valor de $\mathbf{n}_{\mathbf{e i}}$ e calcula-se o valor de $\chi^{2}$, cuja somatória para todos os grupos deve ser comparada com o valor tabelado para o nível de significância adotado (DOEBELIN,1990).

\section{- Média e Desvio Padrão}

Aplicado o teste de aderência aos dados levantados durante a calibração e verificando-se a normalidade da distribuição pode-se calcular a média $\overline{\mathrm{X}}$ e o desvio padrão $\mathbf{s}$, pelas expressões dadas pelas equações [3.4].

$$
\bar{X}=\frac{\sum_{i=1}^{N} X_{i}}{N} \quad \text { e } \quad s=\sqrt{\frac{\sum_{i=1}^{N}\left(X_{i}-\bar{X}\right)^{2}}{N-1}}
$$

onde:

- $\mathrm{X}_{\mathrm{i}}$ é a leitura individual;

- N é o número de leituras; 
Considerando-se uma distribuição normal, pode-se determinar a probabilidade de um valor medido estar num determinado intervalo $[\overline{\mathrm{X}}-i$ s, $\overline{\mathrm{X}}+i$ s $]$ com $i=1,2,3$ através de porcentagens dadas conforme mostrado na Figura 3.1.

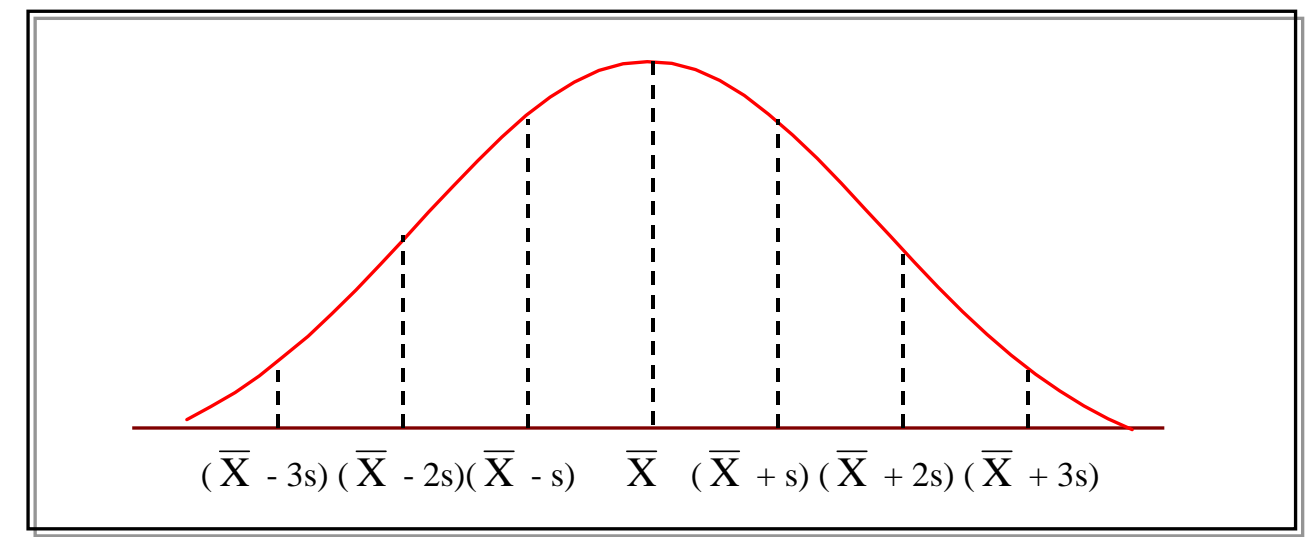

Figura 3.1-Gráfico de uma curva normal reduzida (SPIEGEL, 1993)

\subsection{2 - ClassificAÇÃo dos ERROS QuANTO AO SEU COMPORTAMENTO.}

Os erros de medição das Máquinas Ferramentas e MM3Cs podem ser definidos como as diferenças entre os valores verdadeiros e os valores observados de uma variável. Eles contém duas componentes fundamentais: uma componente aleatória e outra sistemática (SHEN \& DUFFIE,1991). A Figura 3.2 ilustra o resultado de uma calibração hipotética de um dos seis erros de um elemento de máquina.

São denominados erros aleatórios aqueles erros que resultam de influências internas ou externas não controladas (SLOCUM,1992). Estes erros podem ser observados através de medições repetidas pois em geral diferem a cada leitura. Geralmente, métodos estatísticos podem ser usados para quantificar estes tipos de erros. 
Erros sistemáticos, por sua vez, são aqueles que permanecem constantes em sinal e grandeza durante as medições; são causados na maior parte das vezes por problema nas escalas, ausência de rigidez e geometria da máquina. Uma vez determinados, alguns destes erros ocorrem de maneira previsível e podem ser minimizados após análise de dados obtidos a partir de um processo da calibração.

Pode-se também definir o erro de histerese como sendo um erro sistemático, que é a diferença entre as médias dos erros no sentido de ida e volta para cada posição de medição (WECK,1984).

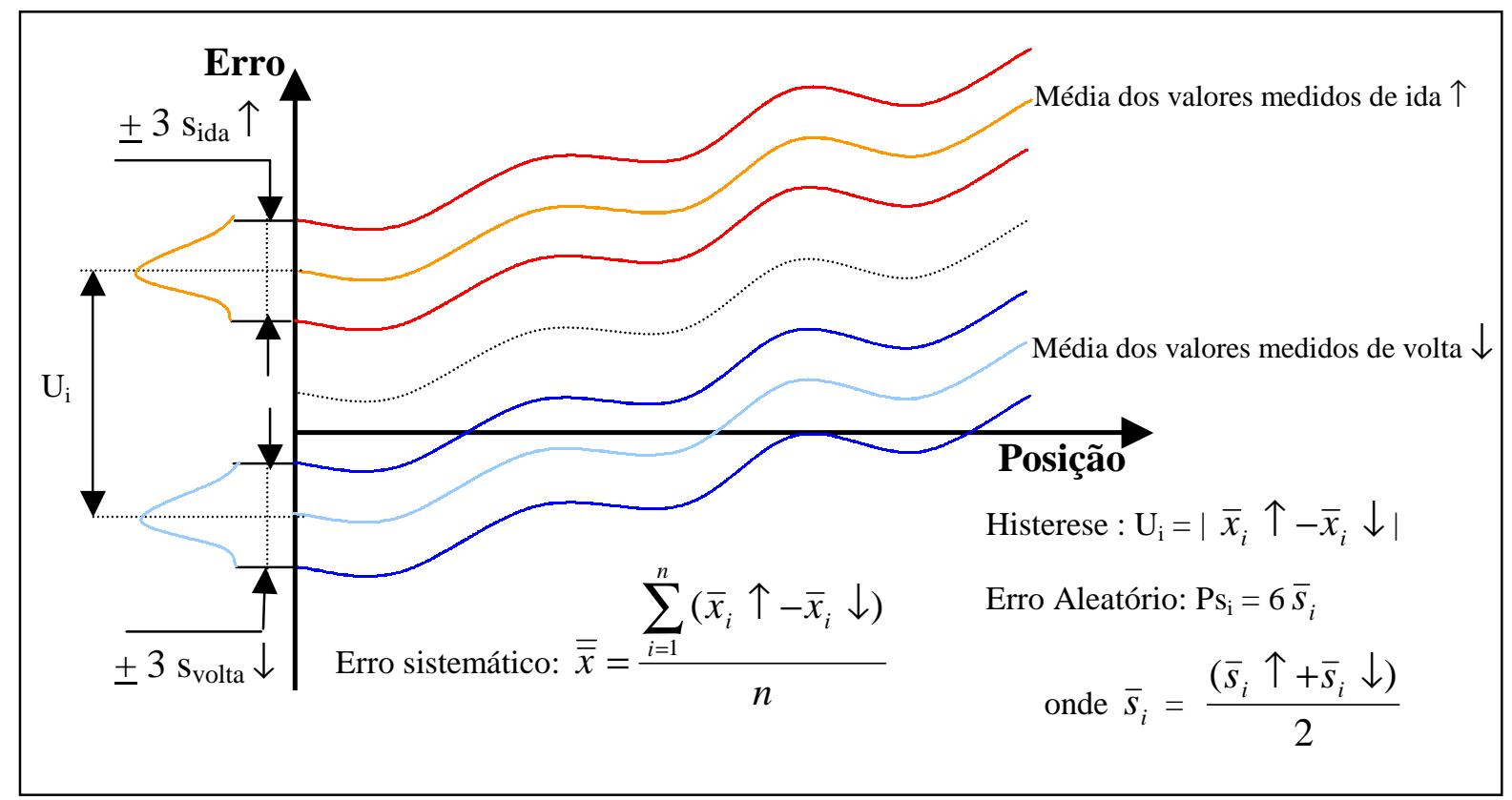

Figura 3.2 - Classificação dos erros quanto ao comportamento.

A parcela de erro aleatório pode ser fixada de acordo com níveis de confiança iguais a $\pm 1,2$ ou 3 vezes o desvio padrão, obtido a partir dos erros medidos para cada posição. Este valor é determinado separadamente para cada sentido do deslocamento. Pode-se assumir, que a máquina esteja ajustada mecanicamente e portanto pode-se assumir que esta parcela é a mesma para o sentido de "ida" e "volta" [VIEIRA SATO,1998].

A parcela sistemática, segundo WECK (1984), pode ser obtida utilizando as médias do trajeto de "ida" e "volta". Entretanto, contrapondo-se 
a esse entendimento pode-se afirmar que se os valores possuírem a mesma grandeza e sinais contrários o erro sistemático será igual a zero apesar deste estar presente.

Na Figura 3.3 pode-se observar o procedimento de coleta de dados durante a mesma calibração hipotética.

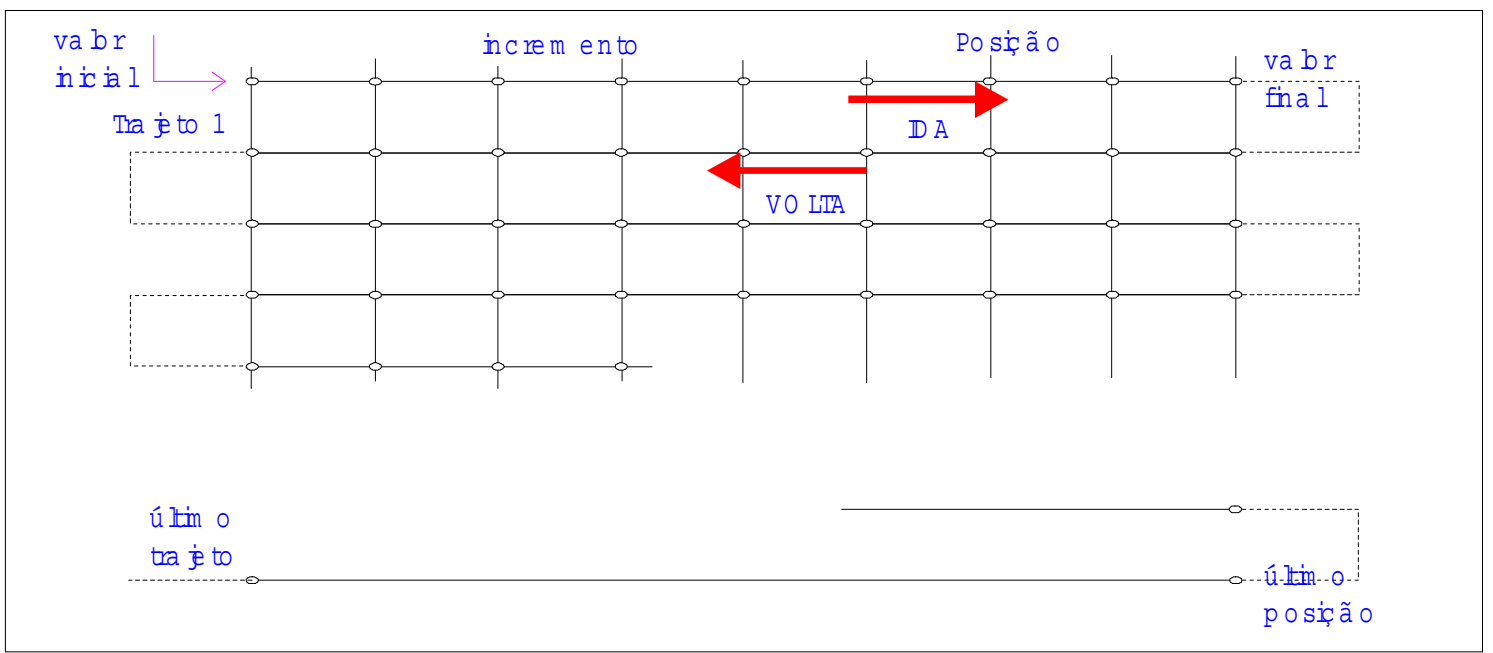

Figura 3.3 - Forma de coleta de dados de um erro geométrico

(De Luca, 1992)

\subsection{3 - ANÁLISE DE REGRESSÃO}

A primeira referência ao termo análise de regressão foi dado por Galton em 1885 (ACHCAR, 1995). Em muitos experimentos pode-se ter duas ou mais variáveis relacionadas entre si associadas às unidades experimentais. Esta ferramenta estatística é extremamente importante no equacionamento de uma certa variável dependente y em função de um conjunto de variáveis independentes $\mathrm{x}_{\mathrm{i}}$ (DRAPER \& SMITH, 1981). 


\section{- ANÁliSE DE REGRESSÃo LINEAR SiMPLES}

A equação de regressão de uma variável y dependente em função de uma única variável independente x é dada pela expressão [3.5]:

$$
f(x)=y=\beta_{0}+\beta_{1} x
$$

onde :

- $\quad \beta_{0}$ é a intersecção da reta de regressão com o eixo y;

- $\beta_{1}$ é o coeficiente de inclinação da reta.

Para estimar os parâmetros desconhecidos de regressão, $\beta_{0}$ e $\beta_{1}$, podese utilizar o método dos mínimos quadrados que minimiza a soma dos quadrados dos resíduos, dado pela equação [3.6].

$$
S=S\left(\beta_{0}, \beta_{1}\right)=\sum_{i=1}^{n}\left(y_{i}-\beta_{0}-\beta_{1} x_{i}\right)^{2},
$$

onde os valores a serem calculados $\beta_{0}$ e $\beta_{1}$, que minimizam a equação [3.6], são chamados de estimadores de mínimos quadrados ( EMQ ).

Para ilustrar o método, toma-se uma amostra de $\mathrm{n}$ pontos $\left(\mathrm{x}_{1}, \mathrm{y}_{1}\right),\left(\mathrm{x}_{2}, \mathrm{y}_{2}\right)$, $\ldots,\left(\mathrm{x}_{\mathrm{n}}, \mathrm{y}_{\mathrm{n}}\right)$, distribuídos como na Figura 3.4.

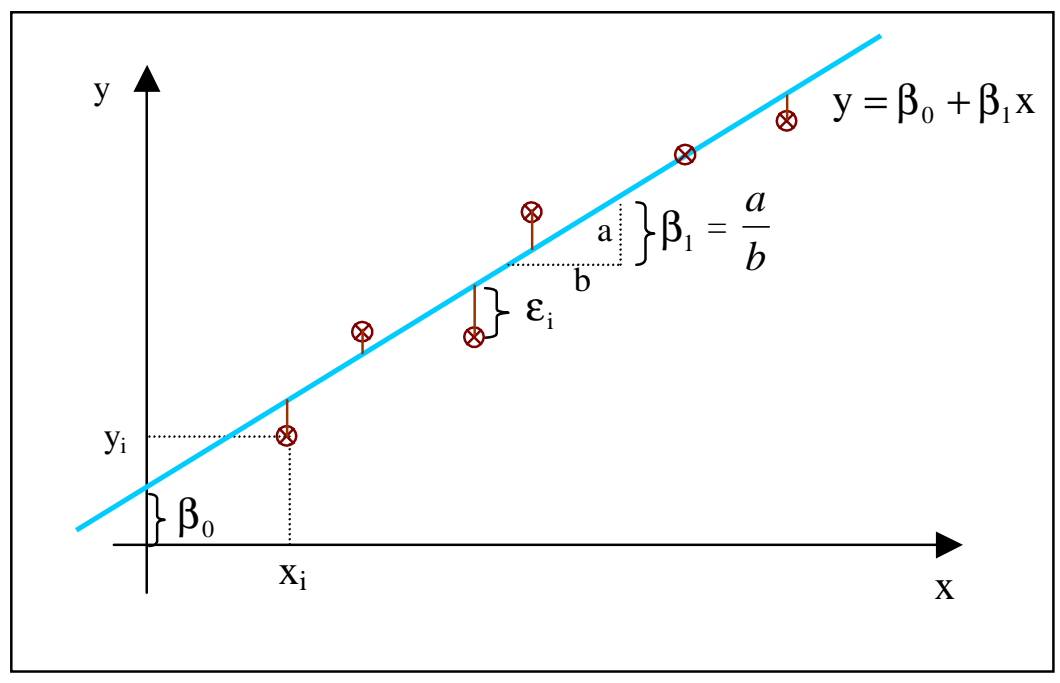

Figura 3.4- Parâmetros da reta de regressão 
A Figura 3.4 mostra o valor de $\beta_{0}$, ponto onde a reta de regressão intercepta o eixo da variável dependente y. $O$ valor de $\beta_{1}$ é o coeficiente de inclinação da reta e os valores $\varepsilon_{\mathrm{i}}$ são os resíduos dados pela diferença entre os valores previstos ou calculados e os reais.

Derivando $S\left(\beta_{0}, \beta_{1}\right)$ em relação a $\beta_{0}$ e $\beta_{1}$ tem-se, respectivamente, as equações [3.7] e [3.8],

$$
\begin{aligned}
& \frac{\partial \mathrm{S}\left(\beta_{0}, \beta_{1}\right)}{\partial \beta_{0}}=-2 \sum_{\mathrm{i}=1}^{\mathrm{n}}\left(\mathrm{y}_{\mathrm{i}}-\beta_{0}-\beta_{1} \mathrm{x}_{\mathrm{i}}\right) \\
& \frac{\partial \mathrm{S}\left(\beta_{0}, \beta_{1}\right)}{\partial \beta_{1}}=-2 \sum_{\mathrm{i}=1}^{\mathrm{n}} \mathrm{x}_{\mathrm{i}}\left(\mathrm{y}_{\mathrm{i}}-\beta_{0}-\beta_{1} \mathrm{x}_{\mathrm{i}}\right)
\end{aligned}
$$

$\operatorname{De} \frac{\partial \mathrm{S}\left(\beta_{0}, \beta_{1}\right)}{\partial \beta_{0}}=0$ e $\frac{\partial \mathrm{S}\left(\beta_{0}, \beta_{1}\right)}{\partial \beta_{1}}=0$, encontra-se $\hat{\beta}_{0}$ e $\hat{\beta}_{1}$ partindo das equações normais [3.9],

$$
\left\{\begin{array}{l}
\hat{\beta_{0}} \mathrm{n}+\hat{\beta_{1}} \sum_{\mathrm{i}=1}^{\mathrm{n}} \mathrm{x}_{\mathrm{i}}=\sum_{\mathrm{i}=1}^{\mathrm{n}} \mathrm{y}_{\mathrm{i}} \\
\hat{\beta_{0}} \sum_{\mathrm{i}=1}^{\mathrm{n}} \mathrm{x}_{\mathrm{i}}+\hat{\beta_{1}} \sum_{\mathrm{i}=1}^{\mathrm{n}} \mathrm{x}_{\mathrm{i}}^{2}=\sum_{\mathrm{i}=1}^{\mathrm{n}} \mathrm{x}_{\mathrm{i}} \mathrm{y}_{\mathrm{i}}
\end{array}\right.
$$

Resolvendo [3.9] encontram-se os estimadores de mínimos quadrados $\hat{\beta}_{0}$ e $\hat{\beta}_{1}$ dados por [3.10],

$$
\left\{\begin{array}{l}
\hat{\beta}_{1}=\frac{\sum_{i=1}^{n}\left(x_{i}-\bar{x}\right)\left(y_{i}-\bar{y}\right)}{\sum_{i=1}^{n}\left(x_{i}-\bar{x}\right)^{2}} \\
\hat{\beta}_{0}=\bar{y}-\hat{\beta}_{1} \bar{x}
\end{array}\right.
$$


Desta forma a reta ajustada por mínimos quadrados é dada por [3.11],

$$
\hat{y}=\hat{\beta}_{0}+\hat{\beta}_{1} x
$$

Considera-se ainda as notações básicas, dadas em [3.12]

$$
\overline{\mathrm{x}}=\frac{1}{\mathrm{n}} \sum_{\mathrm{i}=1}^{\mathrm{n}} \mathrm{x}_{\mathrm{i}}, \quad \overline{\mathrm{y}}=\frac{1}{\mathrm{n}} \sum_{\mathrm{i}=1}^{\mathrm{n}} \mathrm{y}_{\mathrm{i}}
$$

onde $\overline{\mathrm{x}}$ e $\overline{\mathrm{y}}$ são as médias amostrais dos dados de $\mathrm{x}$ e y. São também apresentados os parâmetros:

$$
\begin{aligned}
& S_{x x}=\sum_{i=1}^{n}\left(x_{i}-\bar{x}\right)^{2}=\sum_{i=1}^{n} x_{i}^{2}-\frac{\left(\sum_{i=1}^{n} x_{i}\right)^{2}}{n} \\
& S_{y y}=\sum_{i=1}^{n}\left(y_{i}-\bar{y}\right)^{2}=\sum_{i=1}^{n} y_{i}^{2}-\frac{\left(\sum_{i=1}^{n} y_{i}\right)^{2}}{n} \\
& S_{x y}=\sum_{i=1}^{n}\left(x_{i}-\bar{x}\right)\left(y_{i}-\bar{y}\right)=\sum_{i=1}^{n} x_{i} y_{i}-\frac{\left(\sum_{i=1}^{n} x_{i}\right)\left(\sum_{i=1}^{n} y_{i}\right)}{n}
\end{aligned}
$$

onde $S_{\mathrm{xx}}$ e $\mathrm{S}_{\mathrm{yy}}$ são as somas de quadrados dos desvios das médias e $\mathrm{S}_{\mathrm{xy}}$ é a soma dos produtos cruzados dos desvios.

Assim sendo, pode-se rescrever os estimadores de mínimos quadrados como descrito em [3.16]:

$$
\left\{\begin{array}{l}
\hat{\beta}_{1}=\frac{S_{x y}}{S_{x x}} \\
\hat{\beta}_{0}=\bar{y}-\hat{\beta}_{1} \bar{x}
\end{array}\right.
$$

Os resíduos da regressão são dados pela diferença entre o valor de previsão calculado pela reta de regressão e o valor real, e é calculado por [3.17], 


$$
\hat{\varepsilon}_{i}=y_{i}-\hat{y}_{i}, \quad i=1,2, \ldots, n
$$

\subsection{4 - MÉTODO DE NEWTON PARA SiSTEMAS NÃO-LINEARES}

O método de Newton é usado para resolver um conjunto de equações não-lineares que são acopladas entre si. Dadas $n$ funções $f_{1}, f_{2}, \ldots, f_{n}$ onde cada uma delas é uma função não-linear das $n$ variáveis $x_{1}, x_{2}, \ldots, x_{n}$. Quer se encontrar os valores de $x_{1}^{*}, x_{2}^{*}, \ldots, x_{n}^{*}$, tais que,

$$
\left\{\begin{array}{c}
f_{1}=\left(x_{1}^{*}, x_{2}^{*}, \ldots, x_{n}^{*}\right)=0 \\
f_{2}=\left(x_{1}^{*}, x_{2}^{*}, \ldots, x_{n}^{*}\right)=0 \\
\ldots \ldots \ldots . \ldots . . \\
f_{n}=\left(x_{1}^{*}, x_{2}^{*}, \ldots, x_{n}^{*}\right)=0
\end{array}\right.
$$

Procede-se a linearização através da série de Taylor, que é um meio muito útil na aproximação de funções, que será:

$$
f(x)=f\left(x^{k}\right)+f^{\prime}(x)\left(x-x^{k}\right)+E
$$

onde $x^{k}$ é um vetor aproximação da k-ésima iteração e $E$ é um vetor que representa o erro da aproximação linear.

$\mathrm{Na}$ expressão $3.19, f^{\prime}(x)$ é a derivada de uma função vetorial com variáveis vetoriais e representa uma matriz que contém todas as derivadas parciais de todas as componentes da $f(x)$. Tal matriz é conhecida como Jacobiana de $f(x)$, e dada por:

$$
J(x)=f^{\prime}(x)=\left[J_{i j}\right]=\left[\frac{\partial f_{i}(x)}{\partial x_{j}}\right]
$$

Para estabelecer o método iterativo, na iteração $k+1$ a aproximação será definida pelo vetor que anula a aproximação linear da equação, ou seja, o vetor $\mathrm{x}^{\mathrm{k}+1}$, tal que : 
$f\left(x^{k}\right)+f^{\prime}\left(x^{k}\right)\left(x^{k+1}-x^{k}\right)=0$

Para explicitar $\mathrm{x}^{\mathrm{k}+1}$, multiplica-se a equação 3.21 pela inversa da matriz Jacobiana e tem-se:

$$
x^{k+1}=x^{k}-\left[f^{\prime}\left(x^{k}\right)\right]^{-1} f\left(x^{k}\right)
$$

Como a inversão de matrizes é geralmente uma operação difícil, podese evitá-la através da equação 3.21, encontrando a aproximação da iteração $\mathrm{k}+1$ resolvendo o sistema linear

$J\left(x^{k}\right) v=-f\left(x^{k}\right)$

e atualizando-se o novo valor:

$$
x^{k+1}=x^{k}+v
$$




\section{2 - ANÁlise dos ERRos DE RETILINEIDADE}

Durante a medição do erro de retilineidade, os eixos de medição e do sistema de medição devem estar perfeitamente alinhados. Qualquer ausência de paralelismo entre estes eixos será refletida em deslocamento transversal e fatalmente interpretada como erro de retilineidade. Também os padrões de retilineidade possuem erros que estarão presentes nos resultados das medições. Sabendo-se da impossibilidade de eixos perfeitamente paralelos e de padrões perfeitamente retilíneos pode-se lançar mão de artifícios matemáticos, tais como, os métodos clássicos das reversões para eliminar ou pelo menos minimizar estes efeitos.

\subsection{1 - MÉTODO CLÁSSICO DAS REVERSÕES}

Estas técnicas são todas caracterizadas por uma manipulação mecânica com respeito a um grau de liberdade que é a direção sensitiva de um indicador. Estas operações mudam o sinal de um componente do erro.

\section{- ReVersão da RÉgua Padrão}

A concepção básica do problema associado à medição de retilineidade usando artefatos mecânicos está ilustrada na Figura 3.5. Sabe-se que mesmo uma régua padrão não tem a face de medição perfeitamente retilínea. Então os seus erros de forma se misturam com os erros da máquina dificultando a medição. Este problema pode ser resolvido por uma técnica conhecida como técnica da reversão da régua (CAMPBELL, 1995).

Segundo EVANS et al (1996) a técnica da reversão da régua padrão é talvez a melhor técnica conhecida na literatura para a medição de erros de 
retilineidade e é aparentemente datada de antes de 1941. É facilmente entendida através das Figuras 3.6 e 3.7.

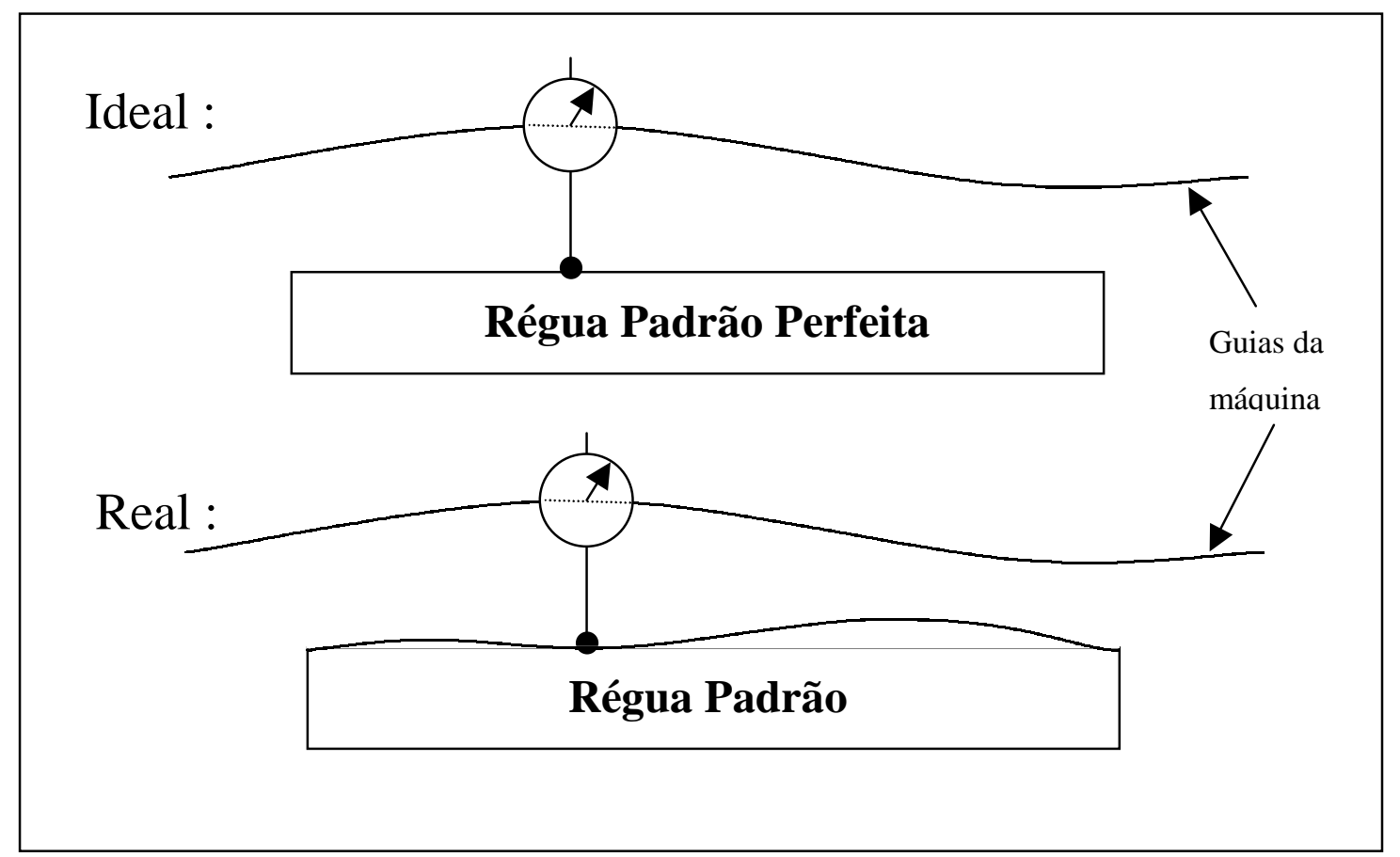

Figura 3.5-Problema básico na medição utilizando artefato mecânico

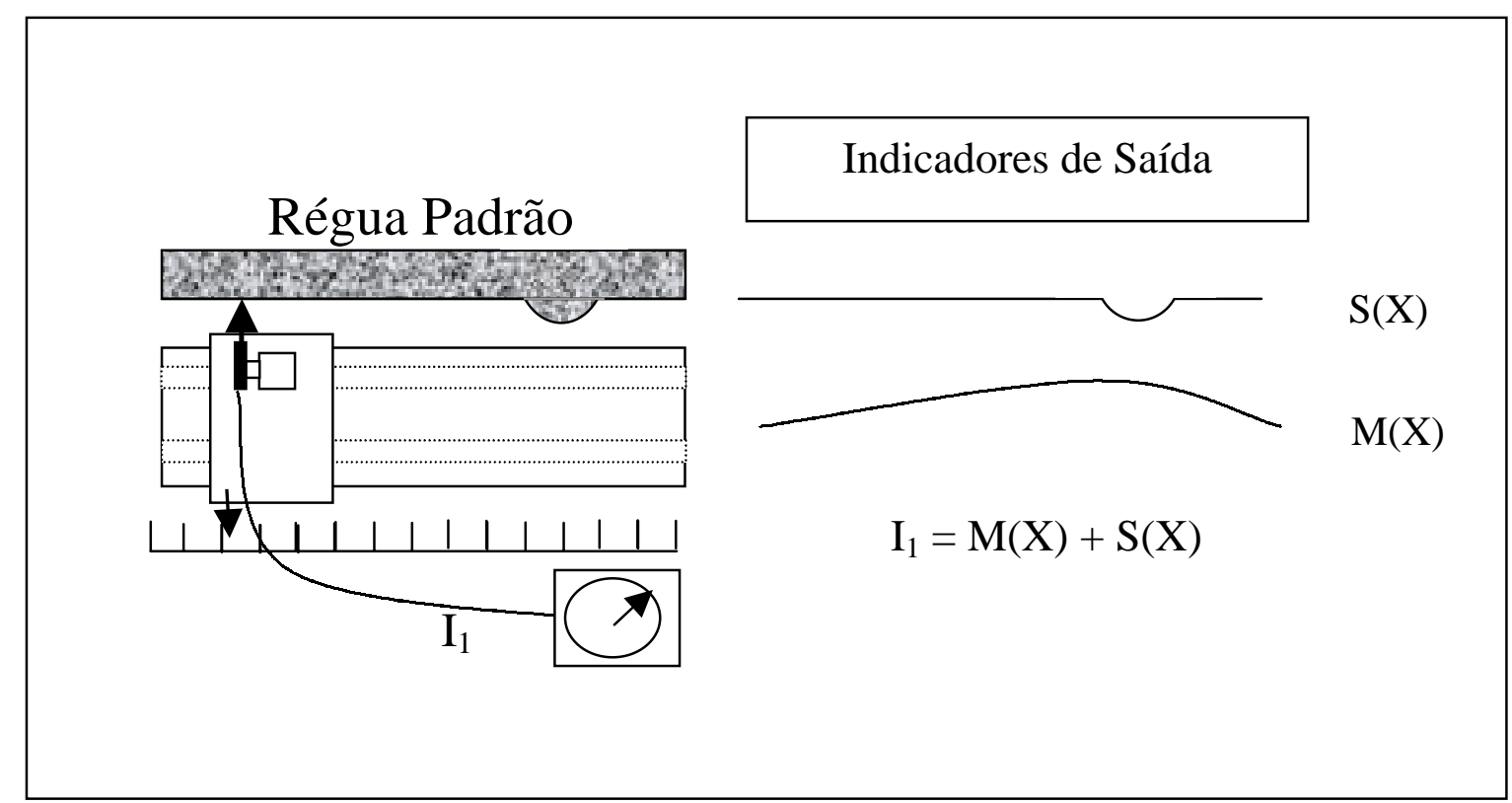

Figura 3.6 - Esquema de reversão da régua 
A Figura 3.6 mostra uma montagem típica para a medição de retilineidade de uma guia utilizando-se uma régua padrão. Pode-se observar a régua, a escala e um transdutor de deslocamento, que mostra o valor $\mathrm{I}_{1}$. Na Figura 3.7 tem-se a régua padrão girada em $180^{\circ}$. No transdutor de deslocamento tem-se a saída $\mathrm{I}_{2}$.

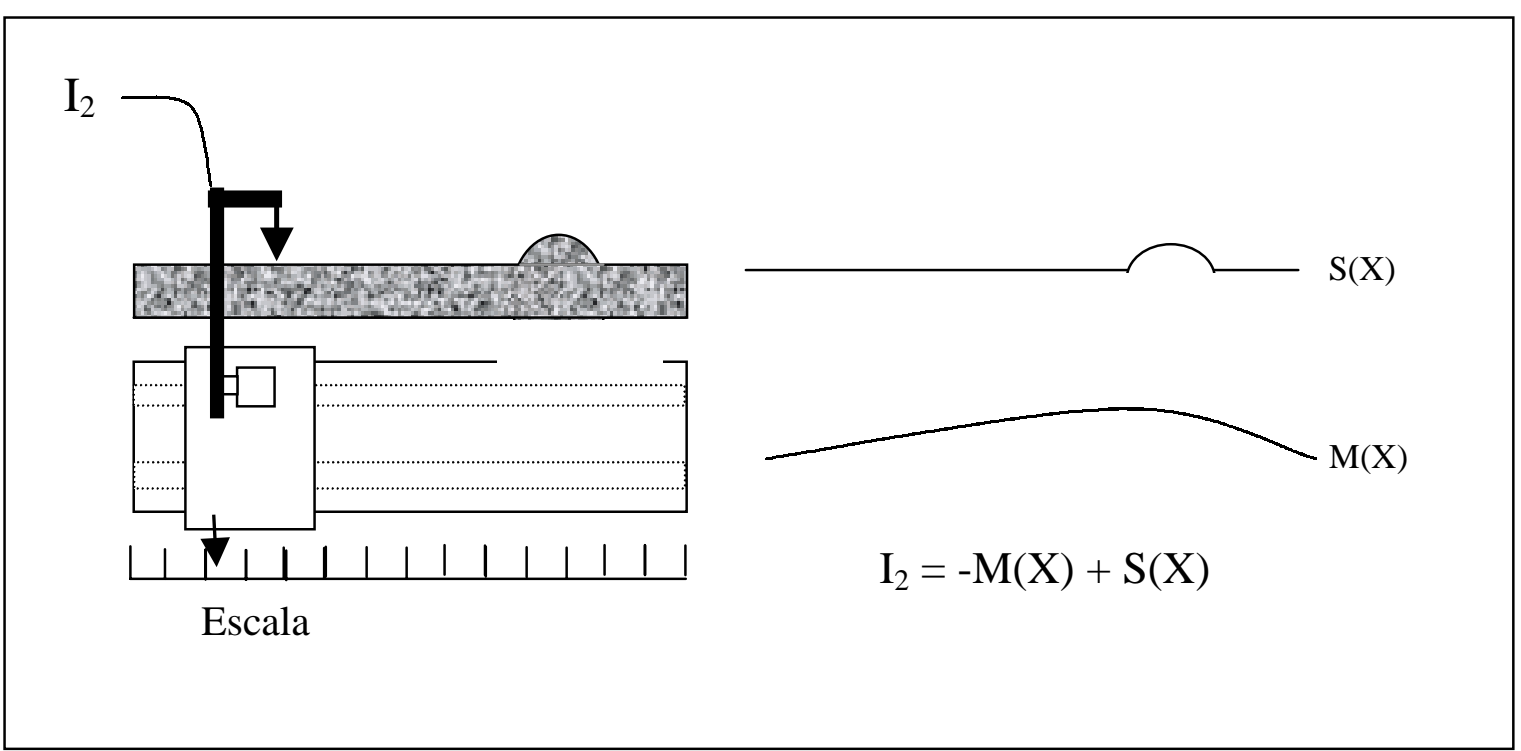

Figura 3.7 - Esquema após a reversão

Assumindo-se que o erro de retilineidade do carro da máquina é dado por $\mathrm{M}(\mathrm{x})$ e que o desvio da régua padrão é dado por $\mathrm{S}(\mathrm{x})$, o indicador de saída $\mathrm{I}_{\mathrm{n}}(\mathrm{x})$ para as duas posições é dado pelas expressões [3.18] e [3.19]:

$$
\begin{aligned}
& I_{1}(x)=M(x)+S(x) \\
& I_{2}(x)=-M(x)+S(x)
\end{aligned}
$$

Deste modo os erros de retilineidade do carro e o da régua podem ser calculados respectivamente por [3.20] e [3.21] :

$$
\begin{array}{r}
M(x)=\frac{I_{1}(x)-I_{2}(x)}{2} \\
\text { e } \quad S(x)=\frac{I_{1}(x)+I_{2}(x)}{2}
\end{array}
$$


Observa-se que os dados obtidos através das medições são apenas os indicadores de saída $\mathrm{I}_{1}$ e $\mathrm{I}_{2}$ e não os erros de retilineidade do carro e da régua, separadamente.

A maior fonte de incertezas no método de reversão da régua padrão provém de efeitos ambientais. Controlados os efeitos do ambiente, outra fonte de incerteza é a recolocação da régua padrão e do indicador. Tipicamente, o sistema de coordenadas de medição é definido pelo sistema metrológico da guia da máquina. Assim, se ocorrer um erro de deslocamento $\Delta \mathrm{x}$ na reversão, isto é, variações de deslocamento na direção de movimentação do eixo, as equações [3.18] e [3.19] tornar-se, respectivamente, [3.22] e [3.23] :

$$
\begin{aligned}
& \mathrm{I}_{1}(\mathrm{x})=\mathrm{M}(\mathrm{x})+\mathrm{S}(\mathrm{x}) \\
& \mathrm{I}_{2}(\mathrm{x})=-\mathrm{M}(\mathrm{x})+\mathrm{S}(\mathrm{x}+\Delta \mathrm{x})
\end{aligned}
$$

O desvio da guia da máquina, por sua vez é calculado por [3.24] :

$$
M(x)-\delta_{x}=\frac{I_{1}(x)-I_{2}(x)}{2}
$$

Onde $\delta_{\mathrm{x}}$ é dado por [3.25] :

$$
\begin{aligned}
\delta_{x} & =\frac{(\mathrm{S}(\mathrm{x})-\mathrm{S}(\mathrm{x}+\Delta \mathrm{x}))}{2} \\
& =-\frac{1}{2} \Delta \mathrm{x} \frac{\mathrm{d}}{\mathrm{dx}} \mathrm{S}(\mathrm{x})
\end{aligned}
$$

Usando a máxima inclinação do perfil de $\mathrm{S}(\mathrm{x})$ encontrada na equação [3.21], a equação [3.25] admite um limite $\Delta x$ como sendo um erro aceitável do termo $\delta_{x}$ da equação [3.24] .

Pode-se, ainda, citar as incertezas nas montagens como sendo outra fonte de incertezas na medição. Tal incerteza é dada pelo produto dos erros de montagem e de inclinação da régua padrão, equação [3.26] :

$$
\delta_{y}=\frac{1}{2} \Delta y \frac{d}{d y} S(x),
$$


onde $\Delta y$ é o erro de montagem, ortogonal ao plano definido pelo eixo x e pela direção sensitiva do indicador.

O efeito dos erros de montagem é dado em função da amplitude e do comprimento de ondas do erro de retilineidade da régua padrão.

\section{- REVERSÃO DO INTERFERÔMETRO ÓTICO DE RETILINEIDADE}

Várias empresas lançaram no mercado óticas para medição de retilineidade usando interferômetria diferencial. Um sistema comercial típico é mostrado na Figura 3.8 (EVANS et al, 1996).

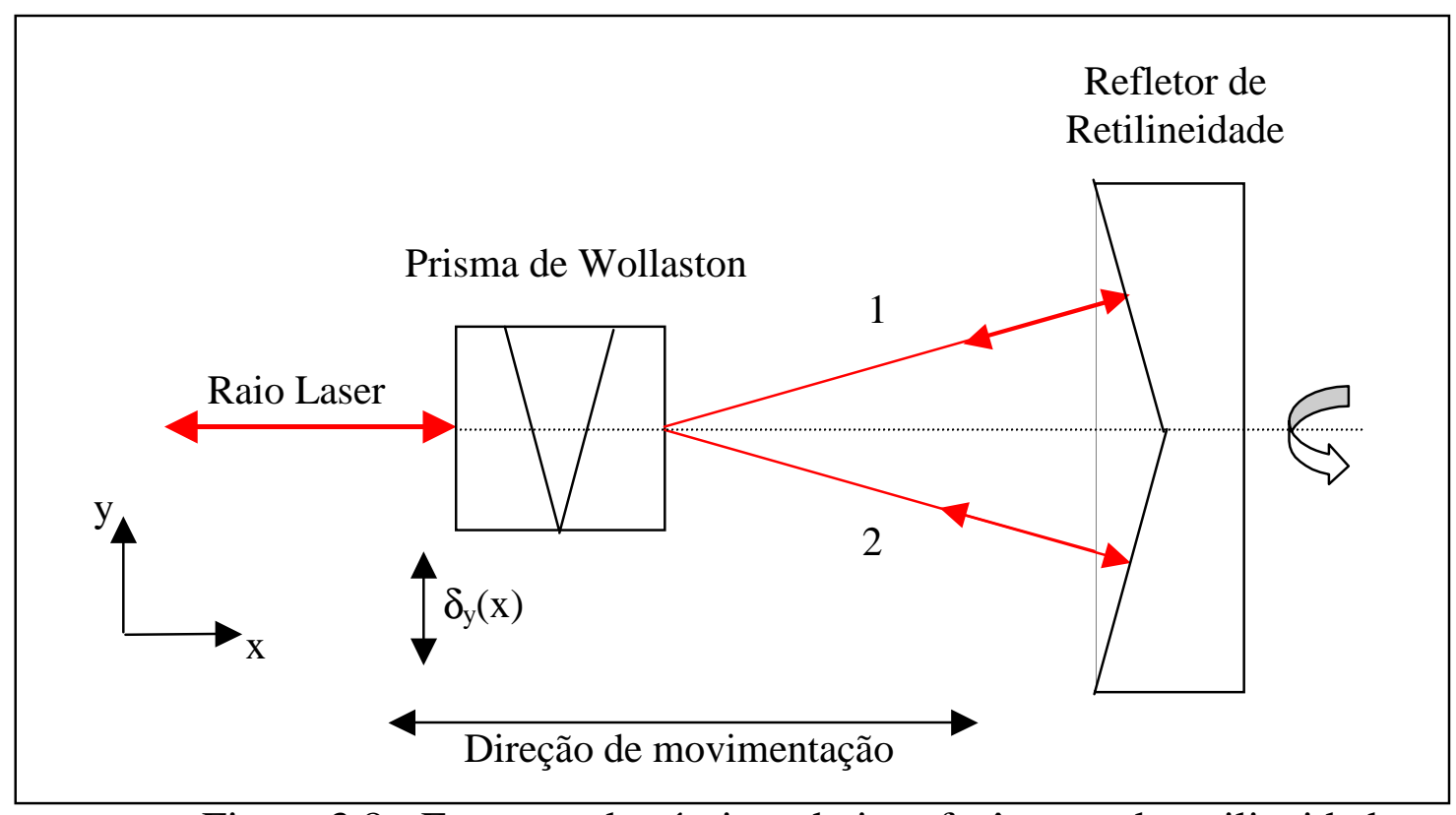

Figura 3.8 - Esquema das ópticas do interferômetro de retilineidade

Durante a medição há movimento relativo entre duas ópticas, o prisma de Wollaston e o refletor de retilineidade na direção do eixo Y. Estes movimentos causam mudanças na diferença dos caminhos ópticos dos feixes 1 e 2. Está diferença pode ser relacionada ao movimento transversal, isto é, o erro de retilineidade e o cálculo realizado para medidas interferométricas com espelhos perfeitos é feito da seguinte forma:

$$
\Delta \phi_{1}=2 \delta_{\mathrm{Y}}(\mathrm{X}) \operatorname{sen}(\theta)
$$




$$
\Delta \phi_{2}=-2 \delta_{\mathrm{Y}}(\mathrm{X}) \operatorname{sen}(\theta)
$$

Consequentemente

$$
\begin{aligned}
\Delta \phi & =\Delta \phi_{1}-\Delta \phi_{2} \\
& =4 \delta_{\mathrm{Y}}(\mathrm{X}) \operatorname{sen}(\theta)
\end{aligned}
$$

onde:

- $\Delta \phi_{1}$ é a mudança de caminho ótico do raio 1 ;

- $\Delta \phi_{2}$ é a mudança de caminho ótico do raio 2;

- $\Delta \phi$ é a mudança de caminho visto pelo detetor;

- $\delta_{\mathrm{Y}}(\mathrm{X})$ é erro de retilineidade na direção de $\mathrm{Y}$ para movimentos na direção de X; e

- $\theta$ é metade do ângulo entre o raio 1 e 2 .

Se os espelhos do refletor não são perfeitamente planos, que é sempre o caso, a falta de planicidade pode produzir mudanças na fase dos feixes e consequentemente no caminho percorrido. $\mathrm{O}$ erro causado pela falta de planicidade pode ser removido através da aplicação de técnica de reversão. Primeiro uma medição de retilineidade é feita com o refletor de retilineidade em uma posição. Depois este é rotacionado em $180^{\circ}$ ao redor da linha de centro e feita uma nova medição. Então, quando a posição dos espelhos é revertida, a diferença dos dois resultados é a medida do erro de retilineidade desejada. A situação é descrita na Figura 3.9, onde as planicidades dos espelhos são $F_{1}(d)$ e $F_{2}(d)$, sendo $d=X \operatorname{sen}(\theta)$. Como o refletor de retilineidade é movimentado na direção $\mathrm{X}$, a diferença dos dois caminhos é $\Delta \phi_{\mathrm{F}}$ :

$$
\begin{aligned}
& \Delta \phi_{1}=-2 \mathrm{~F}_{1}(\mathrm{~d})+2 \delta_{\mathrm{Y}}(\mathrm{X}) \operatorname{sen}(\theta) \\
& \Delta \phi_{2}=-2 \mathrm{~F}_{2}(\mathrm{~d})-2 \delta_{\mathrm{Y}}(\mathrm{X}) \operatorname{sen}(\theta)
\end{aligned}
$$

Que produz um $\Delta \phi$ para o espelho na primeira posição :

$$
\Delta \phi_{\mathrm{F}}=-2 \mathrm{~F}_{1}(\mathrm{~d})+2 \mathrm{~F}_{2}(\mathrm{~d})+4 \delta_{\mathrm{Y}}(\mathrm{X}) \operatorname{sen}(\theta)
$$


$\mathrm{O}$ refletor de retilineidade é agora rotacionado sobre o eixo $\mathrm{X}$ e novamente o erro de retilineidade é medido produzindo :

$$
\begin{aligned}
& \Delta \phi_{3}=-2 \mathrm{~F}_{2}(\mathrm{~d})+2 \delta_{\mathrm{Y}}(\mathrm{X}) \operatorname{sen}(\theta) \\
& \Delta \phi_{4}=-2 \mathrm{~F}_{1}(\mathrm{~d})-2 \delta_{\mathrm{Y}}(\mathrm{X}) \operatorname{sen}(\theta)
\end{aligned}
$$

então:

$$
\Delta \phi_{\mathrm{R}}=-2 \mathrm{~F}_{2}(\mathrm{~d})+2 \mathrm{~F}_{1}(\mathrm{~d})+4 \delta_{\mathrm{Y}}(\mathrm{X}) \operatorname{sen}(\theta)
$$

Fazendo uma média da diferenças de caminhos encontra-se:

$$
\Delta \phi_{\mathrm{A}}=4 \delta_{\mathrm{Y}}(\mathrm{X}) \operatorname{sen}(\theta)
$$

que remove o erro de planicidade dos espelhos.

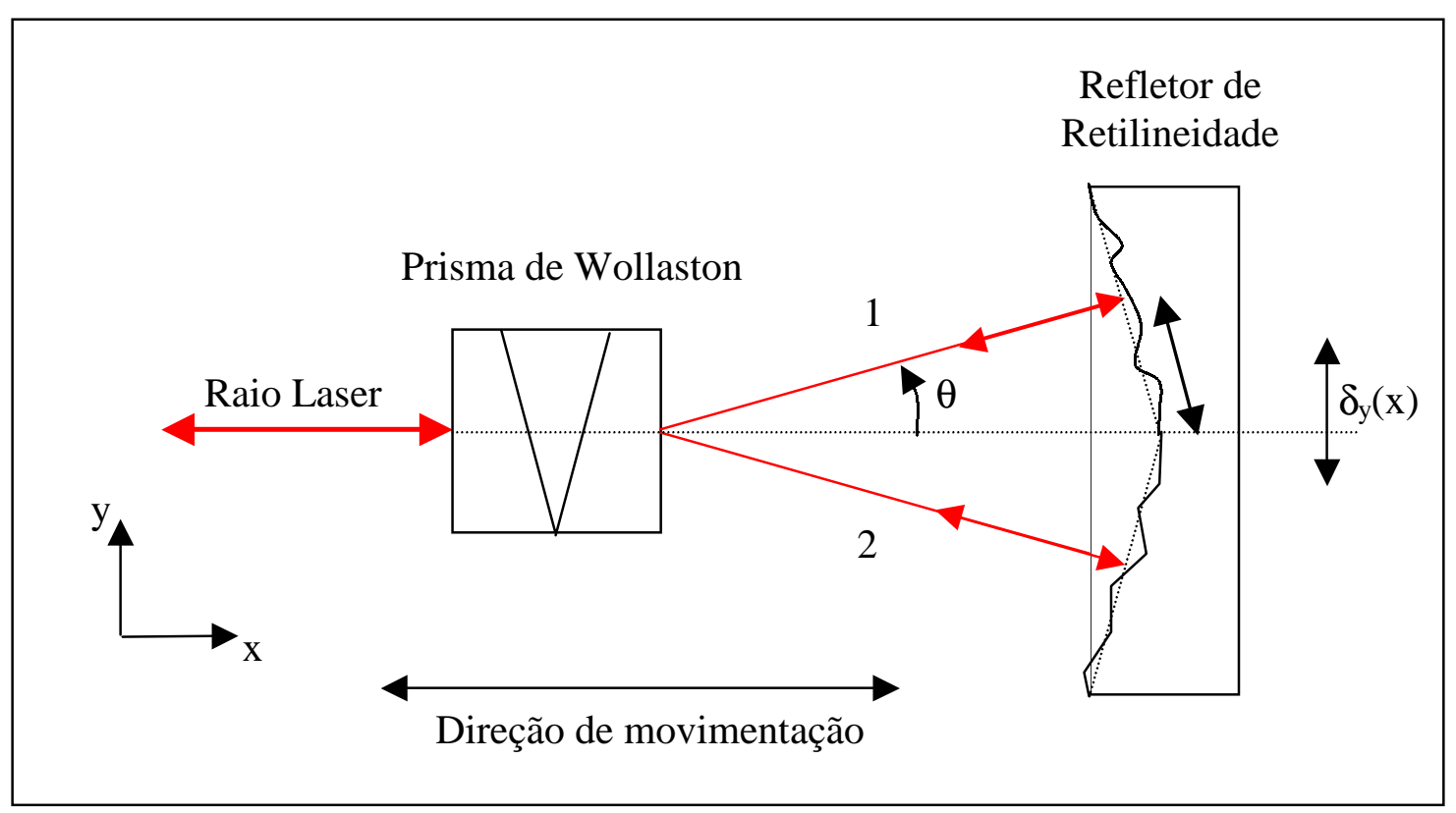

Figura 3.9 - Efeito da planicidade do espelho 


\subsection{2 - ELIMINAÇÃO DO DESALINHAMENTO}

$\mathrm{Na}$ medição de erro de retilineidade, as leituras obtidas incluem os deslocamentos devido a um provável desalinhamento entre o artefato de medição (referência) e o eixo de movimentação da máquina.

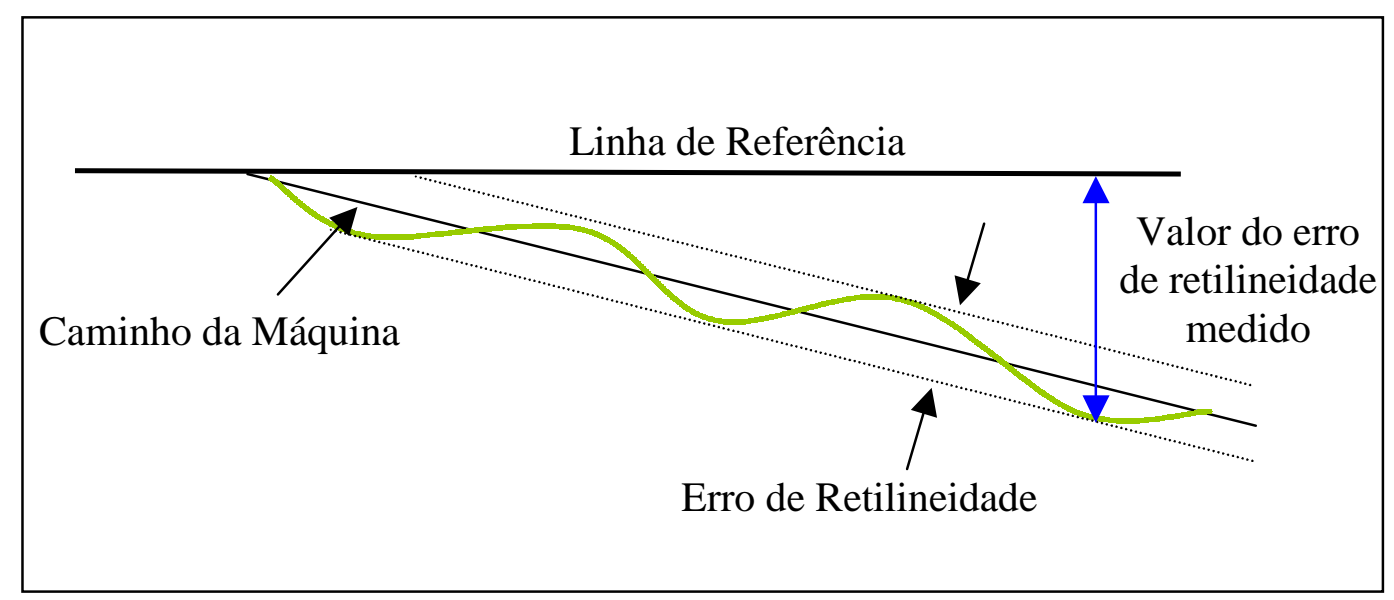

Figura 3.10 - Provável desalinhamento

$\mathrm{Na}$ medição de erro de retilineidade, as leituras obtidas incluem os deslocamentos devido a um provável desalinhamento entre o artefato de medição (referência) e o eixo de movimentação da máquina. Tal desalinhamento deve ser eliminado dos dados antes de qualquer manipulação numérica. (Hewlett-Packard,1988)

A Figura 3.10 está ilustrando o desalinhamento entre as direções do feixe de luz e do eixo de movimento da máquina, durante a utilização do interferômetro laser na medição do erro de retilineidade.

O desalinhamento pode ser eliminado através de vários métodos. Dois métodos mais comuns são: o método de "Pontos Extremos" e o de "Mínimos Quadrados". 


\section{- MÉtodo dos Pontos Extremos}

Para remover o desalinhamento dos dados, utilizando o método dos pontos extremos deve-se, primeiramente, determinar a inclinação da reta, equação [3.37] que passa pelos primeiro e último ponto de medição, como ilustrado na Figura 3.11

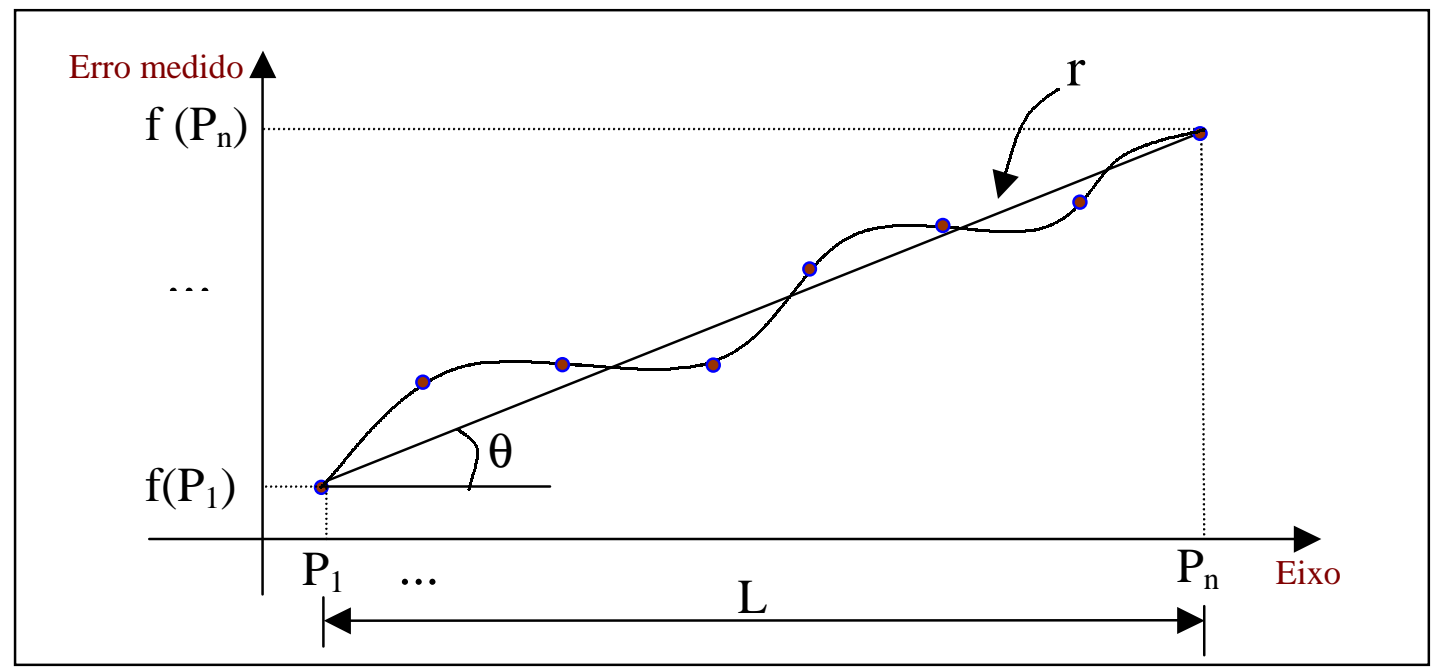

Figura 3.11 - Ilustração do método dos pontos extremos

$$
\theta=\mathrm{m}(\text { inclinação })=\frac{\mathrm{f}\left(\mathrm{P}_{\mathrm{n}}\right)-\mathrm{f}\left(\mathrm{P}_{1}\right)}{\mathrm{L}}
$$

Desta forma determina-se a reta $\mathbf{r}$ pela equação [3.38]

$$
\mathrm{Y}_{\text {incliną̧ão }}=\mathrm{mX}+\mathrm{b}
$$

onde :

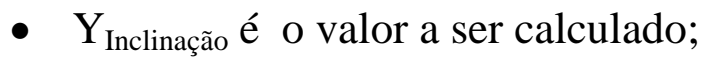

- X é a distância percorrida ao longo do caminho de medição;

- b é a primeira leitura da retilineidade 
Conhecido o desalinhamento [3.38], determina-se a inclinação $Y_{\text {inclinação }}$ para cada $\mathrm{X}$ ao longo do caminho de medição e utiliza-se a expressão [3.39] para calcular o $\mathrm{Y}_{\text {Verdadeiro, }}$ isto é , o erro de retilineidade

$$
\mathrm{Y}_{\text {Verdadeiro }}=\mathrm{Y}_{\text {Laser }}-\mathrm{Y}_{\text {Inclinação }}
$$

\section{- Método de Mínimos Quadrados}

O calculo do erro de retilineidade, utilizando-se o método dos mínimos quadrados para remover o desalinhamento dos valores medidos, está ilustrado na Figura 3.12

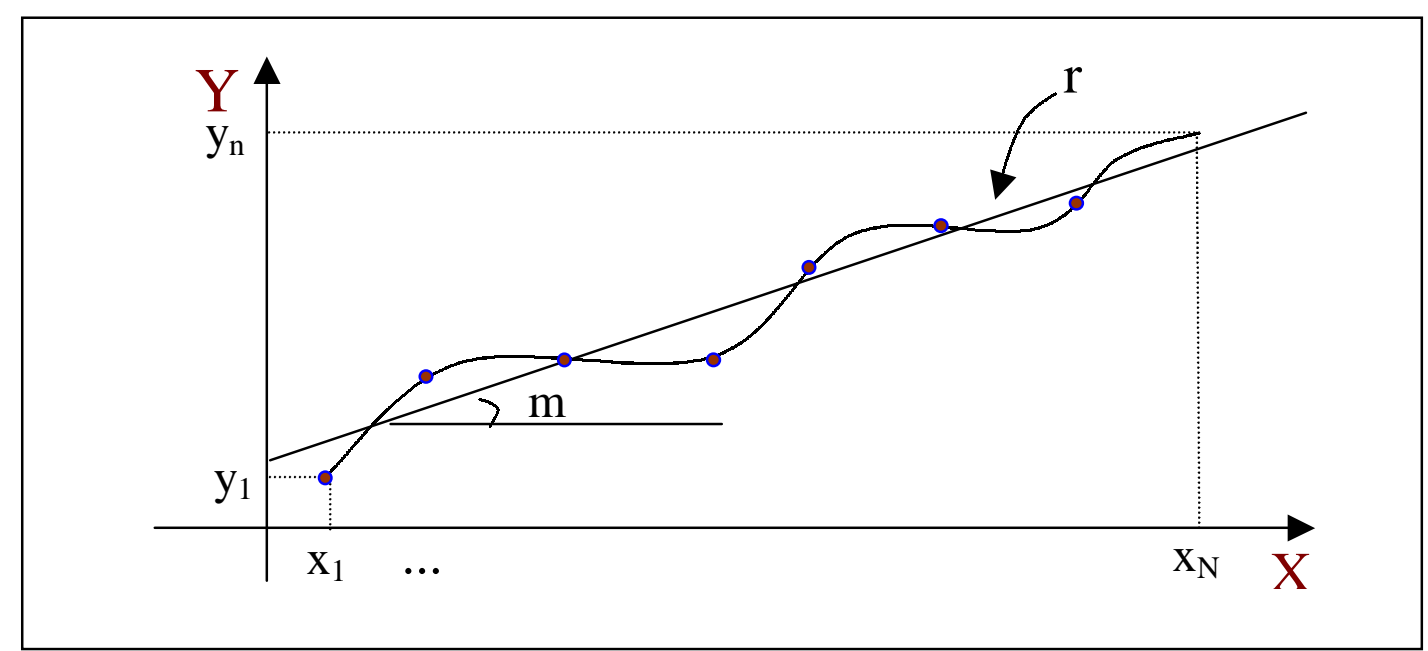

Figura 3.12 - Ilustração do método dos mínimos quadrados

A equação da reta de mínimos quadrados é dada pela expressão [3.40]:

$$
\mathrm{Y}_{\text {incliną̧̃̃o }}=\mathrm{mX}+\mathrm{b}
$$

onde:

- Y Inclinação é o valor a ser calculado;

- X é a distância percorrida ao longo do caminho de medição;

$$
\text { - } \mathrm{m}=\frac{\sum \mathrm{X} \cdot \sum \mathrm{Y}-\mathrm{N} \cdot \sum \mathrm{X} \cdot \mathrm{Y}}{\left(\sum \mathrm{X}\right)^{2}-\mathrm{N} \cdot \sum \mathrm{X}^{2}}
$$




$$
\text { - } b=\frac{\sum \mathrm{X} \cdot \sum \mathrm{XY}-\sum \mathrm{Y} \cdot \sum \mathrm{X}^{2}}{\left(\sum \mathrm{X}\right)^{2}-\mathrm{N} \cdot \sum \mathrm{X}^{2}}
$$

Determinada a equação da reta $\mathbf{r}$ [3.40], calcula-se $Y_{\text {inclinação }}$ para cada $\mathrm{X}$ ao longo do caminho de medição e utiliza-se a expressão [3.43] para calcular o erro de retilineidade, $\mathrm{Y}_{\text {Verdadeiro. }}$.

$$
\mathrm{Y}_{\text {Verdadeiro }}=\mathrm{Y}_{\text {Laser }}-\mathrm{Y}_{\text {Inclinação }}
$$

\section{3 - O ESTUdo de CASOS DE BRYAN}

BRYAN, J.B., 1979 reavaliou e propôs um novo enunciado para o princípio de Abbè para situações onde o projeto de máquinas com o sistema de medição do deslocamento alinhado ao eixo de medição não era possível, como já exposto no Capítulo 2.

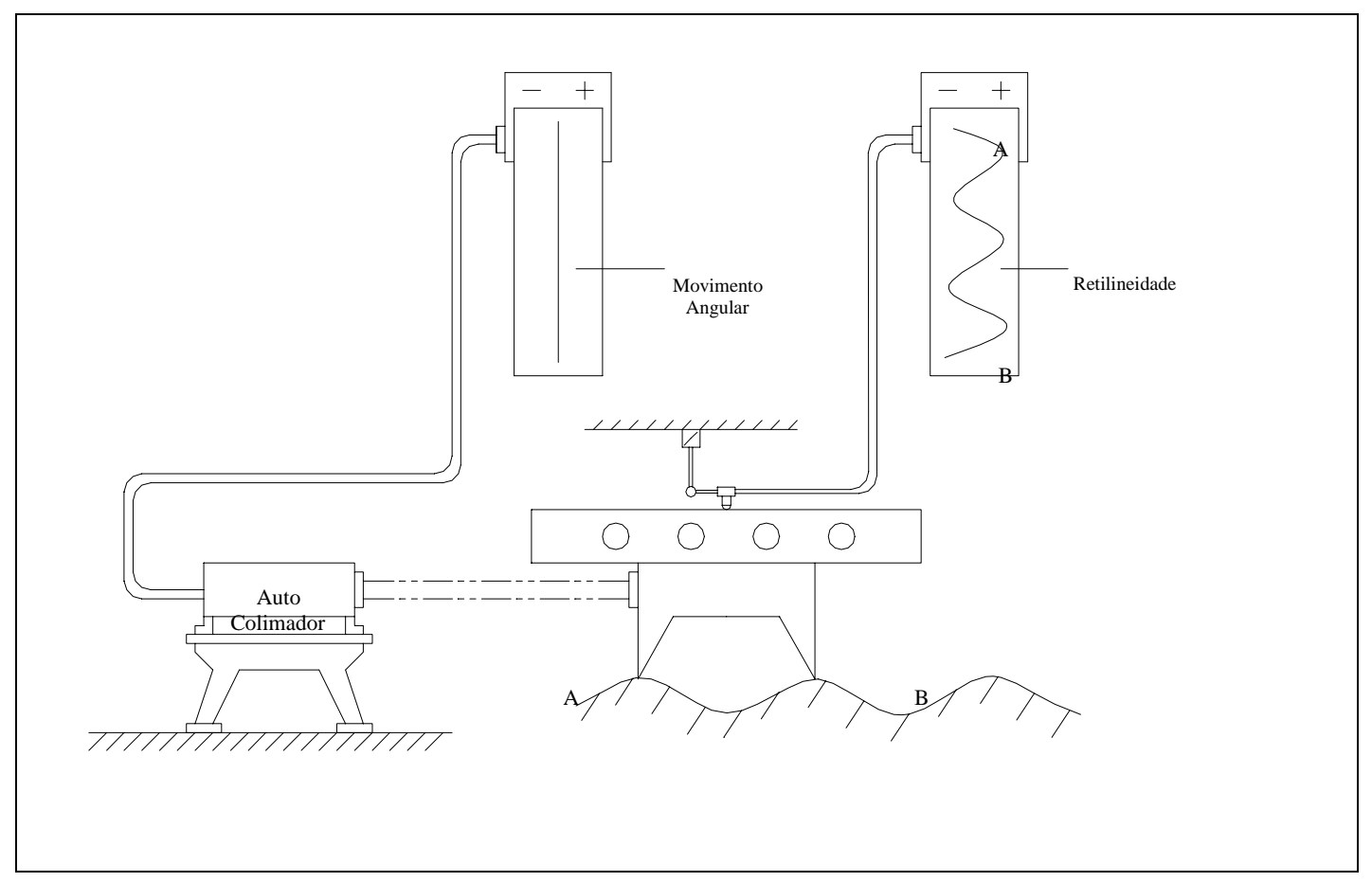

Figura 3.13 - Erro de retilineidade e angular de uma guia em forma senoidal e distâncias dos mancais "b" igual a um comprimento de onda. 
BRYAN estendeu o Princípio de Abbè para medição de retilineidade de guias. O Princípio de Bryan, diz o seguinte :

"Um sistema de medição de retilineidade deve estar em linha com o ponto funcional no qual a retilineidade é medida. Se isto não for possível, todas as guias que transferem a medição devem estar livres de movimento angular ou os dados do movimento angular devem ser usados nas compensações dos possíveis desvios."

As Figuras de 3.13 a 3.15 ilustram alguns dos movimentos que podem ocorrer nas guias, o que está mostrado em exagero para um melhor entendimento.

A Figura 3.13 mostra o movimento ao longo de uma guia que tem um desenho senoidal, a distância entre os dois pontos de contato do carro na guia, tem um espaçamento igual ao número inteiro de comprimentos de onda.

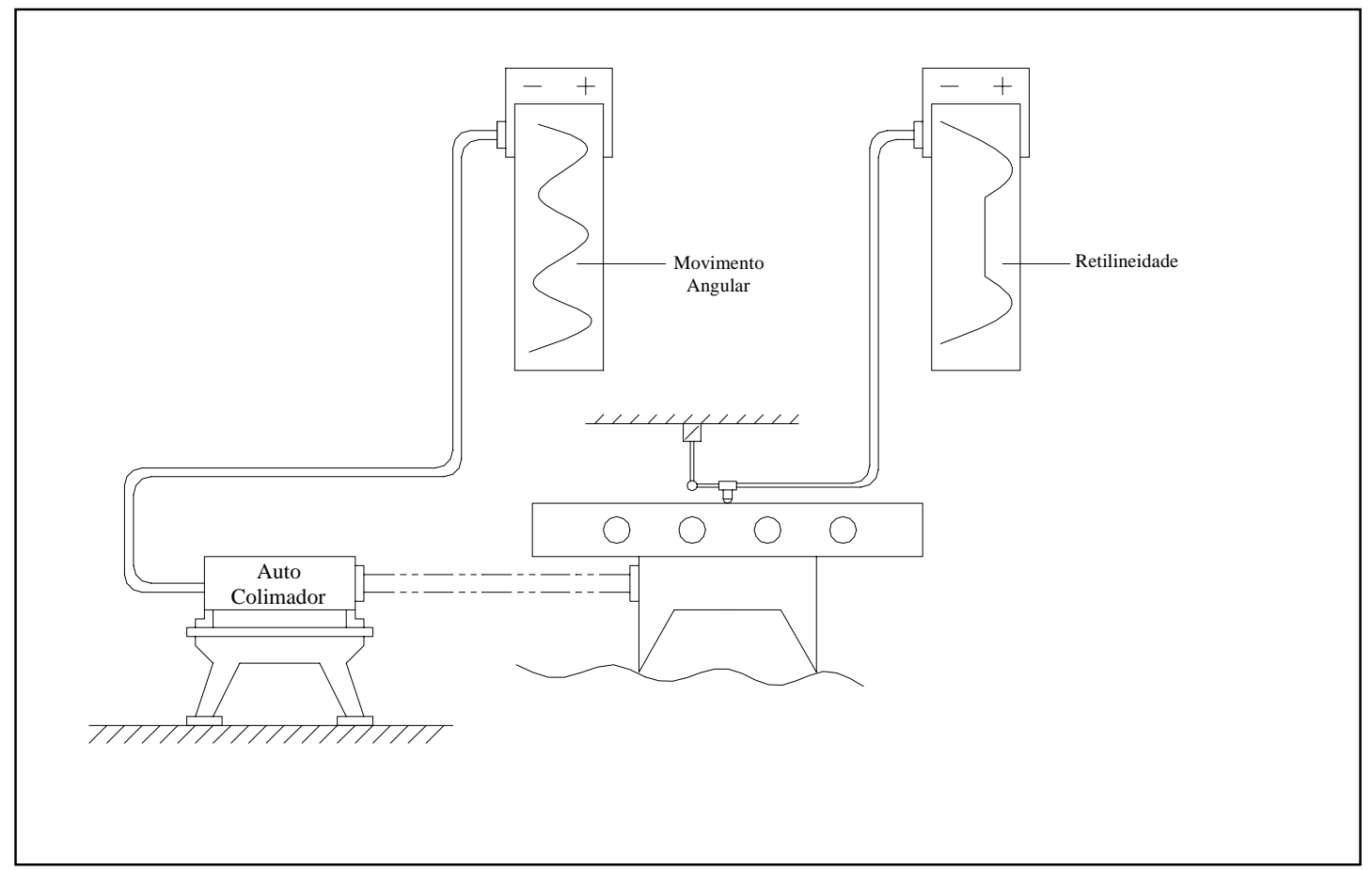

Figura 3.14 - Erro de retilineidade e angular de uma guia em forma senoidal e distâncias dos mancais b igual a metade de um comprimento de onda 
Pode-se reafirmar que o movimento do carro é livre do movimento angular, mas não é retilíneo, ou seja, o erro de retilineidade é o movimento sentido pelo apalpador e o erro angular é zero pois não há nenhuma inclinação do carro em relação ao eixo de movimentação, o carro sempre permanece paralelo a este eixo. Isso nos mostra que se o erro de retilineidade e a distância entre os pontos de contato forem conhecidos o erro angular, pode ser facilmente determinado. Neste caso particular é nulo. (BRYAN, 1979].

$\mathrm{Na}$ Figura 3.14 os pontos de contato do carro com a guia tem agora o espaçamento igual a metade do comprimento de onda, pode-se então observar movimentos angulares sofridos pelo carro e o erro de retilineidade. Neste caso, a régua se movimenta e o indicador linear fica fixo na estrutura da máquina .

A montagem executada na Figura 3.14 é a montagem mais utilizada nas experimentações. Este caso é o mais geral e o mais provável de acontecer.

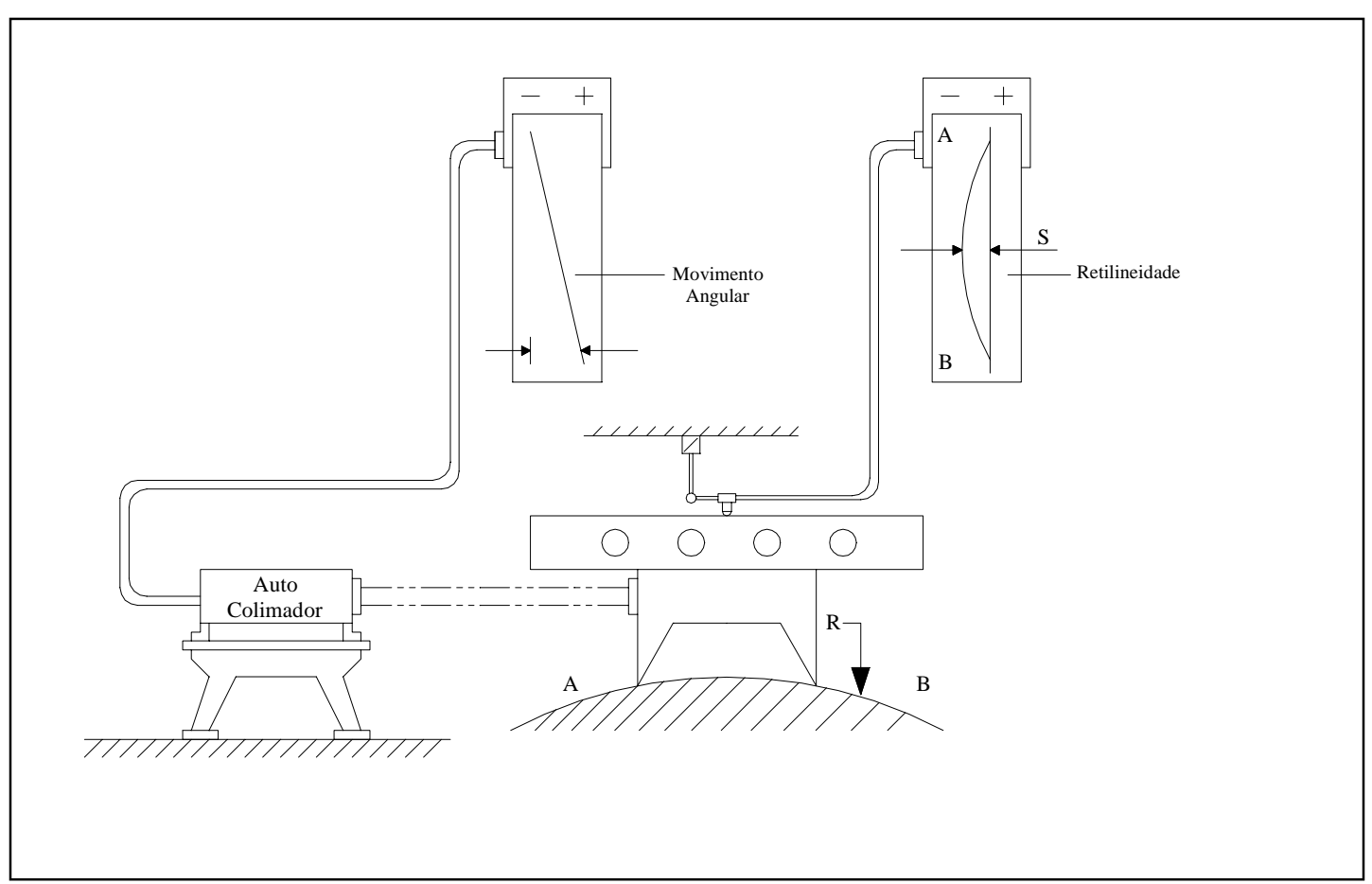

Figura 3.15 - Erro de retilineidade e angular de uma guia em forma circular e distâncias dos mancais "b" conhecida 
A Figura 3.15 mostra a guia em um movimento angular uniforme, ou seja, uma guia circular de raio $\mathrm{R}$. A régua é que se movimenta e o indicador mostra o erro de retilineidade de grandeza igual a $\mathrm{S}$. Tal grandeza deve ser pelo menos 10 vezes menor que o raio para que o método possa ser utilizado.

Neste caso, a montagem é a mesma utilizada na Figura 3.14. O erro de retilineidade mostrado pode ser visualizado como um arco de circunferência , pode-se então dizer que o ângulo formado pelo carro ao longo do deslocamento é um ângulo constante. Para que o erro angular seja determinado deve-se calcular o primeiro ângulo $\theta$ e considera-lo como referência e a cada $\theta$ calculado deve-se subtrair o $\theta$ de referência e somá-lo ao $\theta$ anterior. Obtém-se assim o que foi mostrado na Figura 3.15, sendo o erro angular uma reta cuja inclinação é $\theta$.

\section{4 - Modelagem Matemática das Máquinas de Medir A TRÊS COORDENADAS}

A modelagem das Máquinas de Medir a Três Coordenadas tem crescido na sua importância pois através de modelos matemáticos é possível determinar a grandeza e o comportamento dos erros com o objetivo de compensá-los. Durante muitos anos tem-se dedicado tempo e esforço à modelagem matemática das MM3Cs. Técnicas variadas tem sido utilizadas para este fim. A seguir oferece-se uma breve explicação de algumas destas técnicas.

\section{- ANÁlise Vetorial:}

Através de vetores é feita uma representação dos caminhos de medição. Desta forma, o erro volumétrico é definido como a diferença 
vetorial entre os vetores que descrevem os caminhos de medição com e sem erros.

Através da análise vetorial, ZHANG et al. (1985), baseado na teoria do corpo rígido, obteve um modelo para descrever os erros em uma MM3C do tipo "Ponte Móvel". Este modelo tem a finalidade de compensar os erros geométricos e o efeito da dilatação térmica das escalas de medição.

\section{- Transformadas HoMOgÊNEAS:}

As técnicas de transformação homogêneas foram introduzidas por Denavit-Hartenberg em 1955. Através desta técnica, e mediante o uso de matrizes de transformação $4 \times 4$, é possível representar movimentos de translação, de rotação ou a combinação desses dois, possibilitando estabelecer as relações entre partes móveis de um mecanismo e um sistema de coordenadas de referência.

Cada componente da máquina sofre rotações e translações com relação a um sistema de coordenadas, e cada um destes componentes pode ser representado por um sistema de coordenadas intermediário. Desta forma, através de vetores e matrizes é desenvolvida uma sistemática que generaliza a representação da posição e da orientação da sonda da máquina em relação ao sistema de coordenadas de referência. A definição do comportamento cinemático da máquina consiste na determinação das matrizes de transformação homogênea dos diferentes sistemas de coordenadas, com referência a um sistema de coordenadas.

As matrizes $4 \times 4$ utilizadas para determinar a posição de um corpo rígido com relação a um sistema de coordenadas fixo são dadas conforme mostrado a seguir. 
$\alpha$ - rotação infinitesimal sobre o eixo $\mathrm{x}$. $\delta A=\left[\begin{array}{llll}1 & -\gamma & \beta & \Delta x \\ \gamma & 1 & -\alpha & \Delta y \\ -\beta & \alpha & 1 & \Delta z \\ 0 & 0 & 0 & 1\end{array}\right] \begin{aligned} & \beta \text {-rotação infinitesimal sobre o eixo y. } \\ & \\ & \end{aligned}$

Os valores de $\alpha, \beta, \gamma, \Delta \mathrm{x}, \Delta \mathrm{y}$ e $\Delta \mathrm{z}$ são funções da posição ao longo do eixo.

HOCKEN, (1977), modelaram através das matrizes de transformações homogêneas os erros angulares em máquinas de medir.

DI GIACOMO et al., (1997), utilizando técnica de transformações homogêneas, modelaram MM3Cs com o objetivo de determinar a influência dos termos de segunda ordem no erro volumétrico. Dois modelos foram desenvolvidos, um deles incluindo os termos de segunda ordem e um outro desprezando-os. Como resultado obteve-se que a inclusão dos termos de segunda ordem nos modelos acarreta uma diferença menor que $1 \mathrm{~nm}$, mostrando que eles podem ser desprezados, desde que o valor esperado dos erros volumétricos esteja na ordem do $\mu \mathrm{m}$. No futuro próximo os termos de segunda ordem não poderão ser desprezados. Constituem uma poderosa ferramenta matemática, com relativa facilidade de uso.

\section{- ANÁLISE GEOMÉTRICA:}

Através da análise geométrica da estrutura é verificada a parcela de contribuição de cada erro individual nas componentes do erro volumétrico. A soma algébrica de tais parcelas para cada um dos eixos forma as denominadas equações de sintetização.

DI GIACOMO (1986), apresentou a determinação dos erros geométricos individuais utilizando análise geométrica para, posteriormente, 
determinar as componentes do erro volumétrico em cada direção preferencial "X", "Y" e "Z" de uma MM3C do marca "Ferranti Conquest MKII".

\section{- Análise estatística}

As técnicas estatísticas tem sido utilizadas para avaliar o comportamento dos erros de MM3Cs e portanto de seu desempenho. Através do uso destas técnicas é possível se determinar a incerteza de medição em tais máquinas.

Em 1978 GUYE propôs um método para avaliar os erros de medição de uma MM3C. Tal método consiste na construção de histogramas a partir dos valores dos erros de posição que foram levantados utilizando um interferômetro laser. Neste caso, o desvio padrão do conjunto de resultados é considerado como indicador do desempenho da máquina avaliada.

POOLE (1983) sugeriu um método para verificar o desempenho das MM3Cs usando técnicas de análise de variância. Este método permite investigar o efeito da localização no volume de trabalho na acuracidade da máquina. Para isto o volume da máquina avaliada foi dividido em oito partes iguais, e os erros em cada parte foram determinados utilizando-se uma peça padrão. Esta peça consiste de uma barra com dois furos circulares cuja distância entre centros é conhecida.

$\mathrm{Na}$ atualidade, as técnicas de planejamentos de experimentos vem ganhando destaque na experimentação. Um planejamento adequado dos experimentos permite minimizar o número de ensaios, o tempo de execução e o custo das pesquisas.

PIRATELLI (1997) apresenta um método para avaliação indireta do desempenho de $\mathrm{MM} 3 \mathrm{C}$, através da utilização de técnicas de planejamento de experimentos e do uso de uma barra de esferas. O método proposto consiste no planejamento e execução de dois experimentos, um empregando o arranjo L9 proposto por Taguchi e outro empregando o arranjo fatorial $3^{2}$. Os erros de 
medição obtidos foram analisados através da técnica de análise de variância. Como resultados foram obtidas informações valiosas sobre o desempenho metrológico de uma máquina de medir, que envolve a determinação das variáveis que mais influenciam o desempenho da máquina e a identificação das condições críticas de operação. Embora o teste de avaliação do desempenho, indicado na norma ANSI/ASME B89.4.1 (1995), seja menos complexo que o método proposto, este último apresenta vantagens significativas, que o fazem superior.

\section{5 - RAio de CURVATURA}

$\mathrm{O}$ raio de curvatura, Figura 3.16, foi a princípio estudado como um instrumento para se equacionar o problema da correlação entre os erros de retilineidade e os erros angulares.

O equacionamento matemático se mostrou interessante, pois através de uma função $f(x)$, que poderia representar o erro de retilineidade, encontram-se os raios de curvatura e os respectivos ângulos $\mathrm{d} \varphi$ formados, quando analisados dois pontos da função. As equações 3.44 e 3.45 mostram este fato.

$$
\begin{aligned}
& k=\frac{1}{r}=\frac{f^{\prime \prime}(x)}{\left\{1+\left[f^{\prime}(x)\right]^{2}\right\}^{3 / 2}} \\
& d \varphi=k d x
\end{aligned}
$$

onde:

- $f(x)$ é a função a ser analisada; 
- $k$ é a curvatura da função e

- $r$ é o raio de curvatura.

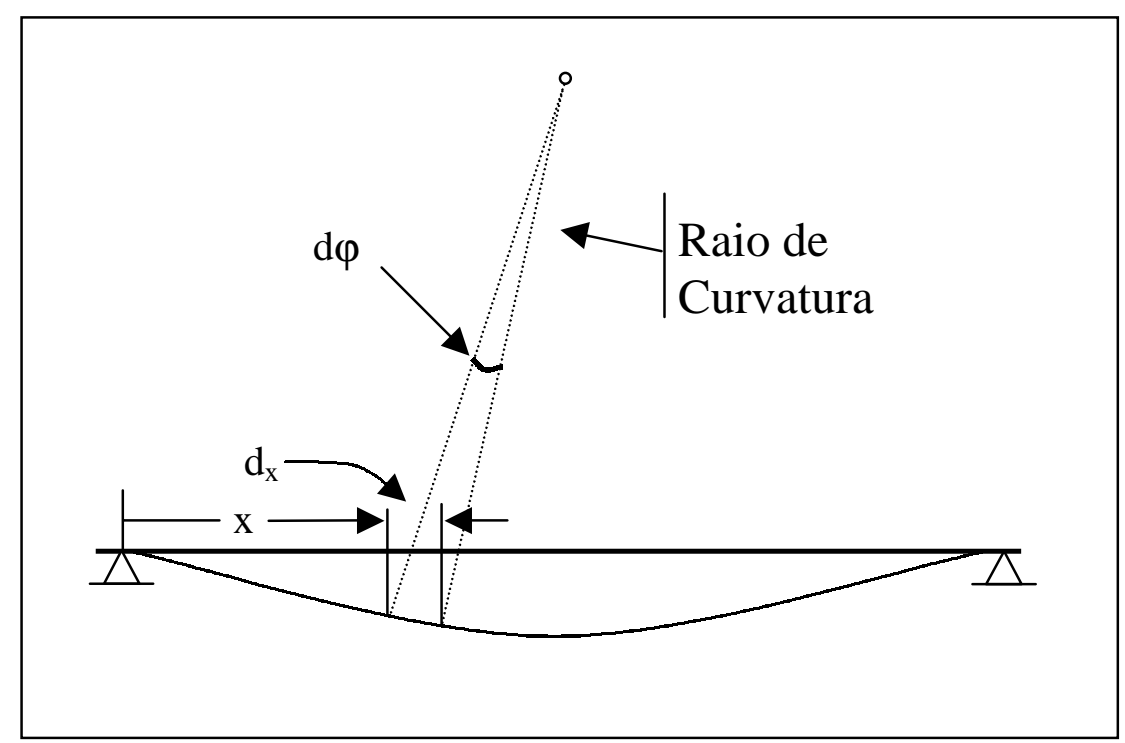

Figura 3.16 - Noção de raio de curvatura

Pode-se observar que em determinados trechos avaliados existiam vários raios de curvaturas, dificultando assim a análise dos ângulos $\mathrm{d} \varphi$. 


\section{CAPÍTULO 4}

\section{MÉtodo PROPOSTO PARA A DETERMINAÇÃO DA CORRELAÇÃO ENTRE OS ERROS DE RETILINEIDADE E OS ERROS ANGULARES}

Neste trabalho é apresentada uma formulação matemática para a determinação da correlação entre o erro de retilineidade e o erro angular correspondente. Tal formulação vai permitir a minimização do número de calibrações necessárias para a determinação dos erros volumétricos e, consequentemente, do tempo de máquina parada requerido para o levantamento do seu comportamento metrológico.

Considerando o modelamento matemático de uma MM3C, através de transformações homogêneas, as equações das componentes do erro volumétrico para as três direções preferenciais são dadas por [4.1]:

$$
\begin{gathered}
E_{X}=\delta x(x)+\delta x(y)+\delta x(z)-\delta \theta y(y)\left[Z_{m e}-Z_{m a}+Z_{56}\right]+\delta \theta z(y) Y_{45}-\delta \theta y(z)\left[Z_{m e}+Z_{56}\right] \\
-\delta \theta y(x)\left[Z_{m e}+Z_{56}\right]+\delta y o\left[Z_{m e}+Z_{56}\right]+\delta z o Y_{45} \\
E_{y}=\delta y(x)+\delta y(y)+\delta y(z)+\delta \theta x(y)\left[Z_{m e}+Z_{56}-Z_{m a}\right]+\delta \theta z(y)\left[X_{m e}+X_{23}\right] \\
\delta \theta x(z)\left[Z_{m e}+Z_{56}\right]+\delta \theta x(x)\left[Z_{m e}+Z_{56}\right]+\delta z o\left[X_{m e}+X_{23}\right]+\delta x o\left[Z_{m e}+Z_{56}\right] \\
E_{Z}=\delta z(y)+\delta z(x)+\delta z(z)-\delta \theta y(y)\left[X_{m e}+X_{23}\right]-\delta \theta x(x) Y_{45}-\delta \theta x(y) Y_{45}
\end{gathered}
$$

A Figura 4.1 mostra os lugares onde foram posicionados os sistemas de coordenadas fixos e intermediários, e os seus respectivos braços. 
Analisando as equações das componentes do erro volumétrico, observase que:

- na direção "X", tem-se a influência de quatro erros angulares: Roll "Y", Yaw "Y", Yaw "Z” e Pitch "X",

- na direção "Y", tem-se, Pitch "Y", Yaw "Y", Pitch "Z" e Roll "X";

- na direção "Z" os três erros que podem ser observados são: Roll "Y", Roll "X" e Pitch "Y"

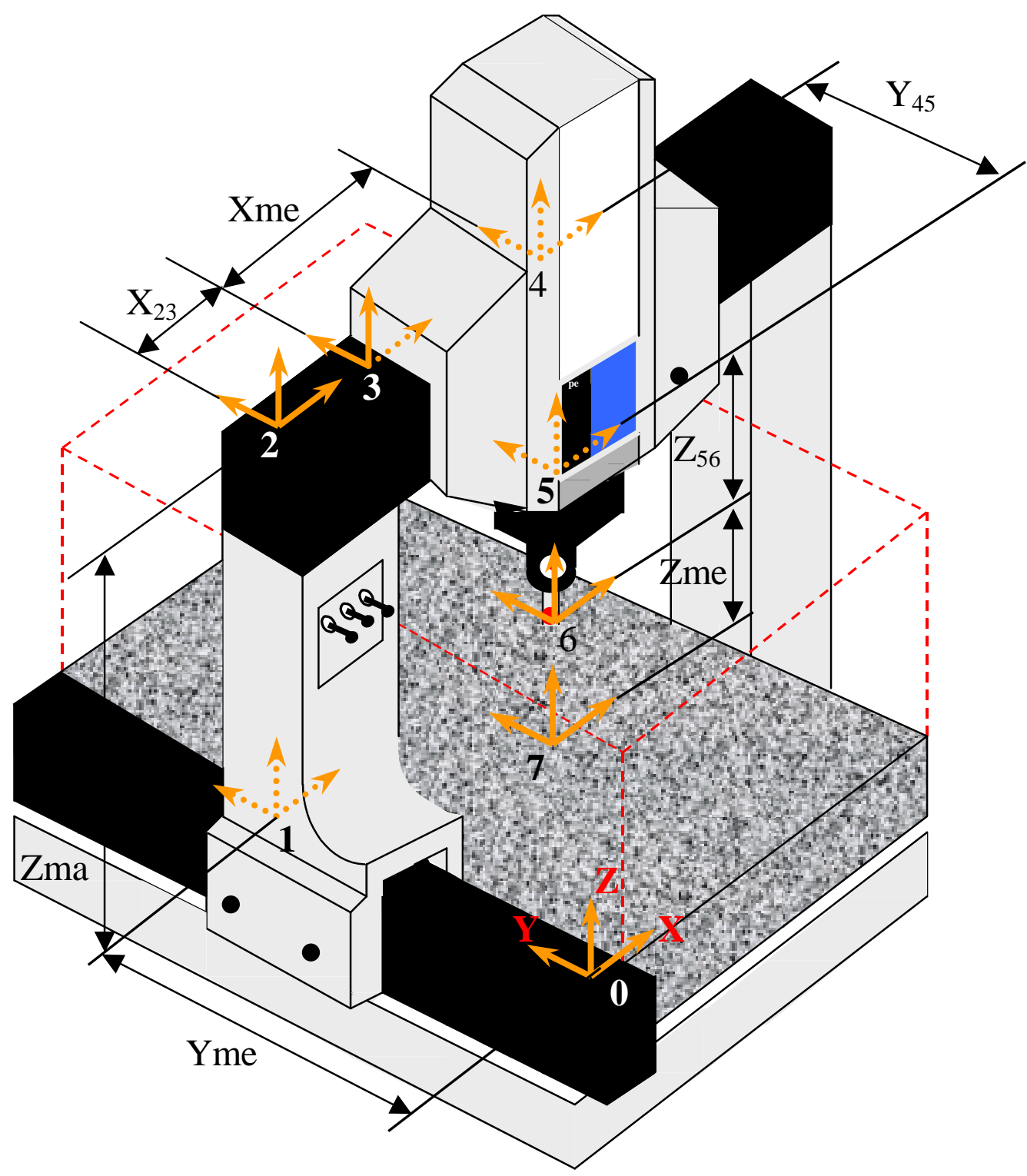

Figura 4.1 - Esboço da MM3C com seus respectivos sistemas de coordenadas 
Portanto, se eliminada, a necessidade da medição desses erros, que neste caso em particular são 7, a incerteza associada ao cálculo da componente do erro volumétrico será diminuída na mesma proporção da diminuição das variáveis. A incerteza do valor calculado estará exclusivamente vinculada à medição do erro de retilineidade.

Para isto é necessária a calibração dos erros de retilineidade da máquina avaliada. A coleta de dados deve ser realizada em pontos discretos ao longo do eixo a ser medido.

De posse dos dados do erro de retilineidade, da formulação proposta e do conhecimento da estrutura da máquina é possível expressar o erro angular.

Tabela 4.1 - Correlação entre os erros de retilineidade e os erros angular

\begin{tabular}{|c|c|}
\hline Erro de retilineidade & Erro angular \\
\hline $\begin{array}{l}\text { Retilineidade na direção "y" devido ao } \\
\text { movimento no eixo " } x "\end{array}$ & Yaw "x" \\
\hline $\begin{array}{l}\text { Retilineidade na direção " } \mathrm{z} \text { " devido ao } \\
\text { movimento no eixo " } \mathrm{x} \text { " }\end{array}$ & Pitch "x" \\
\hline $\begin{array}{l}\text { Retilineidade na direção "x" devido ao } \\
\text { movimento no eixo "y" }\end{array}$ & Yaw "y” \\
\hline $\begin{array}{l}\text { Retilineidade na direção " } \mathrm{z} \text { " devido ao } \\
\text { movimento no eixo "y" }\end{array}$ & Pitch "y" \\
\hline $\begin{array}{l}\text { Retilineidade na direção " } \mathrm{x} \text { " devido ao } \\
\text { movimento no eixo " } \mathrm{z} \text { " }\end{array}$ & Yaw "z” \\
\hline $\begin{array}{l}\text { Retilineidade na direção "y" devido ao } \\
\text { movimento no eixo "z" }\end{array}$ & Pitch "z" \\
\hline
\end{tabular}

Cada erro de retilineidade pode ser correlacionado à um erro angular dependendo da direção analisada, Tabela 4.1. Por exemplo, se considerado o eixo preferencial "Y", pode-se observar que os erros de retilineidade na direção "X" provocam movimentos angulares em torno de "Z", ou seja, Yaw 
"Y". Erros de retilineidade na direção "Z" produzem movimentos angulares em torno de "X", ou seja, Pitch "Y".

As etapas envolvidas para efetivação da proposta foram divididas nos seguintes sub-itens para um melhor entendimento e são elas:

- Medição dos erros de retilineidade e dos erros angulares em máquinas ferramentas e máquina de medir a três coordenadas para levantamento dos dados através de instrumentos adequados.

- Análise estatística dos dados levantados durante a calibração dos erros.

- Desenvolvimento de formulação matemática para determinar o erro angular em função do erro de retilineidade e realização da comparação entre os erros angulares calibrados na primeira etapa e os erros angulares obtidos através da formulação proposta.

\section{MEDIÇÃO dOS ERROS DE RETILINEIDADE E DOS ERROS ANGULARES.}

As medições dos erros foram realizadas em uma Máquina de Medir a Três Coordenadas.

A calibração dos erros de retilineidade e do erro angular foi realizada em uma Máquina de Medir a Três Coordenadas da marca Brown \& Sharpe do tipo Ponte Móvel que se encontra no Laboratório de Máquinas e Ferramentas (LAMAFE) da USP - São Carlos. A calibração do erro de retilineidade foi realizada de duas formas: uma com régua padrão de granito da marca Mitutoyo utilizando o método da reversão e outra com o sistema de Interferômetria Laser da HP. Os erros angulares, por sua vez, também foram calibrados utilizando o sistema de Interferômetria Laser.

ANÁLISE ESTATÍSTICA E TRATAMENTO DOS DADOS

LEVANTADOS DURANTE AS MEDIÇÕES DOS ERROS. 
Após a medição do erro de retilineidade, seja com a régua padrão ou com o interferômetro laser, deve-se eliminar o desalinhamento antes de qualquer manipulação numérica com os dados. Existem vários métodos que podem ser utilizados para a eliminação do desalinhamento, entre eles: o de regressão linear por mínimos quadrados, o método da separação mínima e o método dos pontos extremos. A equação de desalinhamento é obtida aplicando algum destes métodos. Durante a medição com a régua, o desalinhamento está entre o artefato e o eixo de movimentação, enquanto que, na medição com o interferômetro o desalinhamento se encontra entre as direções do feixe laser e do eixo de movimentação da máquina.

$\mathrm{Na}$ medição com a régua padrão utilizando o método da reversão, são observados através dos dados coletados, o erro de retilineidade da máquina, e o erro de retilineidade do artefato. Através de uma formulação são encontrados $\mathrm{o}$ erro de retilineidade da régua e o erro de retilineidade da máquina separadamente. Os cálculos com os dados obtidos após a reversão, devem ser executados após a eliminação do desalinhamento.

Após a retirada do desalinhamento dos dados se faz necessário uma análise estatística dos erros. Esta análise visa: verificar a adequabilidade do modelo de distribuição gaussiana através do teste de aderência do Chiquadrado; calcular a média e o desvio padrão, trabalhando com nível de confiança de 99,7\%; determinar os erros aleatório, sistemático e de histerese; e por fim determinar uma função por meio de regressão linear que represente o erro avaliado.

Foram desenvolvidas formulações que correlacionem o erro de retilineidade e o erro angular. $\mathrm{O}$ erro angular foi descrito em função do dados obtidos na calibração do erro de retilineidade.

A viabilização das formulações adotadas foi verificada através da comparação entre os valores obtidos através da expressão que correlaciona os dois erros e dos dados do erro calibrado. 


\section{CAPÍTULO 5}

\section{DESENVOLVIMENTO DA METOdOlOGia PROPOSTA PARA A DETERMINAÇÃo DA CORRELAÇÃO ENTRE OS ERROS DE RETILINEIDADE E OS ERROS ANGULARES}

Neste capítulo estão apresentados os itens referentes ao desenvolvimento do trabalho, cujo objetivo é apresentar o equacionamento matemático para expressar a dependência entre os erros de retilineidade e os erros angulares. O conteúdo está distribuído em dois itens: calibração dos erros geométricos e formulação matemática para expressar o erro angular em função do erro de retilineidade.

Todos os experimentos necessários para a elaboração e validação do método proposto foram conduzidos em uma MM3C fabricada pela Brown \& Sharpe Mfg. Co., modelo "Micro Validator", classificada como do tipo Ponte Móvel, que se encontra no Laboratório de Máquinas e Ferramentas (LAMAFE) desta escola .

A MM3C (Figura 5.1) utilizada para calibração dos erros de retilineidade e angulares, durante esse trabalho, possui um microcomputador que auxilia na execução de programas computacionais desenvolvidos especialmente para tarefas de medição e calibração. Os movimentos " $X$ ", "Y" e "Z" são manuais e os mancais de todos os eixos são aerostáticos. É uma 
máquina relativamente pequena, comparando-se às máquinas existentes nas indústrias. Sua capacidade volumétrica de trabalho é de aproximadamente 0,5 $\mathrm{m}^{3}$ e possui as seguintes dimensões: $\mathrm{X}=457 \mathrm{~mm}, \mathrm{Y}=610 \mathrm{~mm} \mathrm{e} \mathrm{Z}=381 \mathrm{~mm}$. A MM3C tem peso moderado e desempeno de granito removível (BROWN \& SHARP, 1988).

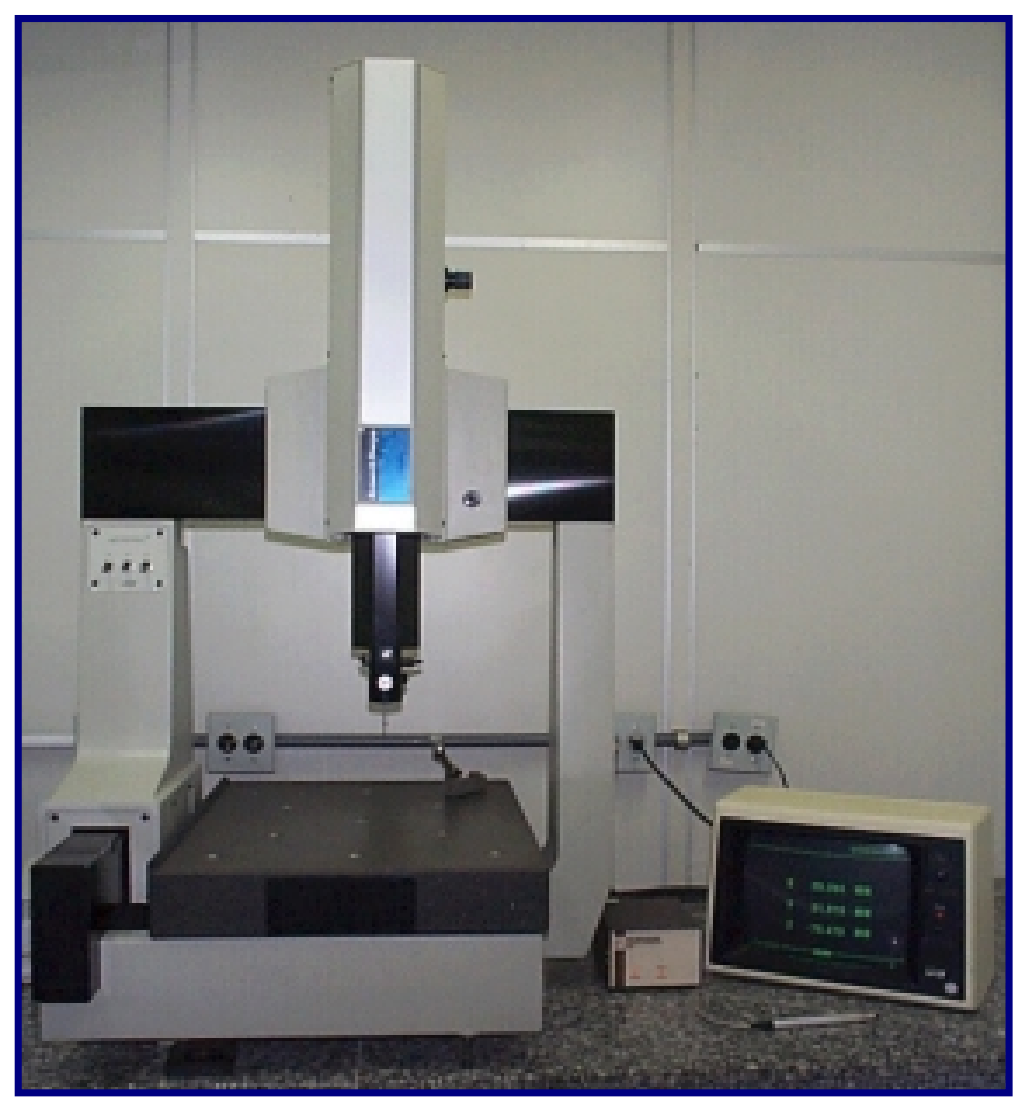

Figura 5.1 - Foto da MM3C

A guia do eixo "Y" que é montada sobre a estrutura da máquina é responsável pelos movimentos executados pela ponte. O eixo "Y" tem duas colunas, uma a esquerda e outra a direita, onde está montado o eixo " $\mathrm{X}$ ". Sobre o carro do eixo "X" está montada a guia do eixo "Z", que se desloca verticalmente. O sistema de leitura é constituído por réguas digitais que utilizam o princípio de franjas de Moirè. 


\section{1 - CALIBRAÇÃO DOS ERROS GEOMÉTRICOS}

Para o desenvolvimento do trabalho são necessárias as calibrações dos erro de retilineidade e dos erros angulares.

$\mathrm{Na}$ coleta de dados dos erros de retilineidade e erros angulares foram utilizados um sistema interferométrico laser da Hewlett Packard modelo HP5528A e uma régua padrão da marca Mitutoyo.

O sistema interferométrico foi utilizado para medição dos erros angulares e dos erros de retilineidade. Ele é composto por um canhão laser, uma base de apoio e ajuste (tripé), uma unidade de processamento eletrônico e conjuntos ópticos específicos para cada tipo de erro. A comunicação entre o sistema interferométrico e o microcomputador é feita por uma interface do tipo GPIB.

Para a realização das medições, utilizando o interferômetro laser, observou-se: o alinhamento do sistema laser acima de 90\%, tempo de equilíbrio do conjunto de $12 \pm 0,5$ horas, as condições do meio ambiente permaneceram em $20 \pm 1^{\circ} \mathrm{C}$, umidade relativa do ar em $40 \pm 10 \%$ e pressão atmosférica em $693 \pm 3 \mathrm{mmHg}$.

A régua padrão, usada para medição do erro de retilineidade, é de granito de comprimento $500 \mathrm{~mm}$ com secção transversal retangular de lados $80 \mathrm{~mm}$ e $40 \mathrm{~mm}$. Para esta medição utilizou-se, também, um apalpador linear ligado a um mostrador de saída do tipo LVDT "Tesatronic" com seis escalas distintas.

A calibração, de cada erro, foi efetuada passo a passo, sendo o erro coletado a cada $25 \mathrm{~mm}$ no eixo "Y" de medição. Foram realizados 5 (cinco) ciclos de medição, sendo cinco trajetos no sentido de ida e cinco trajetos no sentido de volta. Para evitar a interferência de erros de folga e histerese, antes da inversão do sentido de deslocamento, foi realizado o que na literatura é conhecido como "correção de backlash", isto é, avança-se com o carro pouco 
além da última posição de leitura no sentido da medição e retorna-se a ele novamente iniciando a leitura no sentido contrário.

As características metrológicas dos instrumentos utilizados na calibração estão apresentadas na tabela 5.1.

Tabela 5.1 - Características dos instrumentos disponíveis comercialmente para medição de erros de retilineidade e erros angulares (- não disponível) (HOCKEN, 1980).

\begin{tabular}{|c|c|c|c|c|}
\hline & INSTRUMENTO & FAIXA & RESOLUÇÃO & INCERTEZA \\
\hline \multirow{6}{*}{ 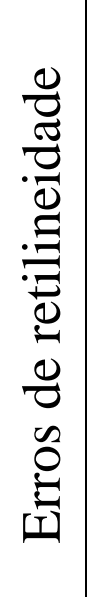 } & Régua Padrão & $1,5 \mathrm{~m}$ & $0,03 \mu \mathrm{m}$ & $0,5 \mu \mathrm{m} / \mathrm{m}$ \\
\hline & Interferômetro Laser & $30 \mathrm{~m}$ & $0,25 \mu \mathrm{m}$ & $0,5 \mu \mathrm{m} / \mathrm{m}$ \\
\hline & Microscópio & & $2 \mu \mathrm{m}$ & - \\
\hline & Microscópio Eletrônico & & $0,1 \mu \mathrm{m}$ & - \\
\hline & Fio Esticado e Microscópio & $50 \mathrm{~m}$ & & \\
\hline & Laser de Alinhamento & $100 \mathrm{~m}$ & $2 \mu \mathrm{m}$ & $5 \mu \mathrm{m} / \mathrm{m}$ \\
\hline \multirow{4}{*}{ 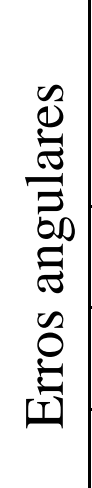 } & Interferômetro Laser & $\begin{array}{l} \pm 50^{\prime} \\
\pm 10^{\circ}\end{array}$ & $0,1 "$ & $0,1 ”$ \\
\hline & Autocolimador & 10 & F.O/1000 & $0,1 ”$ \\
\hline & Nível de Bolha & $10^{\prime}$ & $1 "$ & $1 "$ \\
\hline & Nível Eletrônico & $\pm 1^{\circ}$ & $0,5^{\prime \prime} \rightarrow 0,2 "$ & $1 "$ \\
\hline
\end{tabular}

As montagens utilizadas para o levantamento dos erros são apresentadas a seguir. 


\subsection{1 - CALIBRAÇÃO DOS ERROS ANGULARES}

O princípio de medição dos erros angulares está ilustrado na Figura 5.2

Nesta montagem foi utilizado o interferômetro "angular" fixo à estrutura da máquina e os espelhos refletores foram colocados na parte móvel da mesma. O canhão laser emite o feixe, que é dividido em dois feixes paralelos de frequiências $f_{1}$ e $f_{2}$ que atravessam o interferômetro angular e atingem o refletor angular. Por sua vez, o espelho refletor, que é formado por dois retrorefletores, refletem de volta os feixes, mais sua variação $\Delta f_{i}(i=1,2)$ ao interferômetro angular. Os feixes $\mathrm{f}_{1}, \mathrm{f}_{2}, \mathrm{f}_{1}+\Delta \mathrm{f}_{1}$ e $\mathrm{f}_{2}+\Delta \mathrm{f}_{2}$ tem trajetórias paralelas entre si.

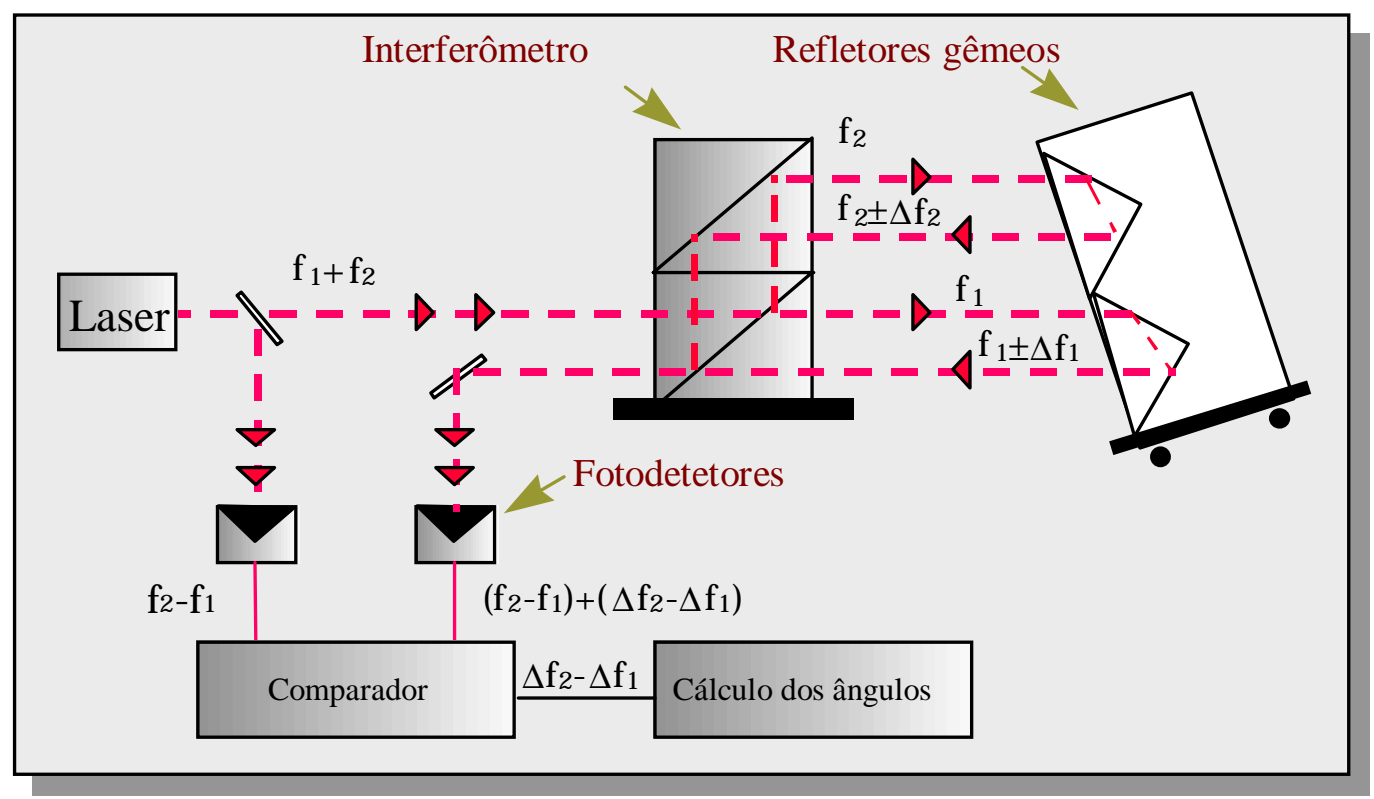

Figura 5.2 - Princípio interferométrico para medir erros de Pitch e Yaw

Os feixes que retornam com defasagens nas frequências $\mathrm{f}_{1}$ e $\mathrm{f}_{2}$ até a fotocélula indicam a diferença entre os caminhos percorridos. A variação desta diferença dividida pela distância entre as duas trajetórias é o deslocamento 
angular desejado, que dependendo da posição dos espelhos pode se chamar de Pitch ou Yaw.

Os erros angulares calibrados foram: o erro de Yaw "Y" da MM3C e o erro Pitch "Y", Figura 5.3 e 5.4.

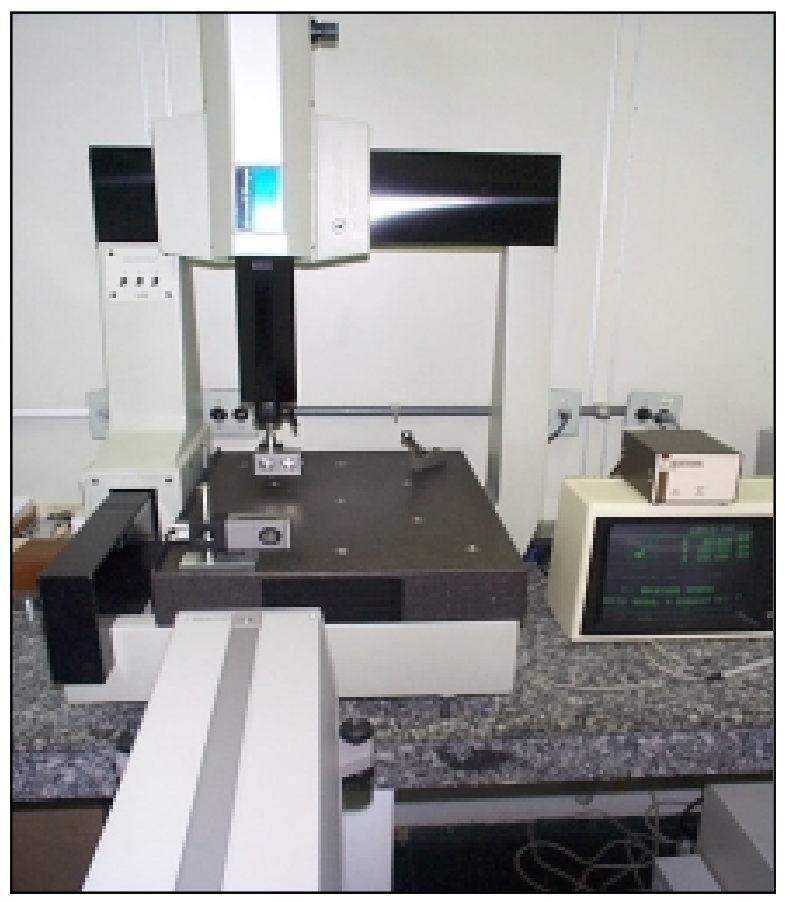

Figura 5.3 - Montagem do erro angular Yaw "Y"

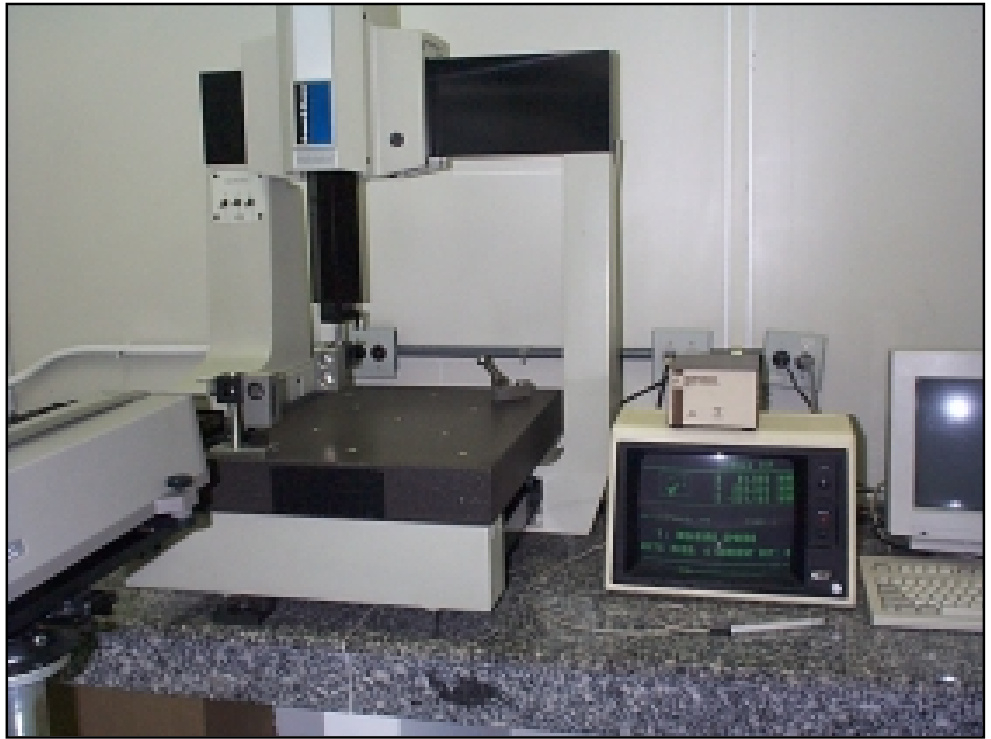

Figura 5.4 - Montagem do erro angular Pitch "Y" 
Na MM3C busca-se expressar Yaw "Y" em função da retilineidade de "X" devido ao movimento em "Y" e o Pitch "Y" em função da retilineidade na direção " $Z$ " devido ao movimento no eixo "Y".

Portanto, a calibração dos erros angulares foram realizadas na mesma posição em que foram medidos os erros de retilineidade. As leituras foram efetuadas nos dois sentidos de medição ida e volta, totalizando 10 trajetos.

\subsection{2 - CALIBRAÇÃO DOS ERROS DE RETILINEIDADE}

O erro de retilineidade foi levantado utilizando dois tipos de instrumentação: sistema de interferômetria laser e régua padrão. Uma comparação entre esses métodos de medição foi realizada.

- MEdição UtiliZANDo o Sistema INTERFERÔMETRICO LASER

A configuração utilizada na calibração do erros de retilineidade é mostrada na Figura 5.5

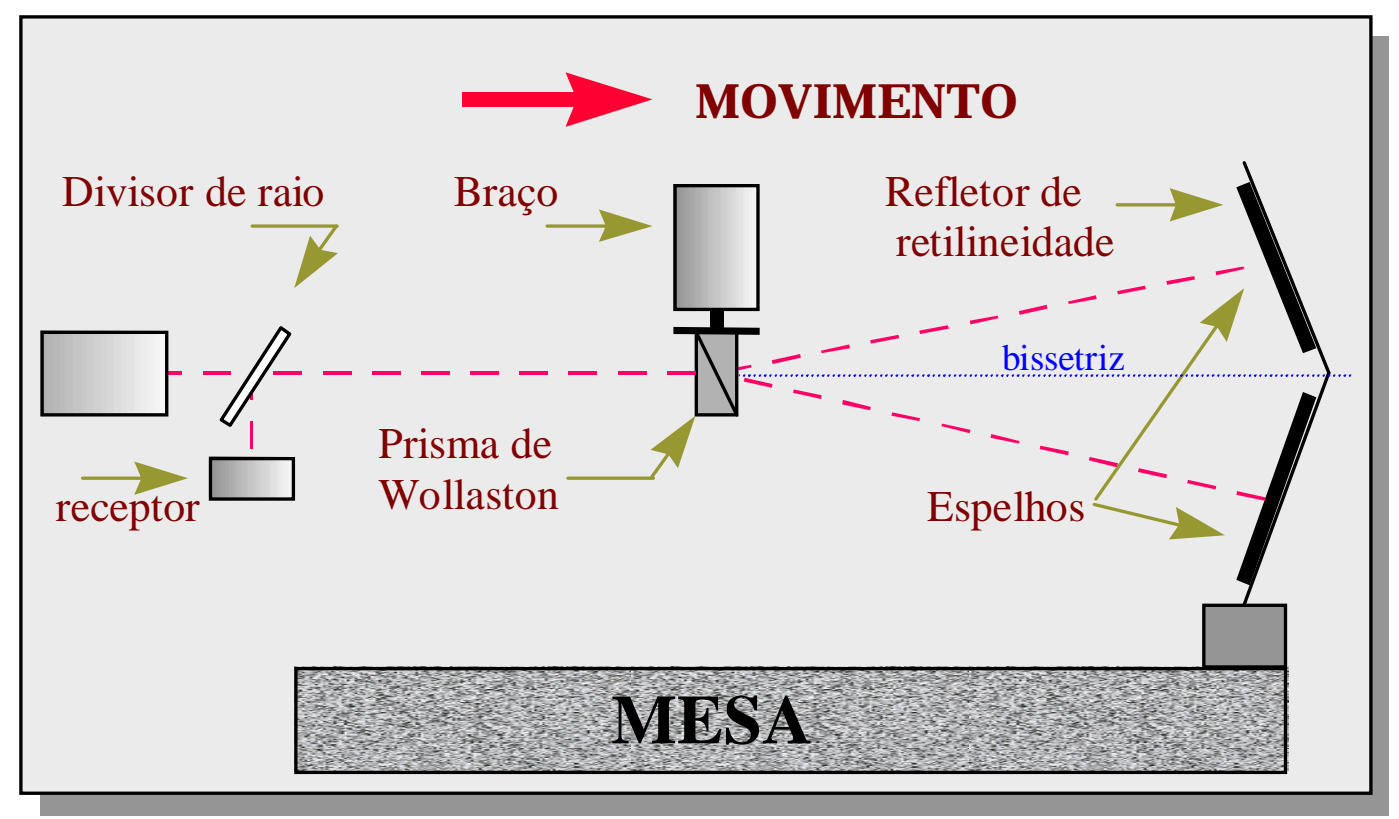

Figura 5.5 - Princípio interferométrico da medição de erro de retilineidade. 
$\mathrm{Na}$ montagem, um interferômetro específico para medição de retilineidade, o qual contém um "Prisma de Wollaston", é fixado na parte móvel da máquina entre o canhão laser e os espelhos refletores que estão fixos à mesa da máquina.

O canhão laser emite um feixe de luz composto pela combinação de dois feixes de frequiência muito próximas $\mathrm{f}_{1}$ e $\mathrm{f}_{2}$. O "Prisma de Wollaston" separa os dois feixes que percorrem caminhos diferentes e incidem perpendicularmente nos espelhos inclinados que os refletem com o mesmo ângulo de incidência, retornando ao Interferômetro. Os feixes são então reagrupados e retornam ao ponto de partida no canhão laser. Eventuais variações $\Delta \mathrm{f}_{1}$ e $\Delta \mathrm{f}_{2}$ indicam mudanças proporcionais ao movimento lateral relativo entre o Prisma de Wollaston e os espelhos. A referência para o erro de retilineidade é a bissetriz do ângulo entre os espelhos.

Os valores indicados pelo mostrador do laser não correspondem aos valores reais do erro de retilineidade. Tais valores tem neles incluídos o desalinhamento entre o feixe de luz laser e a direção de movimentação, como mostrado na Figura 5.6.

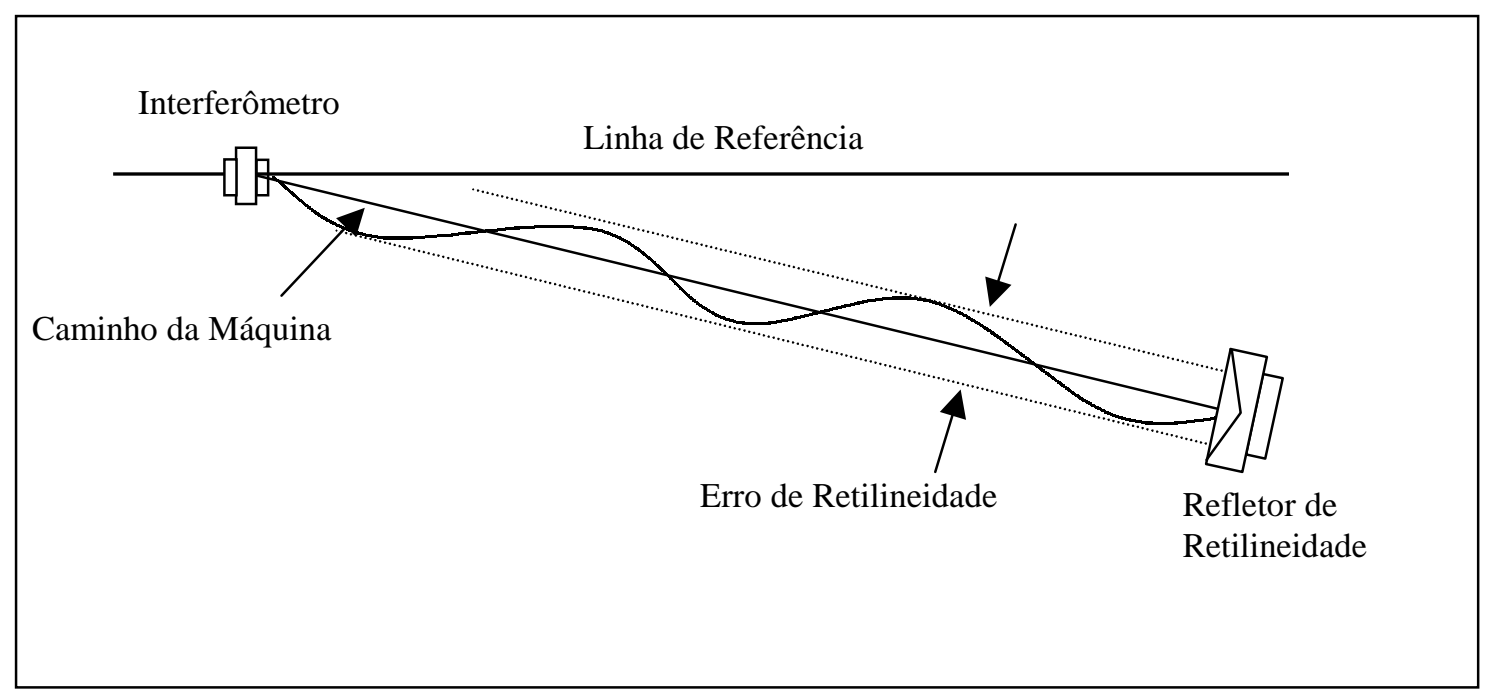

Figura 5.6 - Efeito do desalinhamento na medição de erros de retilineidade 
Para a eliminação desse desalinhamento é necessário uma correção, por um dos dois métodos já mencionados anteriormente: o método dos mínimos quadrados ou o método dos pontos extremos.

Aplicando um dos métodos tem-se a equação do desalinhamento e o erro de retilineidade é obtido através da equação [5.1]:

Erro de retilineidade $=\left(\begin{array}{l}\text { valor encontrado através da } \\ \text { equação de desalinhamento }\end{array}\right)-\left(\begin{array}{l}\text { Valor indicado } \\ \text { na instrumentação }\end{array}\right)$

Na Figura 5.7 pode ser visualizada a disposição física dos espelhos, na MM3C, utilizados para a medição do erro de retilineidade " $\mathrm{X}$ " devido ao movimento em "Y", $\delta_{\mathrm{x}}(\mathrm{y})$.

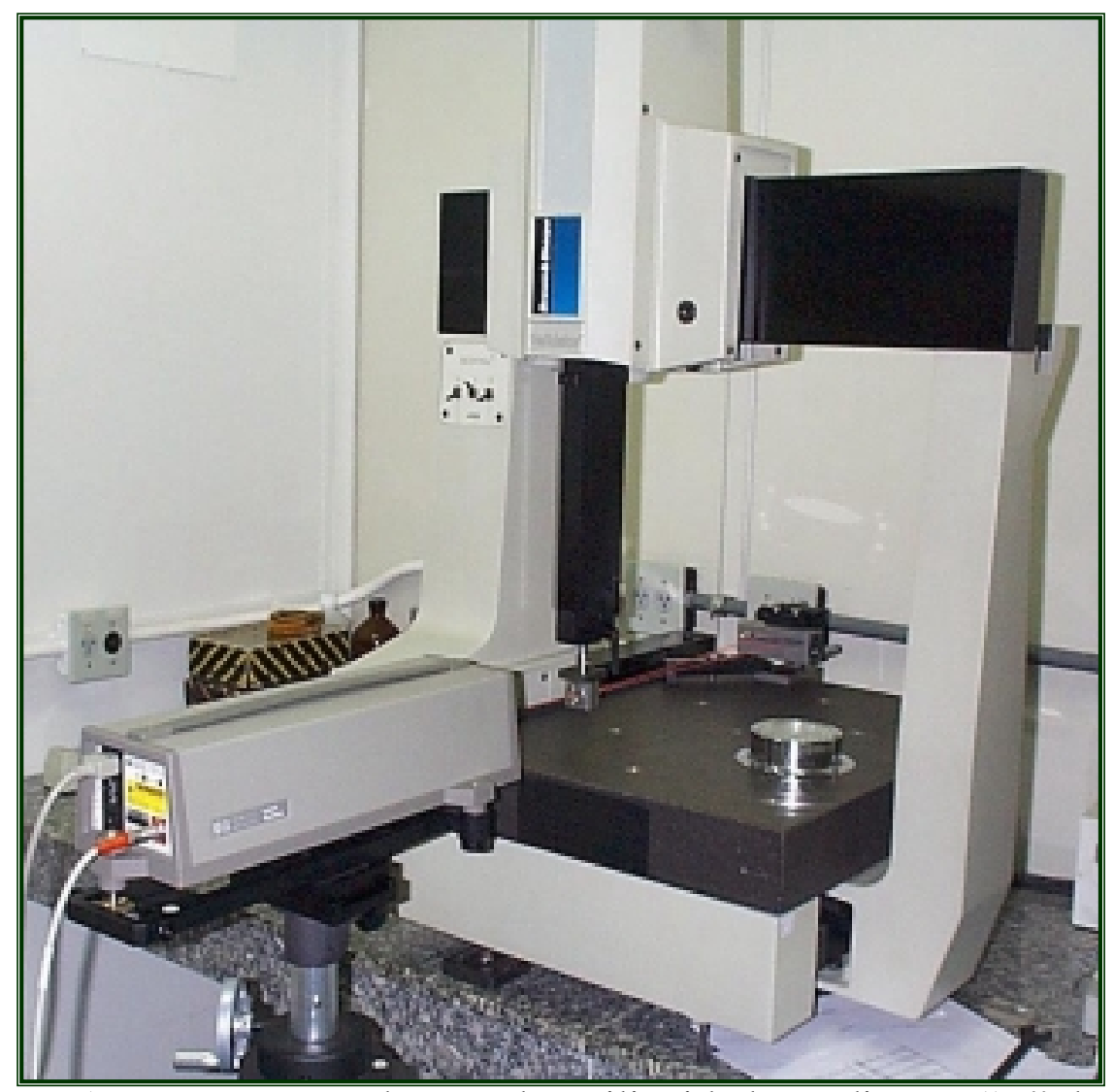

Figura 5.7 - Montagem do erro de retilineidade na direção " $X$ " devido ao movimento em "Y", $\delta_{\mathrm{x}}(\mathrm{y})$. 
A calibração do erro de retilineidade, $\delta_{\mathrm{x}}(\mathrm{y})$, utilizando o interferômetro laser foi efetuada nas posições $X=68,034 \mathrm{~mm}, Z=-262,672 \mathrm{~mm}$. A escolha destas coordenadas se fez devido à facilidade da montagem da régua padrão nesta posição, possibilitando assim a comparação deste erro obtido através dos dois instrumentos de medição.

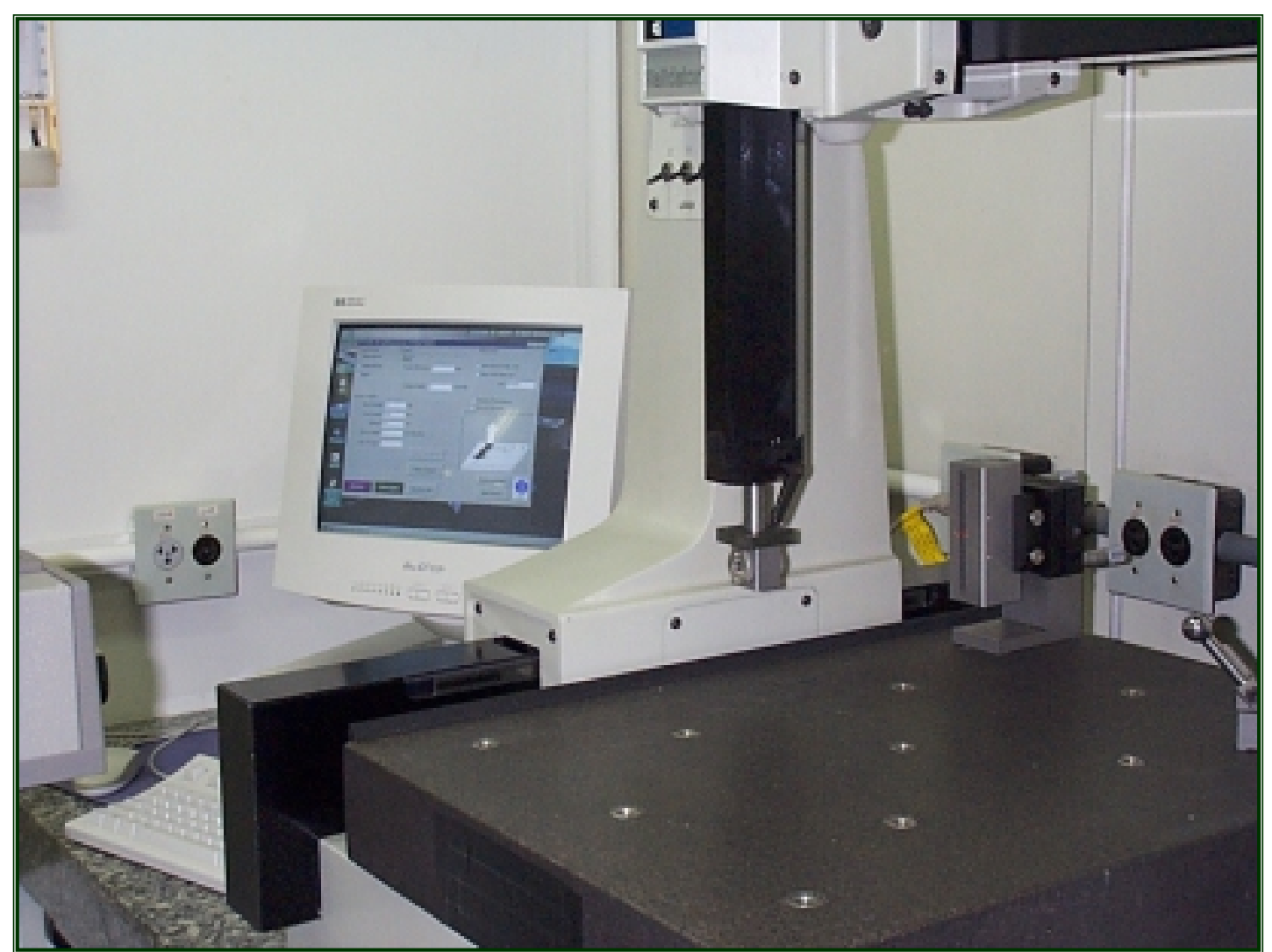

Figura 5.8 - Retilineidade na direção "Z" devido ao movimento no eixo "Y", $\delta_{\mathrm{z}}(\mathrm{y})$.

Na Figura 5.8 pode ser visualizada a disposição física dos espelhos, na MM3C, utilizados para a medição do erro de retilineidade "Z" devido ao movimento em "Y", $\delta_{\mathrm{z}}(\mathrm{y})$. 


\section{- Medição Utilizando RÉGUa Padrão}

Para a calibração do erro de retilineidade da $\mathrm{MM} 3 \mathrm{C}$, utilizando a régua padrão, procedeu-se da seguinte forma: a régua padrão foi primeiramente alinhada sobre a mesa fixa, paralela ao eixo de movimentação, no caso o eixo "Y". O alinhamento foi realizado de forma manual. Na posição reservada para a sonda, durante as medições a três coordenadas, foi fixado o apalpador linear e no mostrador de saída a escala 5 (cinco), cujo fundo de escala é de $\pm 10 \mu \mathrm{m}$ e foi escolhida a resolução de $0,5 \mu \mathrm{m}$. Com o deslocamento do braço da máquina, o apalpador experimenta deslocamentos perpendiculares ao movimento, ou seja, na direção do eixo "X".

Foram coletados dados para 5 trajetos de ida e 5 trajetos de volta. Ao longo do trajeto 15 posições de medição foram observadas. As posições iniciais e finais do trajeto são $25 \mathrm{~mm}$ e $375 \mathrm{~mm}$ com incremento de $25 \mathrm{~mm}$ respectivamente. Em seguida, reverteu-se a régua de $180^{\circ}$ sobre o eixo de movimentação e utilizou-se o mesmo processo de leitura.

Depois de obtidas todas as leituras, as equações do método da reversão foram aplicadas e os valores da retilineidade da MM3C e da régua foram calculados. Entretanto, estes valores incluem os desalinhamentos, que foram eliminados através do método de mínimos quadrados.

As calibrações feitas na MM3C tem as seguintes características: a medição de erro de retilineidade foi realizada com o sistema interferométrico laser e com a régua padrão. $\mathrm{O}$ erro angular foi calibrado com o sistema interferômetro laser.

As Figuras 5.9 e 5.10 apresentam as montagens utilizadas na medição do erro $\delta_{\mathrm{x}}(\mathrm{y})$ utilizando a régua padrão. Nestas figuras podem ser visualizados o mostrador de leituras Tesatronic, a régua de medição e o apalpador linear. 


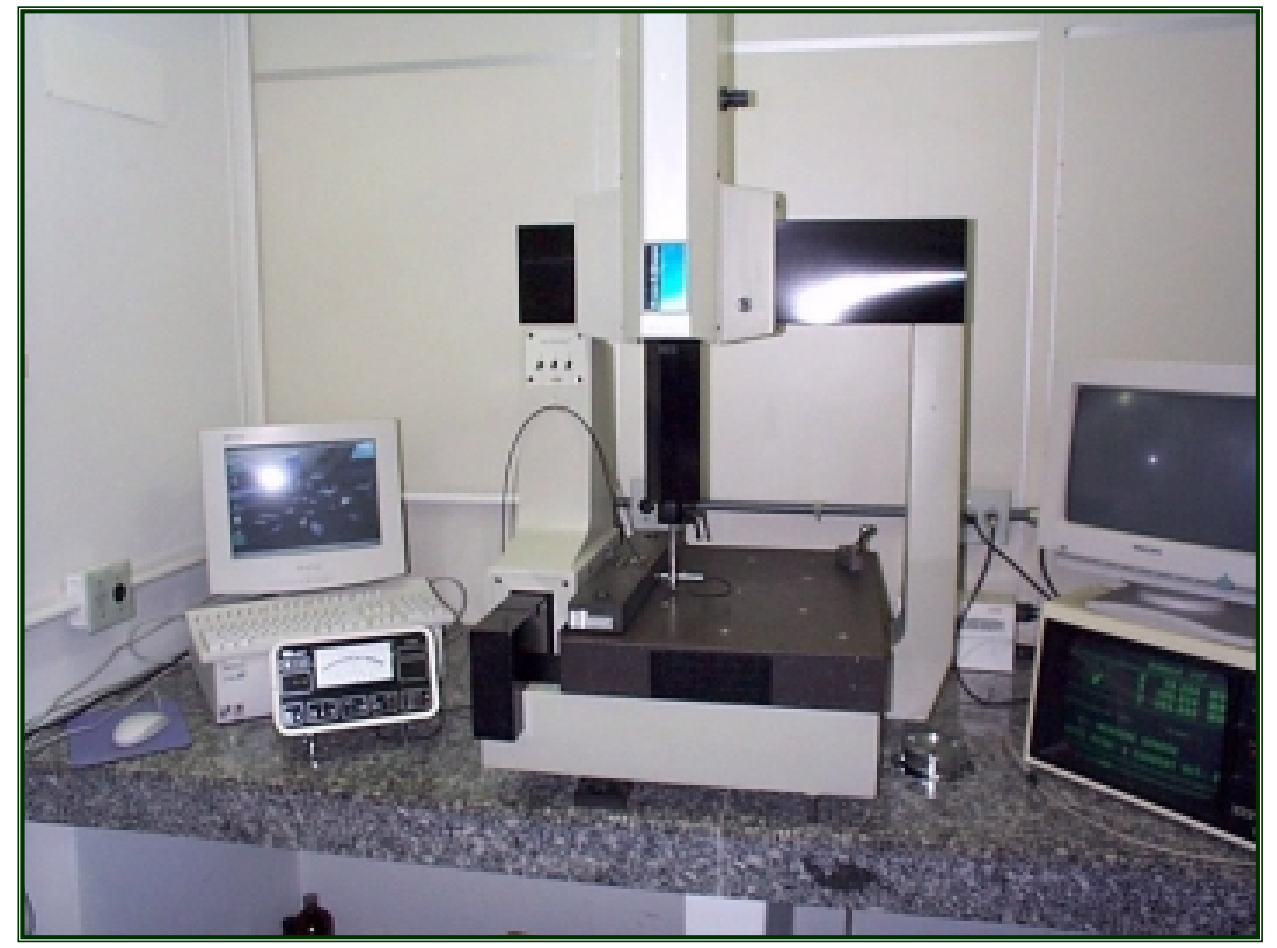

Figura 5.9 - Montagem da régua padrão para a medição do erro de retilineidade na direção " $\mathrm{X}$ " devido ao movimento em " $\mathrm{Y}$ ", $\delta_{\mathrm{x}}(\mathrm{y})$.

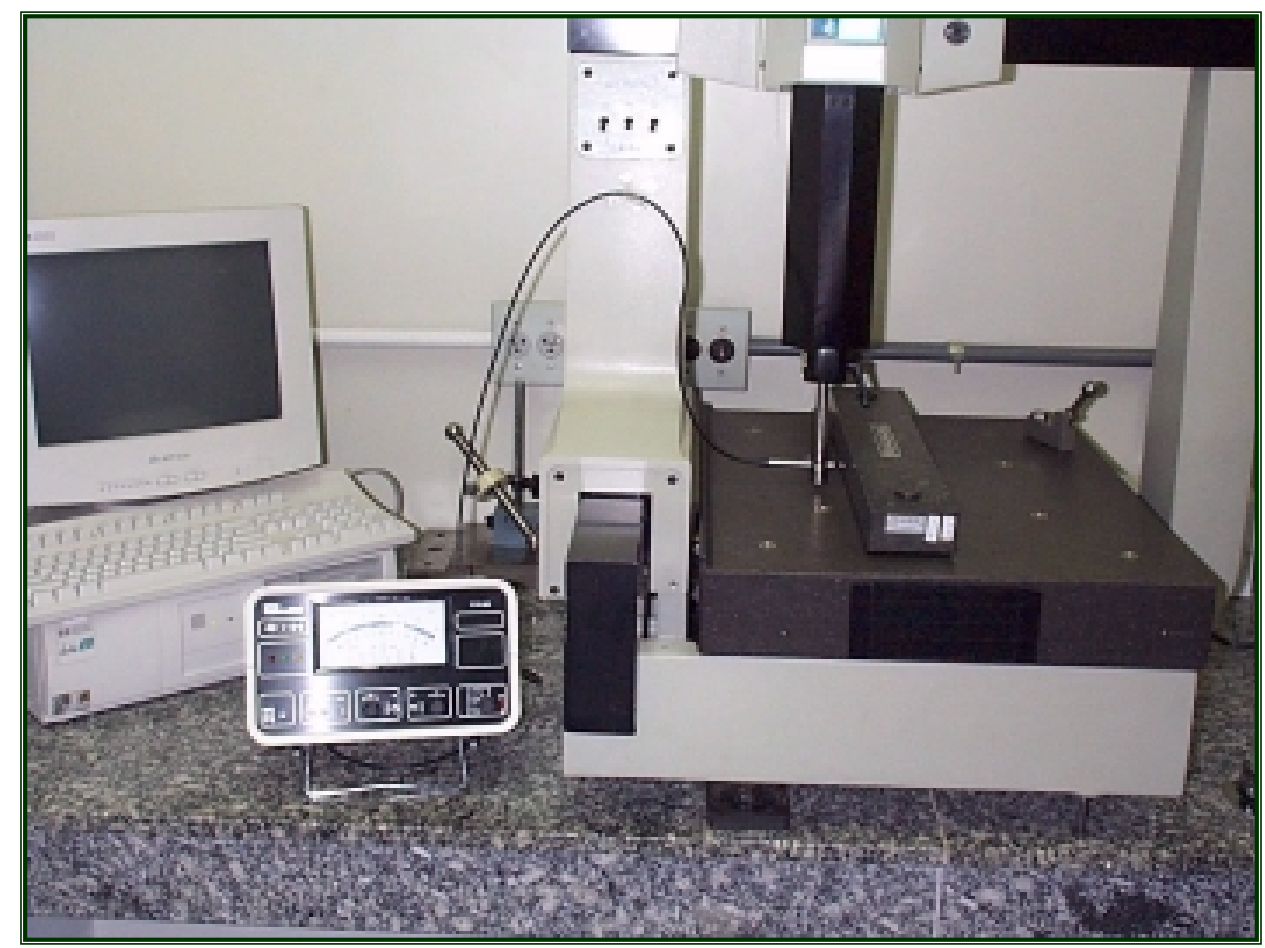

Figura 5.10 - Montagem da régua padrão após a reversão para a medição do erro de retilineidade na direção " $\mathrm{X}$ " devido ao movimento em " $\mathrm{Y}$ ", $\delta_{\mathrm{x}}(\mathrm{y})$. 


\section{2 - EQUACIONAMENTO MATEMÁTICO}

$\mathrm{O}$ equacionamento matemático que modela a dependência dos erros de retilineidade e os erros angulares utilizado neste trabalho será agora apresentado. Tal equacionamento foi baseado nos estudos de caso de Bryan, mostrados no capítulo 3 .

Para melhor compreensão do equacionamento matemático proposto, considere o gráfico da Figura 5.11, sendo o resultado obtido a partir dos dados levantados durante a calibração hipotética de um erro de retilineidade. Nesta Figura pode-se observar o erro de retilineidade no sentido de ida e no sentido de volta, além dos desvios padrões do sentido de ida. Os desvios padrões para o sentido de volta não estão apresentados para que seja evitado o acumulo de curvas na Figura.

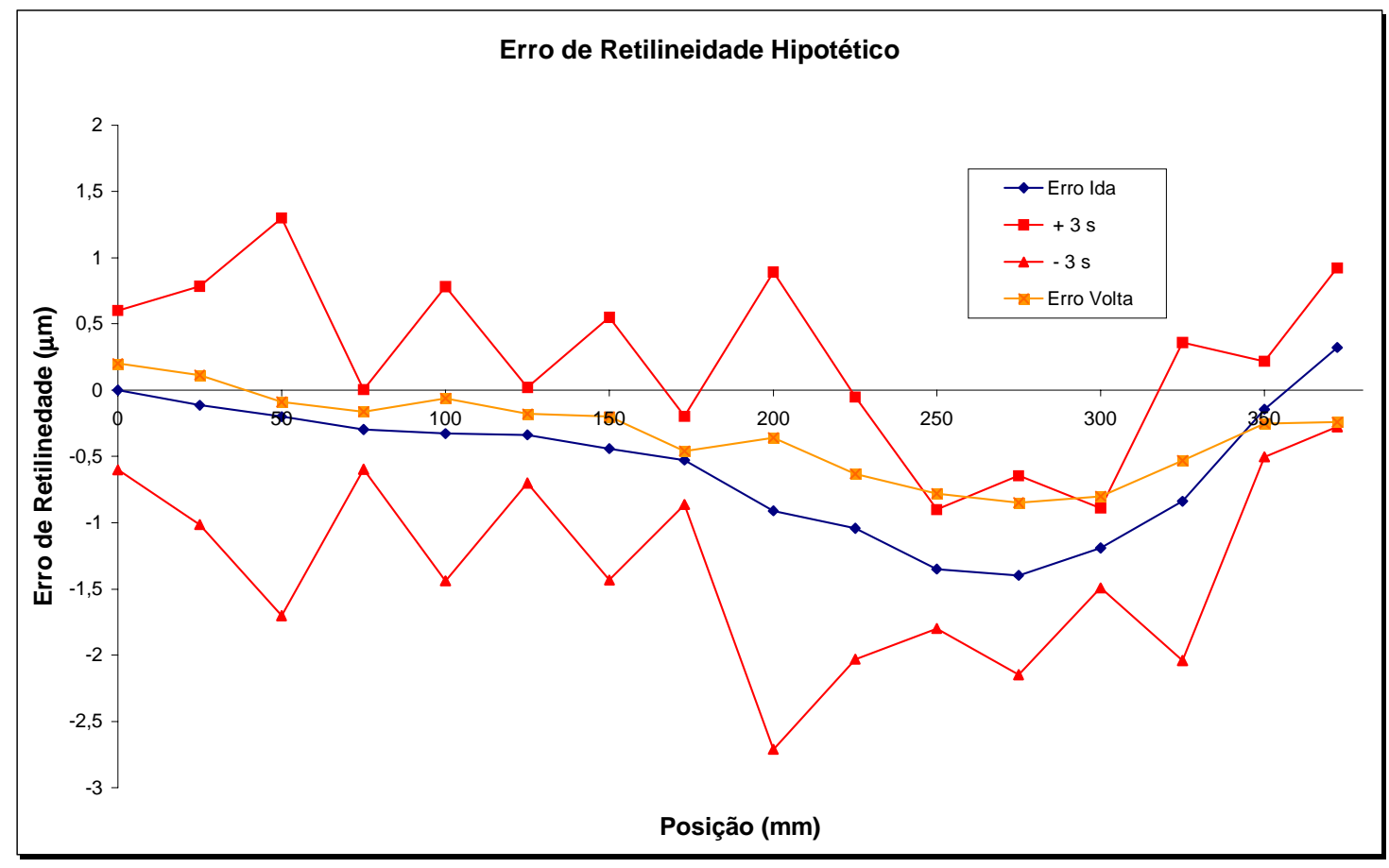

Figura 5.11 - Calibração hipotética de um erro de retilineidade

A formulação para calcular o erro angular a partir do erro de retilineidade deve ser realizada para cada sentido de medição. 
Como exemplo, considere os dados do erro no sentido de ida, apresentado agora isoladamente na Figura 5.12.

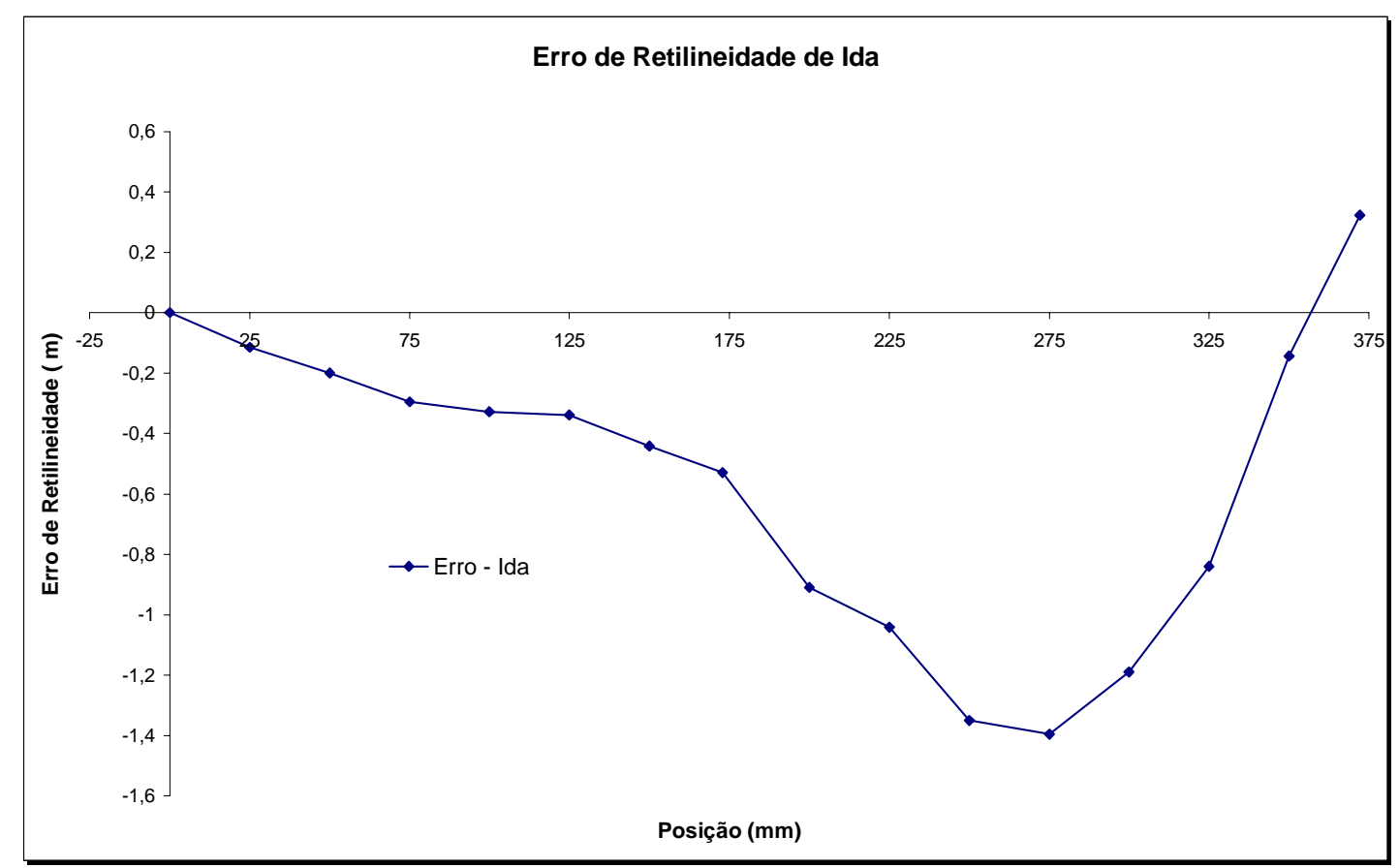

Figura 5.12 - Curva de erro no sentido de ida da Figura 5.11

Aplicando técnicas de regressão a esses dados, obtém-se uma equação $y=f(x)$, sendo $x$ a posição do carro no eixo de deslocamento, $y$ o valor do erro de retilineidade e $f(x)$ um polinômio que representa o valor da função no ponto $x$, que representa o erro em todo o eixo, neste sentido de medição, Figura 5.12. Pode-se, então, escrever $f_{l}=y-f(x)$

Conhecendo-se a curva $f(x)$ pretende-se determinar o erro angular correspondente de qualquer ponto pertencente ao eixo de movimentação.

Utilizando-se um ponto $\mathrm{P}_{0}$ conhecido pertencente a $f(x)$, pode-se para iniciar os cálculos, se conhecida a distância, b, entre os mancais. Determina-se então uma nova função $f_{2}$ dada em [5.2].

$$
\text { - } f_{2}=b-\sqrt{\left(x_{0}^{\prime}-x_{0}\right)^{2}+\left(y_{0}^{\prime}-y_{0}\right)^{2}} \text {, }
$$

onde $\left(x_{0}^{\prime}, y_{0}^{\prime}\right)$ são coordenadas do ponto $\mathrm{P}_{0}^{\prime}$ pertencente a $f(x)$ e dista $\mathrm{b}$ do $\mathrm{P}_{0}$ 
e a função $f_{2}$ é a diferença entre o comprimento dos mancais $b$ e a distância entre seus pontos de apoio na guia.

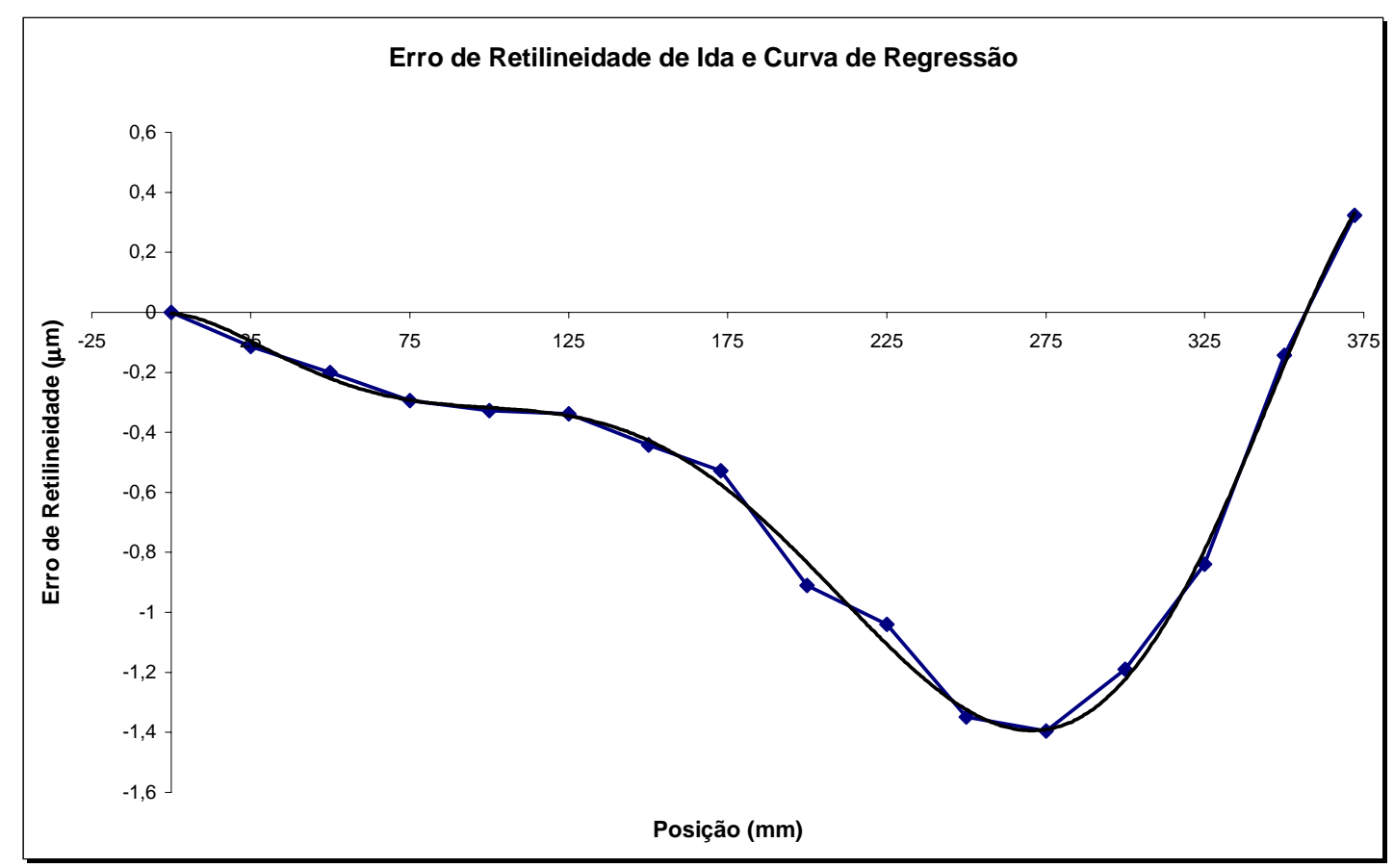

Figura 5.13 - Curva de ajuste para o erro de retilineidade hipotético, no sentido de ida.

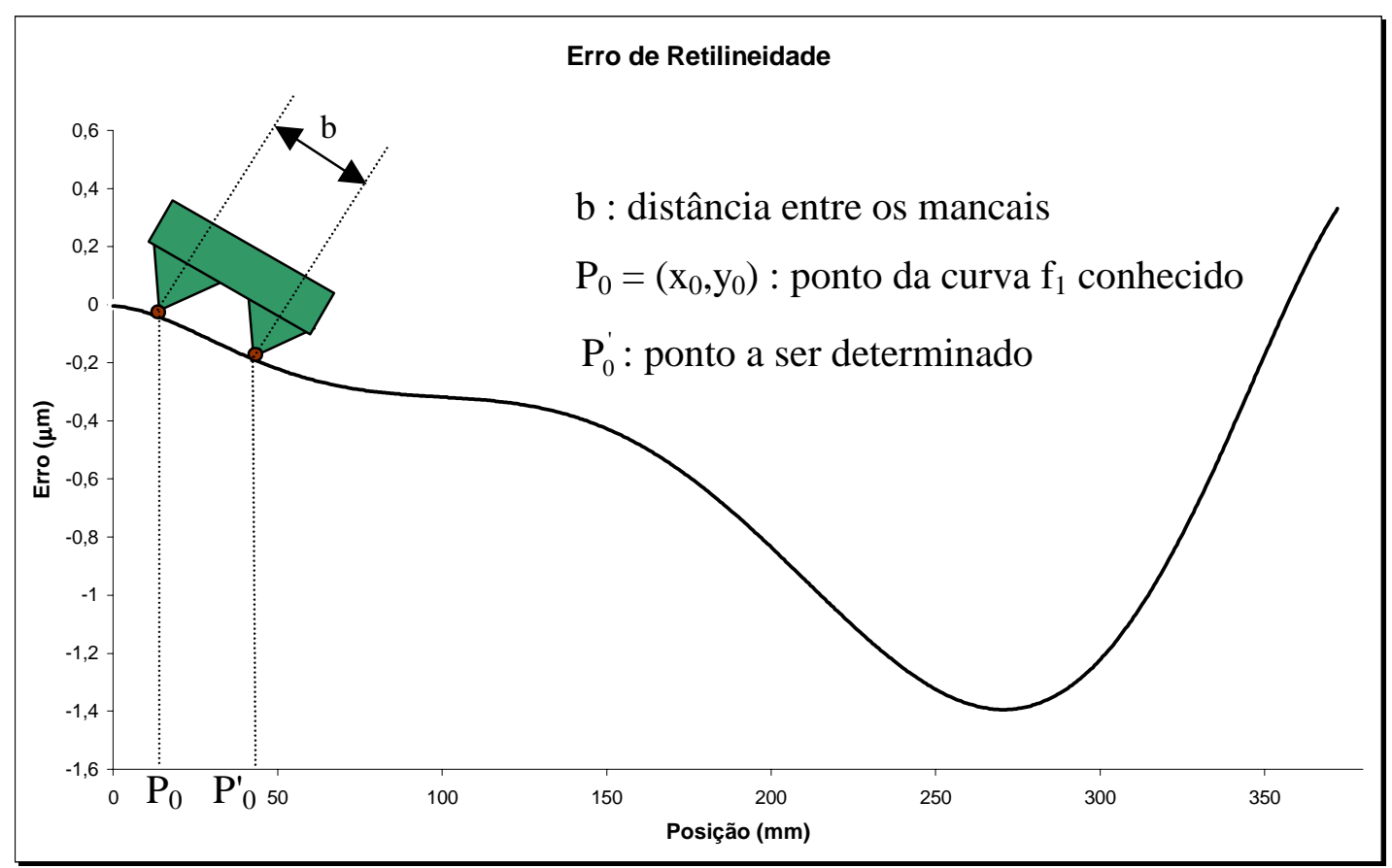

Figura 5.14 - Visão do carro da máquina sobre a curva de erro de retilineidade 
As coordenadas do ponto $\mathrm{P}_{0}^{\prime}$ podem, então, ser obtidas resolvendo o sistema [5.3] através do método de Newton para sistemas não lineares. Tal método foi programado em ambiente Matlab ${ }^{\circledR}$.

$$
\left\{\begin{array}{l}
f_{1}\left(x_{0}, y_{0}\right)=0 \\
f_{2}\left(x_{0}, y_{0}\right)=0
\end{array}\right.
$$

Conhecidos os pontos $\mathrm{P}_{0}$ e $\mathrm{P}_{0}^{\prime}$, traçou-se uma reta que representa a posição e a inclinação do carro no momento que ele está na posição inicial, $\mathrm{P}_{0}$, do trajeto.

$$
m=\operatorname{tg} \theta=\frac{y_{0}^{\prime}-y_{0}}{x_{0}^{\prime}-x_{0}}
$$

Desta forma o coeficiente angular da reta, ou seja, o ângulo formado pelo carro em relação ao eixo de movimentação da máquina, é obtido. Tal coeficiente é bem pequeno, pois y, o valor do erro de retilineidade é dado em micrômetros, e ainda, é dividido por x, o valor da posição em determinado ponto, transformado em micrômetros. Então pode-se considerar $\operatorname{tg} \theta \operatorname{como} \theta$.

Outra modificação que deve ser feita, é que os dados estarão em radianos, e para que a unidade seja arcsegundos, que é a unidade de saída dos dados calibrados, utiliza-se a seguinte expressão:

$$
\theta=\frac{1.296 .000 *(-m)}{2 \pi}
$$

O primeiro ângulo calculado, $\theta$, denomina-se $\theta_{\mathrm{r}}$, ângulo de referência para os cálculos e os demais $\theta_{\mathrm{Mi}}$. 
Este mesmo procedimento é executado para os $\mathrm{n}$ pontos, $\mathrm{P}_{\mathrm{i}}$, levantados durante a calibração do erro de retilineidade, determinados os pontos $\mathrm{P}_{\mathrm{i}}^{\prime}$ determinam-se todos os ângulos $\theta_{\mathrm{Mi}}(\mathrm{i}=1, . ., \mathrm{n})$ do carro em relação ao eixo de movimentação.

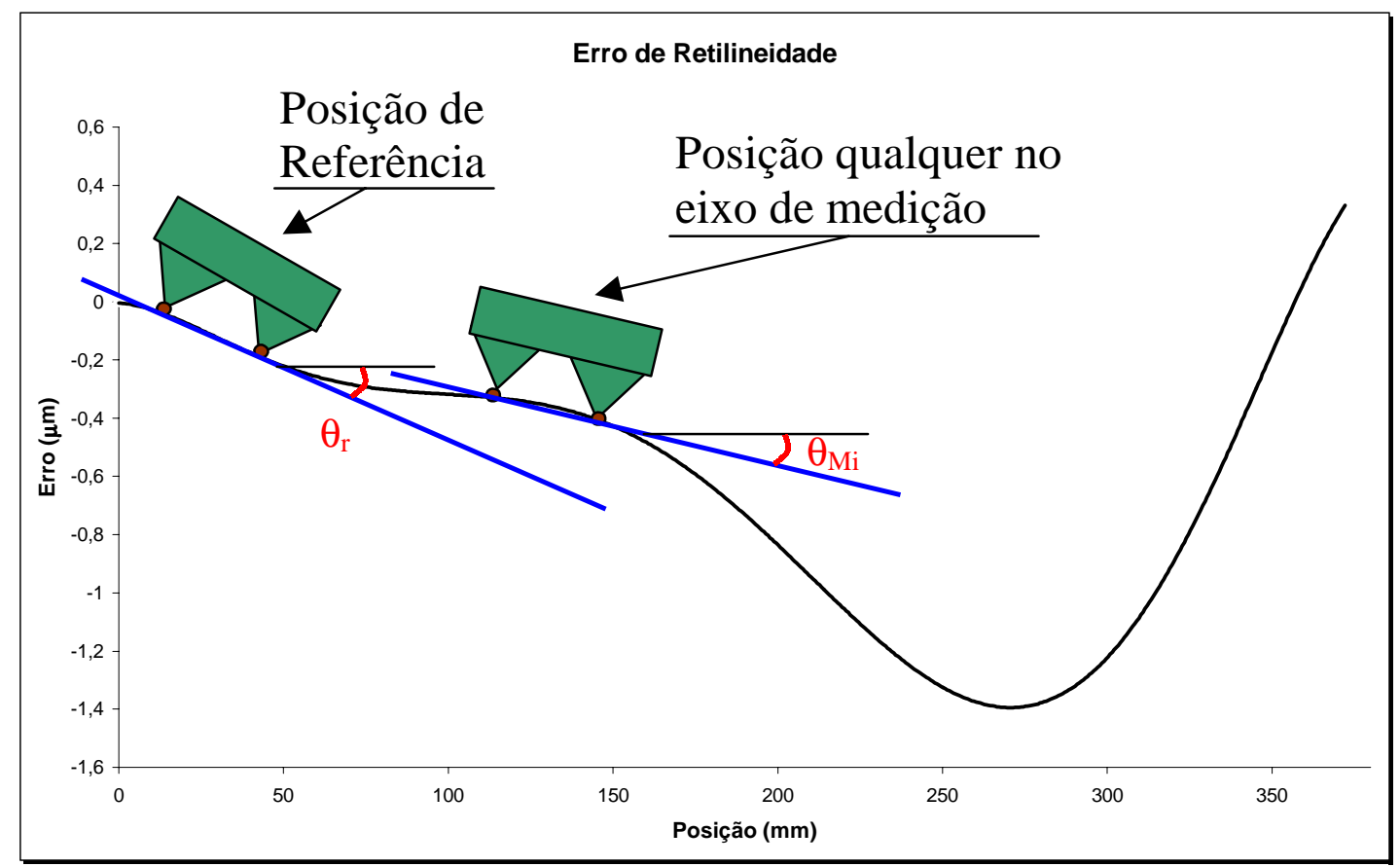

Figura 5.15 - Esquema para encontrar o erro angular

A Figura 5.15 mostra o carro em duas posições distintas: a primeira na posição de referência e, a segunda, em uma posição qualquer ao longo do eixo de medição.

O erro angular obtido a partir da curva de retilineidade é, então, dado pelas equações descritas em [5.6].

$$
\begin{aligned}
& \theta_{1}=\theta_{\mathrm{r}}-\theta_{\mathrm{r}} \\
& \theta_{2}=\theta_{1}+\left(\theta_{\mathrm{M} 2}-\theta_{\mathrm{r}}\right) \\
& \ldots \\
& \theta_{\mathrm{n}}=\theta_{\mathrm{n}-1}+\left(\theta_{\mathrm{Mn}}-\theta_{\mathrm{r}}\right)
\end{aligned}
$$

onde: 
- $\mathrm{n}$ é o número de pontos avaliados durante a calibração do erro de retilineidade

- $\theta_{\mathrm{Mi}}(\mathrm{i}=1, . ., \mathrm{n})$ é o $\theta$ calculado no ponto $\mathrm{P}_{\mathrm{i}}$

- $\theta_{\mathrm{i}}(\mathrm{i}=1, \ldots, \mathrm{n})$ é o erro angular calculado no ponto $\mathrm{P}_{\mathrm{i}}$

\section{3 - DETERMINAÇÃO DA INCERTEZA PADRONIZADA COMBINADA}

A incerteza padronizada combinada é a incerteza de um resultado de medição quando este é obtido através de valores de várias outras grandezas. Portanto o desvio padrão estimado associado com estimativa de saída ou resultado de medição y é chamado de incerteza padronizada combinada e é designada por $\mathrm{u}_{\mathrm{c}}(\mathrm{y})$.

\section{- Grandezas de ENTRAda não CorrelacionadaS}

Pode-se dizer que as grandezas de entrada não são correlacionadas quando elas forem independentes umas das outras. A incerteza padronizada combinada $\mathrm{u}_{\mathrm{c}}(\mathrm{y})$ é a raiz quadrada positiva da variância combinada $u_{c}^{2}(y)$ e é dada pela equação 5.7 :

$u_{c}^{2}(y)=\sum_{i=1}^{n}\left[\frac{\partial f}{\partial q_{i}}\right]^{2} u^{2}\left(q_{i}\right)$

onde $f$ é a função dada por

$\mathrm{Y}=f\left(q_{1}, q_{2}, \ldots, q_{\mathrm{n}}\right)$

Sendo cada variável $\left(\mathrm{q}_{\mathrm{i}}\right)$ uma incerteza padronizada avaliada. A incerteza padronizada combinada $\mathrm{u}_{\mathrm{c}}(\mathrm{y})$ é um desvio padrão estimado e 
caracteriza a dispersão dos valores que poderiam ser atribuídos ao mensurando Y.

As derivadas parciais, frequentemente denominadas de coeficientes de sensibilidade, descrevem como a estimativa de saída y varia com alterações nos valores de entrada.

Sendo, a função $f$ dada pela equação do ângulo:

$f=\theta=\operatorname{arctg}\left(\frac{y_{0}^{\prime}-y_{0}}{x_{0}^{\prime}-x_{0}}\right)$

As derivadas parciais são as seguintes:

$$
\begin{aligned}
& \frac{\partial \theta}{\partial y_{0}^{\prime}}=\frac{1}{\left(x_{0}^{\prime}-x_{0}\right) \cdot\left(1+\frac{\left(y_{0}^{\prime}-y_{0}\right)^{2}}{\left(x_{0}^{\prime}-x_{0}\right)^{2}}\right)} \\
& \frac{\partial \theta}{\partial y_{0}}=-\left(\frac{1}{\left(x_{0}^{\prime}-x_{0}\right) \cdot\left(1+\frac{\left(y_{0}^{\prime}-y_{0}\right)^{2}}{\left(x_{0}^{\prime}-x_{0}\right)^{2}}\right)}\right. \\
& \frac{\partial \theta}{\partial x_{0}^{\prime}}=-\left(\frac{y_{0}^{\prime}-y_{0}}{\left(x_{0}^{\prime}-x_{0}\right)^{2} \cdot\left(1+\frac{\left(y_{0}^{\prime}-y_{0}\right)^{2}}{\left(x_{0}^{\prime}-x_{0}\right)^{2}}\right)}\right. \\
& \frac{\partial \theta}{\partial x_{0}}=\frac{y_{0}^{\prime}-y_{0}}{\left(x_{0}^{\prime}-x_{0}\right)^{2} \cdot\left(1+\frac{\left(y_{0}^{\prime}-y_{0}\right)^{2}}{\left(x_{0}^{\prime}-x_{0}\right)^{2}}\right)}
\end{aligned}
$$

Partido da equação [5.17] e conhecendo a equação de $\theta$, suas derivadas e as incertezas de cada uma das variáveis envolvidas pode-se calcular a propagação de erros. A incerteza $u(q i)$ de cada uma das variáveis em cada ponto de observação, em $y_{0}^{\prime}$ e $y_{0}$, esta variação é o desvio padrão obtido através da calibração do erro de retilineidade e em $x_{0}^{\prime}$ e $x_{0}$, é o erro de posição calibrado do eixo de movimentação "Y". 


\section{CAPÍTULO 6}

\section{RESULTADOS DOS TESTES EXPERIMENTAIS, DAS SiMULAÇÕES COMPUTACIONAIS E DisCUSSÕES}

Após a apresentação da parte teórica e dos procedimentos para $\mathrm{o}$ cálculo do erro angular a partir do erro de retilineidade, estão agora apresentados os resultados obtidos através da aplicação prática do método proposto.

Primeiramente foram efetuadas as calibrações dos erros de retilineidade do eixo "Y" e dos erros angulares Yaw "Y" e Pitch "Y" de uma MM3C. As calibrações dos erros de retilineidade foram efetuadas de duas formas distintas. Numa utilizou-se o interferômetro laser e na outra a régua padrão e o método da reversão. A calibração dos erros angulares foram executadas com o sistema interferométrico laser.

Através dos dados obtidos durante a calibração dos erros de retilineidade, foi possível a determinação dos erros angulares correspondentes pela aplicação da formulação matemática proposta. Estes, por sua vez, foram comparados aos valores obtidos através de calibração. Isto é, a partir dos erros de retilineidade na direção " $\mathrm{X}$ " devido ao movimento no eixo "Y", $\delta_{\mathrm{x}}(\mathrm{y})$, foram encontrados os erros $Y a w$ "Y", $\delta \theta_{\mathrm{z}}(\mathrm{y})$. A partir dos erros de retilineidade na direção " $\mathrm{Z}$ " devido também ao movimento no eixo "Y", $\delta_{\mathrm{z}}(\mathrm{y})$, foram encontrados os erros Pitch " $Y$ ", $\delta \theta_{\mathrm{x}}(\mathrm{y})$. 
As condições do ambiente durante a calibração dos erros, foram as seguintes :

$\rightarrow$ Temperatura do ambiente e das guias da MM3C $=20 \pm 1^{\circ} \mathrm{C}$

$\rightarrow$ Umidade Relativa do ar $=40 \% \pm 2 \%$

$\rightarrow$ Pressão Atmosférica $=693 \pm 3$ mmHg

$\rightarrow$ Alinhamento do feixe laser melhor que $90 \%$

\section{1 - RESUltados da CALIBRAÇÃO dOS ERROS DE RETILINEIDADE E ERROS ANGULARES DA MÁQUINA DE MEDIR A TRÊS COORDENADAS.}

A distância entre os pontos de leitura adotada na calibração foi de 25 mm e a largura máxima dos pontos de medição de $1 \mathrm{~mm}$.

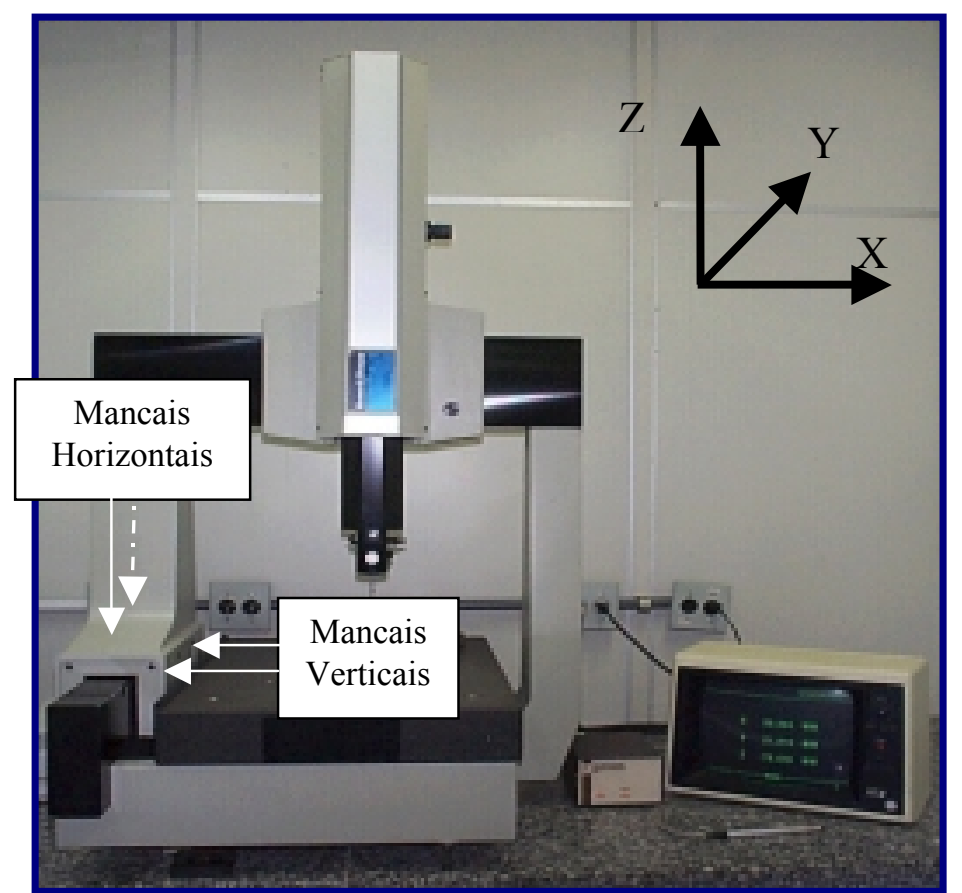

Figura 6.1 - Máquina de Medir a Três Coordenadas tipo Ponte Móvel utilizada 
O sistema de coordenadas de referência adotado pode ser visto na Figura 6.1. O eixo " $\mathrm{X}$ " tem sua origem no lado esquerdo da máquina, se observada de frente, isto é, posição mais recuada a esquerda que o carro pode assumir. O sentido de ida foi adotado da esquerda para a direita, e consequentemente o sentido de volta da direita para a esquerda. A origem do eixo "Y" foi colocada na frente da máquina e o sentido de ida em direção ao fundo. Finalmente, a origem do eixo " $Z$ " foi localizada no ponto extremo inferior. Tal ponto depende do tamanho da ótica utilizada na calibração. $\mathrm{O}$ sentido de ida, será de baixo para cima.

Os dados foram levantados em 5 trajetos de ida e 5 trajetos de volta e foram analisados separadamente. Em cada posição de leitura, tomou-se a média aritmética dos valores levantados para representar o erro sistemático nesta posição. Desta forma, obteve-se um conjunto de valores para representar o erro no sentido de ida ao longo do eixo avaliado. De forma análoga obtevese um conjunto de dados para representar o erro no sentido de volta.

Os resultados da calibração dos erros da MM3C estão apresentados através de gráficos. Eles contém as curvas que representam o erro sistemático no sentido de ida e de volta, além das curvas que representam o erro aleatório encontrados durante a calibração. As curvas que representam o erro aleatório no sentido de volta não foram colocadas por apresentarem um comportamento similar as curvas do erro aleatório no sentido de ida.

\subsection{1 - ERROS DE RETILINEIDADE}

Foram realizados 5 ciclos de leitura, 5 trajetos no sentido de ida e 5 trajetos no sentido de volta.

Como visto anteriormente, os dados de retilineidade levantados durante a calibração devem ser corrigidos, devido ao desalinhamento existente entre o feixe laser e o eixo de movimentação da máquina. No caso de calibrações 
efetuadas com a régua, o desalinhamento será entre o eixo de movimentação e a régua padrão. Tal correção foi efetuada através do método dos mínimos quadrados. Então o erro de retilineidade é dado pela expressão [5.1].

Nos gráficos dos erros de retilineidade apresentados, as parcelas devido ao desalinhamento já foram corrigidas. Esses gráficos apresentam nas abscissas as posições do carro de movimentação, em milimetros (mm), onde os valores de erros foram lidos. No eixo das ordenadas estão os valores dos erros, em microns do metro $(\mu \mathrm{m})$, para os sentidos de ida e de volta e os desvios padrões do sentido de ida.

\section{ERro de RETILINEIDADE NA DiREÇÃo “X” DEVIDO AO MOVIMENTO NO EIXO "Y", $\delta_{\mathrm{X}}(\mathrm{Y})$.}

A medição de retilineidade na direção " $\mathrm{X}$ " devido ao movimento no eixo "Y" foi feita com duas montagens diferentes: com o sistema interferométrico laser e com régua padrão e apalpador linear.

A medição do erro de retilineidade no eixo " $Y$ " na direção " $X$ " foi feita nas posições " $\mathrm{X}$ " = 64,268 $\mathrm{mm}$ e " $\mathrm{Z}$ " $=-264,694 \mathrm{~mm}$ e os erros foram levantados em posições discretas no eixo "Y" a cada $25 \mathrm{~mm}$.

A montagem do conjunto de espelhos do sistema interferométrico laser utilizado para a leitura desse erro pode ser observada na Figura 5.7.

O gráfico da Figura 6.2 apresenta os resultados da calibração do erro de retilineidade do eixo "Y" da máquina. 


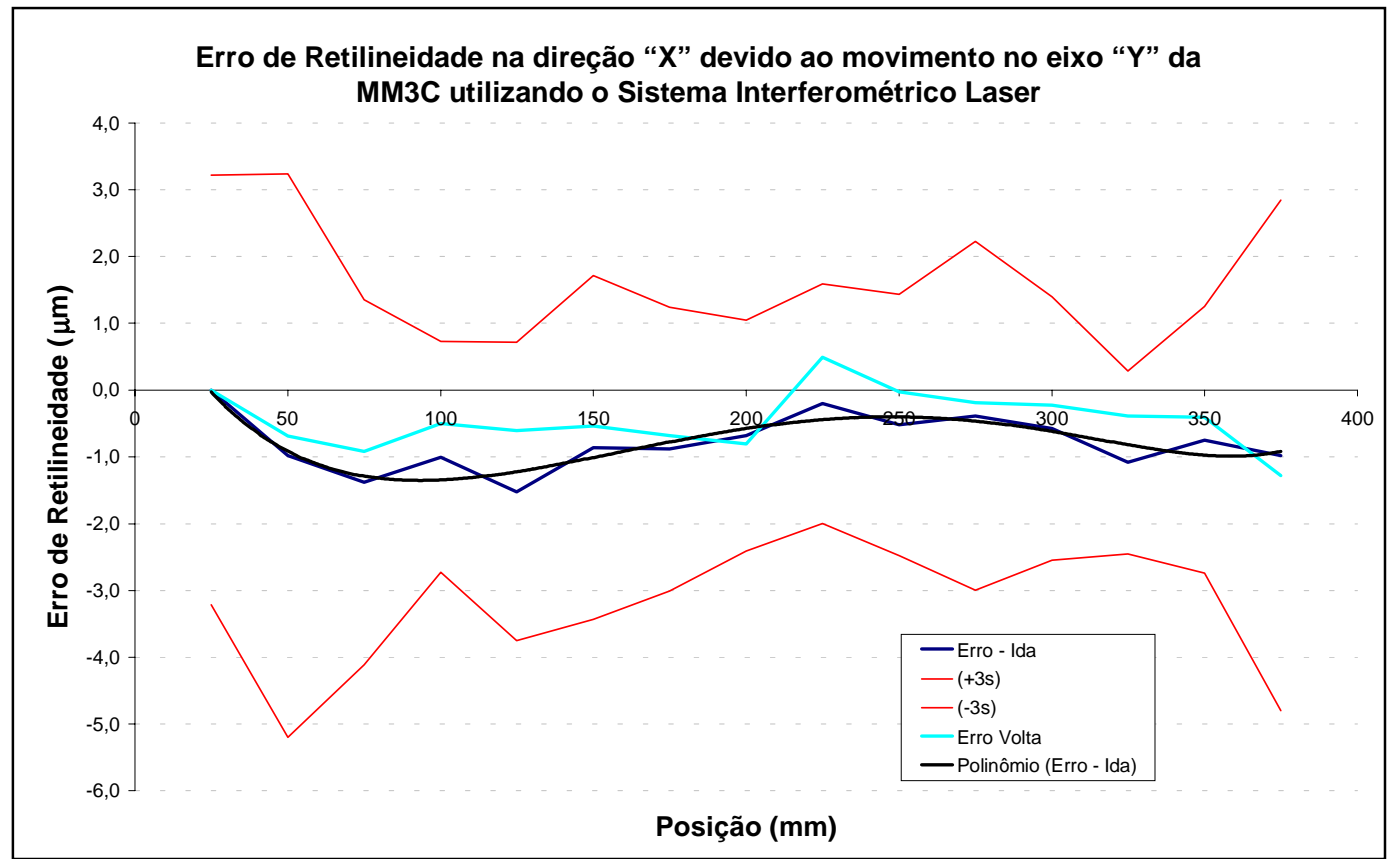

Figura $6.2-$ Erro $\delta_{\mathrm{x}}(\mathrm{y})$ utilizando o sistema interferométrico laser.

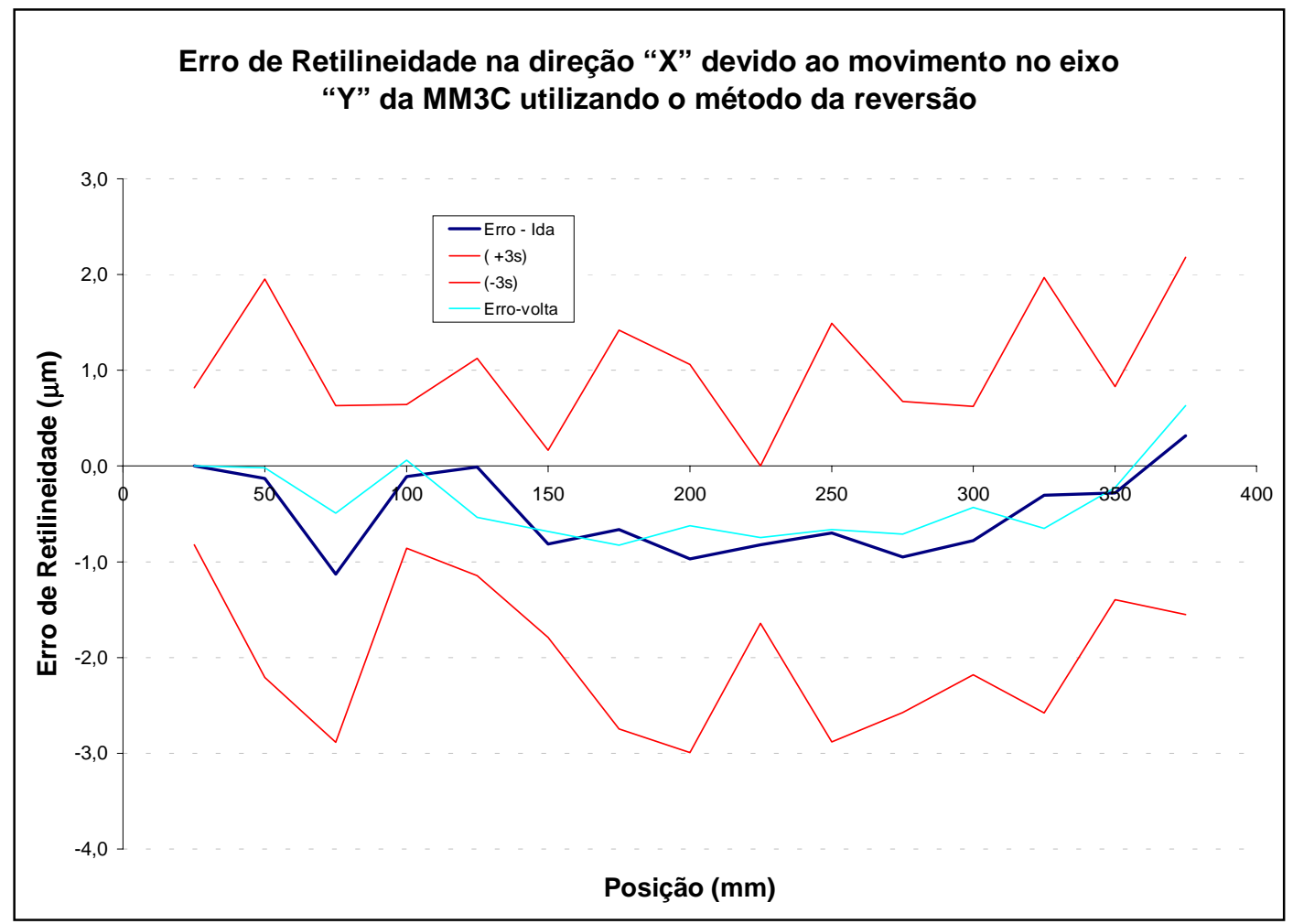

Figura $6.3-$ Erro $\delta_{\mathrm{x}}(\mathrm{y})$ utilizando a régua padrão. 
Observando os gráficos das Figuras 6.2 e 6.3 nota-se que o erro de retilineidade é extremamente pequeno atingindo o máximo $1,5 \mu \mathrm{m}$ e o erro aleatório na medição com o laser é de aproximadamente $8 \mu \mathrm{m}$ e com o método da reversão é de aproximadamente $5 \mu \mathrm{m}$, isto é, apresenta um erro aleatório relativamente grande comparado com os valores médios.

Nota-se também que a diferença entre os dois sentidos de medição é pequena, isto é, praticamente sem histerese. Portanto pode-se avaliar apenas um dos sentidos para descrever o comportamento desse erro.

As duas curvas se assemelham muito nas suas tendências e o que se pode observar é que o erro quando medido utilizando o método da reversão se mostra menor do que o medido com o sistema interferométrico laser. Isto se deve à precisão do sistema interferométrico laser ser maior que na medição com a régua padrão e o apalpador linear.

Na Figura 6.2 pode-se, ainda, observar a curva ajustada ao conjunto de dados para o sentido de ida. Esta curva obtida a partir de análise de regressão apresenta um coeficiente de correlação de $85 \%$, e pode ser considerada adequada devido à amplitude do erro de retilineidade ser muito pequena. A expressão obtida foi a seguinte:

$$
\begin{aligned}
& \delta_{\mathrm{X}}(\mathrm{Y})=2 * 10^{-14} * \mathrm{x}^{6}-3 * 10^{-11} * \mathrm{x}^{5}+10^{-8} * \mathrm{x}^{4}-5 * 10^{-6} * \mathrm{x}^{3} \\
& +0,0009 * \mathrm{x}^{2}-0,0867 * \mathrm{x}+1,6317
\end{aligned}
$$

\section{ERRO DE RETILINEIDADE NA DIREÇÃo “Z” DEVIDO Ao MOVIMENTO NO}

$$
\text { EIXO "Y", } \delta_{\mathrm{Z}}(\mathrm{Y}) \text {. }
$$

$\mathrm{Na}$ medição do erro de retilineidade na direção " $Z$ " devido ao movimento no eixo "Y" foram tomados pontos com o intervalo de $25 \mathrm{~mm}$ no eixo "Y". 
Os procedimentos foram os mesmos utilizados na calibração do erro de retilineidade mostrado anteriormente. $\mathrm{O}$ gráfico da Figura 6.4 mostra o comportamento deste erro.

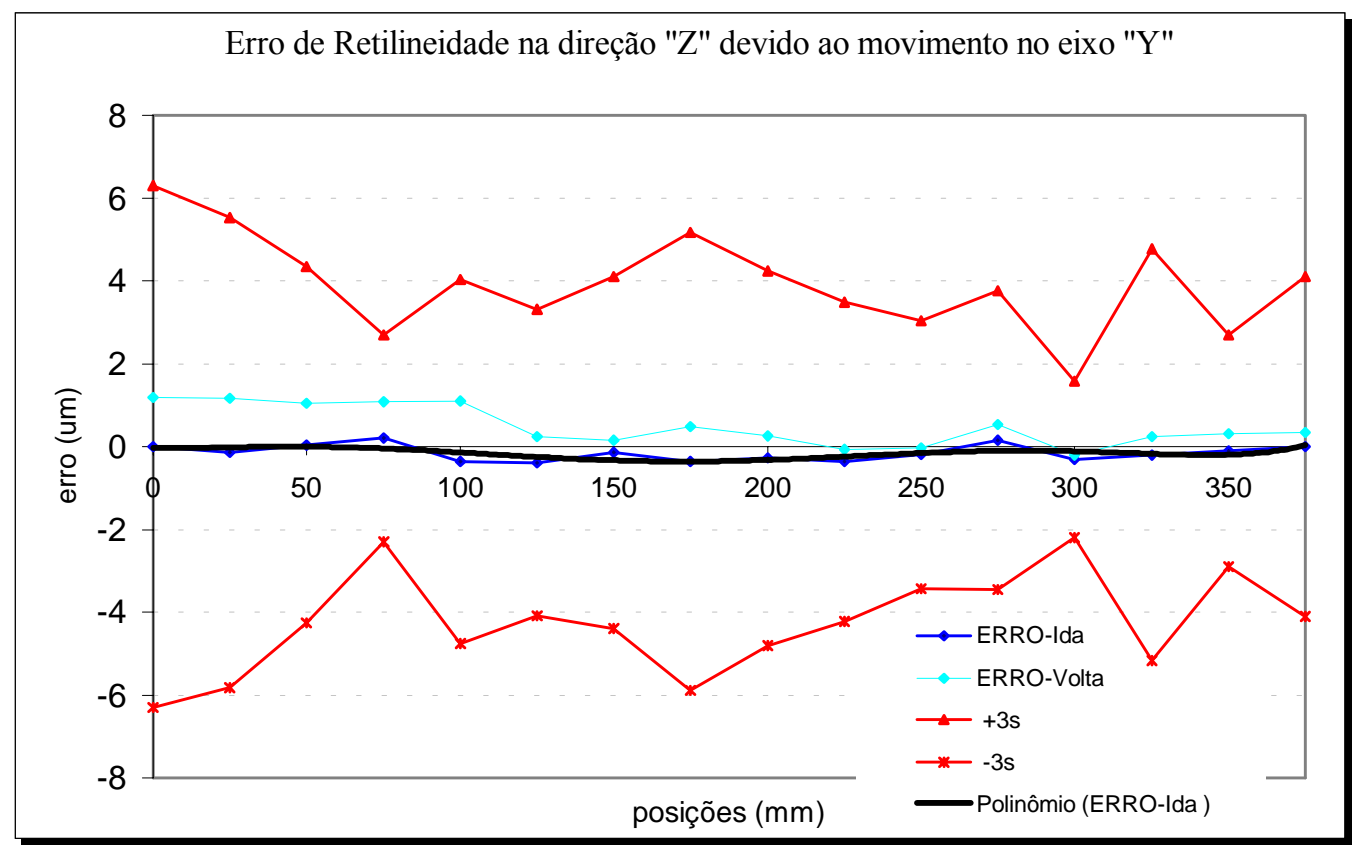

Figura 6.4 - Erro de retilineidade na direção "Z" devido ao movimento no

$$
\text { eixo "Y", } \delta_{Z}(\mathrm{Y}) \text {. }
$$

Analisando o gráfico da Figura 6.4 pode-se observar que o erro de retilineidade na direção "Z" devido ao movimento no eixo "Y" é extremamente pequeno. No entanto, o erro aleatório é relativamente grande quando comparado com os valores médios.

Nota-se, também, que a histerese é grande quando o carro "Y" está posicionado próximo da origem do sistema adotado. Porém, é importante ressaltar que a curva que representa o comportamento do erro no sentido de volta está contida entre as curvas que representam os erros aleatórios de ida. Desta forma pode-se avaliar apenas o comportamento do erro no sentido de ida para descrever o comportamento do erro de retilineidade

Na Figura 6.4 pode-se observar a curva ajustada ao conjunto de dados para o sentido de ida. Esta curva obtida a partir da análise da regressão apresenta um coeficiente de correlação de $70 \%$, e pode ser considerada 
adequada devido ao tamanho do erro de retilineidade ser muito pequeno. A expressão obtida foi a seguinte:

$$
\begin{aligned}
& \delta_{\mathrm{Z}}(\mathrm{Y})=1,74 * 10^{-12} * \mathrm{X}^{5}-1,63 * 10^{-9} * \mathrm{X}^{4}+5,5^{*} 10^{-7} * \mathrm{X}^{3} \\
& -7,1 * 10^{-5} * \mathrm{X}^{2}+1,66^{*} 10^{-3} * \mathrm{X}+2,22 * 10^{-3}
\end{aligned}
$$

\subsection{2 -ERROS ANGULARES}

Para levantar o comportamento dos erros angulares foram efetuados 10 trajetos de leitura, 5 de ida e 5 de volta.

Os gráficos que representam o comportamento do erro angular possuem nas abscissas a posição do carro de movimentação, em milímetro (mm), e nas ordenadas os valores dos erros nos sentidos de ida e volta, em arco de segundos (arcseg), além dos respectivos desvios padrões no sentido de ida.

\section{ERRO DE $Y A W$ DO EIXO "Y"}

A medição do erro angular "Yaw" do eixo "Y", que é o erro de rotação em torno do eixo "Z" devido ao movimento no eixo "Y", foi realizada na mesma posição em que foi calibrado o erro de retilineidade, ou seja, coordenadas " $\mathrm{X}$ " = 64,268 $\mathrm{mm}$ e "Z" = - 264,694 mm. Foram tomadas leitura em pontos com o intervalo de $25 \mathrm{~mm}$ no eixo "Y".

Os espelhos do sistema interferométrico laser para a calibração deste erro foram posicionados na máquina conforme indicado na Figura 5.3

O gráfico da Figura 6.5 mostra o comportamento do erro de "Yaw" do eixo "Y" da MM3C. Analisando este gráfico pode-se observar que os valores médios de ida e volta são progressivos. O erro alcança um valor próximo de 5 arcseg e a histerese é pequena. Além disso, observa-se que o sinal do erro é positivo, indicando que o ângulo de rotação em torno de " $Z$ " faz com que a 
ponta da sonda atinja valores em " $\mathrm{X}$ " menores do que os indicados pela máquina.

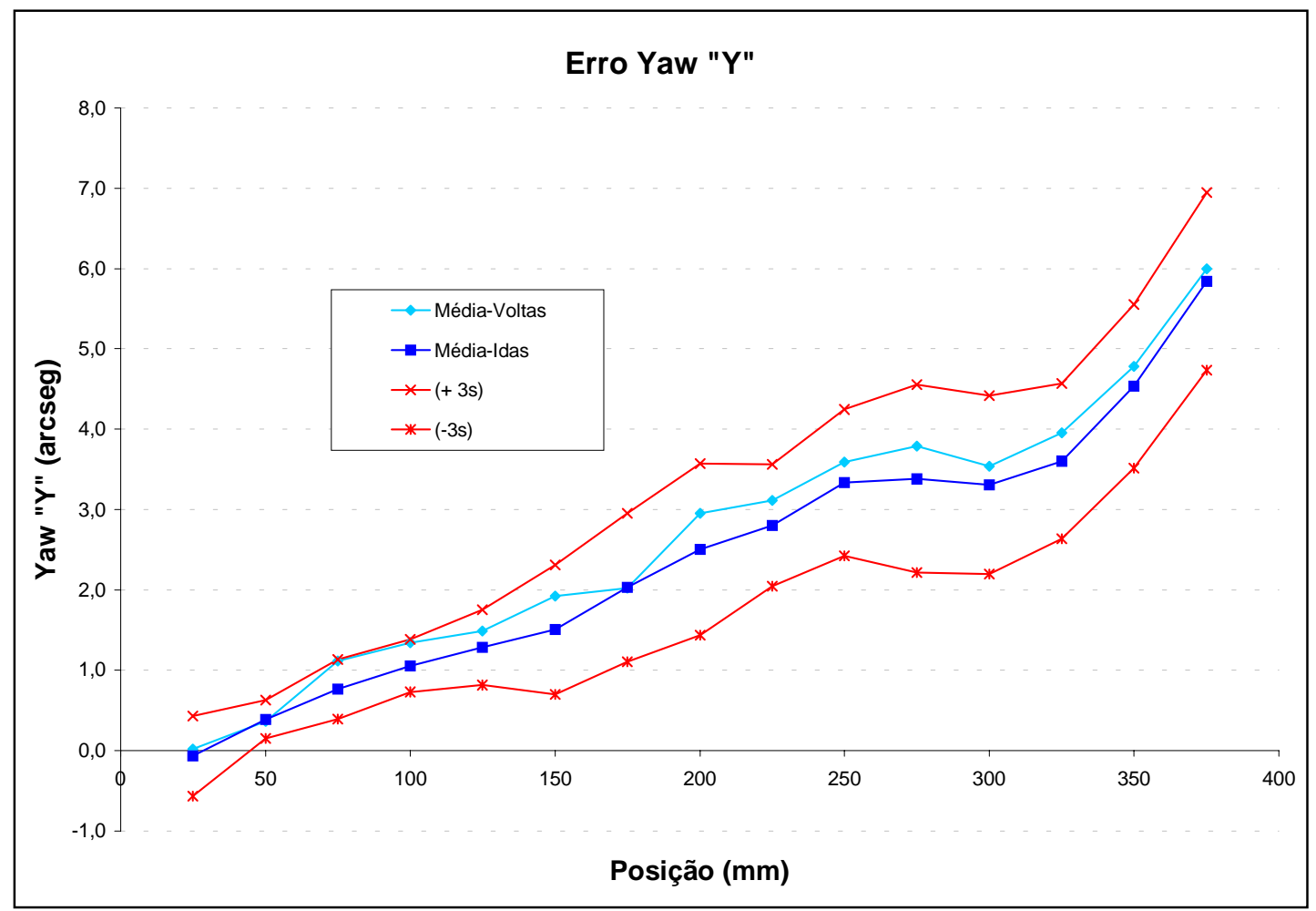

Figura 6.5 - Erro Yaw do eixo "Y"

\section{ERRO DE PITCH DO EIXO "Y"}

O erro de rotação em torno do eixo "X" devido ao movimento no eixo "Y", Pitch "Y", foi medido na mesma posição de calibração do erro de retilineidade e foram tomados pontos com intervalos de $25 \mathrm{~mm}$ no eixo "Y". 
A montagem dos espelhos para tal medição pode ser observada na Figura 5.4.

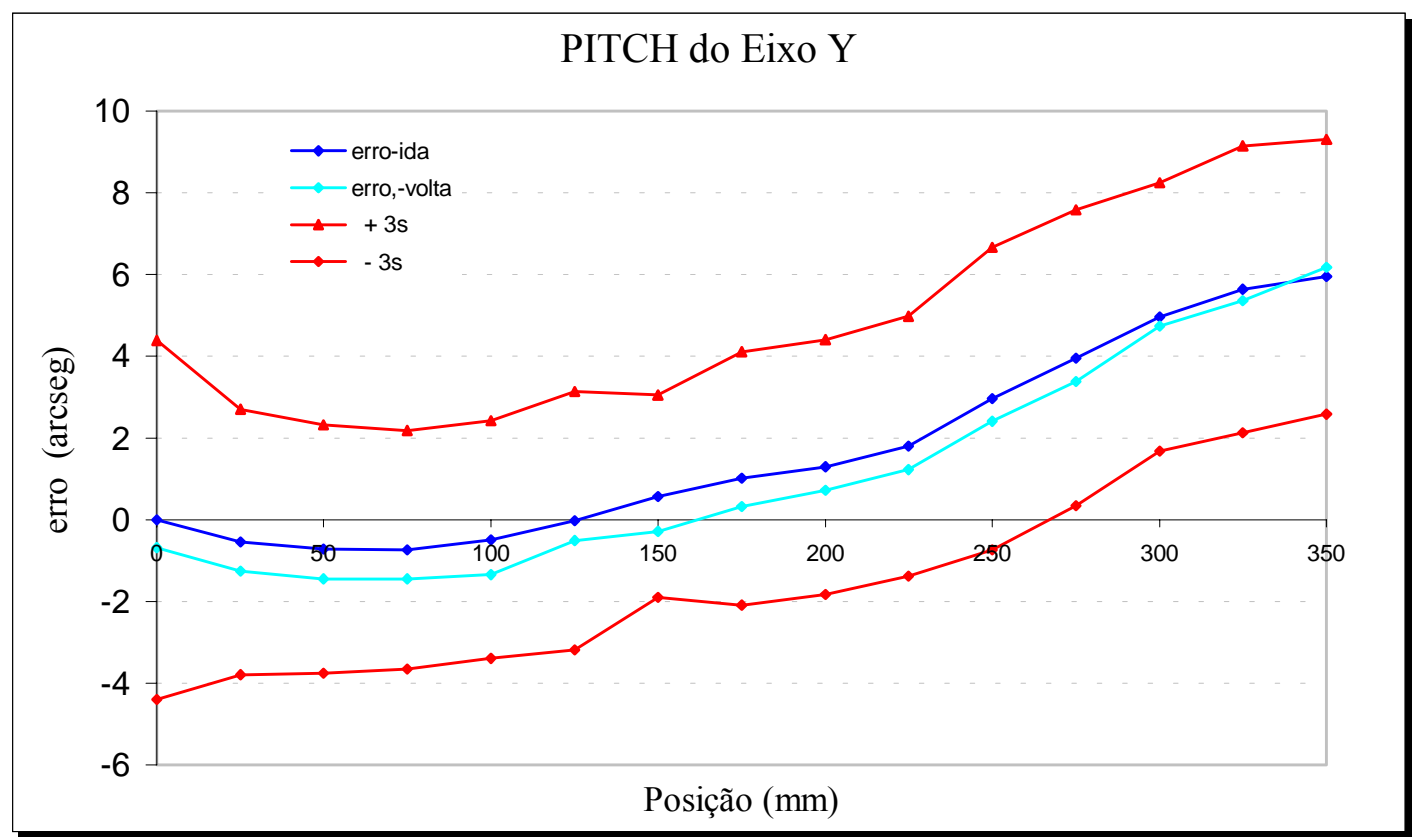

Figura 6.6 - Erro Pitch do eixo "Y"

A calibração do erro angular Pitch "Y" foi efetuada posicionando o carro "Y" no intervalo de $0 \mathrm{~mm}$ a $350 \mathrm{~mm}$.

Analisando esses gráfico pode-se notar que a histerese é pequena atingindo um valor próximo de 0,6 arcseg. Nota-se também que o erro é muito pequeno. 


\section{2 - ANÁliSE DOS RESULTADOS DA APLICAÇÃO DA FORMULAÇÃO MATEMÁTICA PROPOSTA}

\subsection{1 - DETERMINAÇÃO DO ERRO ANGULAR YAW "Y"}

O erro angular Yaw "Y" foi calculado utilizando os valores obtidos a partir da calibração do erro de retilineidade no eixo "Y" na direção " $\mathrm{X}$ " conforme descrito no item 5.4 do capítulo anterior.

Para se utilizar tal método é necessário que se análise a guia "Y" da MM3C e a posição dos mancais aerostáticos. A Figura 6.7 mostra um esquema da guia "Y" da Máquina de Medir a Três Coordenadas. Nela pode-se visualizar a guia, a régua indexável, a régua ótica fixa e a distância entre os mancais verticais e horizontais. É importante observar que quando a régua indexável está na posição $150 \mathrm{~mm}$ aproximadamente, o primeiro mancal está na posição $0 \mathrm{~mm}$ e o segundo na posição $300 \mathrm{~mm}$, Figura 6.8 .

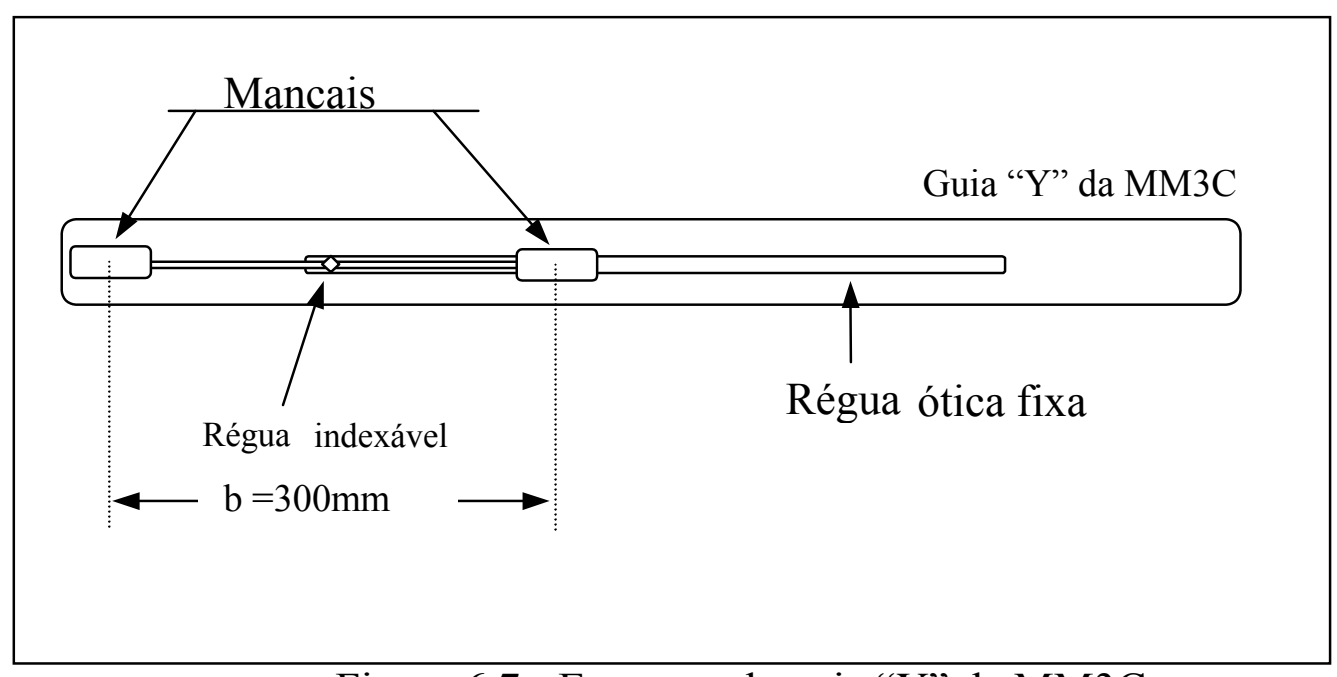

Figura 6.7 - Esquema da guia "Y" da MM3C 
Portanto a partir deste ponto, $150 \mathrm{~mm}$, tem-se o conhecimento dos valores do erro de retilineidade nos dois pontos de contato dos mancais na guia, obtido através da curva de calibração do erro de retilineidade, sendo só agora possível, calcular o erro angular.

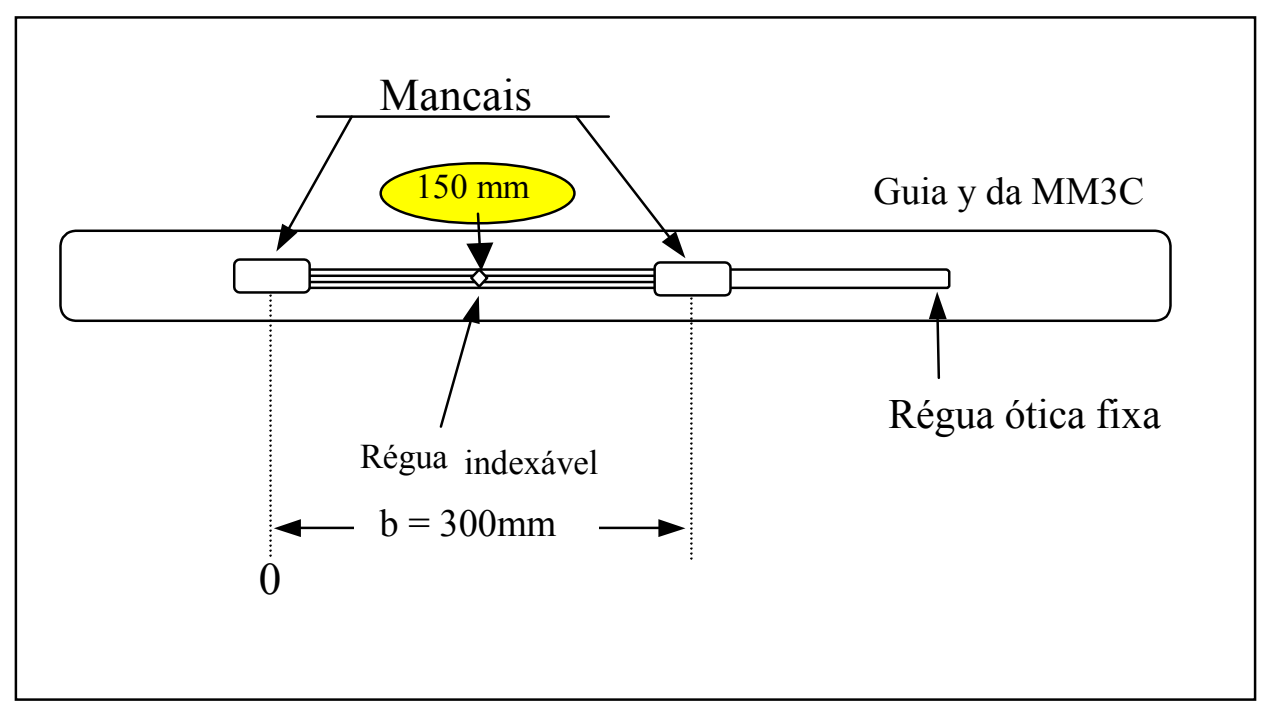

Figura 6.8 - Detalhes do esquema da guia "Y" da MM3C

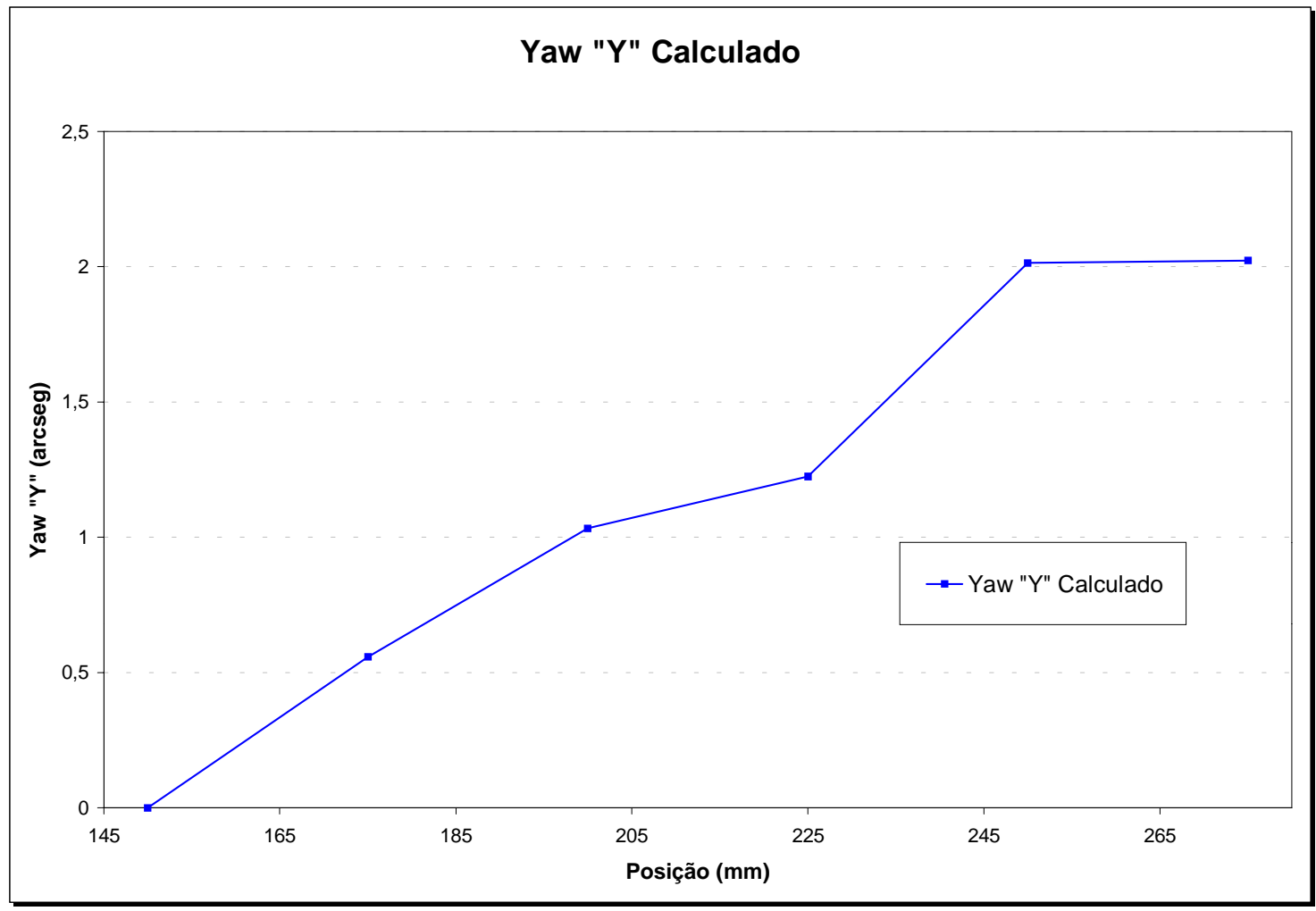

Figura 6.9 - Erro de Yaw "Y" calculado 
Para a determinação dos valores dos erros Yaw "Y" utilizou-se a equação 6.1 e a equação 5.2. Na equação $5.2, f_{2}$ representa a diferença entre o comprimento dos mancais $b$ e a distância entre seus pontos de apoio na guia. Através do sistema de equações 5.3, onde a função $f_{1}$ é dada por $\delta_{\mathrm{X}}(\mathrm{Y})-\mathrm{Y}$, encontra-se o ponto $\mathrm{P}_{0 \mathrm{i}}^{\prime}$. $\mathrm{P}_{0 \mathrm{i}}$ é o ponto conhecido que representa a posição do primeiro mancal e $\mathrm{P}_{0 \mathrm{i}}^{\prime}$ é o ponto a ser determinado, que representa a posição do segundo mancal que dista $\mathbf{b}$ do primeiro mancal.

Após executado todos os passos da formulação matemática, que foram mostrados no capítulo 5, obtém-se o gráfico da Figura 6.9 que representa o erro angular Yaw "Y" da MM3C.

A análise do resultado obtido através da formulação matemática pode então ser comparado com o resultado obtido na calibração do erro angular.

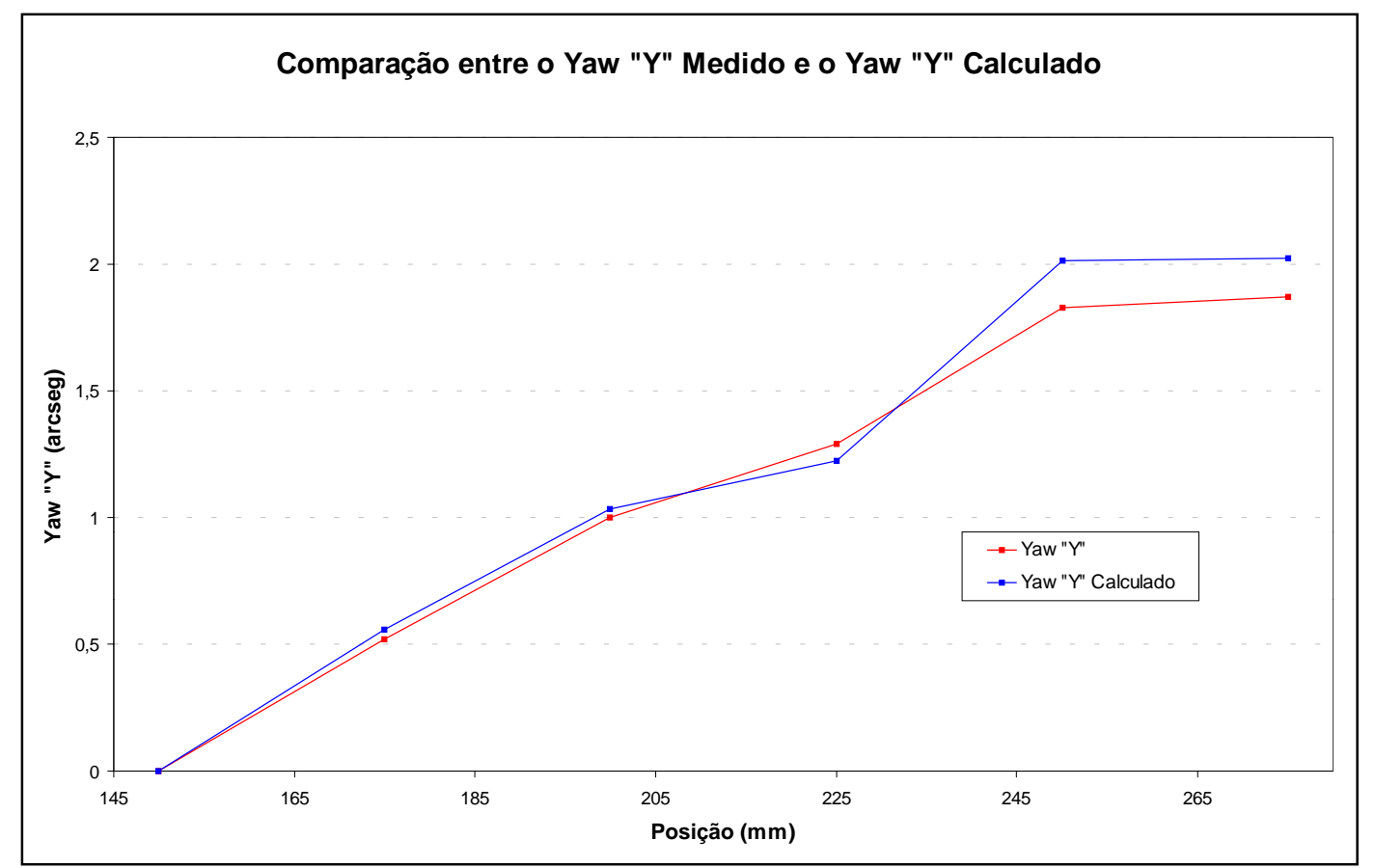

Figura 6.10 - Comparação dos resultados obtidos através da calibração do erro de Yaw "Y" e do calculado através do método proposto

O gráfico da Figura 6.10 apresenta duas curvas do erro de Yaw "Y". Uma é a curva obtida através do método proposto. A curva foi zerada no 
primeiro ponto calculado, isto é, ponto $150 \mathrm{~mm}$. A outra é a curva obtida a partir da calibração do erro, ou seja, curva de ida mostrada na Figura 6.5.

Como pode ser visualizado, na Figura 6.10, as duas curvas tem a mesma tendência e são extremamente parecidas, mostrando que a precisão do cálculo do erro de $Y a w$ "Y" a partir do erro de retilineidade na direção "X" devido ao movimento no eixo "Y" é possível. O erro relativo entre as duas curvas é dado por:

$$
\left(\frac{\theta_{\text {Medido }}-\theta_{\text {Calculado }}}{\theta_{\text {Medido }}}\right) .100
$$

E pode ser visualizada na Tabela 6.1.

Tabela 6.1 - Erro relativo entre as curvas de Yaw "Y"

\begin{tabular}{|c|c|}
\hline Posição $(\mathrm{mm})$ & Erro Relativo (\%) \\
\hline 150 & 0 \\
\hline \hline 175 & 6,7 \\
\hline 200 & 3,2 \\
\hline 225 & 5,0 \\
\hline 250 & 9,2 \\
\hline \hline 275 & 7,6 \\
\hline \hline Média & 5,3 \\
\hline \hline
\end{tabular}

\subsection{2 - DETERMINAÇÃO DO ERRO ANGULAR PITCH "Y"}

O erro angular Pitch "Y" foi calculado utilizando os valores obtidos a partir da calibração do erro de retilineidade no eixo " $Z$ " na direção " $X$ " e o método proposto, descrito no capítulo anterior.

Para se utilizar o método proposto se faz necessária a observação da guia e dos mancais aerostáticos da MM3C. Tal observação é a mesma utilizada no estudo para se encontrar o Yaw "Y", mesmo não sendo os mesmos 
mancais, que neste caso, são os mancais que foram chamados de mancais horizontais.

Para a determinação do erro de Pitch "Y" utilizou-se, as equações 6.2 e 5.2, e procedeu-se da mesma maneira anteriormente mostrada. No sistema de equações 5.3, a função $f_{l}$ é dada por $\delta_{Z}(Y)-Y$.

Após a execução dos passos da formulação matemática, mostrados no Capítulo 5, obtém-se o gráfico da Figura 6.11 que representa o erro angular da MM3C, neste caso o Pitch "Y".

A análise do resultado obtido através da formulação matemática pode agora ser comparado ao resultado obtido na calibração do erro angular.

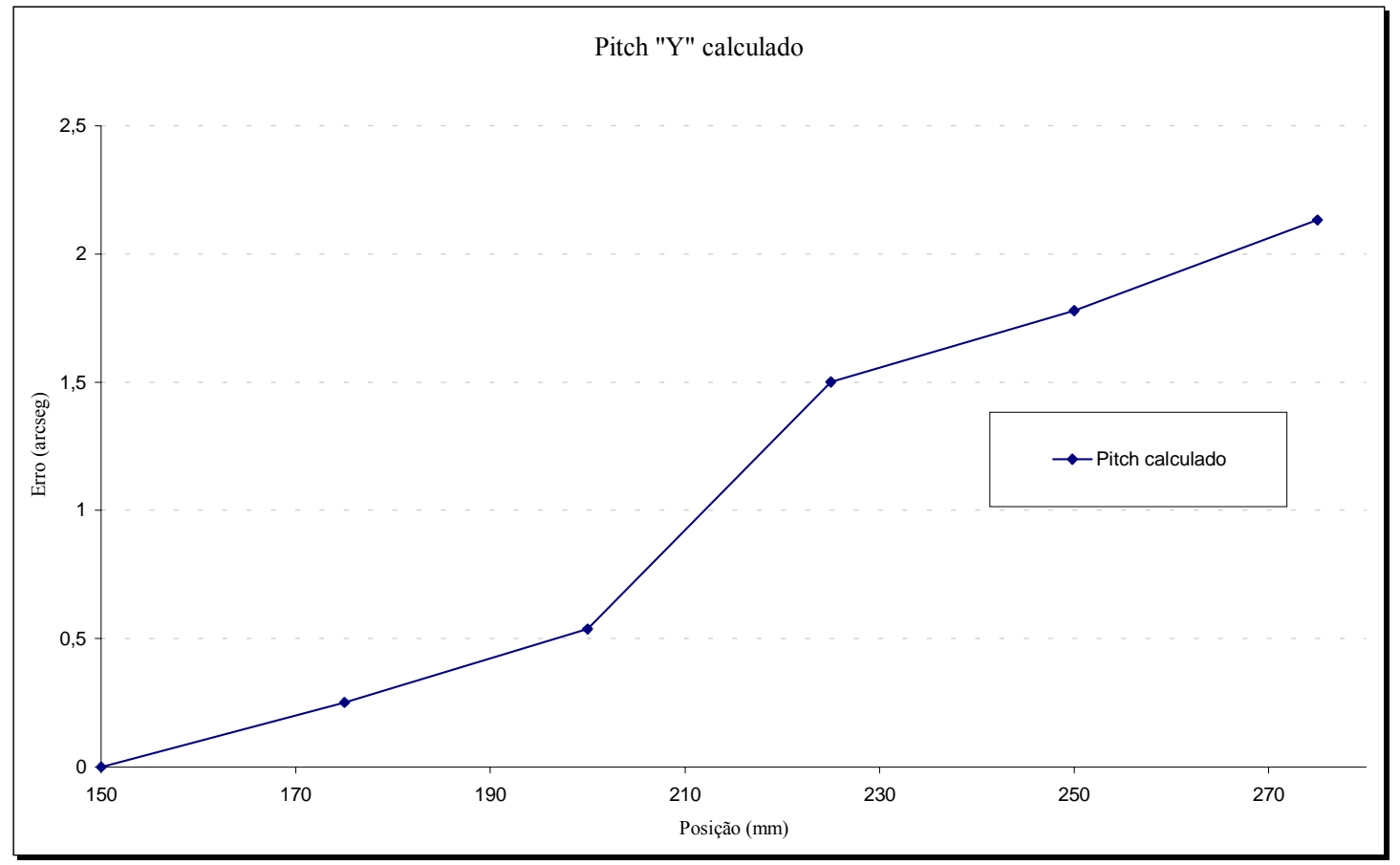

Figura 6.11 - Erro de Pitch "Y" calculado

O gráfico da Figura 6.12 apresenta duas curvas do erro de Pitch "Y". Uma é a curva obtida através do método proposto. A curva foi zerada no primeiro ponto calculado, isto é, ponto $150 \mathrm{~mm}$. A outra é a curva de ida obtida a partir da calibração do erro, Figura 6.6. 
Como pode ser visualizado, na Figura 6.12, as duas curvas tem tendências muito parecidas, mostrando mais uma vez que é possível determinar o erro angular em função do erro de retilineidade. Neste caso, o Pitch "Y" a partir do erro de retilineidade na direção "Z".

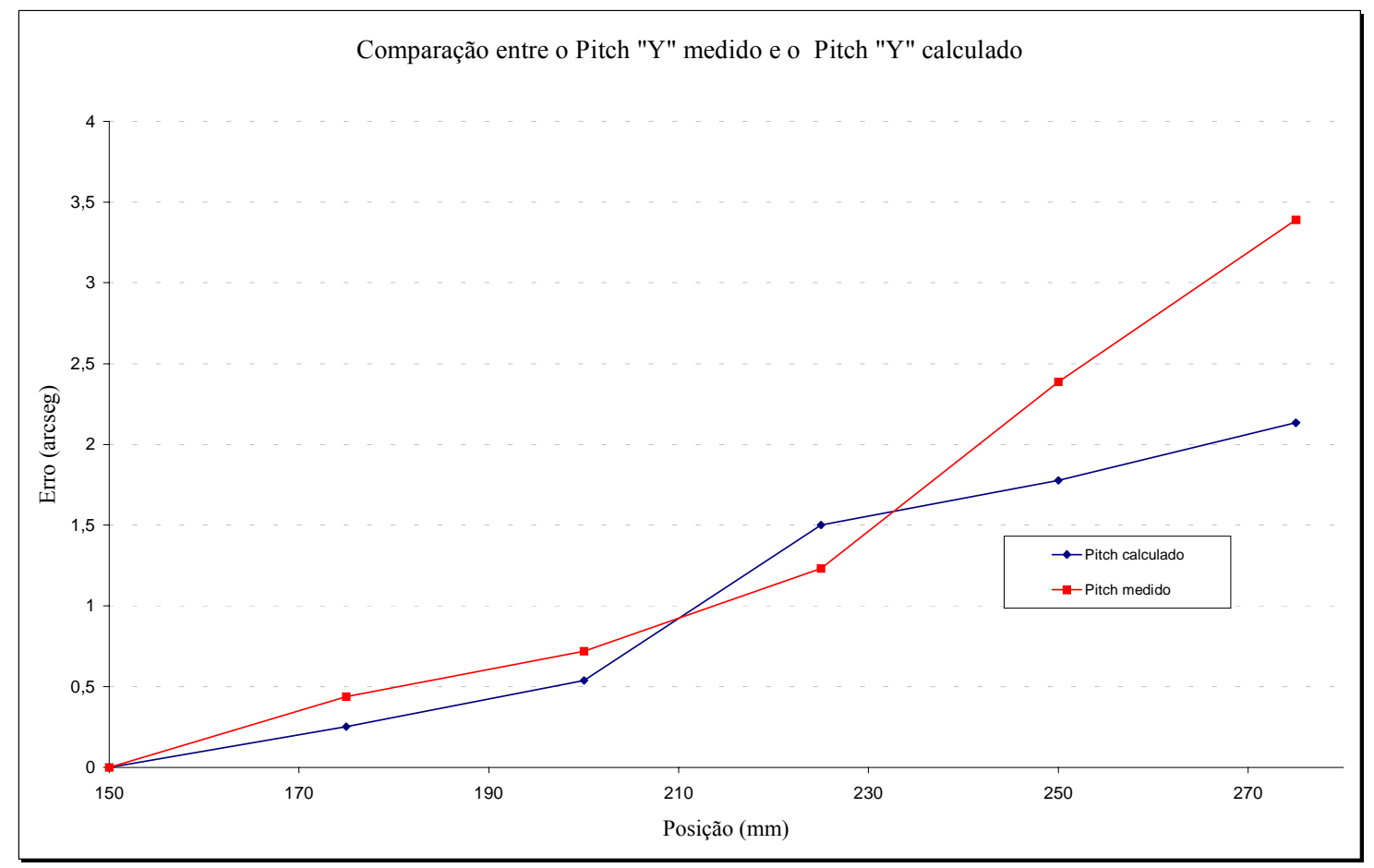

Figura 6.12 - Comparação dos resultados obtidos através da calibração do erro de Pitch "Y" e do calculado através do método proposto

O erro relativo entre as duas curvas pode ser observado na Tabela 6.2.

Tabela 6.2 - Erro relativo entre as curvas de Pitch "Y"

\begin{tabular}{|c|c|}
\hline Posição (mm) & Erro Relativo (\%) \\
\hline 150 & 0 \\
\hline 175 & 42,5 \\
\hline 200 & 25,3 \\
\hline 225 & 17,7 \\
\hline 250 & 25,4 \\
\hline 275 & 37,0 \\
\hline \hline \multicolumn{2}{|c|}{ Média } \\
\hline \hline
\end{tabular}




\section{3 - CÁlCULO DA INCERTEZA PADRONIZADA COMBINADA}

Após a verificação da validade da formulação matemática pode-se analisar a incerteza padronizada combinada ou também chamada propagação de erros.

Utiliza-se a equação 5.9, que é a equação do erro angular $\boldsymbol{\theta}$, e através da equação 6.4 faz-se os cálculos para a determinação da propagação de erros. A incerteza será associada ao erro de retilineidade e consequentemente será a mesma incerteza que é associada ao valor $\boldsymbol{\theta}$. Haverá, portanto, apenas uma incerteza associada aos dois erros e não uma em cada um deles.

$$
u_{c}^{2}(\theta)=\left(\frac{\partial \theta}{\partial y_{0}^{\prime}}\right)^{2} \cdot u^{2}\left(y_{0}^{\prime}\right)+\left(\frac{\partial \theta}{\partial y_{0}}\right)^{2} \cdot u^{2}\left(y_{0}\right)+\left(\frac{\partial \theta}{\partial x_{0}^{\prime}}\right)^{2} \cdot u^{2}\left(x_{0}^{\prime}\right)+\left(\frac{\partial \theta}{\partial x_{0}}\right)^{2} \cdot u^{2}\left(x_{0}\right)[6.4]
$$

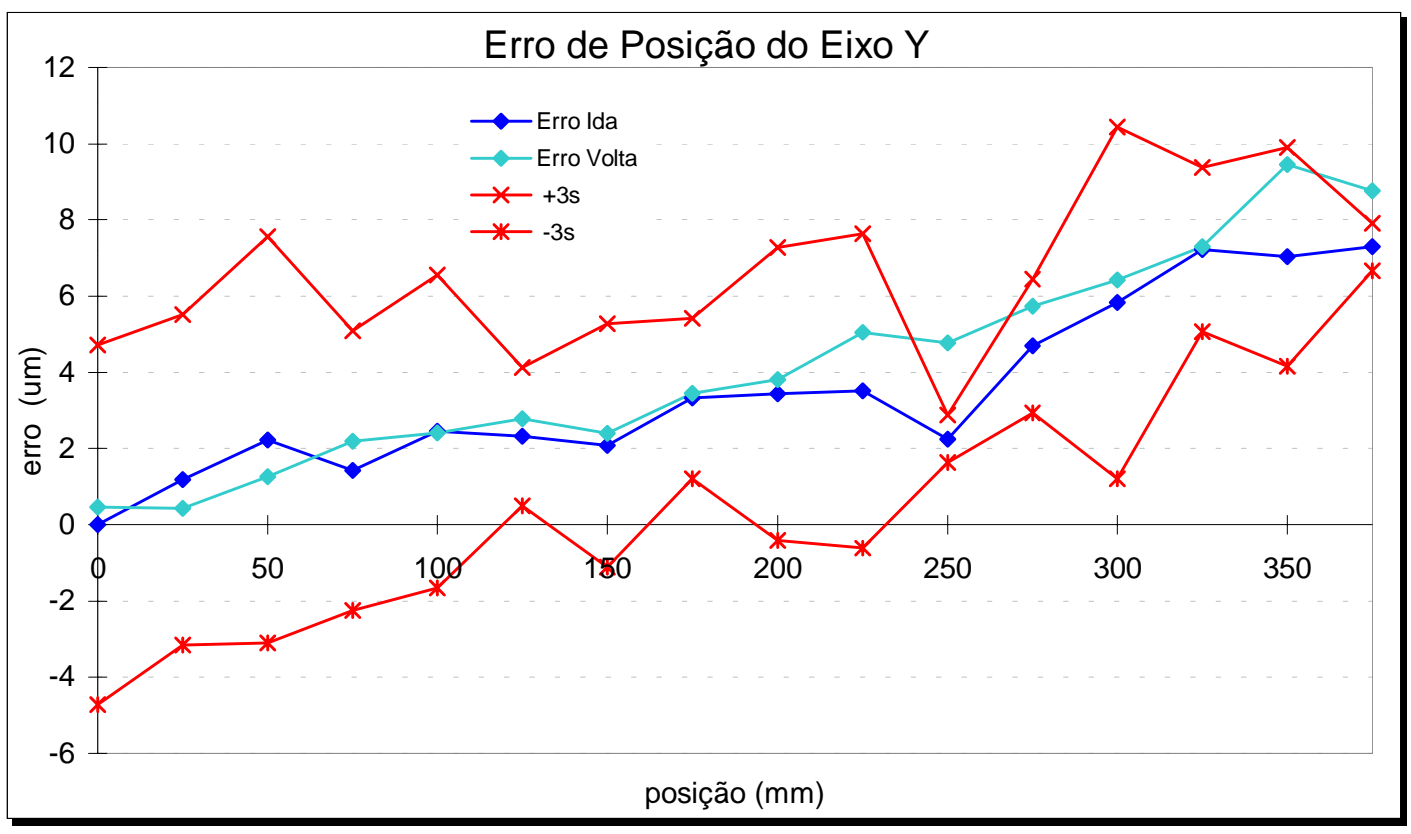

Figura 6.13 - Erro de Posição do Eixo "Y", $\delta_{\mathrm{Y}}(\mathrm{Y})$. 
Na equação 6.4 considera-se $\mathbf{q}_{\mathbf{i}}$ como variáveis da equação 5.9, ou seja, $y_{0}^{\prime}, y_{0}, x_{0}^{\prime}$ e $x_{0}$, e $\mathbf{u}^{2}\left(\mathbf{q}_{\mathbf{i}}\right)$ como a incerteza de cada uma das variáveis em cada ponto de observação. Em $y_{0}^{\prime}$ e $y_{0}$ esta variação é o desvio padrão obtido através da calibração do erro de retilineidade e em $x_{0}^{\prime}$ e $x_{0}$ é o erro de posição calibrado do eixo de movimentação "Y”, Figura 6.13.

Para o erro angular $Y a w$ "Y" a propagação de erros encontrada foi:

\begin{tabular}{||c|c|c||c|c|c||}
\hline \hline Posição & $\mathbf{u}\left(x_{0}\right)$ & $\mathbf{u}\left(y_{0}\right)$ & Posição & $\mathbf{u}\left(x_{0}^{\prime}\right)$ & $\mathbf{u}\left(y_{0}^{\prime}\right)$ \\
\hline 25 & 1,8333 & 1,866 & 250 & 0,9667 & 1,0667 \\
\hline 50 & 2,5333 & 1,4667 & 275 & 2,1667 & 1,3333 \\
\hline 75 & 1,700 & 1,0667 & 300 & 3,4667 & 0,600 \\
\hline 100 & 2,200 & 1,3667 & 325 & 3,1333 & 1,5333 \\
\hline 125 & 1,3667 & 1,1333 & 350 & 3,300 & 1,000 \\
\hline 150 & 1,7667 & 1,400 & 375 & 2,6333 & 1,4667 \\
\hline
\end{tabular}

$$
\frac{\partial \theta}{\partial y_{0}^{\prime}}=\frac{1}{\left(x_{0}^{\prime}-x_{0}\right) \cdot\left(1+\frac{\left(y_{0}^{\prime}-y_{0}\right)^{2}}{\left(x_{0}^{\prime}-x_{0}\right)^{2}}\right)}
$$$$
\frac{\partial \theta}{\partial y_{0}}=-\left(\frac{1}{\left(x_{0}^{\prime}-x_{0}\right) \cdot\left(1+\frac{\left(y_{0}^{\prime}-y_{0}\right)^{2}}{\left(x_{0}^{\prime}-x_{0}\right)^{2}}\right)}\right)
$$$$
\frac{\partial \theta}{\partial x_{0}^{\prime}}=-\left(\frac{y_{0}^{\prime}-y_{0}}{\left(x_{0}^{\prime}-x_{0}\right)^{2} \cdot\left(1+\frac{\left(y_{0}^{\prime}-y_{0}\right)^{2}}{\left(x_{0}^{\prime}-x_{0}\right)^{2}}\right)}\right)
$$

$$
\frac{\partial \theta}{\partial x_{0}}=\frac{y_{0}^{\prime}-y_{0}}{\left(x_{0}^{\prime}-x_{0}\right)^{2} \cdot\left(1+\frac{\left(y_{0}^{\prime}-y_{0}\right)^{2}}{\left(x_{0}^{\prime}-x_{0}\right)^{2}}\right)}
$$


onde:

\begin{tabular}{|c|c|c|c|}
\hline$x_{0}$ & $x_{0}^{\prime}$ & $y_{0}$ & $y_{0}^{\prime}$ \\
\hline 25000 & 255000 & 0,00 & $-0,39$ \\
\hline 50000 & 280000 & $-0,98$ & $-0,57$ \\
\hline 75000 & 300000 & $-1,38$ & $-1,08$ \\
\hline 100000 & 302000 & $-1,00$ & $-1,08$ \\
\hline 125000 & 355000 & $-1,52$ & $-0,98$ \\
\hline 150000 & 376000 & $-0,86$ & 0,00 \\
\hline
\end{tabular}

$\left(\frac{\partial \theta}{\partial y_{0}^{\prime}}\right)^{2} \cdot u^{2}\left(y_{0}^{\prime}\right)=4,03 * 10^{-11} \mathrm{rad}$

$\left(\frac{\partial \theta}{\partial y_{0}}\right)^{2} \cdot u^{2}\left(y_{0}\right)=5,67^{*} 10^{-11} \mathrm{rad}$

$\left(\frac{\partial \theta}{\partial x_{0}^{\prime}}\right)^{2} \cdot u^{2}\left(x_{0}^{\prime}\right)=6,95 * 10^{-21} \mathrm{rad}$

$\left(\frac{\partial \theta}{\partial x_{0}}\right)^{2} \cdot u^{2}\left(x_{0}\right)=4,63^{*} 10^{-21} \mathrm{rad}$

Então encontra-se o valor da propagação de erros:

$u_{c}(\theta)=\sqrt{1,0212 * 10^{-10}}=1,0106 * 10^{-5} \mathrm{rad}$

Sendo que este resultado está em "radianos", deve-se, através da equação 5.5 transforma-lo em "arcseg”. Então o valor será:

$u_{c}(\theta)=\frac{1.296 .000 * u_{c}(\theta)}{2 \pi}=2,084 \operatorname{arcseg}$ 
Para o erro angular Pitch "Y" a propagação de erros encontrada foi:

\begin{tabular}{||c|c|c||c|c|c||}
\hline Posição & $\mathbf{u}\left(x_{0}\right)$ & $\mathbf{u}\left(y_{0}\right)$ & Posição & $\mathbf{u}\left(x_{0}^{\prime}\right)$ & $\mathbf{u}\left(y_{0}^{\prime}\right)$ \\
\hline 25 & 1,8333 & 1,073 & 250 & 0,9667 & 0,480 \\
\hline 50 & 2,5333 & 1,080 & 275 & 2,1667 & 0,743 \\
\hline 75 & 1,700 & 0,450 & 300 & 3,4667 & 0,467 \\
\hline 100 & 2,200 & 0,240 & 325 & 3,1333 & 0,097 \\
\hline 125 & 1,3667 & 0,237 & 350 & 3,300 & 0,417 \\
\hline 150 & 1,7667 & 0,573 & 375 & 2,6333 & 0,950 \\
\hline
\end{tabular}

onde:

\begin{tabular}{|c|c|c|c|}
\hline$x_{0}$ & $x_{0}^{\prime}$ & $y_{0}$ & $y_{0}^{\prime}$ \\
\hline 25000 & 255000 & 0 & $-0,2$ \\
\hline 50000 & 280000 & $-0,1$ & 0 \\
\hline 75000 & 300000 & 0,1 & 0,4 \\
\hline 100000 & 302000 & 0,7 & 0,4 \\
\hline 125000 & 355000 & $-0,3$ & $-0,4$ \\
\hline 150000 & 376000 & $-0,3$ & 0,2 \\
\hline
\end{tabular}

$\left(\frac{\partial \theta}{\partial y_{0}^{\prime}}\right)^{2} \cdot u^{2}\left(y_{0}^{\prime}\right)=1,8086 * 10^{-10} \mathrm{rad}$

$\left(\frac{\partial \theta}{\partial y_{0}}\right)^{2} \cdot u^{2}\left(y_{0}\right)=2,3743 * 10^{-11} \mathrm{rad}$

$\left(\frac{\partial \theta}{\partial x_{0}^{\prime}}\right)^{2} \cdot u^{2}\left(x_{0}^{\prime}\right)=4,9294 * 10^{-21} \mathrm{rad}$

$\left(\frac{\partial \theta}{\partial x_{0}}\right)^{2} \cdot u^{2}\left(x_{0}\right)=2,3387 * 10^{-21} \mathrm{rad}$

$u_{c}(\theta)=\sqrt{3,6950 * 10^{-10}}=1,9223 * 10^{-5} \mathrm{rad}$ 
Através da equação 5.5, o valor será:

$$
u_{c}(\theta)=3,965 \text { arcsegundos }
$$

Pode-se observar que a maior contribuição para a incerteza total do cálculo dos erros angulares é dada pelas componentes $\left(\frac{\partial \theta}{\partial y_{0}^{\prime}}\right)^{2} \cdot u^{2}\left(y_{0}^{\prime}\right)$ e $\left(\frac{\partial \theta}{\partial y_{0}}\right)^{2} \cdot u^{2}\left(y_{0}\right)$ que são resultantes da variância do erro de retilineidade. 


\section{CAPÍTULO 7}

\section{CONCLUSÕES E SUGESTÕES PARA TRABALHOS FUTUROS}

Neste trabalho foi apresentado o desenvolvimento de uma formulação matemática para determinação da correlação existente entre os erros de retilineidade e os erros angulares.

Para concretização da metodologia proposta, foi necessário o levantamento das curvas de erro de retilineidade, o estudo da estrutura da máquina, o desenvolvimento de programas computacionais para a execução de algoritmos e de ferramentas estatísticas para a análise dos erros.

O levantamento das curvas de erros de retilineidade da MM3C do tipo Ponte Móvel, foi realizado com o sistema interferométrico laser e com a régua padrão, conforme descrito nos capítulos anteriores. O estudo da estrutura da máquina serviu para a localização e análise dos mancais aerostáticos, verificação da distância entre eles e de seu comportamento sobre as guias.

O algoritmo computacional utilizado no cálculo do erro angular foi desenvolvido em um programa matemático, o MatLab ${ }^{\circledR}$, que utiliza linguagem de alto nível. 
Os resultados das medições dos erros de retilineidade foram, antes de qualquer manipulação, submetidos à análise estatística e tratamento numérico dos erros.

A viabilidade da formulação proposta foi verificada comparando-se os erros angulares obtidos através dela com os erros angulares medidos por meio do sistema interferométrico laser. Além das observações já feitas, pode-se ressaltar a partir dos desenvolvimentos teóricos e experimentais, os seguintes pontos essenciais e conclusões:

- O método permite diminuir o número de calibrações necessárias para a determinação do erro volumétrico da máquina.

- Uma boa estimativa do erro angular foi obtido através do erro de retilineidade quando utilizada a formulação proposta. No melhor caso, Yaw "Y", a média foi de 94,7\% de correlação e no pior caso, Pitch "Y", $75,3 \%$.

- As equações de correlação entre o erro de retilineidade encontrado durante a calibração e o polinômio ajustado para esse erro, podem ser consideradas adequadas devido à dimensão do erro de retilineidade ser extremamente pequena, onde o coeficiente de correlação foi de $70 \%$, para $\delta_{\mathrm{z}}(\mathrm{y})$, e $85 \%$, para $\delta_{\mathrm{x}}(\mathrm{y})$.

- Um problema clássico de Engenharia Mecânica é poder prever o erro de retilineidade das guias usinadas em uma máquina ferramenta conhecendo esta a partir de uma calibração simples. A determinação das componentes do erro volumétrico da MM3C pode ser avaliada durante a fase do projeto. Tal determinação pode ser facilitada se o erro de retilineidade das máquinas ferramentas, que produzem as guias das máquinas de medir, e o erro de escala utilizadas na máquina de medir forem conhecidos. Desta forma, é possível prever 15 (quinze) erros 
geométricos da MM3C antes mesmo de sua fabricação: dois erros de retilineidade, um erro de posição e dois angulares para cada eixo de movimentação da máquina. Sendo que o erro angular será obtido a partir do erro de retilineidade medido.

- A técnica de regressão utilizada apesar de ser dispensável, facilitou os cálculos do erro angular.

- Observando as equações de propagação de erros, pode-se notar que a medição da distância entre os mancais pode ser feita sem grandes cuidados. Entretanto a medição do erro de retilineidade deve ser feita com extremo rigor.

- O método proposto pode ser estendido para máquinas ferramentas sem nenhuma modificação.

- O método proposto pode ser estendido para o cálculo de Roll através da combinação de dois erros de retilineidade.

- As equações de sintetização das componentes do erro volumétrico tem seu nível de incerteza sensivelmente reduzido uma vez que as variâncias são apenas aquelas dos erros de retilineidade.

Como resultado destas observações e conclusões, podem ser feitas algumas propostas para trabalhos futuros, relacionadas a seguir:

- Implementar um novo modelo de sintetização das componentes do erro volumétrico.

- Aplicar a metodologia utilizada em outras máquinas de geometrias diferentes. 


\section{REFERÊNCIAS BIBLIOGRÁFICAS}

ABNT/NBR 6409 (1980). Tolerância de forma e tolerância de posição.

ACHCAR, J. A.(1995) Planejamento de experimentos em engenharia e industria. notas de aula, ICMSC-USP - São Carlos.

ANSI/ASME B 89.4.1 (1995). Methods for Performance Evaluation of Coordinate Measuring Machines.

BALSAMO, A.; MARQUES, D.; SARTORI, S. (1990) A method for thermaldeformation corrections of CMMs Annals of the CIRP, v.39, n. 1, p.557-560

BOSCH, J.A. (1995). Coordinate Measuring Machines and Systems. New York, Marcel Dekker, Inc.

BROWN \& SHARP (1988) Coordinate Measuring Systems User's manual, North Kingstown, U.S.A.

BRYAN, J.B. (1979) The Abbè principle revisited: an updated interpretation. Precision Engineering, vol.1, № 1, Jul.: 129-132.

BRYAN, J.B.(1990) International status of thermal error research. Annals of the CIRP, vol.39, № 2 .

BRYAN,J.B. \& VANHERCK,J. (1975) Unification of terminology - concerning the error motion of axes of rotation. Annals of the CIRP, vol.24, № 2 : 555-562.

CAMPBELL, A (1995) Measurement of lathe Z-axis straightness and parallelism using a flat land, Precision Engineering Vol 17 no 3 pp 207-210.

CARR, K.; FERREIRA, P. (1995).Verification of form tolerances . Part I : Basic issues, flatness and straightness . Precision Engineering. V.17, n.2, p.131-143, Apr. 
CHERAGHI, S. H et al (1996), Straightness and flatness tolerance evaluation: an optimization approach v.18, n.1, p.30-37, Jan.

DE LUCA,C.J.G. (1992) Calibração de erros geométricos em centros de usinagem assistida por computador. São Carlos. 105p. Dissertação (Mestrado) - EESC USP.

DI GIACOMO, B.; MARTINEZ ORREGO, R. M. \& VIEIRA SATO, D. P. (1997). An exploratory study about the second order errors in mathematical models of coordinate measuring machines. Metrocal.

DI GIACOMO,B.(1986) Computer aided calibration and hybrid compensation of geometric errors in coordinate measuring machines. MANCHESTER. 418p. PhD Thesis - THE VICTORIA UNIVERSITY OF MANCHESTER.

DOEBELIN, E. O.(1990) Measurement systems - application and design McGrawHill Kogakusha, Ltda.

DRAPER, N. R., SMITH, H. (1981) Applied regression analysis, Chapter 10 An introduction to Nonlinear Estimation, p. 458-529.

ESTLER,W.T. (1985) Calibration and use of optical straightedges in the metrology of precision machines. Optical Engineering, vol. 24, № 3, May/Jun: 372-379.

ETESAMI, F.; QIAO, H. (1990) Analysis of two-dimensional measurement data for automated inspection J Manufac Sys, v.9, p. 21-35 apud CARR, K.; FERREIRA, P. (1995).Verification of form tolerances . Part I : Basic issues, flatness and straightness . Precision Engineering. V.17, n.2, p.131-143, Apr.

EVANS, C.J.; HOCKEN, R.J.; ESTLER, W.T. (1996) Self-Calibration: reversal, redundancy, error separation, and “absolute testing”, CIRP Annals, Vol 45/2. 
FRENCH,D. \& HUMPHRIES,S.H. (1967) Compensation for the backlash and alignment errors in a numerically controlled machine tool by a digital computer programme. Proceedings of $8^{\text {th }}$ MTDR Conference : 707-726.

GUYE, J. J. (1978) Metrological inspection of machining centers, jig boring machines and measuring machines through a statistical approach. Sociéte Genovice d'Instruments de Physique, Geneva: 141-5.

HARVIE,A. (1986) Factors affecting component measurement on coordinate measuring machines. Precision Engineering, vol.8, № ${ }^{\mathrm{o}}$ 1,: 13-18.

HEWLETT- PACKARD (1996) .Laser Measuring System Model 5528A-Users Guide: Parts 1 and 2 Santa Clara, USA.

HOCKEN, R. J.. (1977) Three dimensional metrology Annals of the CIRP. V. 36, p. 403-408.

HOCKEN, R.J. \& MACHINE TOOL TASK FORCE (1980). Machine tool accuracy. Technology of Machine Tools, vol.5, Oct.

HUANG, S.T.; FAN, K.C.; WU, J.H. (1993) A new minimum zone method for evaluating straightness errors, Precision Engineering, v.15 p.158-165.

ISO/R1101 (1983). Technical Drawings - Geometrical Tolerancing.

KANADA, T.; SUZUKI, S. (1993) Application of several computing techniques for minimum zone straightness Precision Engineering, v. 15, p. 274-280

KASEI, S. ; ONDA, K.(1987) Measurement of Straightness by Means of Overlap Coupling of Data. JSME International Journal.V.30, n.261, p.992-5.

KIM, K. ; KIM, M. K. (1991) Volumetric Accuracy Analysis Based On Generalized Geometric Error Model In Multi-Axis Machine Tools. Mech Mach Theory. v.26,n.2, p207-219, Mar. 
KNAPP,W.; TSCHUDI,U.; BUCHER,A. (1991), Comparison of different artefacts for interim coordinate-measuring machine checking : a report from the Swiss Standards Committee, Precision engineering, v.13, n.4, p.277-291, Oct.

LINGARD P. S. et al (1991) Temperature pertubation effects in a high precision cmm Precision Engineering, Pag. 41 - 56.

MURTHY, T.S.R; ABDIN, S.Z. (1980) Minimum zone evaluation of surfaces, Int J Machine Tool Des and Res, v.20, p.123-136 apud CARR, K.; FERREIRA, P. (1995).Verification of form tolerances . Part I : Basic issues, flatness and straightness . Precision Engineering. V.17, n.2, p.131-143, Apr.

PAHK,H.J. \& BURDEKIN,M.S (1991). Evaluation of the effective parametric errors in coordinate measuring machines using the locus of stylus on the horizontal plane. Proc. Instn. Mech. Engrs., vol.205,123-138.

PARAMETRIC CALIBRATION OF COORDINATE MEASURING MACHINES. (1991) The American Society of Mechanical Engineers. 14 p.

PEREIRA,P.H. (1995) Levantamento e modelamento dos erros térmicos de uma retificadora cilíndrica cnc. São Carlos. 156p. Dissertação (Mestrado) - EESC USP.

PIRATELI, A. (1997) Método para avaliação do desempenho de máquinas de medir a três coordenadas através do planejamento de experimentos. Tese de Doutorado, EESC-USP.

POOLE, A.B. (1983) The calibration of coordinate measuring machines by statistical method Quality Assurance, 9 (2), may: 71-97.228 apud PIRATELI, A.(Filho) Método para avaliação do desempenho de máquinas de medir a três coordenadas através do planejamento de experimentos. Tese de Doutorado, EESC-USP, 1997. 
SAKUMA, H.H. ; WADA, H. (1987) Straightness measurement using a heterodyne Moiré method. Precision Engineering V.9, n.1,p. 19-22, Jan.

SHEN, Y. L. \& DUFFIE, N.A. (1990) Uncertainties in the acquisition and utilization of coordinate frames in manufacturing systems. Annals of the CIRP, v.40, n 1,p. 527-530.

SLOCUM, A.H. (1992) Precision Machine Design. Prentice Hall, 58-107.

SOSA CARDOZA, J.A. (1995) Máquinas virtuais de medir a três coordenadas. São Carlos. 209p. Tese (Doutorado) - EESC - USP.

SUEN, D.S.; CHANG, C.N. (1997) Application of neural network interval regression method for minimum zone straightness and flatness Precision Engineering, v. 20, n.3, p. 196-207

THOMAS, G. (1974) Engineering Metrology, chapter 1. Butterworth\&Co. Ltd.

VDI/VDE 2617 (1989) Accuracy of Coordinate Measuring Machines Part 3: Components of Measurement Deviation of the Machine.

VIERA SATO, D. P. (1998) Uma contribuição ao modelo de sintetização de erros em máquinas ferramentas. São Carlos. 200p. Tese (Doutorado) - Escola de Engenharia de São Carlos - USP.

WECK, M. (1984) Handbook of machine tools - Metrological analysis and performance tests. London, John Wiley \& Sons, vol.4, 1-145.

WECKENMANN, A. \& HEINRICHOWSKI, M. (1985). The use of virtual volumetric standards. Precision Engineering, 7(2) p.87-91.

YAMAMOTO, K. et al (1985), Accuracy of straightness measurement by steppingoff method, Precision engineering, v.19, n.1, Mar. 
ZHANG, G. X.(1989). A Study On The Abbè Principle and Abbè Error. Annais of the CIRP. V.38, n.1, p.525 - 528, Jan.

ZHANG,G.X. et al (1992), Distance-distance method for straightness measurement, Annals of the CIRP, v.41, n.1, p.581-584, Jan.

ZzzzzzzzzFAN \& BURDEKIN (1986) P.32 


\section{APÊNDICE 1}

Dados da MÁquina de MEdir A TRÊS COORDENADAS

\section{DADOS TÉCNICOS DA MM3C TIPO PONTE MÓVEL}

Máquina: Máquina de Medir a Três Coordenadas (MM3C)

Tipo: Ponte Móvel (Moving Bridge)

Número de Série: 098066

Ano de Fabricação : 1988

País de Origem : U.S.A

Proprietário: LAMAFE - Depto. Mecânica - São Carlos - USP DIMENSÕES

Faixa de operação

$$
\begin{aligned}
& X=356 \mathrm{~mm} \\
& Y=406 \mathrm{~mm} \\
& Z=305 \mathrm{~mm}
\end{aligned}
$$

Capacidade de Trabalho

$$
\begin{aligned}
& X=457 \mathrm{~mm} \\
& Y=610 \mathrm{~mm} \\
& Z=381 \mathrm{~mm}
\end{aligned}
$$

Dimensões Totais

Comprimento $(\mathrm{X})=743 \mathrm{~mm}$

Largura $(Y)=730 \mathrm{~mm}$

Altura $(\mathrm{Z})=1.340 \mathrm{~mm}$

Pesos

$\begin{array}{ll}\text {. Somente máquina } & 149 \mathrm{~kg} \\ \text { Sistema completo } & 168 \mathrm{~kg} \\ \text { Embalada } & 220 \mathrm{~kg} \\ \text { Max. Peso da Peça a ser Medida } & 68 \mathrm{~kg}\end{array}$

\section{NÍVEIS OPERACIONAIS EXIGIDOS}

Temperatura de Calibração

$20^{\circ} \mathrm{C} \pm 1^{\circ} \mathrm{C}$

Faixa de Temperatura de Operação

10 a $40{ }^{\circ} \mathrm{C}$

Pressão Mínima de Ar

4,8 bar

Consumo de $\mathrm{Ar}$

$357 \mathrm{~m}^{3} / \mathrm{h}$

Tensão de Alimentação

$110 / 220 \mathrm{AC}, 50 / 60 \mathrm{~Hz}$

Potência Consumida

60 Watts

Monitor

25 Watts 


\section{APÊNDICE 2}

\section{ANÁLISE DE REGRESSÃO LINEAR MÚLTIPLA}

Vamos analisar agora a equação de regressão de $\mathrm{n}$ observações numa variável resposta e $\mathrm{p}$ variáveis independente $\mathrm{x}_{1}, \mathrm{x}_{2}, \mathrm{x}_{3}, \ldots, \mathrm{x}_{\mathrm{p}}$, como mostrado na tabela:

\begin{tabular}{|lccccc|}
\hline $\mathrm{y}$ & $\mathrm{x}_{1}$ & $\mathrm{x}_{2}$ & $\mathrm{x}_{3}$ & $\ldots$ & $\mathrm{x}_{\mathrm{p}}$ \\
$\mathrm{y}_{1}$ & $\mathrm{x}_{11}$ & $\mathrm{x}_{21}$ & $\mathrm{x}_{31}$ & $\ldots$ & $\mathrm{x}_{\mathrm{p} 1}$ \\
$\mathrm{y}_{2}$ & $\mathrm{x}_{12}$ & $\mathrm{x}_{22}$ & $\mathrm{x}_{32}$ & $\ldots$ & $\mathrm{x}_{\mathrm{p} 2}$ \\
$\mathrm{y}_{3}$ & $\mathrm{x}_{13}$ & $\mathrm{x}_{23}$ & $\mathrm{x}_{33}$ & $\ldots$ & $\mathrm{x}_{\mathrm{p} 3}$ \\
$\vdots$ & $\vdots$ & $\vdots$ & $\vdots$ & & $\vdots$ \\
$\mathrm{y}_{\mathrm{n}}$ & $\mathrm{x}_{1 \mathrm{n}}$ & $\mathrm{x}_{2 \mathrm{n}}$ & $\mathrm{x}_{3 \mathrm{n}}$ & $\ldots$ & $\mathrm{x}_{\mathrm{pn}}$ \\
\hline
\end{tabular}

E dado pela expressão [A2.1]

$$
y_{i}=\beta_{0}+\beta_{1} x_{1 i}+\beta_{2} x_{2 i}+\ldots+\beta_{p} x_{p i}+\varepsilon_{i}
$$

onde :

- $\beta_{0}, \beta_{1}, \ldots, \beta_{\mathrm{p}}$ são os coeficientes de regressão a serem determinados;

- $\varepsilon_{\mathrm{i}}$ é o resíduo da regressão;

- $\mathrm{x}_{1}, \mathrm{x}_{2}, \ldots, \mathrm{x}_{\mathrm{p}}$ são as variáveis fixadas. 
Para estimar os parâmetros da regressão $\beta_{0}, \beta_{1}, \ldots, \beta_{\mathrm{p}}$ utiliza-se o método dos mínimos quadrados que minimiza a soma de quadrados dos erros, dada por [A2.2]

$$
\begin{aligned}
S=S\left(\beta_{0}, \beta_{1}, \ldots, \beta_{p}\right)= & \sum_{i=1}^{n} \varepsilon_{i}^{2} \\
& =\sum_{i=1}^{n}\left(y_{i}-\beta_{0}-\beta_{1} x_{1 i}-\ldots-\beta_{p} x_{p i}\right)^{2}
\end{aligned}
$$

Derivando $S\left(\beta_{0}, \beta_{1}, \ldots, \beta_{\mathrm{p}}\right)$ em relação à $\beta_{0}, \beta_{1}, \ldots, \beta_{\mathrm{p}}$ e igualando a zero, temos a equação [A2.3]:

$$
\left\{\begin{array}{l}
S_{11} \hat{\beta}_{1}+S_{12} \hat{\beta}_{2}+\ldots+S_{1 p} \hat{\beta}_{p}=S_{y 1} \\
S_{12} \hat{\beta}_{1}+S_{22} \hat{\beta}_{2}+\ldots+S_{2 p} \hat{\beta}_{p}=S_{y 2} \\
\vdots \\
S_{1 p} \hat{\beta}_{1}+S_{p 2} \hat{\beta}_{2}+\ldots+S_{p p} \hat{\beta}_{p}=S_{y p}
\end{array}\right.
$$

onde:

$$
\begin{aligned}
& S_{i j}=\sum_{k=1}^{n}\left(x_{i k}-\bar{x}_{i}\right)\left(x_{j k}-\bar{x}_{j}\right) ; \quad i, j=1,2, \ldots, p ; \\
& S_{y i}=\sum_{k=1}^{n}\left(y_{k}-\bar{y}\right)\left(x_{i k}-\bar{x}_{i}\right), \quad i, j=1,2, \ldots, p ; \\
& \bar{x}_{i}=\sum_{k=1}^{n} \frac{x_{i k}}{n} ; \\
& \bar{y}=\sum_{k=1}^{n} \frac{y_{k}}{n} ;
\end{aligned}
$$

Sendo:

$\bar{\beta}_{0}=\bar{y}-\hat{\beta}_{1} \bar{x}_{1}-\hat{\beta}_{2} \bar{x}_{2}-\ldots-\beta_{\mathrm{p}} \bar{x}_{\mathrm{p}}$. 
Resolvendo [A2.3] encontram-se os estimadores de mínimos quadrados $\hat{\beta}_{0}, \hat{\beta}_{1}, \ldots, \hat{\beta}_{\mathrm{p}}$. Pode-se escrever assim a equação [A2.9]

$$
\hat{y}_{i}=\beta_{0}+\beta_{1} x_{1 i}+\beta_{2} x_{2 i}+\ldots+\beta_{p} x_{p i}
$$

Os resíduos ' $\varepsilon$ ' da regressão são dados pela expressão [A2.10]. Assim a diferença entre os valores calculados e os valores reais é igual a:

$$
\hat{\varepsilon}_{\mathrm{i}}=\mathrm{y}_{\mathrm{i}}-\hat{\mathrm{y}}_{\mathrm{i}}, \quad \mathrm{i}=1,2, \ldots, \mathrm{n}
$$




\section{APÊNDICE 3}

\section{O ERRO DE RETILINEIDADE EM FUNÇÃO DO ERRO ANGULAR}

Além das formulações anteriores para encontrar o erro angular a partir do erro de retilineidade foi desenvolvida uma formulação que determina o erro de retilineidade a partir do erro angular conhecido.

\section{A3.1- ERro De Retilineidade Na Direção “X” DeVido Ao Movimento No EIXO “Z”}

As medições dos erros de retilineidade na direção " $\mathrm{X}$ " devido ao movimento no eixo " $Z$ " foram tomadas em pontos com o intervalo de $25 \mathrm{~mm}$ no eixo "Z". Foi feita a montagem do sistema interferométrico laser, e devido ao tamanho das óticas necessárias para executar a medição, a faixa de calibração não ultrapassou $100 \mathrm{~mm}$.

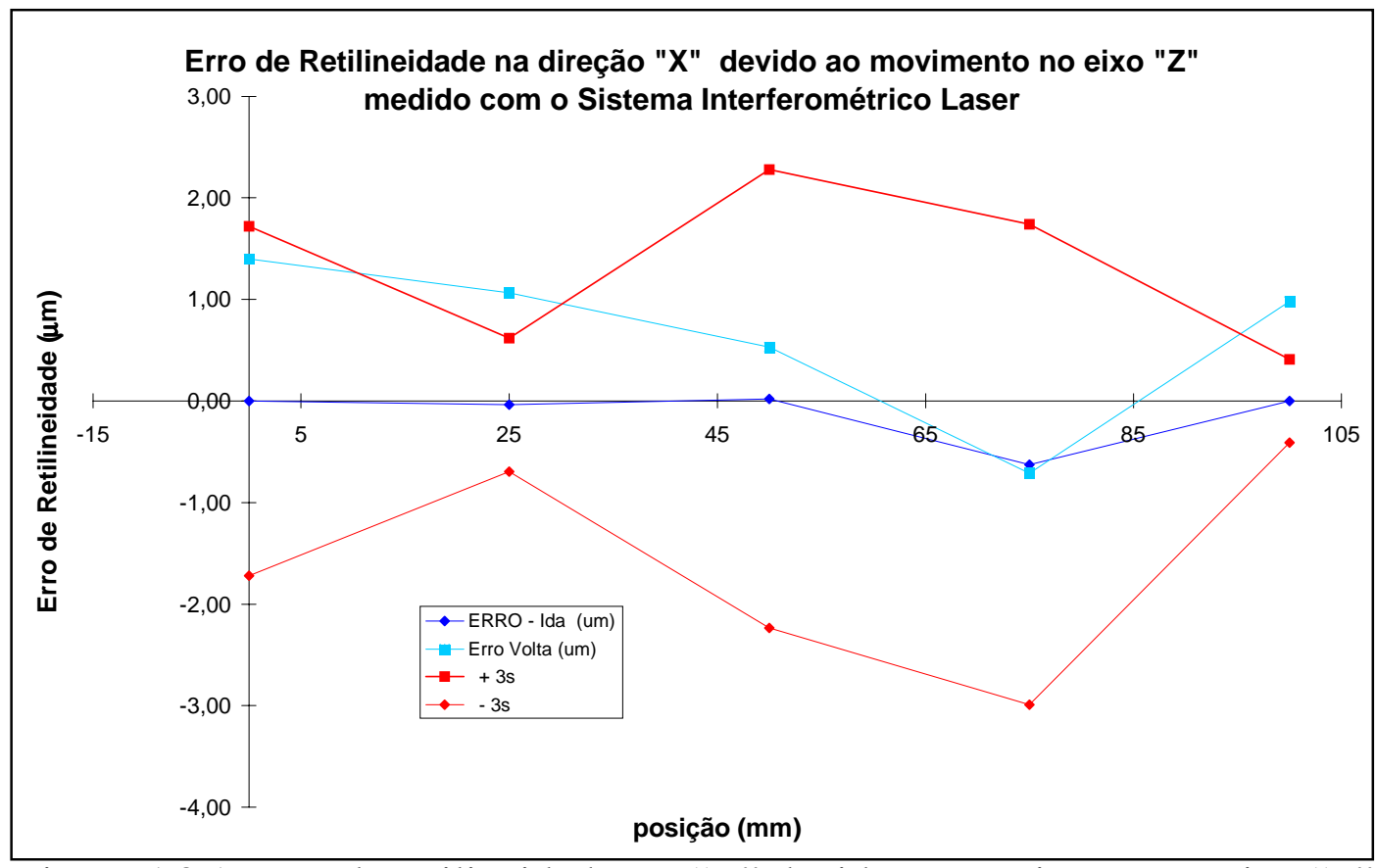

Figura A3.1-Erro de retilineidade em "X" devido ao movimento no eixo " $Z$ " 
Os procedimentos foram os mesmos utilizados na calibração do erro de retilineidade conforme mostrado no capítulo 5. O gráfico da figura A3.1 mostra o comportamento deste erro.

Analisando o gráfico da figura A3.1 pode-se observar que o erro de retilineidade na direção "X" devido ao movimento no eixo "Z" é extremamente pequeno. No entanto, o erro aleatório é relativamente grande quando comparado com os valores médios.

Nota-se, também, que a histerese é grande quando o carro "Z" está posicionado próximo da origem do sistema adotado. Porém, é importante ressaltar que a curva que representa o comportamento do erro no sentido de volta está contida entre as curvas que representam o erro aleatório de ida. Desta forma, pode-se avaliar o comportamento do erro apenas no sentido de ida para descrever o comportamento do erro de retilineidade " $\mathrm{X}$ " devido ao movimento " $\mathrm{Z}$ "

\section{CALIBRAÇÃO DO ERRO DE YAW DO EIXO “Z”}

O erro de rotação em torno do eixo "Y" devido ao movimento no eixo "Z", Yaw "Z”, foi medido na mesma posição de calibração do erro de retilineidade e foram tomados pontos com o intervalo de $25 \mathrm{~mm}$ no eixo " $\mathrm{Z}$ ".

A calibração do erro angular Yaw "Z" foi efetuada posicionando o carro "Z" no intervalo de $0 \mathrm{~mm}$ a $250 \mathrm{~mm}$, porque o tamanho do conjunto das óticas para medição angular é menor do que o utilizado na calibração do erro de retilineidade, como pode ser observado na figura A3.3.

No erro de retilineidade o tamanho do conjunto das óticas é aproximadamente $200 \mathrm{~mm}$ e no caso do erro angular de aproximadamente 80 mm. 
O gráfico da figura A3.2 apresenta o comportamento do erro "Yaw Z" da MM3C.

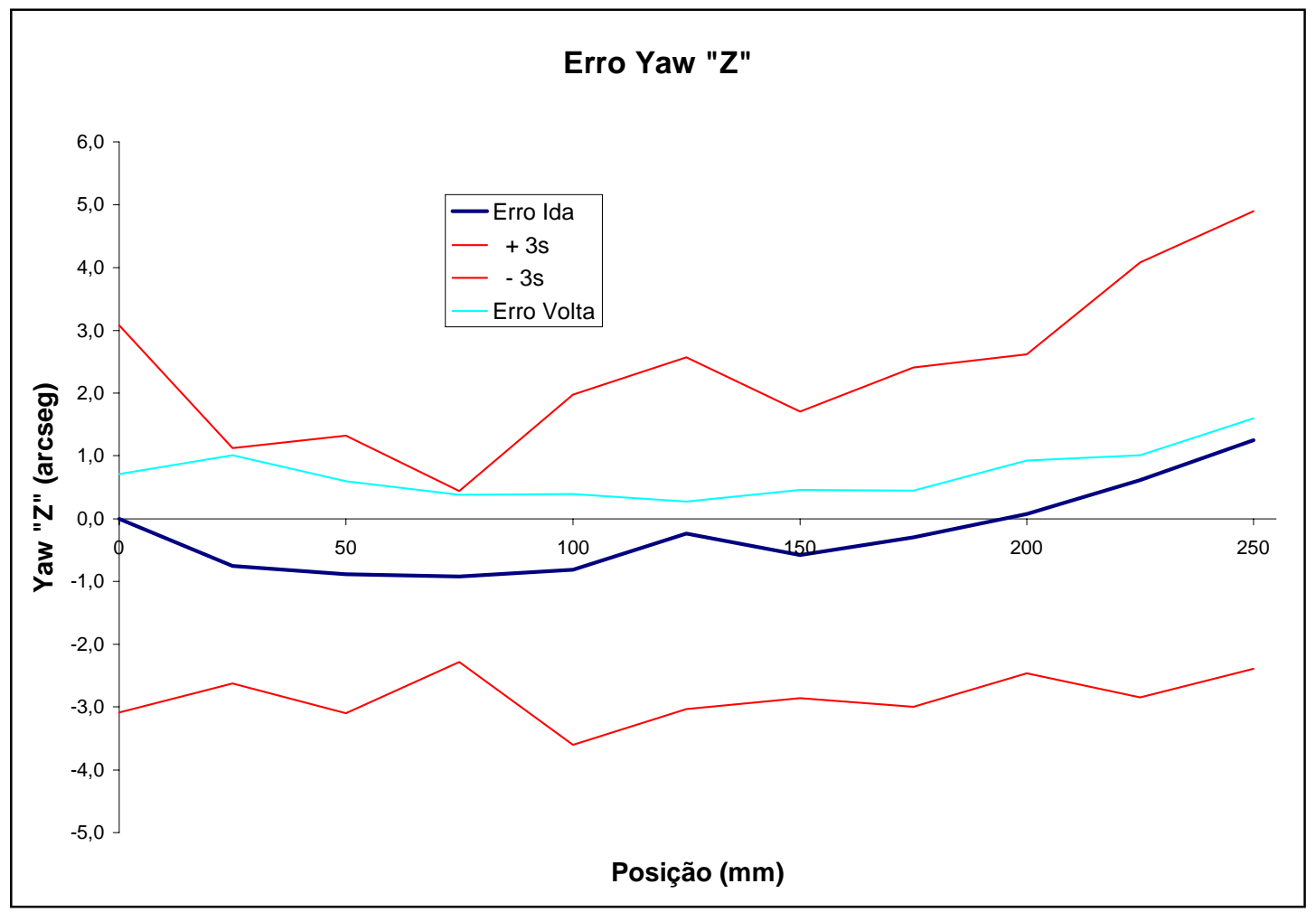

Figura A3.2 - Erro de rotação em torno do eixo "Y" devido ao movimento no

$$
\text { eixo "Z", "Yaw" do eixo "Z" }
$$


Analisando esses gráfico pode-se notar que a histerese é pequena atingindo um valor próximo de 2 arcsegundos. Nota-se também que o erro é muito pequeno.

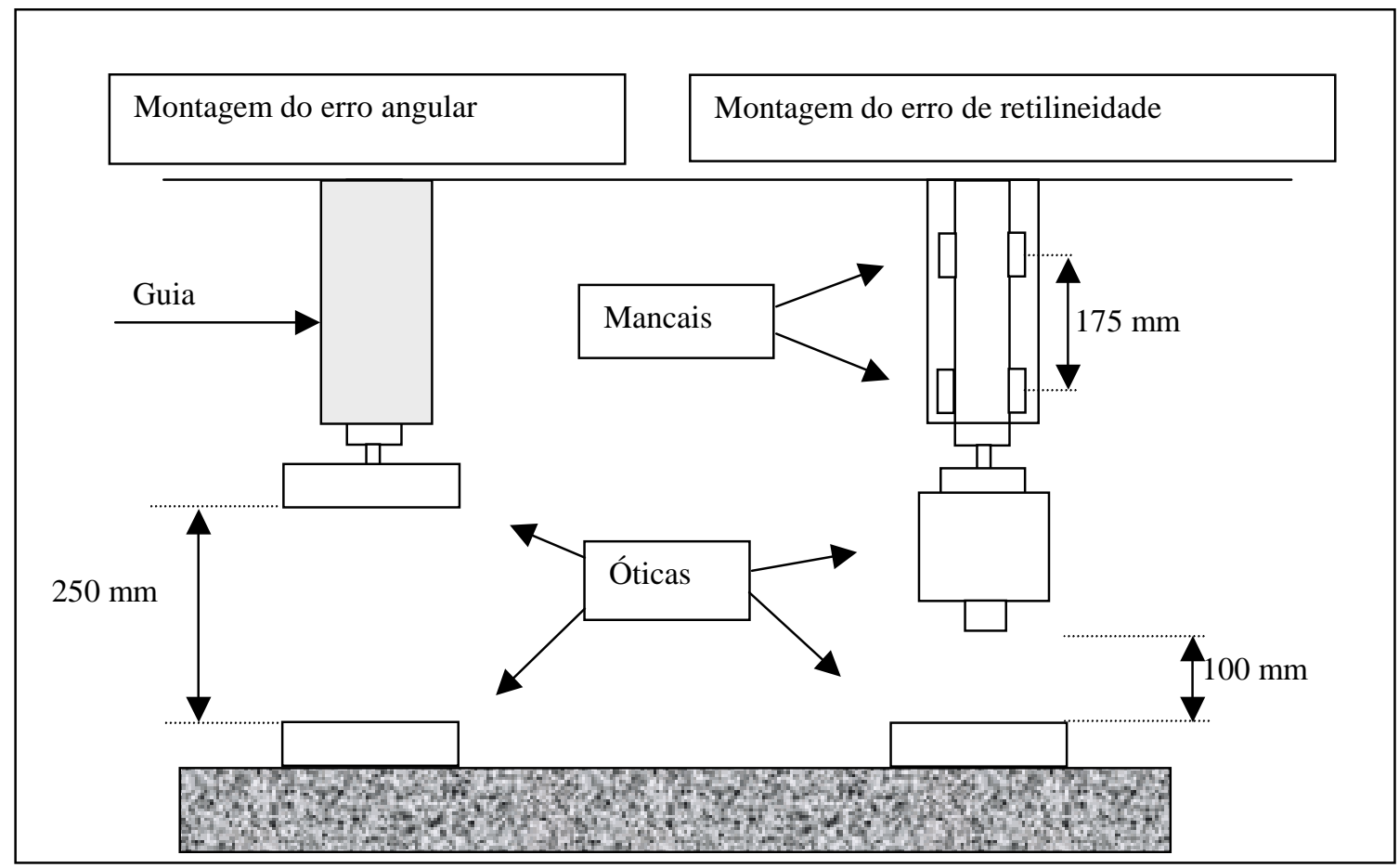

Figura A3.3 - Esquema das montagens do erro angular e do erro de retilineidade para o eixo "Z" da MM3C.

\section{A3.2 - ERro de Retilineidade Calculado da MÁquina de Medir a TrêS COORDENADAS}

Como a distância entre os mancais da guia "Z”, $175 \mathrm{~mm}$, é maior que a faixa utilizada na calibração do erro de retilineidade, $100 \mathrm{~mm}$, não foi possível avaliar o erro angular a partir dos valores do erro de retilineidade . Neste caso, portanto, o método proposto foi utilizado para se calcular o erro de retilineidade. 
Assim sendo, o erro de retilineidade que a princípio foi calibrado numa faixa de $100 \mathrm{~mm}$, devido a ótica necessária para a calibração. Pode ser determinado, então, em quase toda a extensão da guia.

$\mathrm{O}$ erro de retilineidade na direção " $\mathrm{X}$ " em quase toda a dimensão da guia "Z" foi, então, determinado a partir dos valores obtidos com a calibração do erro angular "Yaw Z" e dos dados levantados durante a calibração do próprio erro de retilineidade na direção "X", na faixa de $100 \mathrm{~mm}$.

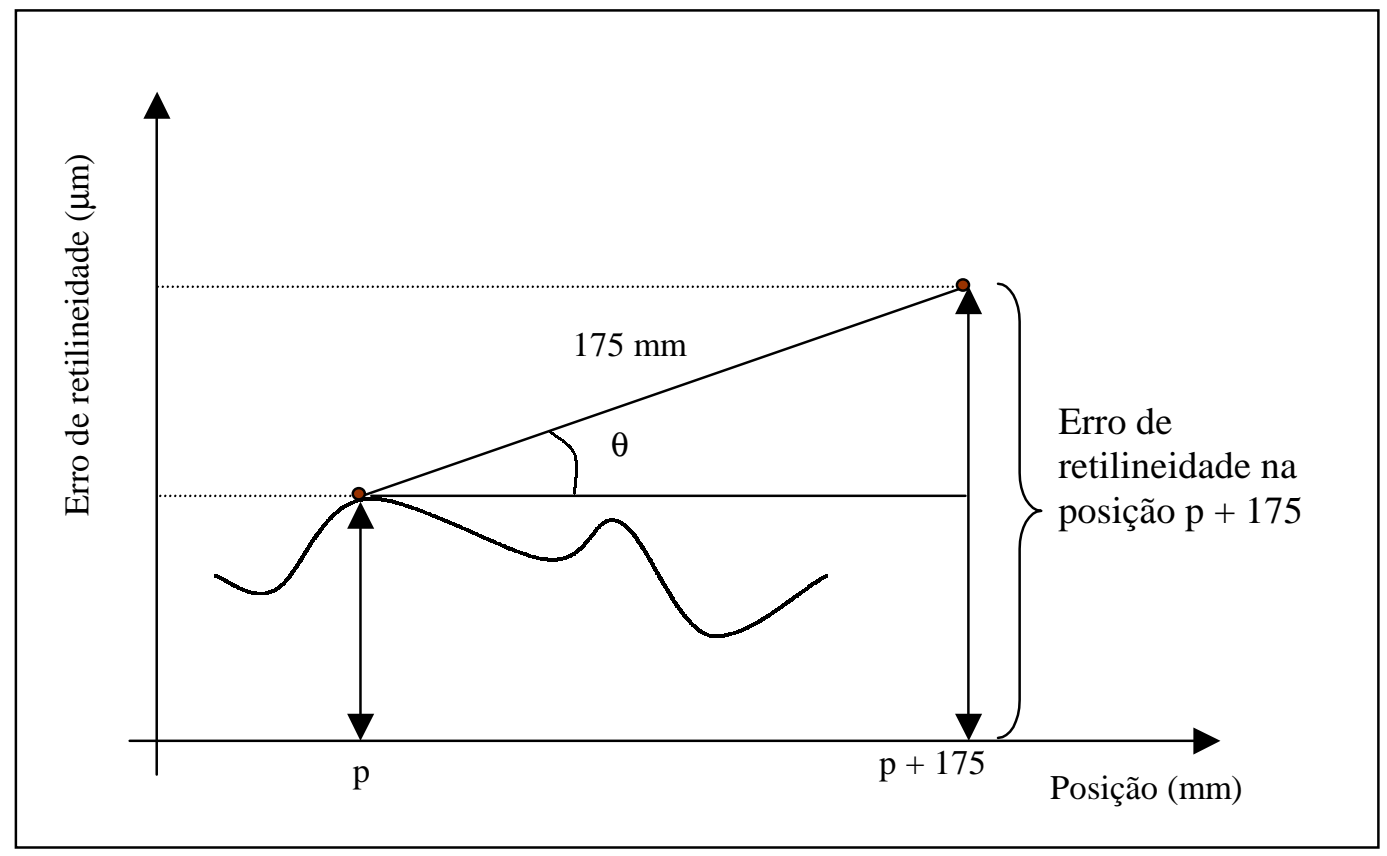

Figura A3.4 - Esquema para o cálculo trigonométrico

Dado, então, um ponto " $\mathrm{p}$ " pertencente a faixa de 0 a $100 \mathrm{~mm}$, pode-se determinar através da curva do erro angular o erro de "Yaw" nesta posição. Sabendo-se que a distância entre os mancais é de 175 mm, o erro de "Yaw" na posição “ $(p+175)$ " é conhecido, isto é, "Yaw $(p)=$ Yaw $(p+175)$. Conhecendo-se o erro de retilineidade na posição “ $p$ ” determina-se a partir de 
cálculos trigonométricos o valor do erro de retilineidade em “ $p+175$ ”, figura A3.4.

O gráfico da figura A3.5 mostra o erro de retilineidade do sentido de ida assim calculado.

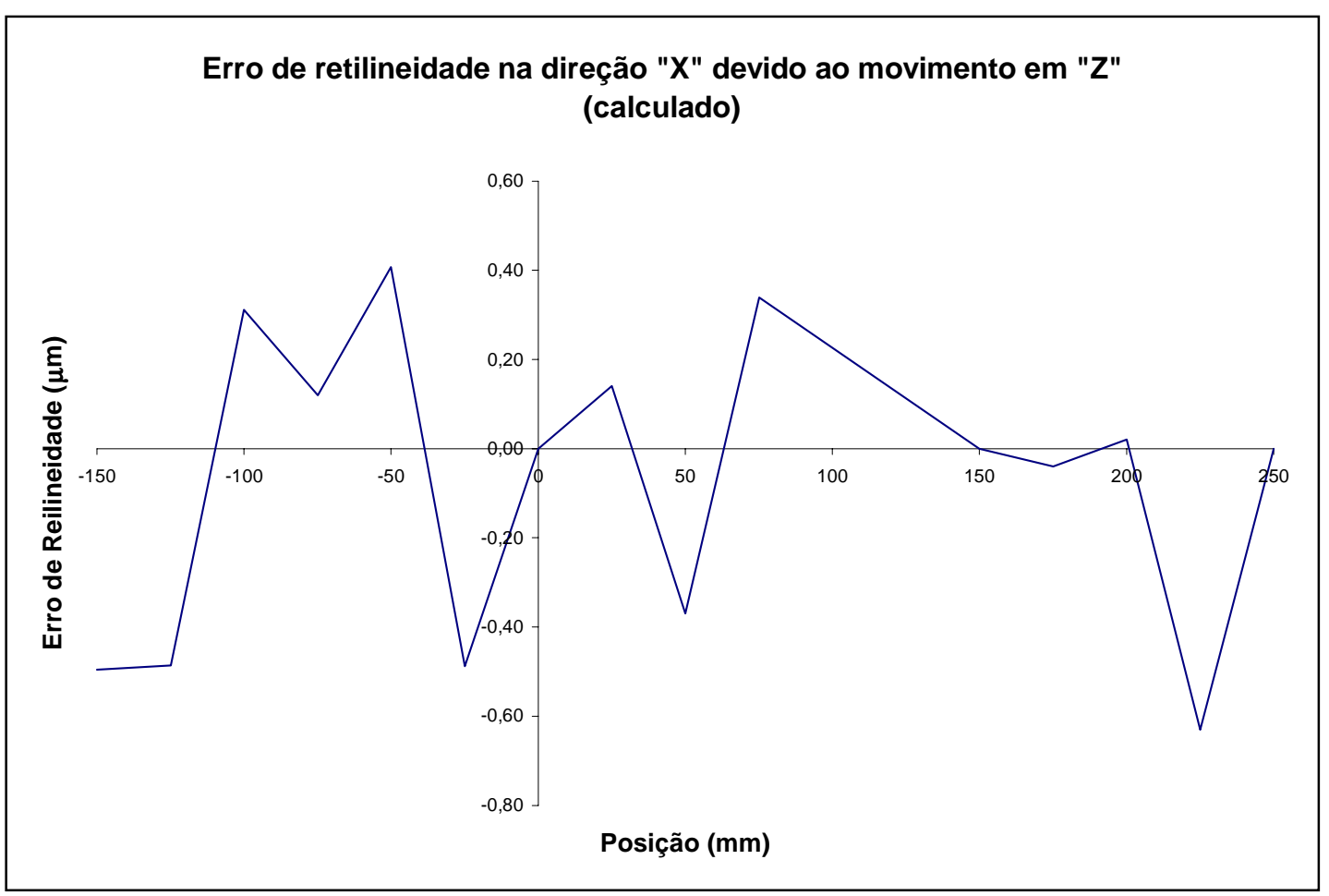

Figura A3.5 - Erro de retilineidade do eixo "Z"

Analisando esse gráfico pode-se verificar que o erro de retilineidade " $\mathrm{X}$ " na direção " $Z$ " pode ser determinado em praticamente toda a guia "Z". Pode-se notar também que o erro de retilineidade é extremamente pequeno. 